NIST GCR 15-986-2

\title{
Proceedings of the Measurement Science for Sustainable Construction and Manufacturing Workshop Volume II. Presentations
}

\author{
Bilal M. Ayyub \\ Gerald E. Galloway \\ Richard N. Wright \\ University of Maryland
}

This publication is available free of charge from:

http://dx.doi.org/10.6028/NIST.GCR. 15-986-2
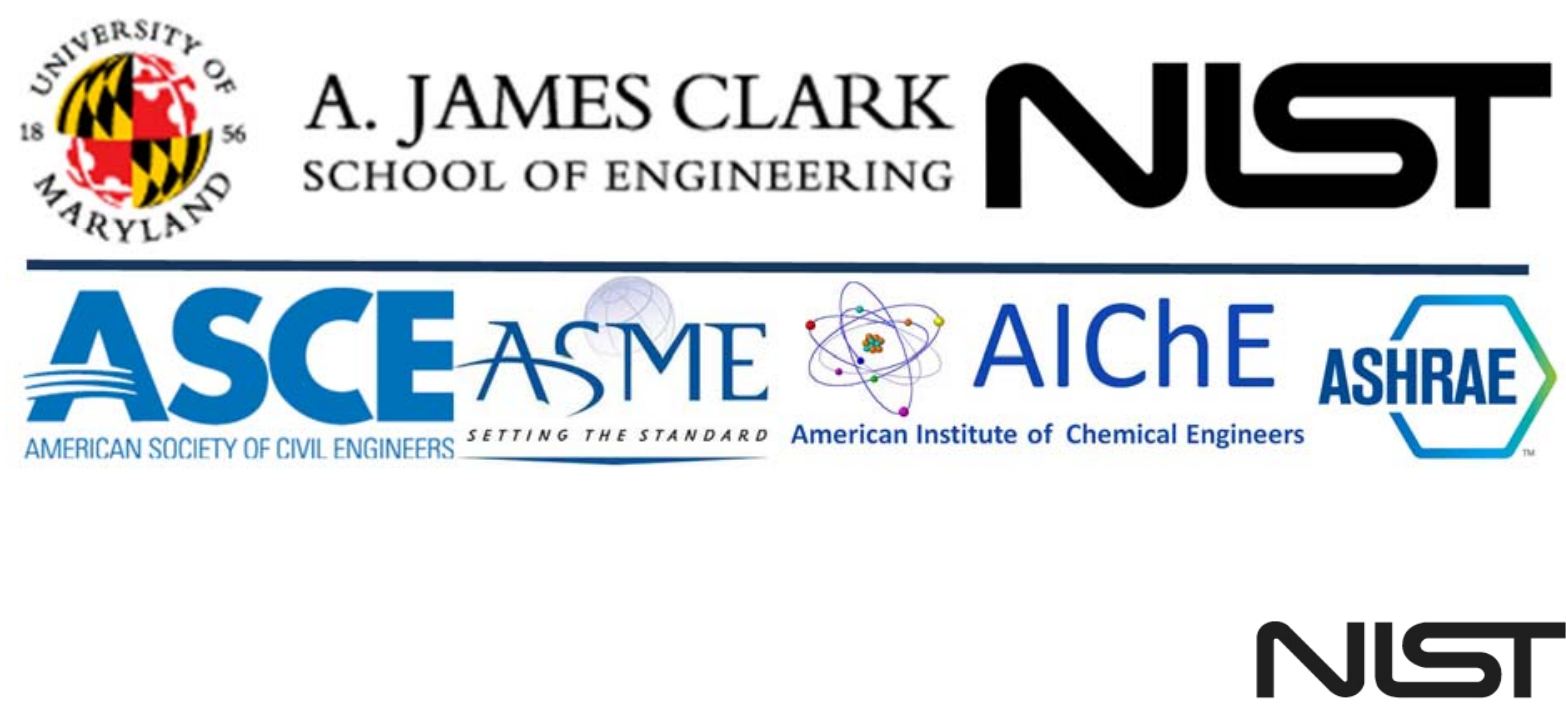

National Institute of Standards and Technology U.S. Department of Commerce 

NIST GCR 15-986-2

\title{
Proceedings of the Measurement Science for Sustainable Construction and Manufacturing Workshop Volume II. Presentations
}

\author{
Prepared for \\ U.S. Department of Commerce \\ Engineering Laboratory \\ National Institute of Standards and Technology \\ Gaithersburg, MD 20899-8600
}

By

Bilal M. Ayyub

Gerald E. Galloway

Richard N. Wright

University of Maryland

http://dx.doi.org/10.6028/NIST.GCR. 15-986-2

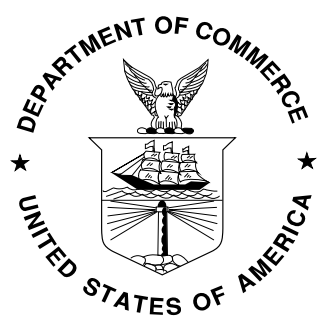

February 2015

U.S. Department of Commerce

Penny Pritzker, Secretary

National Institute of Standards and Technology Willie May, Acting Under Secretary of Commerce for Standards and Technology and Director 
This publication was produced as part of Cooperative Agreement \#70NANB13H211 with the National Institute of Standards and Technology. The contents of this publication do not necessarily reflect the views or policies of the National Institute of Standards and Technology or the US Government. 


\section{Organizing Committee}

Bilal M. Ayyub, University of Maryland

Robert Chapman, National Institute of Standards and Technology

Joannie Chin, National Institute of Standards and Technology

Gerald E. Galloway, University of Maryland

I. S. Jawahir, University of Kentucky

Josh Kneifel, National Institute of Standards and Technology

Sudarsan Rachuri, National Institute of Standards and Technology

Jelena Srebric, University of Maryland

Richard N. Wright, University of Maryland

\section{Sponsors}

National Institute of Standards and Technology

American Society of Civil Engineers (ASCE)

American Institute of Chemical Engineers (AIChE)

American Society of Mechanical Engineers (ASME)

American Society of Heating, Refrigerating and Air Conditioning Engineers (ASHRAE)

University of Maryland

\section{Recommended Citations}

Ayyub, B. M., Galloway, G. E., and Wright, R. N. (editors), 2014, Measurement Science for Sustainable Construction and Manufacturing, Volume I. Position Papers, University of Maryland Report to the National Institute of Standards and Technology, Office of Applied Economics, NIST Grant/Contractor Report 15-986-1, Gaithersburg, MD.

Ayyub, B. M., Galloway, G. E., and Wright, R. N. (editors), 2014, Measurement Science for Sustainable Construction and Manufacturing, Volume II. Presentations, University of Maryland Report to the National Institute of Standards and Technology, Office of Applied Economics, NIST Grant/Contractor Report 15-986-2, Gaithersburg, MD. 
[This page is internationally left blank] 
Ayyub, Bilal M., Galloway, Gerald E., and Wright, Richard N., University of Maryland

\section{About the Workshop on Measurement Science for Sustainable Construction and Manufacturing}

\section{Background}

Achieving long-term suitability poses a linked-systems challenge for policy makers to assess the consequences, trade-offs and synergies in economic, environmental and social domains. A sustainable society can be defined as the one that can thrive over generations; one that is farseeing enough, flexible enough, and wise enough not to undermine its economic, environmental and social systems of support. A major need for achieving sustainable construction and manufacturing is to establish meaningful measurements for the complex attributes of sustainability suitable for lifecycle considerations. What one can measure, one can manage. NIST, ASCE, ASME and the University of Maryland are hold this workshop to address this challenge.

\section{Objectives}

The objective of the workshop was to examine the measurement science needed to guide decisions for sustainability throughout the life cycle of design, construction/manufacturing, operations, and maintenance of facilities and systems of the built environment and manufactured products, and to guide NIST and other key stakeholders in developing a portfolio of related programs. The workshop engaged key international and domestic thought leaders and experts from stake-holding disciplines including construction, manufacturing, codes and standards development, economics, government, industry, and academia, and addressed trends and needs relating to sustainable construction and manufacturing. The results from this effort are documented herein in coordination with NIST, ASCE and ASME.

\section{Discussion Topics}

Discussion topics included:

- Measurement science (definition, standards, metrics, indicators and ratings)

- Systems (aggregation, linkages, system of systems, sustainability-resilience synergy and interdependencies)

- Planning, design and supply chain (lifecycle analyses and treatments, and material and energy efficiency), or

- Economic, environmental and social aspects (valuation, impacts and behavior).

\section{Participants}

The workshop was attended by about 77 people. A complete list is provided in Appendix A. 


\section{Agenda}

Day 1: June 12, 2014

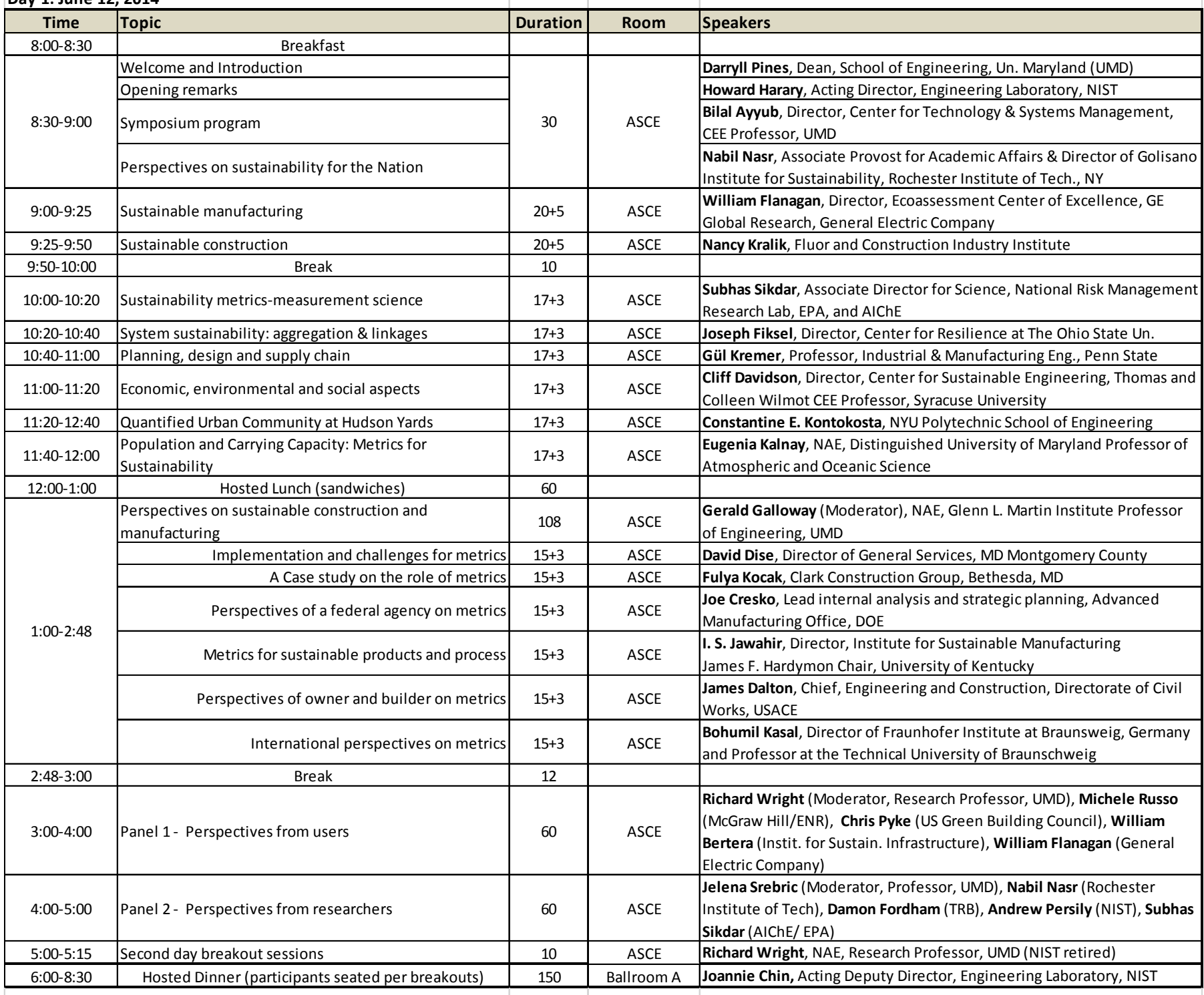

Day 2: June 13, 2014

\begin{tabular}{|c|c|c|c|c|}
\hline Time & Topic & Duration & Room & Speakers \\
\hline $8: 45-9: 45$ & Breakout 1: Measurement science & 60 & CH2M Hill & Co-moderators: I. S. Jawahir and Subhas Sikdar \\
\hline $8: 45-9: 45$ & Breakout 2: Systems & 60 & Harris & Co-moderators: Joseph Fiksel \& John Carberry (affiliation, invited) \\
\hline $8: 45-9: 45$ & Breakout 4: Economic, environmental and social aspects & 60 & ASCE & Co-moderators: Cliff Davidson and William Flanagan \\
\hline 9:45-10:00 & Break & 15 & & \\
\hline 10:00-11:00 & Breakout 3: Planning, design and supply chain & 60 & President & $\begin{array}{l}\text { Co-moderators: Nabil Nasr (Rochester Instit. of Tech) and Fazleena } \\
\text { Badurdeen (U. Kentucky) }\end{array}$ \\
\hline 10:00-11:00 & Breakout 4: Economic, environmental and social aspects & 60 & ASCE & Co-moderators: Cliff Davidson and William Flanagan \\
\hline 11:00-11:15 & Break to regroup & 15 & & \\
\hline $11: 15-12: 15$ & Summaries of breakouts 1, 2, 3 and 4 & 60 & ASCE & By Co-moderators, report requirements (facilitor Richard Wright, UMD) \\
\hline $12: 15-12: 30$ & \begin{tabular}{|l|} 
Expected products and adjournment \\
\end{tabular} & 15 & ASCE & Bilal Ayyub, UMD \\
\hline
\end{tabular}




\section{Disclaimer and Limitations}

This report was prepared for the National Institute of Standards and Technology (hereafter referred to as NIST) as the primary sponsor, and the American Society of Civil Engineers (hereafter referred to as ASCE), the American Society of Mechanical Engineers (hereafter referred to as ASME), the American Institute of Chemical Engineers (hereafter referred to as AIChE) and the American Society of Heating, Refrigerating and Air Conditioning Engineers (hereafter referred to as ASHRAE) by the Center for Technology and Systems Management of the University of Maryland and its associates and subcontractors (hereafter referred to as the UMD). Although this product was prepared using the best available resources, NIST, ASCE, ASME, AIChE and UMD do not make any warranty, expressed or implied, or assume any legal liability or responsibility for the accuracy, completeness, or usefulness of any information, apparatus, product or process disclosed, or represent that its uses would not infringe on privately owned rights. Reference herein to any specific commercial product, process, or service by trade name, trademark, manufacturer, or otherwise does not necessarily constitute or imply its endorsement, recommendation, or favoring by NIST, ASCE, ASME, AIChE, ASHRAE and UMD. Opinions expressed in this report are personal opinions of the participants and do not reflect the opinions of the respective employers of the participants. 
[This page is internationally left blank] 


\section{Table of Contents}

[Presentation delivered are listed in the chronological order of presentation.]

Measurement Science for Sustainable Construction and Manufacturing: Welcome, Background and Program

Bilal M. Ayyub

Measurement Science for Sustainable Construction and Manufacturing: Opening Remarks Howard Harary

Workshop on Measurement Science for Sustainable Construction and Manufacturing:

Perspectives on Sustainability for the Nation

Nabil Nasr

Sustainable Manufacturing from a Life Cycle Perspective

William P. Flanagan

Sustainable Construction: An EPC Perspective

Nancy K. Kralik

How to Quantify Sustainability in Construction and Manufacturing, and the Need for Standards Subhas Sikdar

A Systems Approach to Sustainability and Resilience

Joseph Fiksel

Sustainability Improvement at the Supply Chain Level Through Product Architecture Optimization

Gül E. Okudan Kremer

Economic, Environmental, and Social Aspects

Cliff I. Davidson

The Quantified Community: Measuring, Modeling, and Understanding the Urban Environment Constantine E. Kontokosta

Population and Carrying Capacity: Metrics for Sustainability Eugenia Kalnay, Jorge Rivas, and Safa Motesharrei

Challenges and Metrics in Public Buildings and Infrastructure David Dise 
Measuring Sustainable Construction

Fulya Kocak

Technology Analysis: Efficiency, Manufacturing, Processes \& Materials Joe Cresko

Metrics for Sustainable Products and Processes

I. S. Jawahir

Perspectives of an Owner \& Builder on Metrics

James Dalton

Perspectives of an Owner \& Builder on Metrics

Bohumil Kasal

High Performance Green Buildings

Chris Pyke

Introduction to Breakout Sessions

Richard Wright

Charge to the Breakout Groups

Joannie Chin

Concluding Remarks and Adjournment

Bilal M. Ayyub 


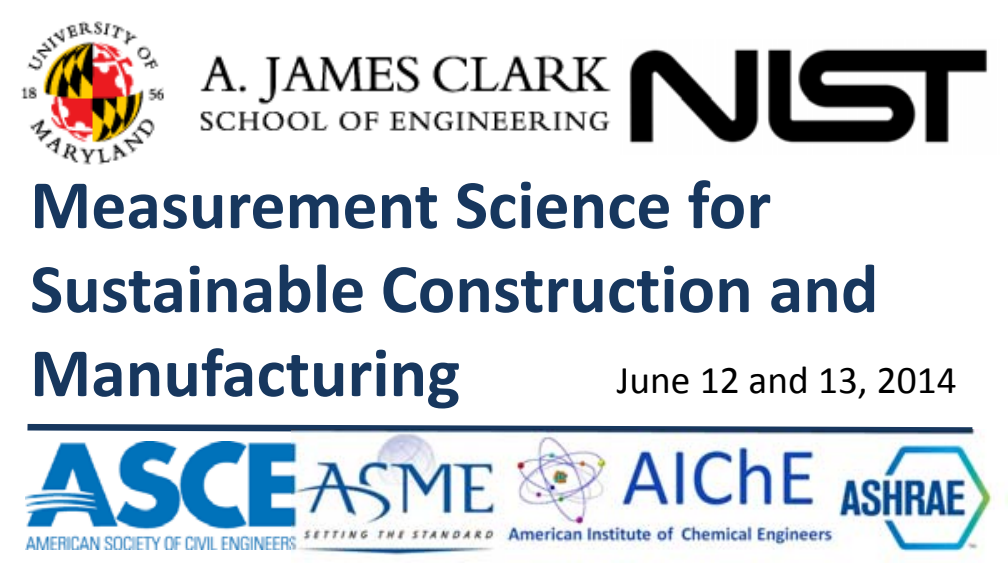

\section{Workshop on Measurement Science for Sustainable Construction and Manufacturing$$
\text { 8:30-9:00 am }
$$

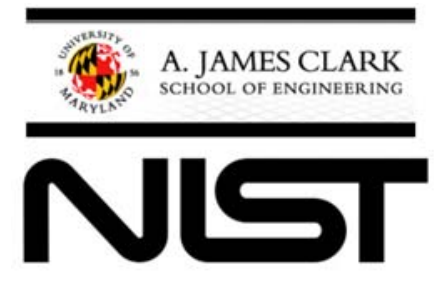

Welcome and Introduction

Bilal Ayyub, CEE Professor, UMD* Darryll Pines, Engineering Dean, UMD

Opening remarks Howard Harary, Acting Director, Engineering Laboratory, NIST

Symposium program

Bilal Ayyub, CEE Professor, UMD Nabil Nasr, Associate Provost for Perspectives on sustainability Academic Affairs \& Director of for the Nation Golisano Institute for Sustainability, Rochester Institute of Tech., NY

* CEE Chair Professor Charles Schwartz, and ME Chair Professor Balakumar Balachandran 


\section{Symposium Objectives}

- Examine measurement science for sustainability throughout the lifecycle of the built environment and manufactured products

- Guide NIST and other key stakeholders in developing a portfolio of related research and development programs

- Engage key international and domestic thought leaders and experts from stakeholding disciplines

- Document in coordination with NIST, ASCE and ASME

\section{Discussion Topics}

- Measurement science (definition, standards, metrics, indicators and ratings)

- Systems (aggregation, linkages, system of systems, sustainability-resilience synergy and interdependencies)

- Planning, design and supply chain (lifecycle analyses and treatments, and material and energy efficiency)

- Economic, environmental and social aspects (valuation, impacts and behavior) 
Workshop on Measurement Science

for Sustainable Construction and

Manufacturing

Program - June 12, 2014

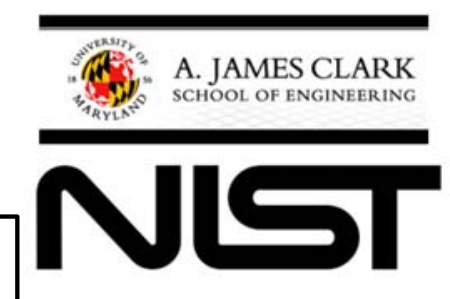

Opening

Keynotes

Breakout presentations

Case studies

Lunch

Six Ted-like lectures

Discussion panels

Orientation for day 2
Welcome, introduction \& national needs

Two on manufacturing \& construction

Four sessions

Two cases

Cutoff time for breakout assignments

Perspectives on manufacturing \& construction

Two from users and researchers

Presentation \& banquet
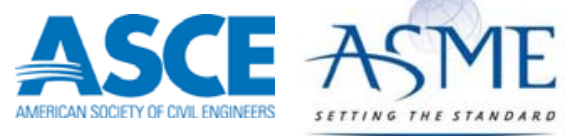

AIChE ASHRAE)

\section{Workshop on Measurement Science for Sustainable Construction and} Manufacturing

$$
\text { Program - June 13, } 2014
$$

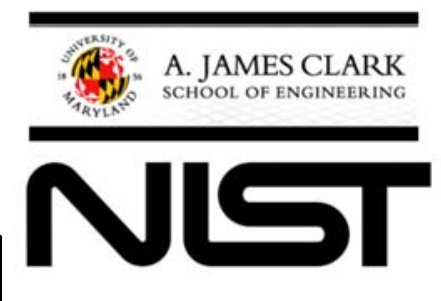

Orientation

Four concurrent sessions

Summary

Expected products and adjournment
All participants

Problem lists

Problem descriptions

All participants by the co-moderators

Proceedings

Recommendations 


\title{
Workshop on Measurement Science
}

for Sustainable Construction and

Manufacturing

9:00-10:00 am

\begin{abstract}
William Flanagan, Director,
Sustainable manufacturing

Ecoassessment Center of Excellence, GE Global Research, General Electric Company

Sustainable construction

Nancy Kralik, Fluor and the

Construction Industry Institute Break
\end{abstract}

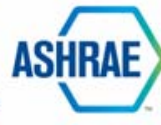

Workshop on Measurement Science for Sustainable Construction and Manufacturing

Sustainability metrics10:00-11:20 am

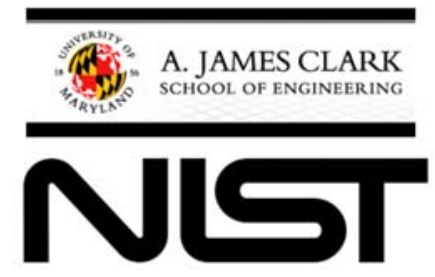
measurement science Subhas Sikdar, Associate Director for Science, National Risk Management

System sustainability: Research Lab, EPA, and AIChE aggregation \& linkages Joseph Fiksel, Director, Center for Planning, design and supply chain Resilience at The Ohio State University Gül Kremer, Professor, Industrial \& Manufacturing Eng., Penn State Cliff Davidson, Director, Center for Economic, environmental and Sustainable Engineering, Thomas and social aspects Colleen Wilmot CEE Professor, Syracuse University 


\section{Workshop on Measurement Science \\ for Sustainable Construction and \\ Manufacturing

Quantified Urban Community Constantine E. Kontokosta, NYU at Hudson Yards

Polytechnic School of Engineering Eugenia Kalnay, NAE, Distinguished

Population and Carrying Capacity: Metrics for Sustainability University of Maryland Professor of Atmospheric and Oceanic Science, and Sofa Motesharrei, Systems Scientist at SESYNC, PhD candidate in Econophysics at UMD

Hosted Lunch (sandwiches)

Perspectives on sustainable construction and Gerald Galloway (Moderator), NAE, Glenn L. Martin manufacturing Institute Professor of Engineering, UMD

Implementation and challenges for metrics

David Dise, Director of General Services, MD Montgomery County

A Case study on the role of metrics Fulya Kocak, Clark Construction Group, Bethesda, MD Perspectives of a federal agency on metrics Joe Cresko, Lead internal analysis and strategic planning, Advanced Manufacturing Office, DOE

I. S. Jawahir, Director, Institute for Sustainable

Metrics for sustainable products and process Manufacturing James F. Hardymon Chair, University of Kentucky

Perspectives of owner and builder on metrics James Dalton, Chief, Engineering

Bohumil Kasal, Director of Fraunhofer Institute at International perspectives on metrics Braunsweig, Germany and Professor at the Technical University of Braunschweig 


\section{Workshop on Measurement Science for Sustainable Construction and Manufacturing \\ 3:00-5:15 pm}

Richard Wright (Moderator, Research Professor, UMD), Michele Russo (McGraw Hill/ENR), Chris

Panel 1 - Perspectives from users Pyke (US Green Building Council), William Bertera (Instit. for Sustain. Infrastructure), William Flanagan (General Electric Company) Jelena Srebric (Moderator, Professor, UMD), Nabil

Panel 2 - Perspectives from researchers Nasr (Rochester Institute of Tech), Damon Fordham (TRB), Andrew Persily (NIST), Subhas Sikdar (AIChE/ EPA)

Second day breakout sessions Richard Wright, NAE, Research Professor, UMD (NIST retired)

Hosted Dinner (participants seated per Joannie Chin, Acting Deputy Director, Engineering breakouts) Laboratory, NIST 
Measurement Science for Sustainable Construction and Manufacturing

Dr. Howard Harary

Acting Director

Engineering Laboratory

National Institute of Standards and Technology

U.S. Department of Commerce

NGT
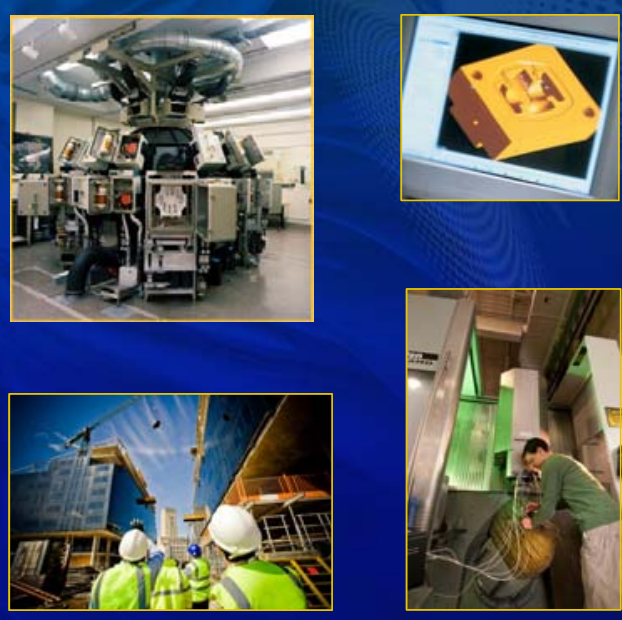


\section{Golisano Institute for Sustainability}

AT ROCHESTER INSTITUTE OF TECHNOLOGY

\section{Workshop on Measurement Science for Sustainable Construction and Manufacturing}

By: Prof. Nabil Nasr

Associate Provost for Academic Affairs \&

Director, Golisano Institute for Sustainability

Rochester Institute of Technology

June 12, 2014

Golisano Institut

\section{Sustainability Science ${ }^{1}$}

- Defined by problems it addresses rather than by disciplines it employs

- Seeks understanding of fundamental interactions between nature and society ${ }^{2}$

- Has a goal of creating and applying knowledge in support of decision making for sustainable development

- Energy systems, ecosystem resilience, industrial ecology, earth system complexity

${ }^{1}$ Term established by National Research Council, 1999, Our Common Journey.

${ }^{2}$ Kates et al. 2004. Science 292:641-642; ${ }^{3}$ Clark \& Dickson, 2003. PNAS 100:8059-8062. 


\section{Sustainability Science}

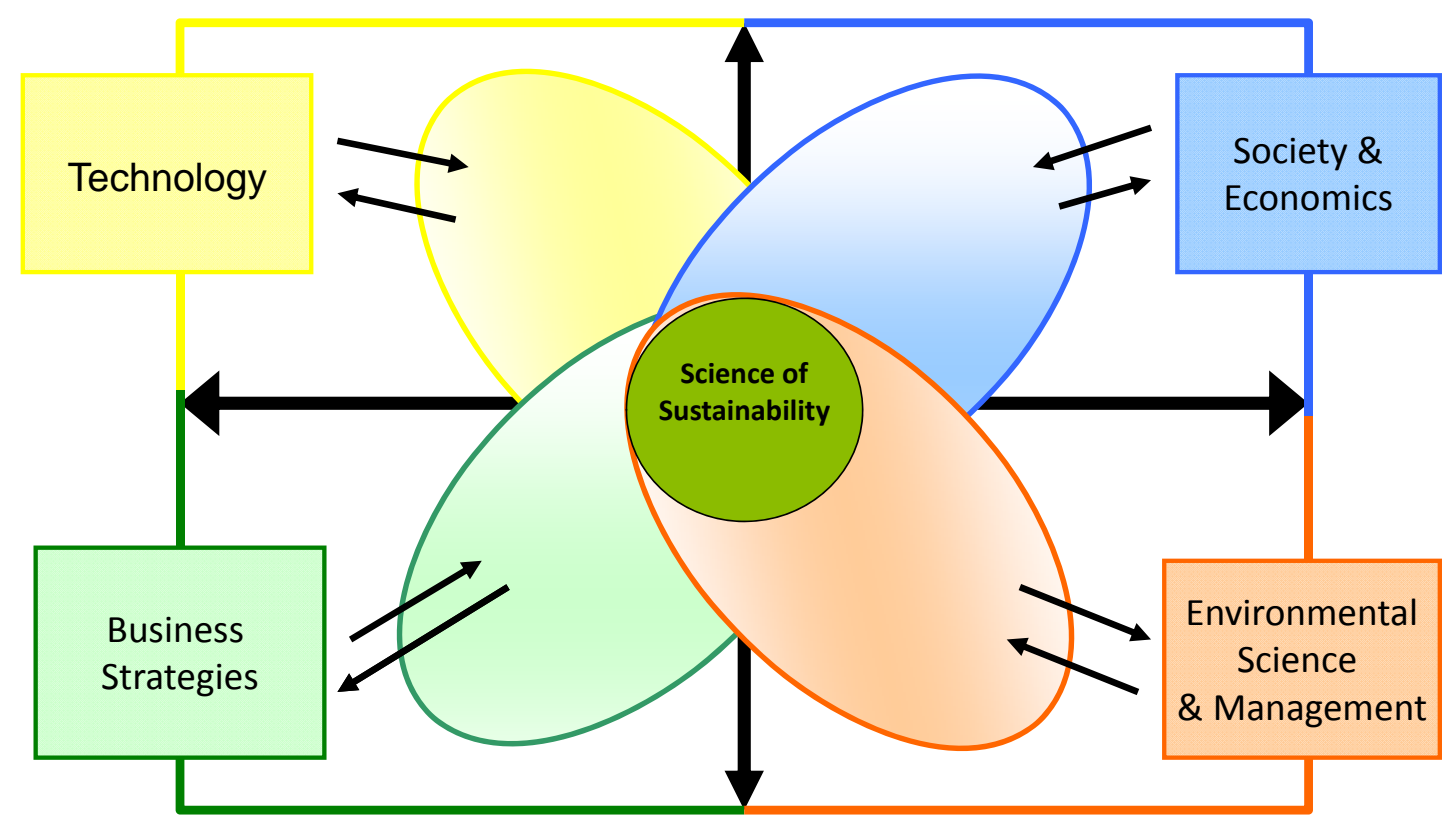

\section{$\mathrm{R} \cdot \mathrm{I} \cdot \mathrm{T}$}

\section{The Japanese Model - Inverse Manufacturing}

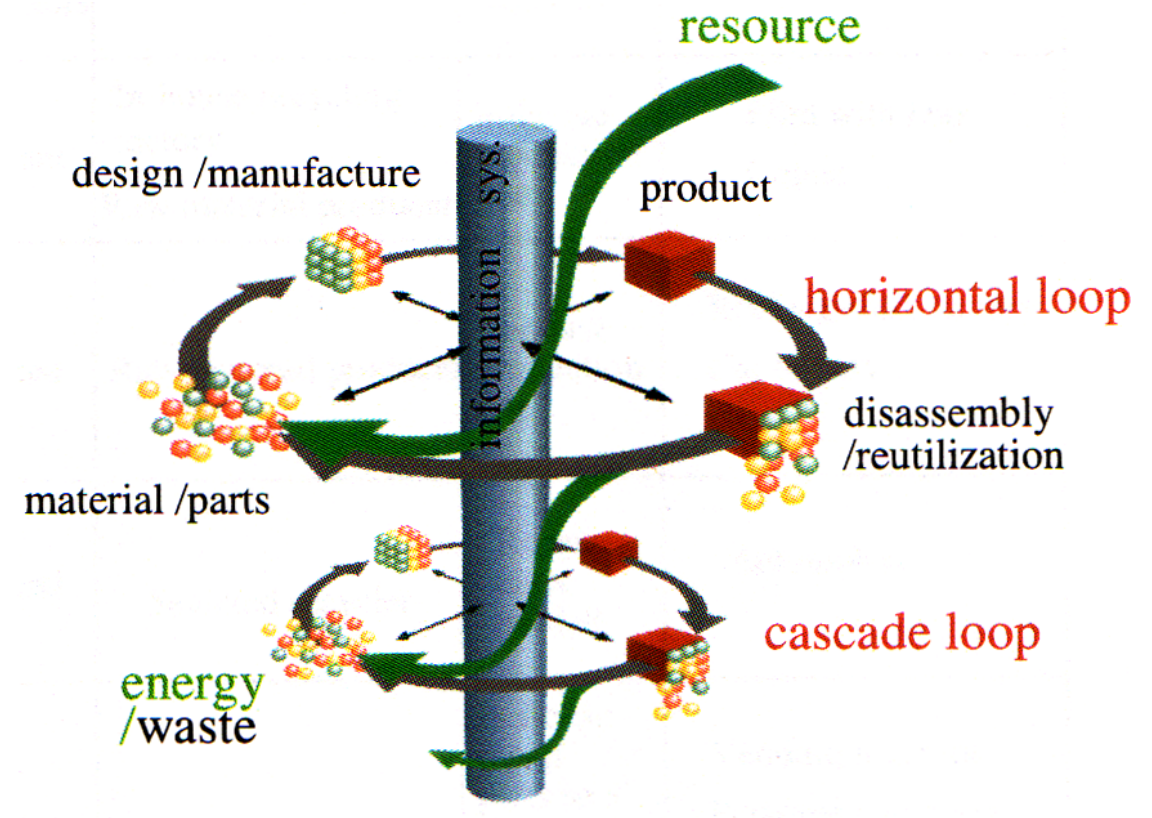




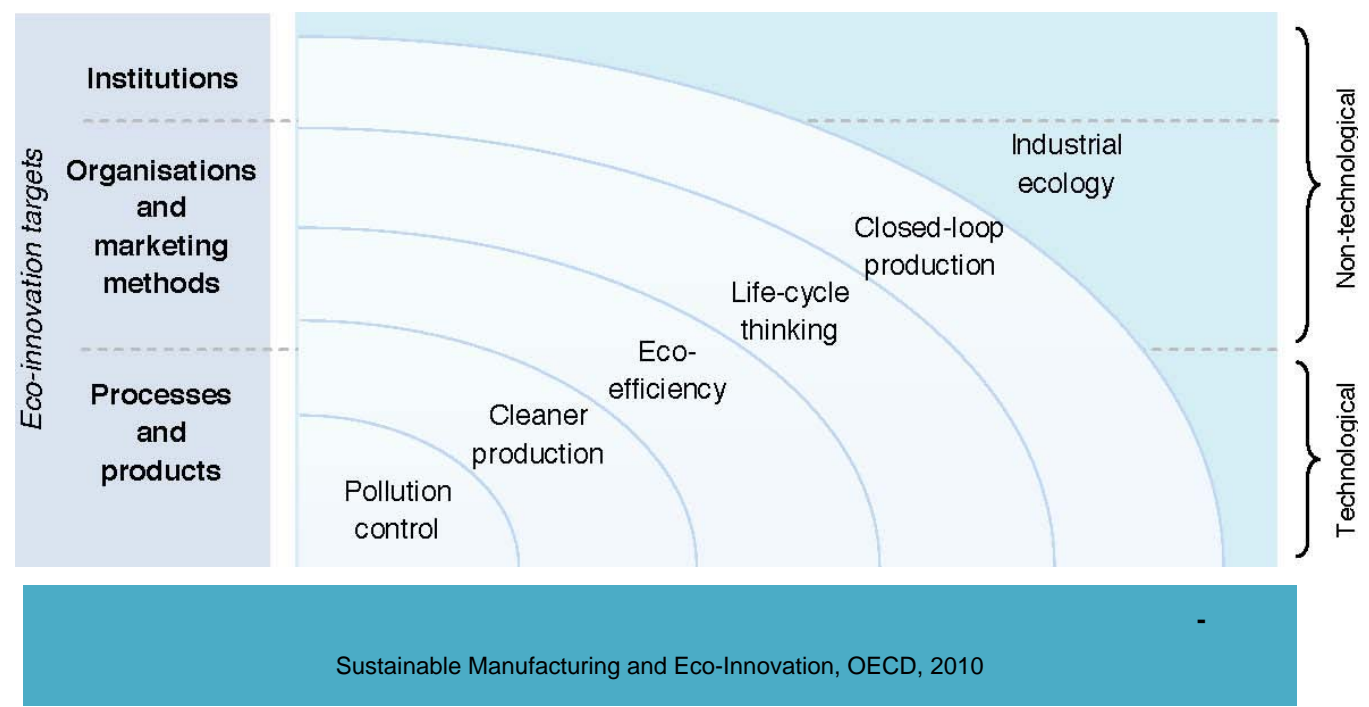

\section{$\mathrm{R} \cdot \mathrm{I} \cdot \mathrm{T}$}

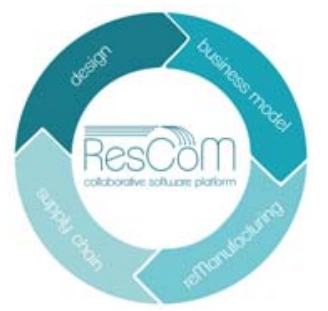

\section{EU Initiatives}

"In a world with growing pressures on resources and the environment, the EU has no choice but to go for the transition to a resource-efficient and ultimately regenerative circular economy" Manifesto for a Resource Efficient Europe, December 2012

Transforming waste into high value resources is a high priority in today's global economy. ResCoM is an European Commission cofunded project working on the development of closed-loop product systems. The project will focus on some of the key ways to do this including remanufacturing, reuse and multiple lifecycles. 


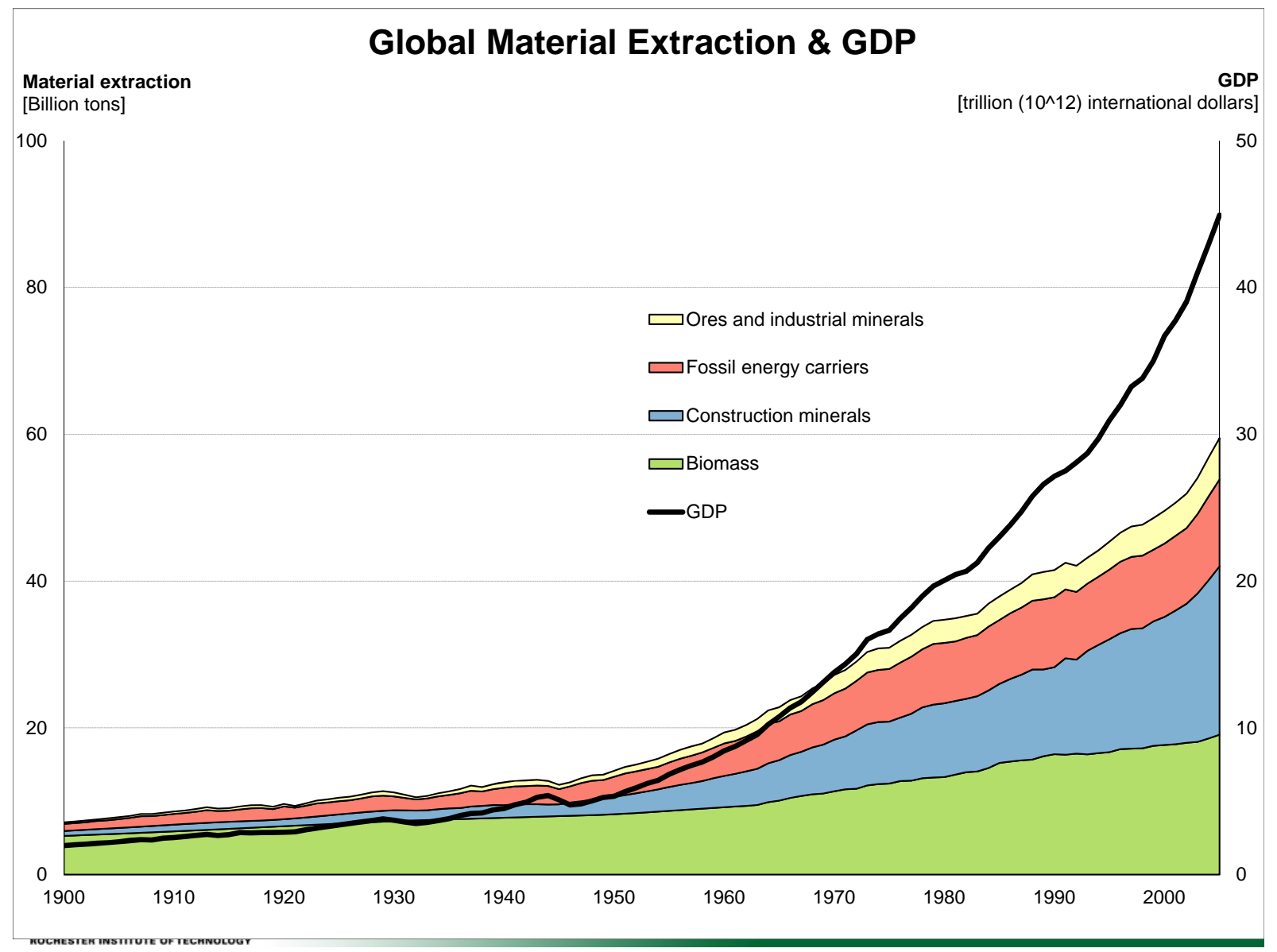

Population Growth (1950-2050)

Population, in billions

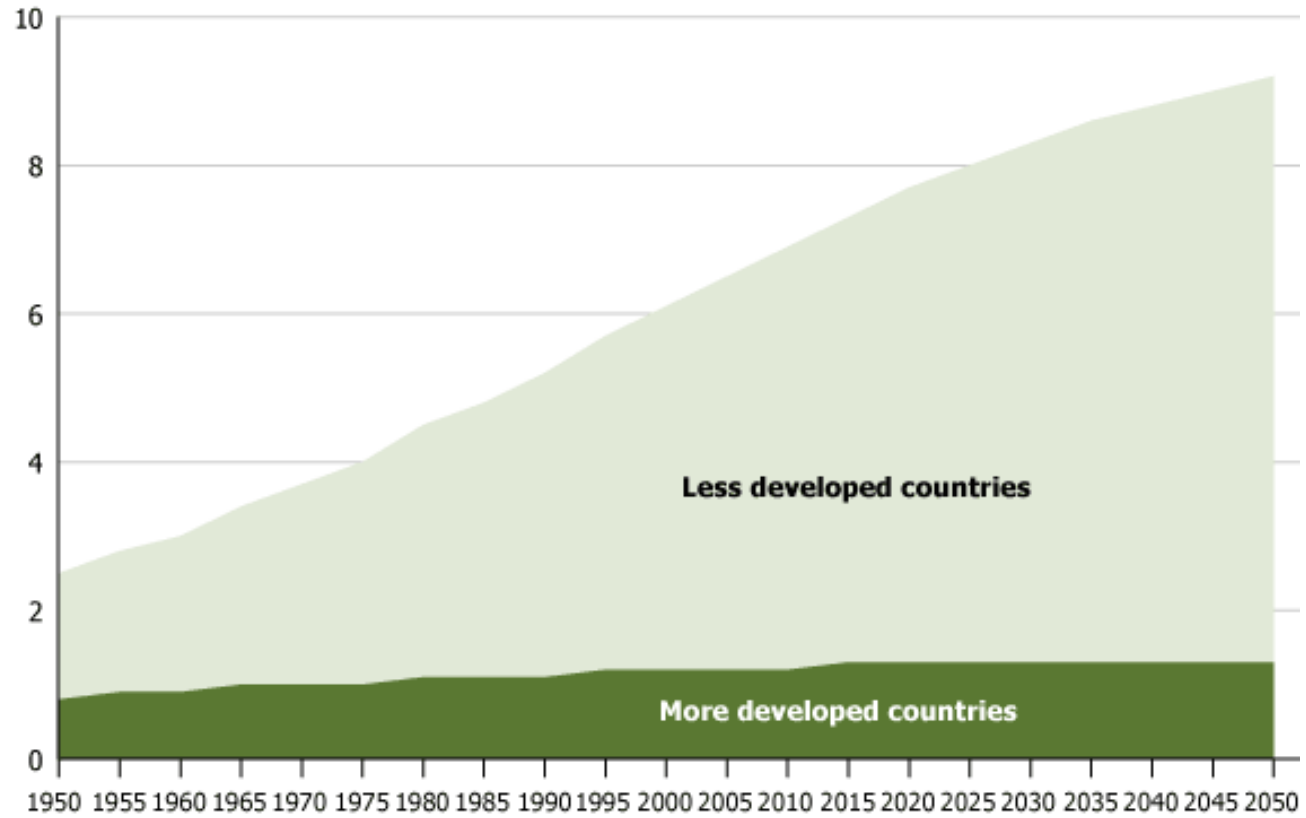

Source: United Nations Population Division, World Population Prospects, The 2008 Revision. 


\section{OECD Project on Sustainable Manufacturing \& Eco- Innovation}

\section{Process overview}

- Formed an Advisory Expert Group (AEG)

- 50 members from 17 countries + EC

- Web-forum for ongoing discussions

- Supported questionnaire surveys \& focus group meetings

- Review of report drafts prepared by the Secretariat ... DSTI/IND(2009)5/PART1-5 


\section{Existing Metrics Approaches}

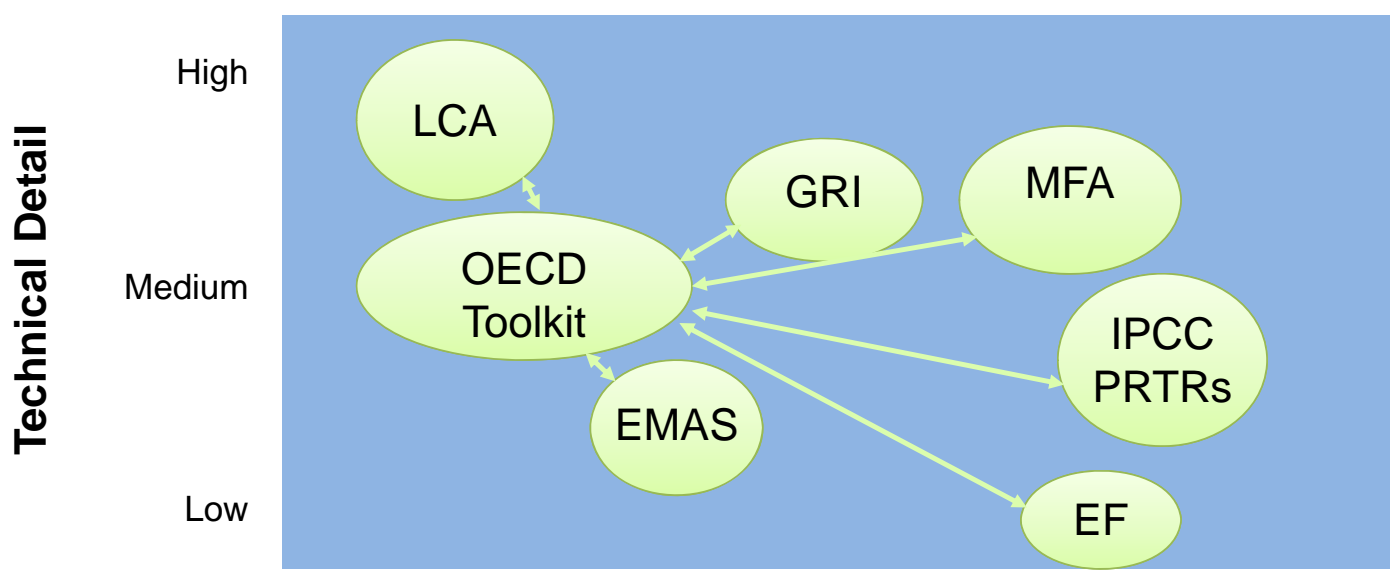

Product | process | facility | corporation | sector | country | global

\section{Measurement unit}

\section{Indicator Categories}
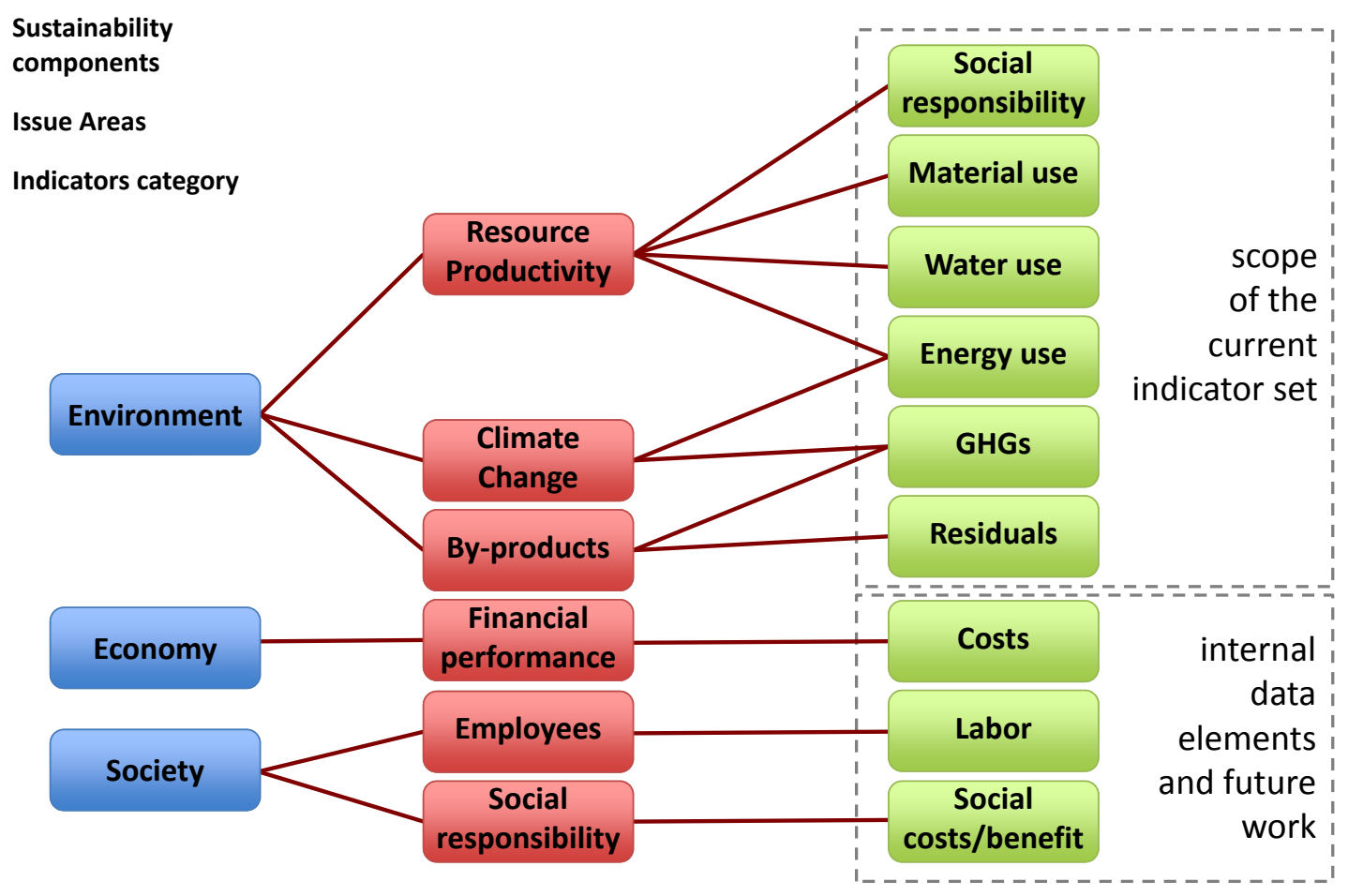


\title{
- Recycling rates of metals
}

- According to the United Nations, recycling rates of metals are often far lower than their potential for reuse. Less than one-third of some 60 metals studied have an end-of-life recycling rate above $50 \%$ and 34 elements are below $1 \%$ recycling, yet many are crucial to promising clean technologies ranging from hybrid car batteries to the high-efficiency magnets in wind turbines.

- Decoupling natural resource use and environmental impacts from economic growth

- By 2050, humanity could devour 140 billion tons of minerals, ores, fossil fuels and biomass per year - $3 \mathrm{X}$ its current appetite - unless the economic growth rate is "decoupled" from the rate of natural resource consumption. We need to rethink the links between resource use and economic prosperity and invest in technological, financial and social innovation to at least freeze per capita consumption in wealthy countries and help developing nations follow a more sustainable path.

\section{$\mathrm{R} \cdot \mathrm{I} \cdot \mathrm{T}$}

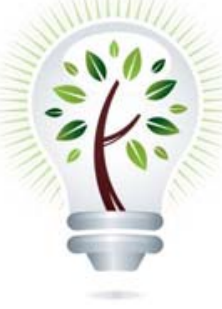

\author{
Prof. Nabil Nasr \\ Caterpillar Professor
}

Associate Provost for Academic Affairs

\& Director, Golisano Institute for Sustainability (GIS)

Rochester Institute of Technology

Rochester, NY USA

Email: nasr@rit.edu

Phone: +1 585-475-5106

http://www.sustainability.rit.edu/ 


\section{Sustainable Manufacturing from a Life Cycle Perspective}

William P. Flanagan, PhD

Director, Ecoassessment Center of Excellence General Electric Company

GE Global Research

Niskayuna, NY

Measurement Science for Sustainable Construction \& Manufacturing NIST - ASCE - ASME - University of Maryland

ASCE Bechtel Center, Reston, VA

June 12-13, 2014

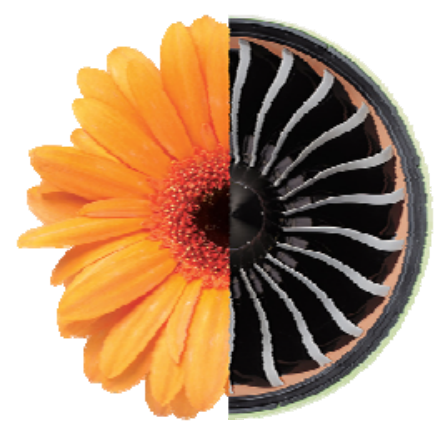

\section{GE today}

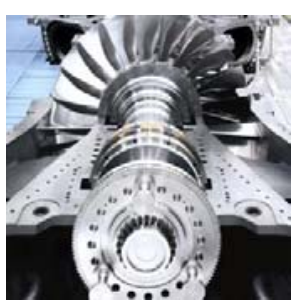

Power \& Water

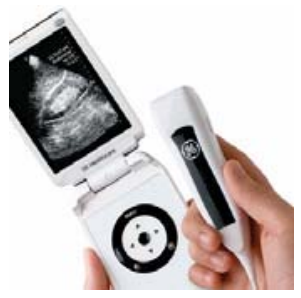

Healthcare

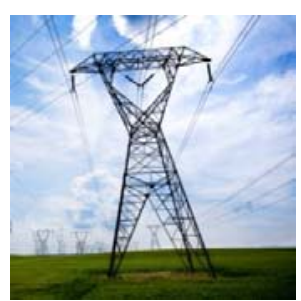

Energy Management

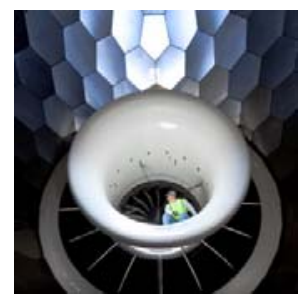

Aviation

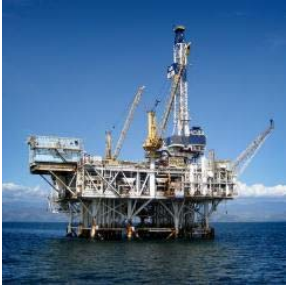

Oil \& Gas

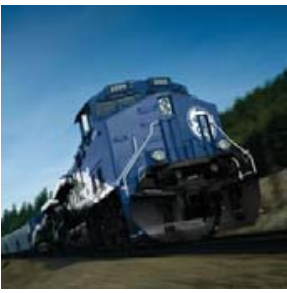

Transportation

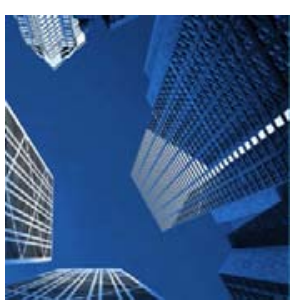

GE Capital

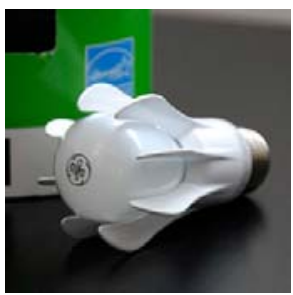

Home \& Business Solutions

\section{Aligned for growth}




\section{GE ... A heritage of innovation}

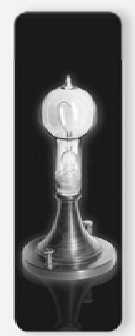

1879

Carbon

Filament

Largest

Locomotive

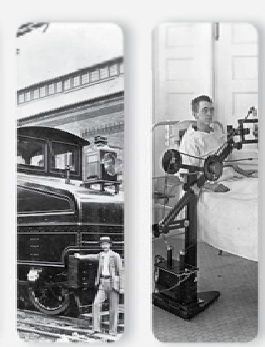

1920

Portable

X-Ray Machine

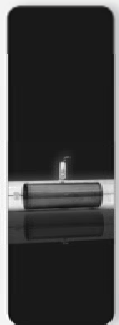

1921

The 1941

Magnetron

Entering

the Jet Age
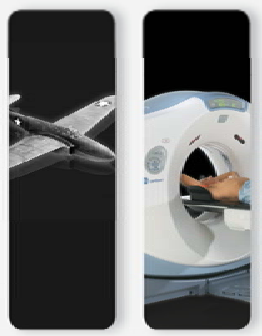

1998

Lightspeed $^{\text {TM }}$

CT Scanner

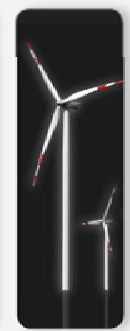

2002

Wind Power

Locomotive

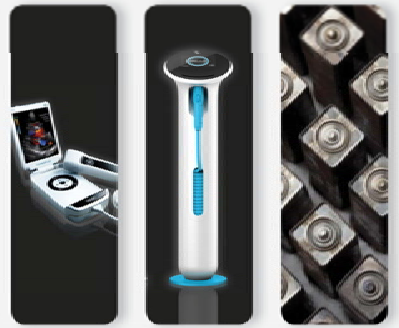

2009

Vscan $^{T M}$

2010

WattStation $^{T M}$ Durathon $^{\text {TM }}$ Battery

\section{The Hush Hush Boys}

In 1941, a group of GE engineers called the Hush Hush Boys (pictured left) worked in secret on a jet engine design developed by Britain's Sir Frank Whittle (pictured right) and built America's first jet engine.

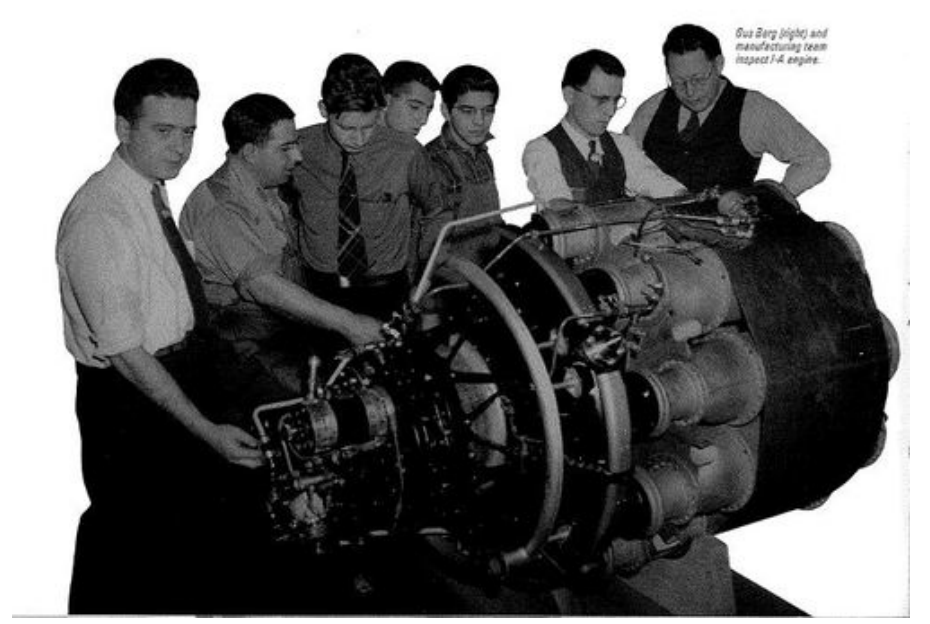

GE's Hush Hush Boys

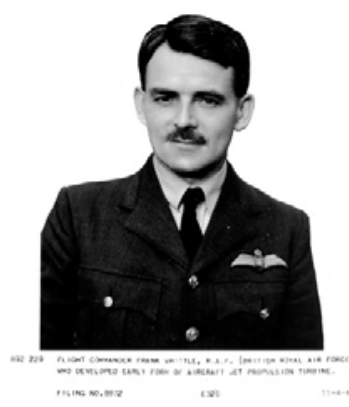

Sir Frank Whittle 


\section{WWII}

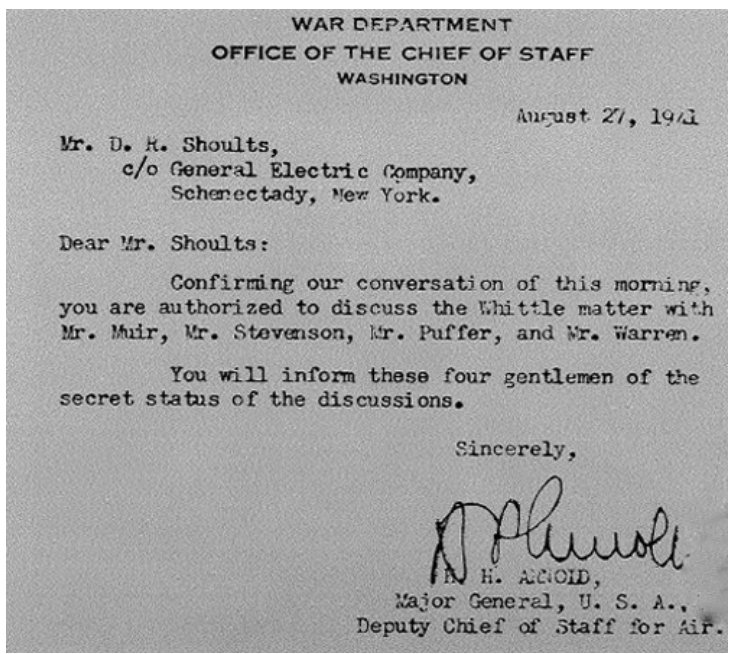

The U.S. War Department picked GE to build the country's first jet engine because of its research and innovation in turbine technology.

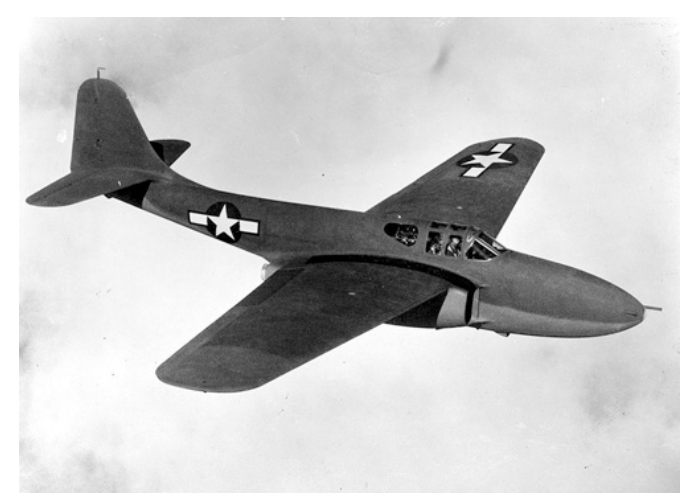

The first GE jet engine powered Bell's experimental XP-59 aircraft.

\section{GE Aviation}

That engine, called I-A (pictured on left), launched GE's aviation business and started an engine dynasty culminating today in the largest and most powerful jet engines ever built: the GE90, GE9X, and GEnx (pictured on right).
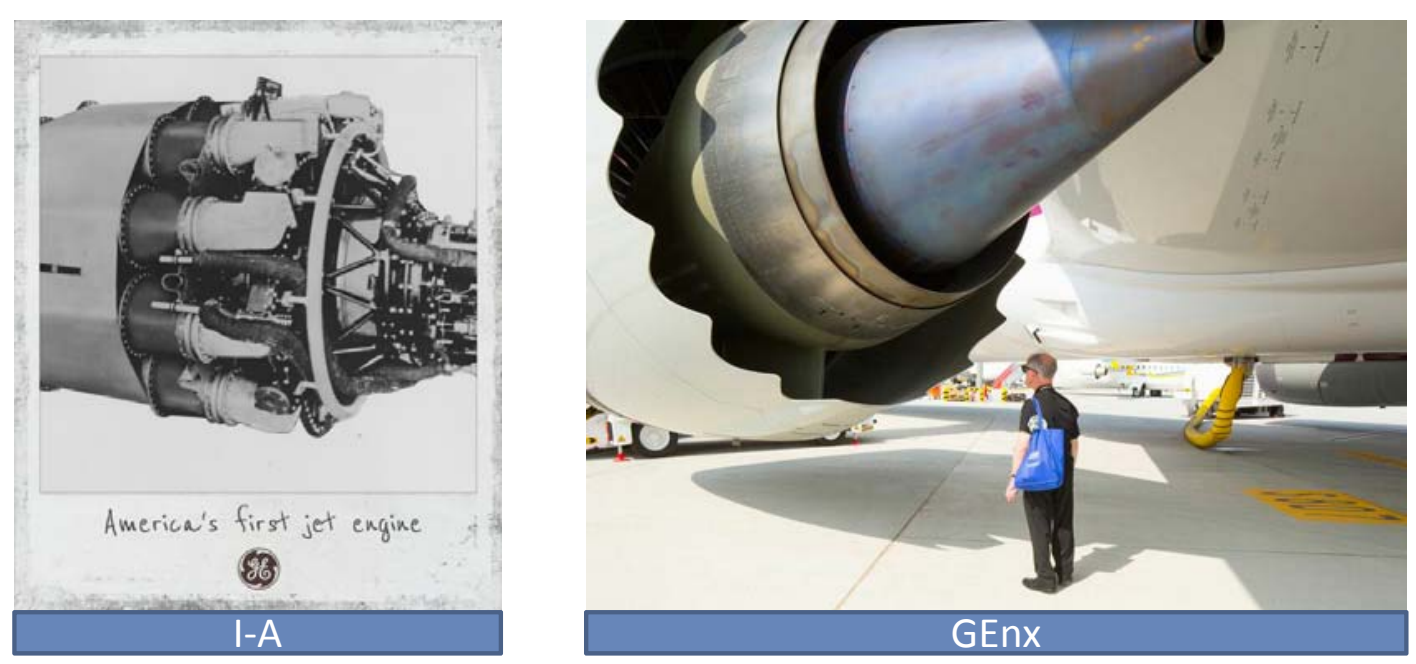


\section{Star Wars Episode VII}

Coming May 2015
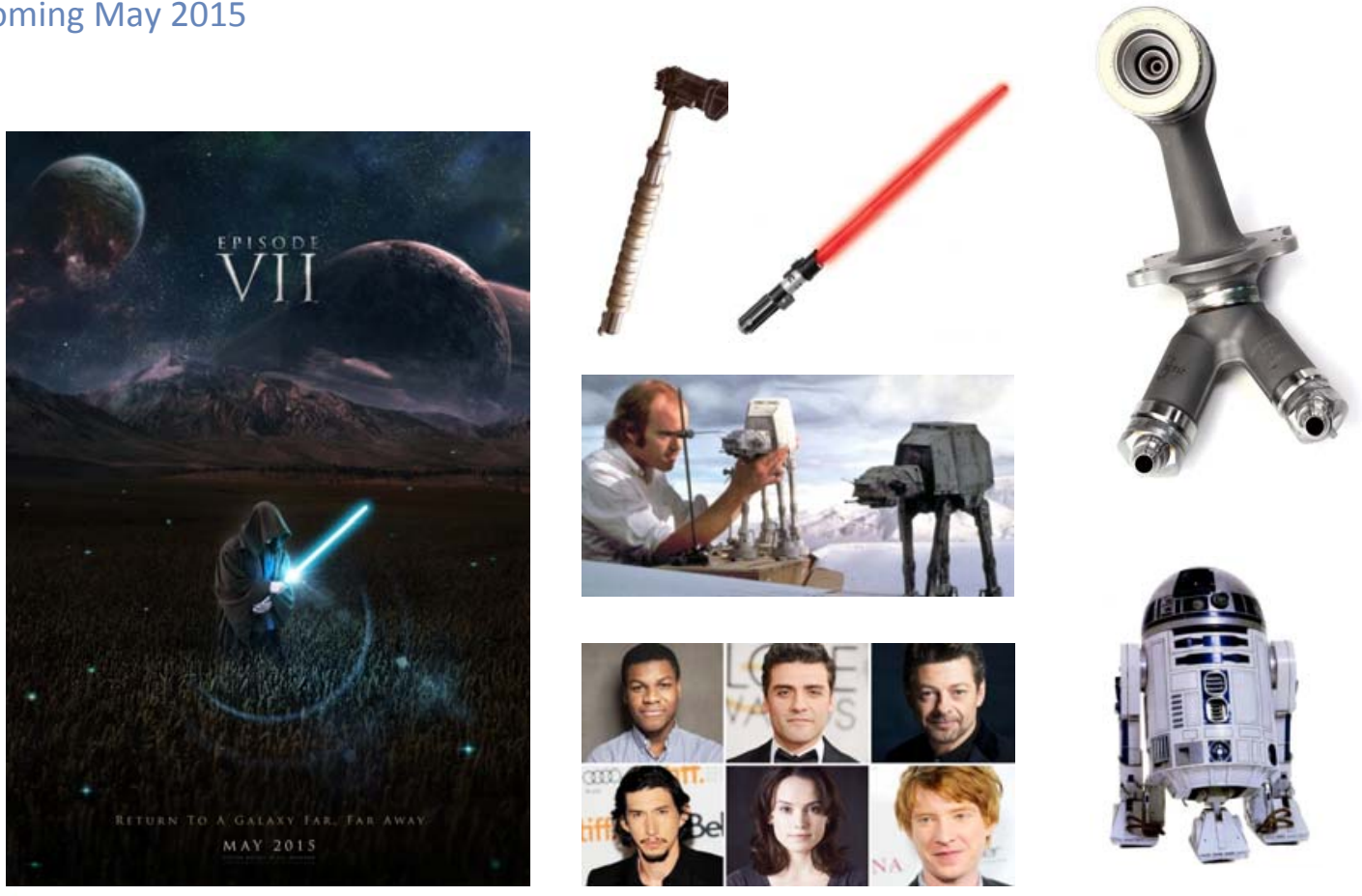

\section{CFM LEAP Engine}

Coming 2016

- CFM International is a 50/50 joint venture between GE and France's Snecma

- The LEAP engine is CFM's next-generation high-bypass turbofan jet engine

-3D-printed fuel nozzles offer: $0>20 \%$ weight reduction $05 x$ longer part life
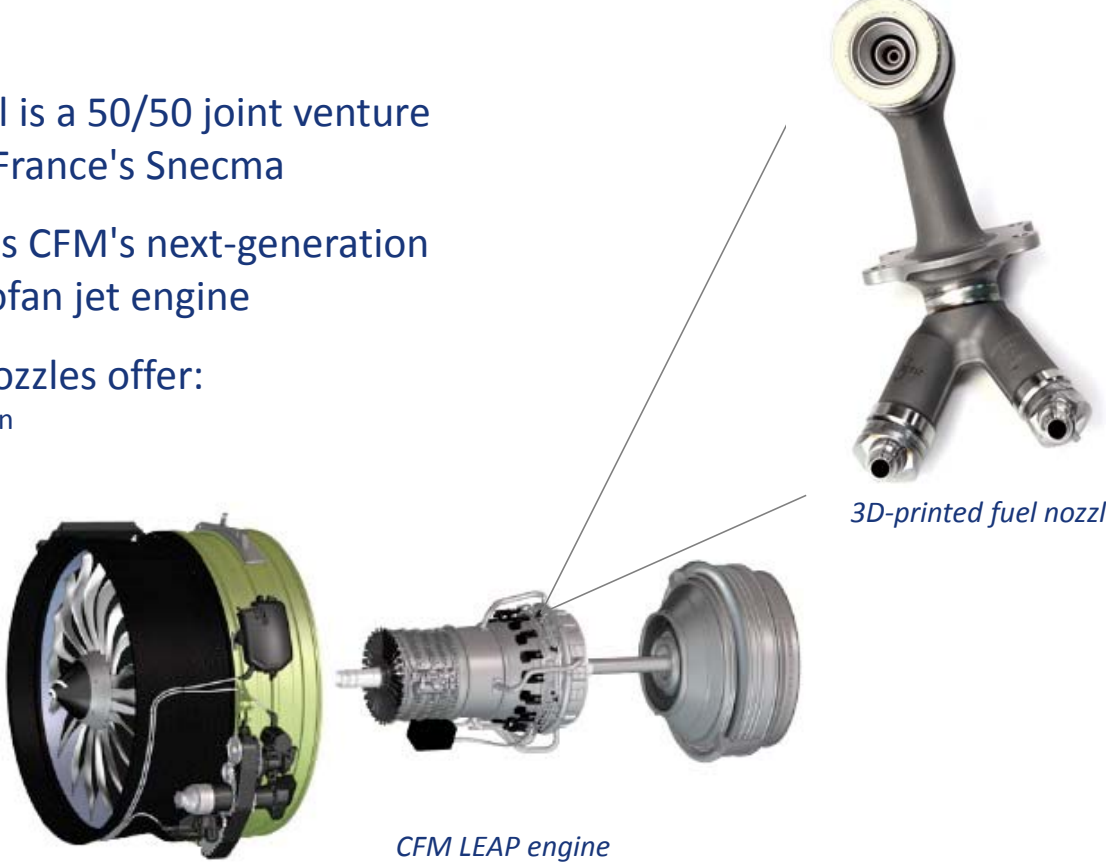

3D-printed fuel nozzle 


\section{LCA and systems level thinking}

\section{GE Ecoassessment}

Center of Excellence

Technical credibility \& product support

- Product LCA + LCM toolkits

-Strategic \& selective application

Drive eco further into product development

- Customize to business context

-Identify opportunities for real improvement

\section{Deliver customer value}

-Strategic engagement

-Environmental and operational savings

\section{Thought leadership}

- Drive business perspective on sustainability

- Create \& maintain momentum toward real change

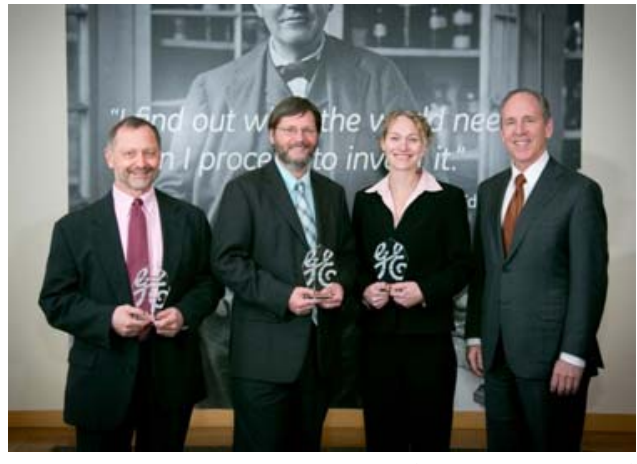

Ron Wroczynski, Bill Flanagan, Angela Fisher (with GE CTO Mark Little)

\section{Key Roles:}

- Expertise and guidance

$\checkmark$ Life cycle assessment (LCA)

$\checkmark$ Life cycle management (LCM)

$\checkmark$ Carbon, energy, water footprint

$\checkmark$ ecoDesign / Design for Environment

- Tools and resources

- Education and awareness

- External networks

\section{Support:}

- Policy and advocacy

- Business strategies / integration

-Stakeholder engagement 


\section{Life Cycle Assessment (LCA)}

Assess overall environmental impact throughout a product or service's life cycle
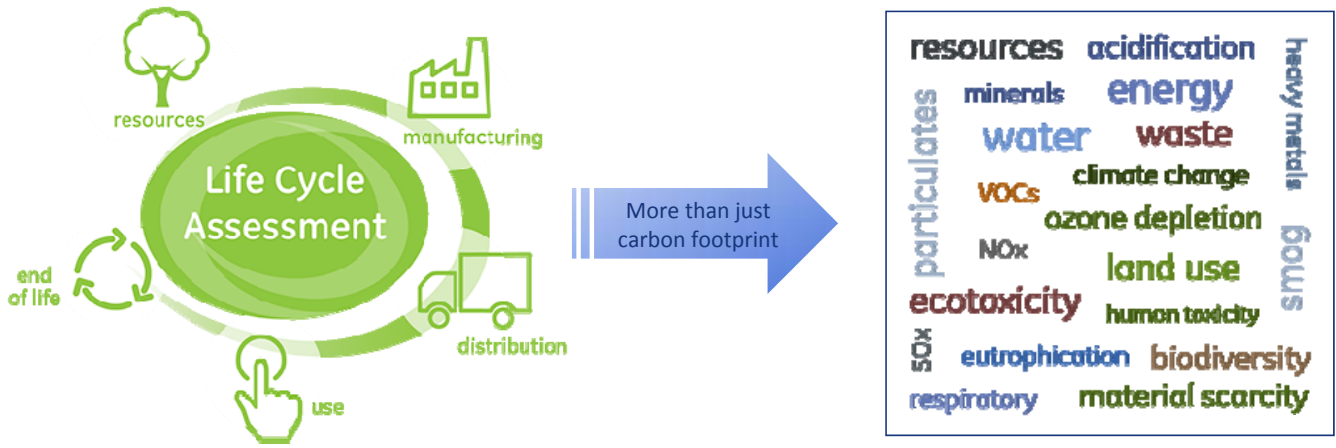

Understanding the net environmental impact of a product/service across its value chain, how and where to make improvements

Differentiate products

Evaluate alternatives

Prioritize opportunities for improvement

Mitigate environmental issues

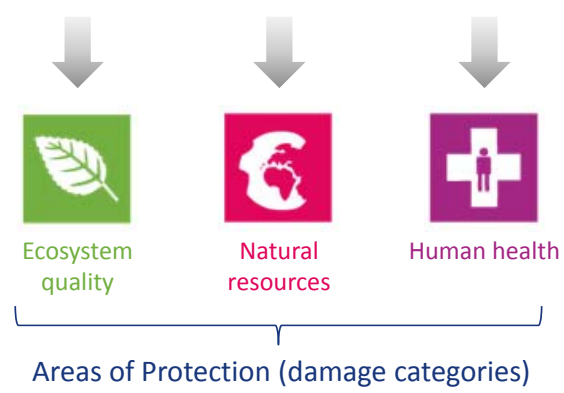

go. ecoassessment center of excellence

\section{LCA is not a panacea}

Holistic, but not comprehensive

- In practice, limited to existing impact categories and characterization factors

- Difficult to address specific effects and emerging issues (e.g., endocrine disruptors, nano materials)

Global vs. local perspective

- Difficult to address region-specific or application-specific impacts (e.g., regional species impacts, actual vs. potential exposures, other localized issues)

Water impacts under-represented

Social / economic / behavioral aspects often missing

Difficult to apply to emerging technologies (R\&D) 


\section{A tiered life cycle management strategy}

Environmental Product LCM Tool

(qualitative)

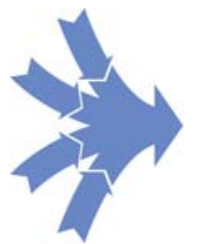

Apply level 1 tool early in product development across broad product portfolio

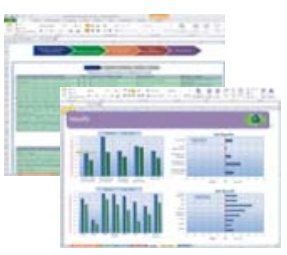

Tool rapidly identifies followup needs

Address identified issues

Substances of concern

Material scarcity

Toxicology assessments

Environmental risk assessment

Nanomaterial EH\&S

Product regulatory compliance

Etc.

\section{2 screening LCA}

3 Streamlined LCA

4 Detailed LCA per ISO 14044

\section{Strategic | Comprehensive | Efficient | Effective}

\section{Anticipatory LCA}

Wender et al.

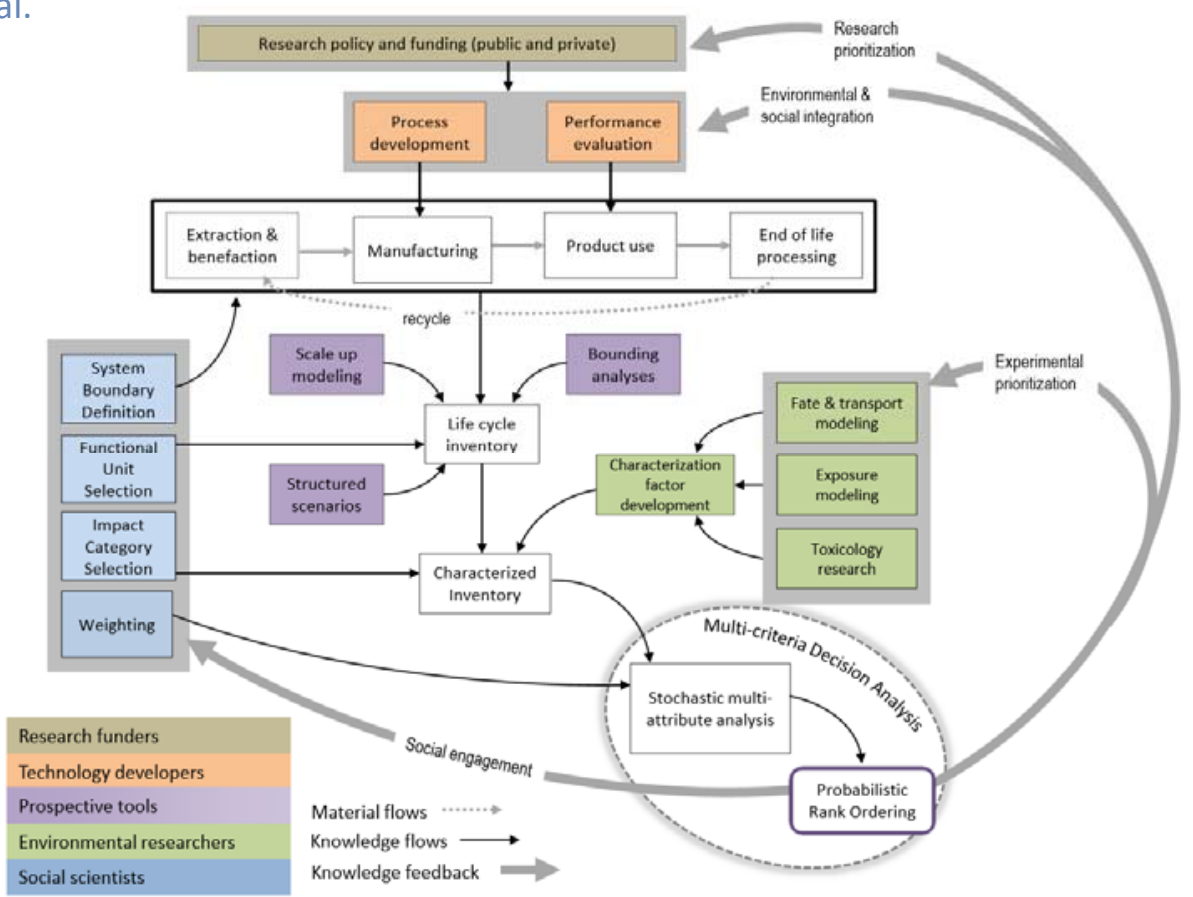




\section{Additive manufacturing}

\section{Billet vs. additive manufacturing}

Conventional
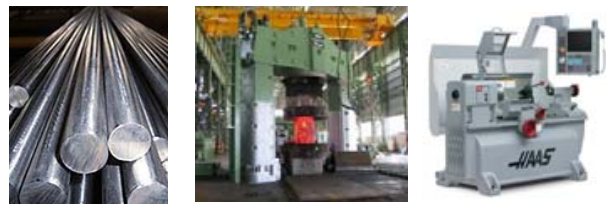

Start with a pre-formed billet, which gets formed and machined

Material properties unchanged and cannot be location specific

Limited to known set of geometries

Design constrained by manufacturing

Requires extensive tooling
Additive
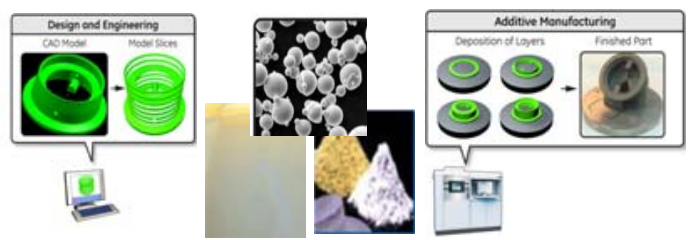

Starts with a powder or wire and produces part layer upon layer upon layer

Build material properties as you build the part ... location specific

More complex geometries possible

Allows for faster iterations between design, materials and manufacturing

Minimal tooling required 


\section{EADS Additive Case Study}

Hinge Redesign
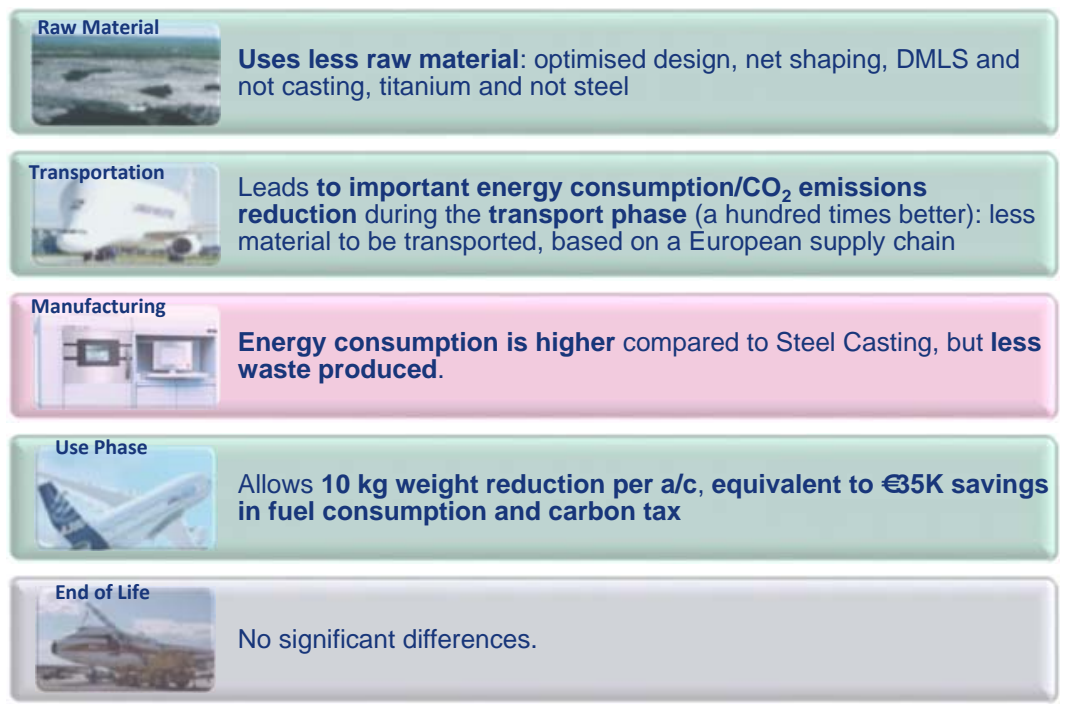

Conventional Steel Design

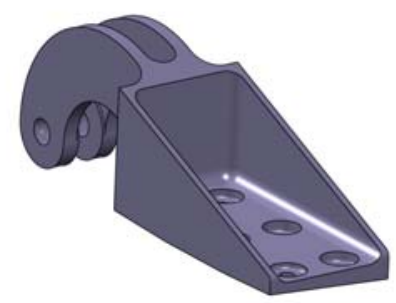

Ti ALM Optimized Design

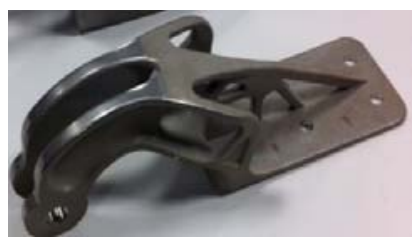

In this case, additive manufacturing has higher energy consumption during manufacturing, but lower overall life cycle impact

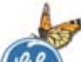

\section{GE Aviation Additive Case Study}

Fan Blade Metal Leading Edge (MLE)

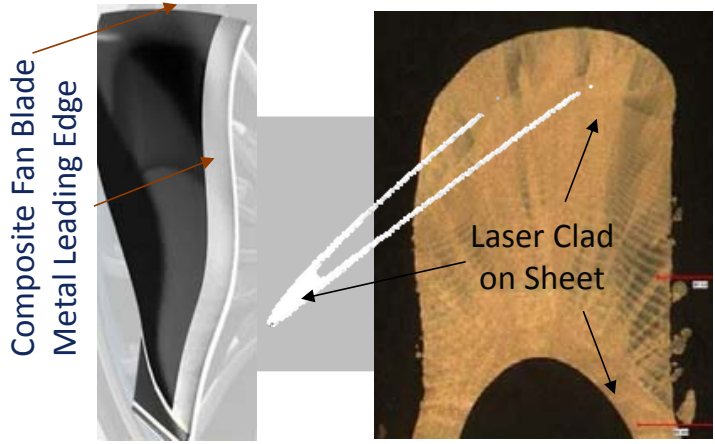

- Cost reduction over extensive machining cycles of near net shape forging

- Laser cladding, cold spray, wire technologies and hybrids (e.g., forging/additive) emerging

- Establish new Supply Chain and footprint

\section{PROBLEM}

- Composite fan blades enable significant engine performance vs. titanium forged blades

- Composites require metal leading edge for erosion protection

- Cost of machining Ti and other superalloys

\section{OBJECTIVE OR SOLUTION}

- Form inner face of MLE from sheet stock and laser clad (or other additive) bulk material

\section{APPROACH}

- Establish bulk and hybrid laser clad material properties

- Perform static impact testing of scaled hybrid

- Perform rotational impact on FAA cert program engines 


\section{US Department of Defense}

- Defense industry consortium: Mission Ready Sustainability Initiative o GE Aviation, Lockheed Martin, BASF, 3M, General Dynamics, others

- Aimed at DoD sustainability initiatives:

oDoD Strategic Sustainability Performance Plan, Air Force Energy Plan, Presidential Executive Orders 13514 / 13423

oSustainability tools and metrics may be imposed on DoD acquisitions

- Strong, active engagement from DoD:

o Office of Secretary of Defense, Deputy Director of Chemical \& Material Risk Management

- DoD Streamlined LCA / LCC methodology developed for use in defense acquisitions

o Pilots underway: GE, 3M, BASF, Lockheed Martin

o Method integrates environmental and cost aspects

o Total Cost of Ownership
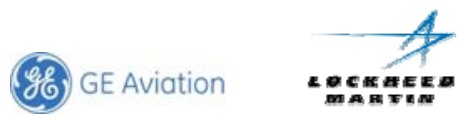

D-BASF

$\operatorname{mankEND}$

B: anenal dynamies

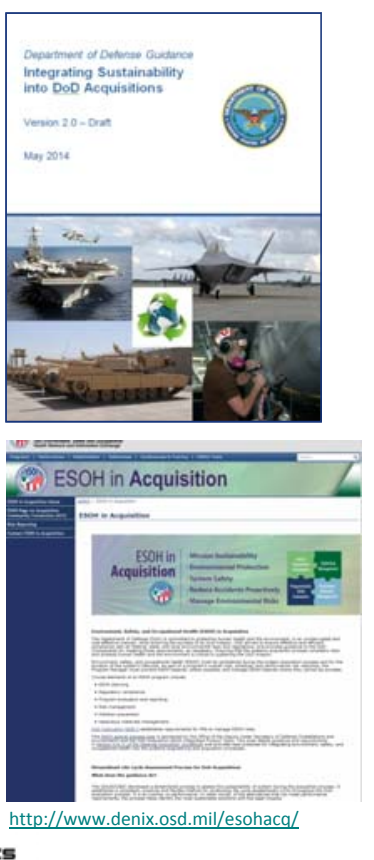

Understand and build capability for emerging acquisition criteria

\section{Additive Manufacturing of Fuel Nozzles}

Pilot of US DoD streamlined LCA/LCC methodology

Traditional fuel nozzles are manufactured via forging and machining processes

Fuel nozzles manufactured by additive manufacturing processes offer:

- $>20 \%$ weight reduction

- $5 x$ longer part life

Potential for significantly reduced life cycle environmental impact and total cost of ownership due to:
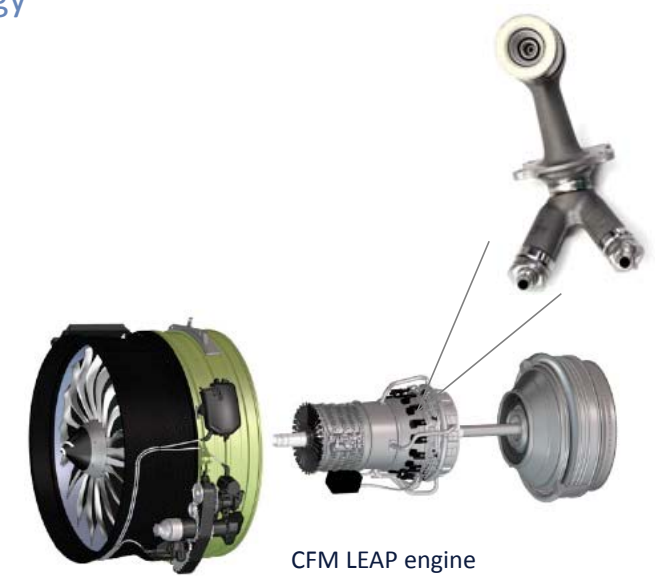

- Reduced part weight:

o Reduced fuel consumption over the life of the aircraft system

o Increased mission capability (load capacity)

- Net lower raw material consumption

- Enhanced performance

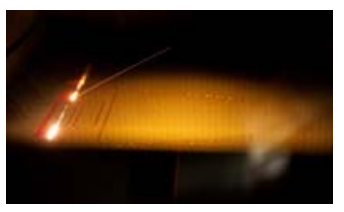

Direct metal laser sintering Courtesy EADS Innovation Works 


\section{Pilot project benefits}

\section{Clear need for trade-off assessment}

o Environmental impact

o Total cost of ownership

o Trade-offs relevant to supplier: design, supply chain, manufacturing, performance

o Trade-offs relevant to US DoD: total cost, mission, sustainment \& operations

Opportunity to pilot methodology early in product development

o Ability to leverage insights gained

\section{Focus on additive manufacturing}

o Understand trade-offs before paradigm shift

LCA XIV, San Francisco, Oct 6-8, 2014 Special session: "Streamlined LCA/LCC in Defense Acquisitions"

\section{Understand net benefit and trade-offs associated with}

\section{Sustainable manufacturing}

Sustainable manufacturing should consider all life cycle stages

Different manufacturing processes may:

$\checkmark$ enable novel material choices

$\checkmark$ have different material and energy efficiencies

$\checkmark$ enable unique part geometries or other features affecting performance

$\checkmark$ offer enhanced repair-ability, re-usability, recyclability at end of life

Different materials may have different:

$\checkmark$ supply chain impacts

$\checkmark$ manufacturability

$\checkmark$ performance properties (e.g., thermal, mechanical)

$\checkmark$ end of life options (e.g., recyclability, re-usability) 


\section{Thanks! Bill Flanagan}

\section{Acknowledgements}

Angela Fisher

GE Ecoassessment

Ron Wroczynski

GE Ecoassessment

Todd Rockstroh

GE Aviation 


\section{Sustainable Construction: An EPC Perspective}

Nancy Kralik

Senior Director, Health, Safety, Environment \& Sustainability

Fluor Corporation

June 12, 2014

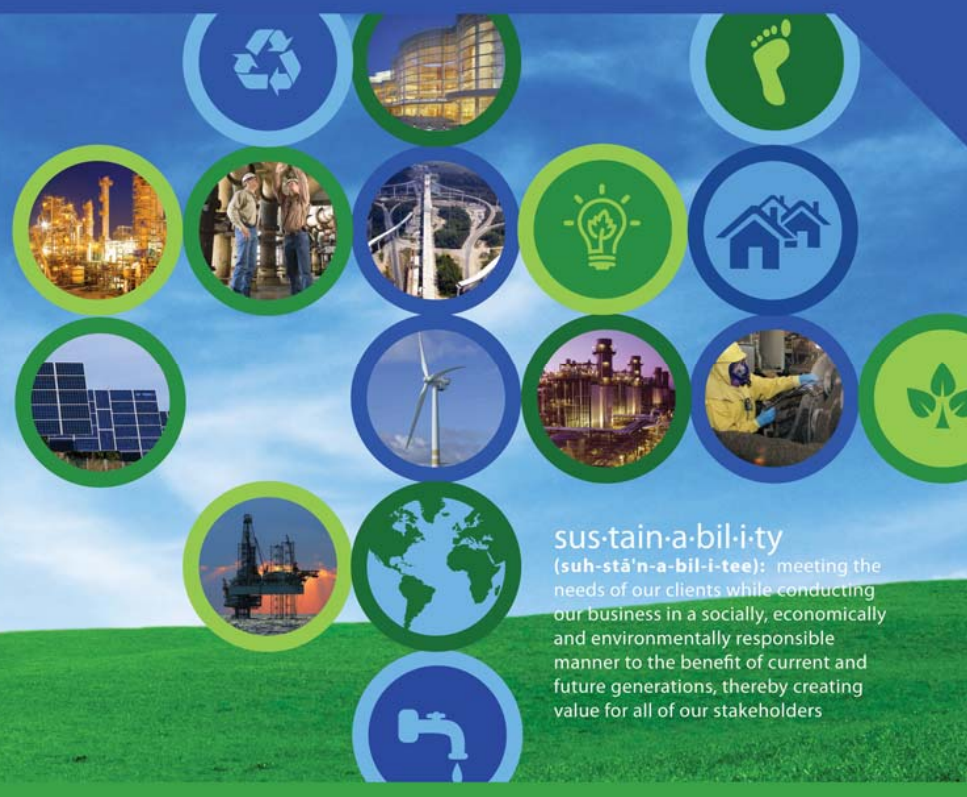

FLUOR。

\section{Influence Curve}

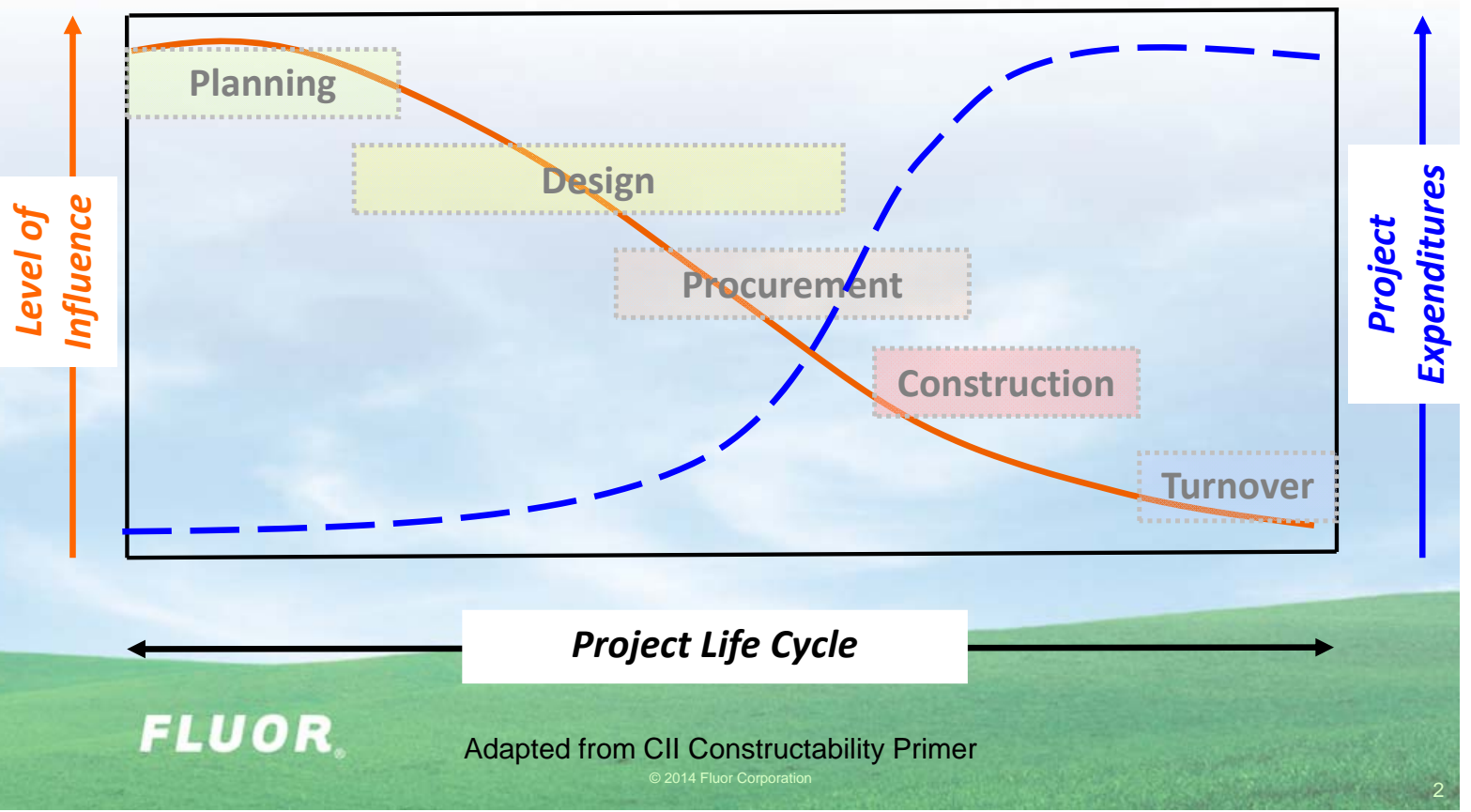




\section{Construction Phase}

\section{6}

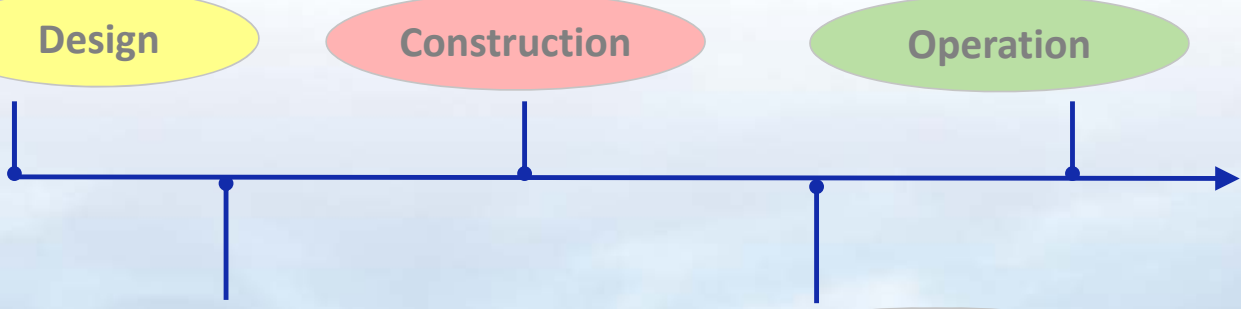

Site Planning

Final Commissioning

Report

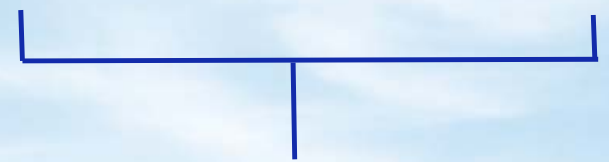

Construction Phase

\section{FLUOR}

\section{Safety Metrics (Social)}

\section{Lagging}

- Lost time incidence rate

- Recordable incident rate

- Etc.

\section{Leading}

- Audits

- Inspections

- Training

- Etc. 
Economic Metrics

Budget

$\checkmark$ Schedule

Cost of energy

$\checkmark$ Cost of raw materials

Water consumed

\section{FLUOR.}

\section{Environmental Metrics}

Brownfield

$\checkmark$ Greenfield 


\section{Social Metrics}

$\checkmark$ Human Rights

$\checkmark$ Labor Practices

Community Impact and Involvement

Worker Safety

\section{FLUOR.}

\section{Construction Industry Institute}

Guidance on sustainability during construction

- RT304

Compendium of sustainability practices

- RT250 


\section{Sustainability Action Catalog}

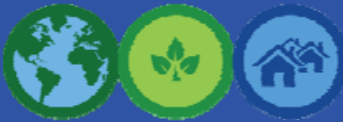

- Sustainability Impacts

- Project Conditions

- Output Metrics

\section{FLUOR}

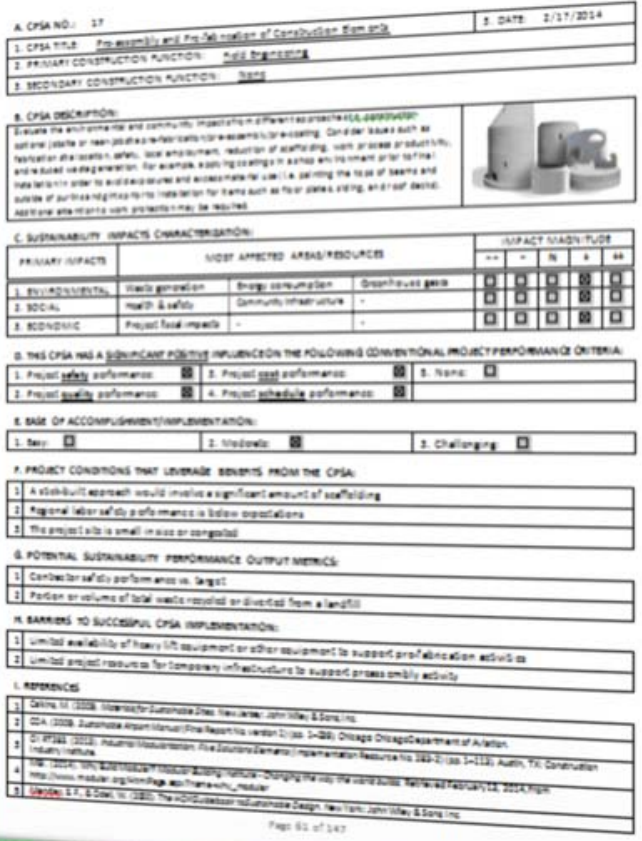

\section{Sustainability Action Screening Tool}

\section{2 types of Input:}

- Relative priorities/weightings of desired Sustainability impacts

- Applicability of project conditions 


\section{Screening Tool Output}

\section{6}

Also available for Tablet or Smart Phone

\section{FLUOR}

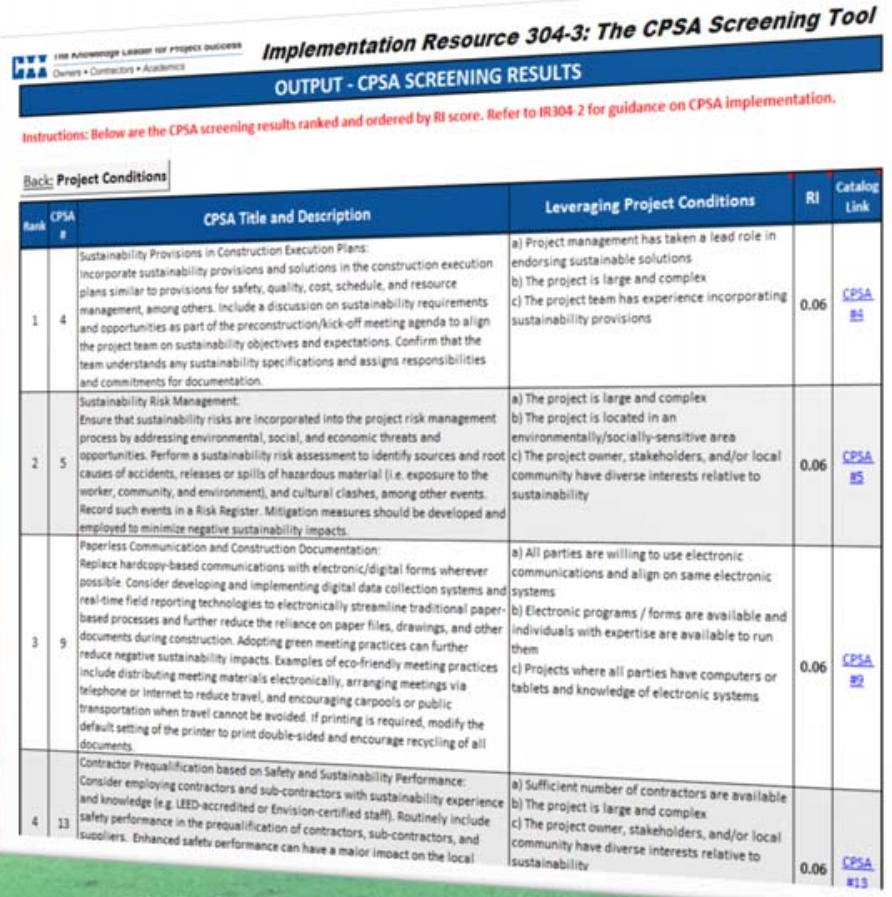

\section{Implementation Index}

IR 304-4: CPSA Implementation Index Calculator

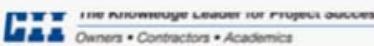

\section{INPUT - CPSA IMPLEMENTATION EFFORT CHECKLIST}

Instructions: Please read the descriptions for the following 54 CPSAs and select/check the degree to which the CPSAs were implemented on your project.

Back: Project Information

CLEAR ALL CHECKBOXES

Next: Implementation Index

\section{CPSA Title and Description}

CPSA \#1. Leadership Team Staffine for Sustainable Proiects:

Seek to establish a "hearts and minds" sustainability-oriented culture much like organizations pursue a safety or qua lity culture. Employ administrative staff that possess skills and experience in the management of sustainable projects. Identify voids in knowledge and be prepared to offer supplemental training on project environmental and community impacts, worker safety cultures, effective project communication, etc.

\section{CPSA \#2. Community Social Responsibility Program:}

Consider establishing a formal community social responsibility program as a way to respond to stakeholder needs. Formal community signoffs on individual initiatives can be very beneficial. Related volunteer-based programs can have a significant impact as well. This responsibility program should include the development and maintenance of a project website for the local community and holding community forums to discuss project issues, such as traffic impacts and upcoming construction lwork.

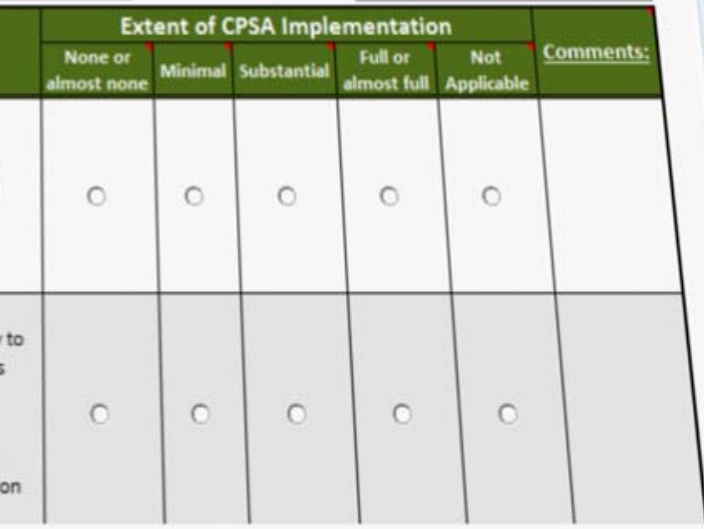

\section{FLUOR}




\section{Predominant Output Metrics}

Percent of projects with Sustainability Performance section in project reports;

Cost savings;

Portion or volume of total waste recycled or diverted from a landfill;

Street value of recycled material;

Equipment environmental performance;

$\checkmark$ Size of carbon footprint from project; and

Number of complaints from community, agency, or camp residents.

\section{FLUOR}

\section{7-Step Implementation Process}

- Establish Objectives

- Rank Top Actions

- Select Actions

- Plan Action Implementation

- Implement Actions

- Measure Outcomes

- Improve Process 


\section{Gaps \& Research Needs}

$\checkmark$ Quantitative social metrics

Easy-to-generate life-cycle assessments

$\checkmark$ Industrial Sustainability Index Metrics

Case studies for identified sustainability actions

- New metrics?

- Benchmarking

Field use

\section{FLUOR}

\section{Questions and Comments Welcome}

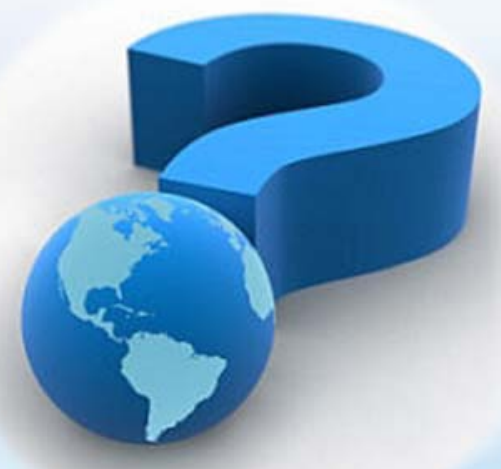




\section{How to Quantify Sustainability in Construction and Manufacturing, and the Need for Standards}

Subhas Sikdar, US EPA, and

Humberto S. Brandi, INMETRO, Brazil

NIST-ASCE-ASME Sustainability Workshop, Rockville, MD, June 12-13, 2014

\section{Essential Relationships of Sustainability}

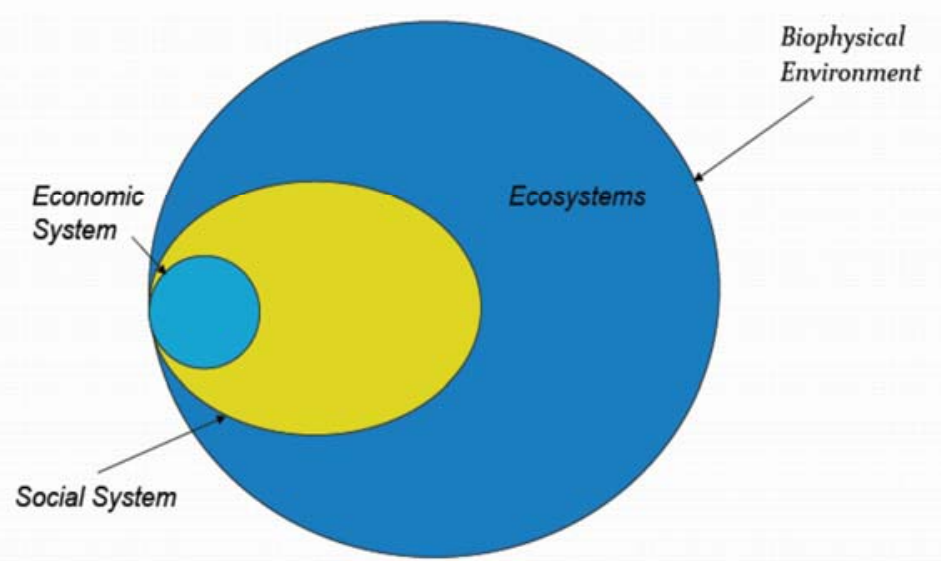

Sustainability is like the proverbial elephant. We, much like blind people, describe it in terms that depend on our field of expertise. Thus .... - 
Many Men, Many Minds

Sustainability through disciplinary lenses

- For an economist, sustainability is at first related to new economic models of growth and regulation, taking into account not only the traditional quantifiable components of welfare, but also a lot of environmental "externalities" and qualitative assets.

- For an ecologist, sustainability means the use of natural resources to the extent that the carrying and regenerative capacities of the ecosystems are not jeopardized.

- For a physicist, sustainability means the ability of biological systems to fight against degradation of energy and resources (entropy) by creating new forms of order (negentropy) using the various inputs of solar energy.

- For a chemist or an engineer, the challenge of sustainability is to complete material and energy life cycles created by human activities, through new techniques for material design, re-use, recycling and waste management.

- For a social scientist, sustainability implies the social and cultural compatibility of human intervention in the environment with its images constructed by different groups within society.

Economic development (i.e. by technology application) with decreasing environmental impact and improving societal benefit
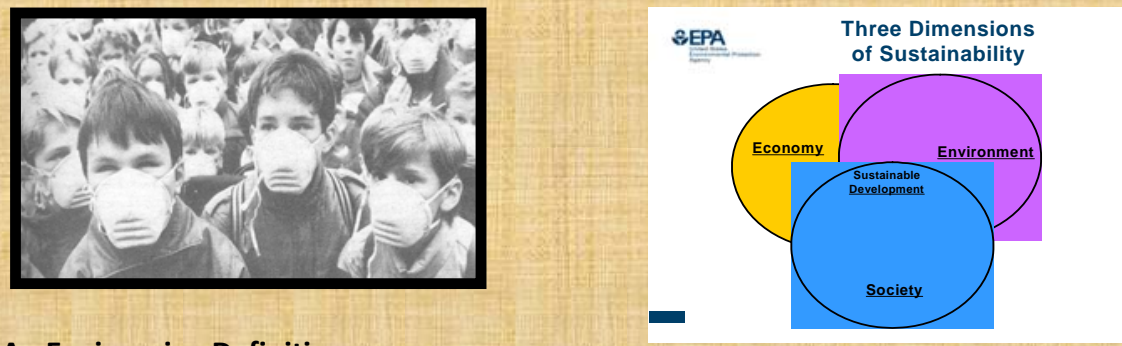

An Engineering Definition:

For a man-made system, sustainable development is continual improvement in one or more of the three domains of sustainability, i.e., economic, environmental, and societal without causing degradation in any of the rest, either now or in the future, when compared with quantifiable metrics, to a similar system it is intended to replace. 


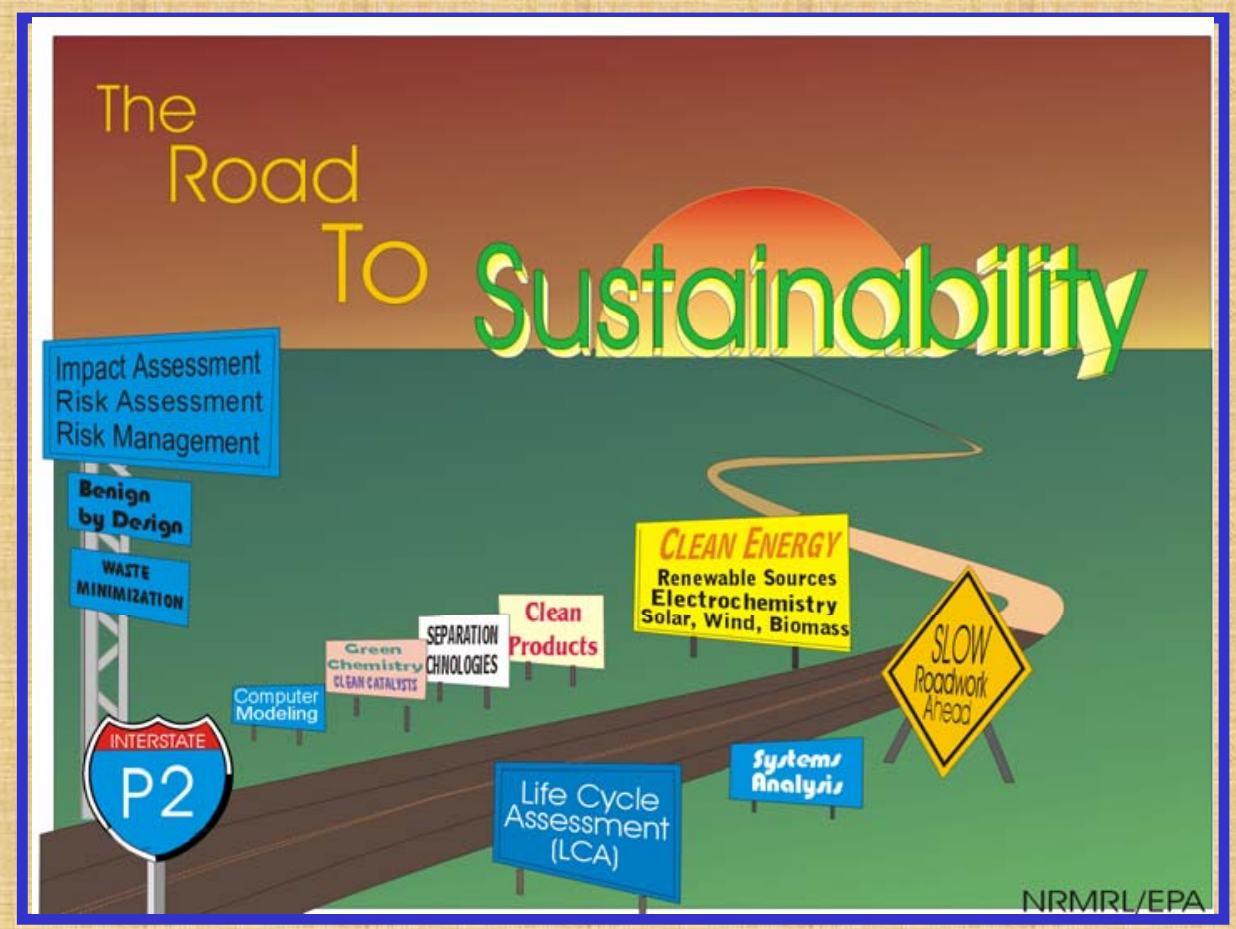

\section{Scale and Nesting of Sustainable Systems}

Level I: Global Systems (e.g. global C02 budgeting)
Level II: National Systems (energy system, material flow)
Level III: Regional Systems (e.g. watersheds, Brownfields)
Level IV: Business Systems (e.g. business networks, waste exchange networks
Type V: Sustainable technologies (e.g. green materials, sustainable products)

I: Global Scale
(e.g. global $\mathrm{CO}$ budgeting) II. National Scale (e.g. energy)

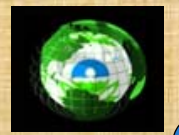

System-Surrounding Paradigm

Sustainability analysis is essentially an accounting of what impacts (environmental, economic, and societal) the system is causing to itsel and to the surrounding, and how these impacts can be minimized.

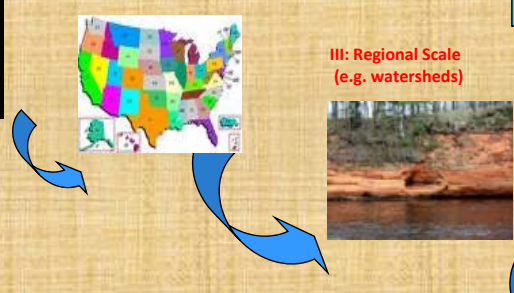




\title{
Measurement and Standards
}

Quality, Uniformity, Confidence: Three Pillars of Sustainable Development

\author{
Clear understanding of what is wanted: \\ Standardization - Documentary standards \\ Proceeding to implement "what is wanted": \\ Conformity Assessment - Certication, labelling, supliers declaration, auditing. Accreditation \\ Guaranty that "what one has is what is wanted": \\ Trust in measurements: \\ Metrology-Measurement standards
}

Example: GHG emision standards require:

Harmonize knowledge

Harmonize measurements

Harmonize methodologies

Harmonize inventories

\section{Metrics and Indicators}




\section{Methods of Sustainability Analysis:}

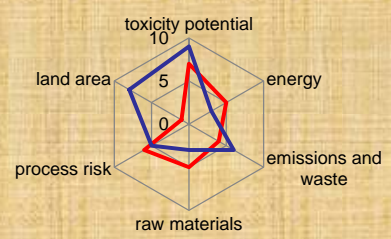

BASF Eco-efficiency Analysis

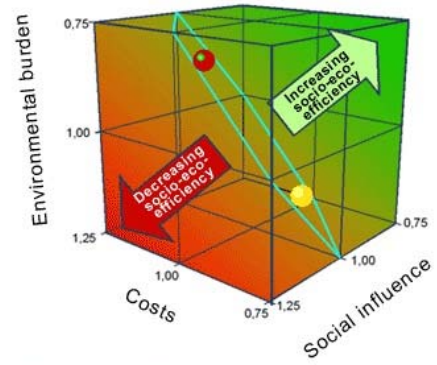

Alternative 10 Alternative 2

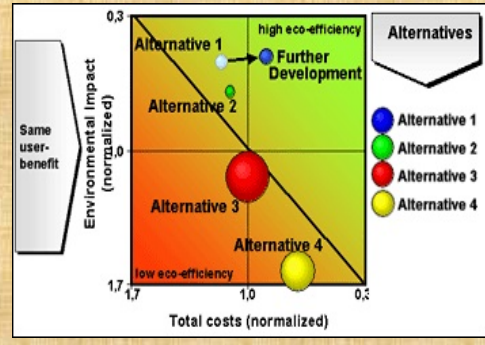

BASF Eco-efficiency analysis: combines Environmental and Economic Dimensions Of Sustainability

BASF Sustainability Analysis: combines All three dimensions of sustainability (called socio-eco-efficiency)

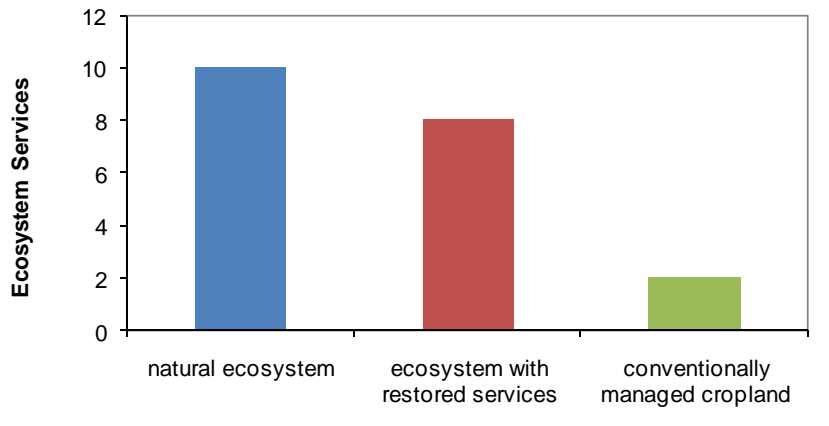

Eco services indicator is a qualitative composite of 8 indicators: crop production, forest production, preserving habitats and biodiversity, water flow regulation, water quality regulation, carbon sequestration, regional climate and air quality regulation, infectious disease mediation.

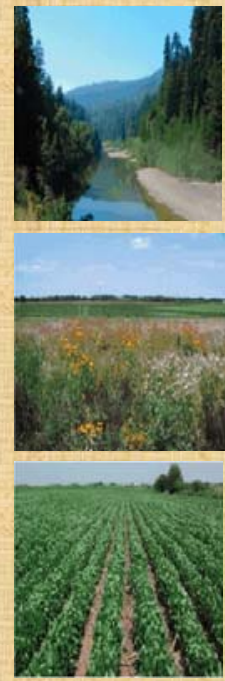




\section{Construction of aggregate index:}

hypothesis: sustainability footprint $D_{e}$ or $D=f\left(x_{i}, i=1\right.$ to $\left.n\right)$,

represents the overall state of the system as revealed by the

set of chosen indicators

Sustainability footprint

$$
D_{e}=\sqrt{\sum_{j}^{n}\left[c_{j} \frac{\left(y_{j}-x_{j 0}\right)}{\left(y_{j}-x_{j 0}\right)_{\max }}\right]^{2}}
$$

- Euclidean Distance Method

$D=\left(\prod_{i}^{n}\left[c_{i}\left(y_{i}^{\prime} / x_{i}^{\prime}\right)\right]\right)^{1 / n}$

- Canberra Index Method

- Others

$y_{i}^{\prime}=y_{i}-\left(x_{i 0}-C_{\text {offset }}\right)$

$x_{i}^{\prime}=x_{i}-\left(x_{i 0}-C_{\text {offer }}\right)$

or perfect sustainability, the value of

Sustainability Footprint is

zero

Indicators, $\mathrm{X}$

\begin{tabular}{|c|c|c|c|c|c|c|c|c|c|}
\hline $\begin{array}{l}\text { Process } \\
\text { options }\end{array}$ & $X_{1}$ & $x_{2}$ & $x_{3}$ & $X_{4}$ & $X_{5}$ & $x_{6}$ & $x_{7}$ & $X_{8}$ & $X_{9}$ \\
\hline Option 1 & $x_{1,1}$ & $x_{1,2}$ & & & & & & & $x_{1,9}$ \\
\hline Option 2 & $x_{2,1}$ & $x_{2,2}$ & & & & & & & $x_{2,9}$ \\
\hline Option 3 & $x_{3,1}$ & $x_{3,2}$ & & & & & & & $x_{3,9}$ \\
\hline Option 4 & $x_{4,1}$ & $x_{4,2}$ & & & & & & & $x_{4,9}$ \\
\hline Option 5 & $x_{5,1}$ & $x_{5,2}$ & & & & & & & $x_{5,9}$ \\
\hline Option 6 & $x_{6,1}$ & $x_{6,2}$ & & & & & & & $x_{6,9}$ \\
\hline Option 7 & $x_{7,1}$ & $x_{7,2}$ & & & & & & & $x_{7,9}$ \\
\hline
\end{tabular}




\section{PCA-PLS-VIP (Finding Redundant Indicators, and Rank Order)}

Starting point: $\mathbf{m x n}$ data matrix $X$, $\mathbf{m}$ options, $n$ indicators

PCA designs n-dimensional unit vectors (q's) and a correlation matrix $R(n \times n)$, such that the following eigen value Problem represents the data set.

\section{$R Q=\Delta Q$}

Mapping $\sqrt{ } \lambda$ onto $Q$, we get the loading matrix $L$. The product of $L$ and $X$ is called score matrix $T \quad(X L=\pi)$

\section{PCA-PLS-VIP, contd.}

PLS-VIP is based on projecting the information from data with more variables to that with fewer.

Using the score of $X$, PLS develops a regression model between $X$ and $D_{e}$. In a reduced subspace of dimension a $(a \leq n)$

$$
X=T L^{T}+E=\sum_{j=1}^{a} t_{j} l_{j}^{T}+E
$$

$T$ is score matrix, $L$ is load matrix, $E$, the residual. Score matrix $T$ can be related to response vector $D_{e}$ through a regression matrix B.

Each option vector $x$ from $X$ can be related to the score vector $\mathbf{t}_{\mathbf{j}}$ Through weight vectors $w_{j}$ as $t_{j}=w_{j}^{T} x_{i}$

VIP for $k$ is

$$
V I P_{K}=\sqrt{n \frac{\sum_{j=1}^{a} b_{j}^{2} t_{j}^{T} t_{j}\left(\frac{w_{k j}}{\left\|w_{j}\right\|}\right)^{2}}{\sum_{j=1}^{a} b_{j}^{2} t_{j}^{T} t_{j}}}
$$


Case: Automotive Shredder Residue Treatment (Catholique U, Leuven) (where improvement is described as negative)

\begin{tabular}{|c|c|c|c|c|c|c|c|c|c|}
\hline Treatment strategy & EI & & & & GI & & $\mathrm{HT}$ & & ic \\
\hline y & & & & & ST & LT & ST & LT & \\
\hline Landfill & 1.8 & 3.6 & 1.7 & 8.7 & 637 & 3844 & 472 & 533 & 106 \\
\hline Recycle+Landfill & -13.1 & -408 & -4.3 & -3.6 & -641 & 1614 & -675 & -2617 & 161 \\
\hline Energy recovery & -24.6 & -48.2 & -5.2 & -11.5 & 841 & 841 & 12 & -383 & 133 \\
\hline recycle+Energy Recovery & -26 & -438 & -7.8 & -14.6 & -325 & -325 & -812 & -3000 & 177 \\
\hline Minimum & -26 & -438 & -7.8 & -14.6 & -641 & -325 & -812 & -3000 & 106 \\
\hline \multicolumn{10}{|l|}{$y^{\prime}$} \\
\hline Landfill-Minimum & 27.8 & 441.6 & 9.5 & 23.3 & 1278 & 4169 & 1284 & 3533 & 0 \\
\hline Recycle+Landfill-Minimum & 12.9 & 30 & 3.5 & 11 & 0 & 1939 & 137 & 383 & 55 \\
\hline Energy recovery-Minimum & 1.4 & 389.8 & 2.6 & 3.1 & 1482 & 1166 & 824 & 2617 & 27 \\
\hline recycle+Energy Recovery-Minimum & 0 & 0 & 0 & 0 & 316 & 0 & 0 & 0 & 71 \\
\hline Maximum & 27.8 & 441.6 & 9.5 & 23.3 & 1482 & 4169 & 1284 & 3533 & 71 \\
\hline
\end{tabular}

\begin{tabular}{|c|c|c|c|c|c|c|c|c|c|c|}
\hline Normalized & \multicolumn{10}{|c|}{ Root Square $D^{\prime}$} \\
\hline Landfill & 1 & 1 & 1 & 1 & 0.86235 & 1 & 1 & 1 & 0 & 2.78 \\
\hline Recycle+tandfill & 0.464029 & 0.067935 & 0.36842 & 0.472103 & 0 & 0.4651 & 0.1067 & 0.108406 & 0.774648 & 1.19 \\
\hline Energy recovery & 0.05036 & 0.882699 & 0.27368 & 0.133047 & 1 & 0.279683 & 0.64174 & 0.74073 & 0.380282 & 1.75 \\
\hline cycle+Energy Recovery & 0 & 0 & 0 & 0 & 0.21323 & 0 & 0 & 0 & 1 & 1.02 \\
\hline
\end{tabular}

Best->>Worst

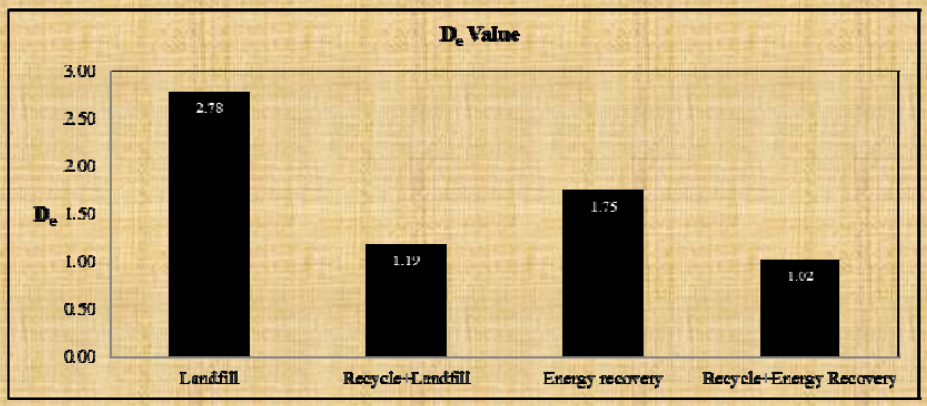




\section{PLS-VIP}

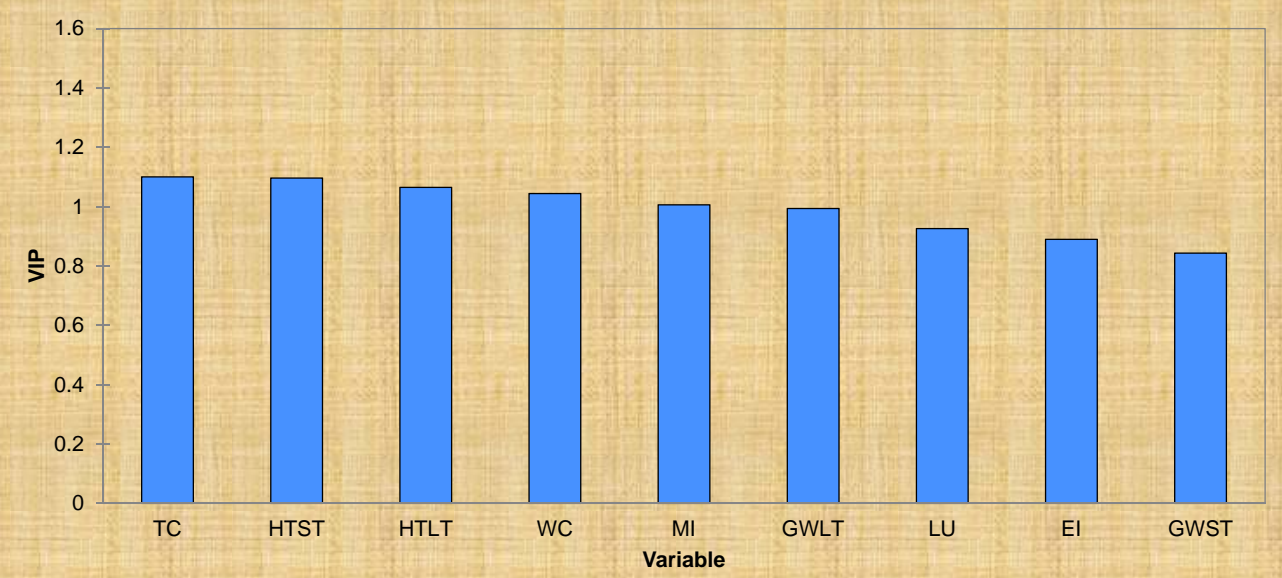

The PLS-VIP score shows that Total Cost (TC) has the maximum contribution to overall sustainability.

Case: Comparison of Sustainability Footprint $\left(D_{e}\right)$ for OECD Countries over 20 Years

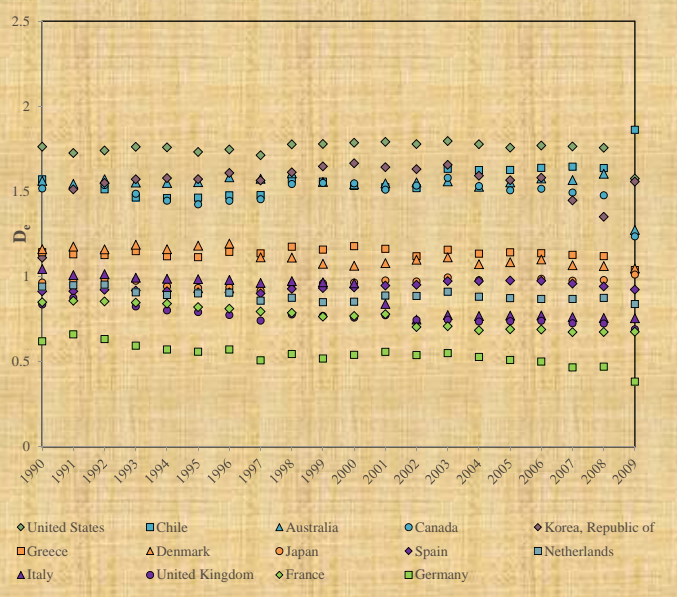

Environmental sustainability of OECD countries using UN MDG data and indicators

Only 6 Indicators could be used because of data availability:

$\mathrm{CO} 2 / \$ G D P, \mathrm{CO} 2 /$ capita, $\mathrm{CO} 2$ giga tons, ODP Metric tons, Population NOT using safe drinking water, and wetlands protection 


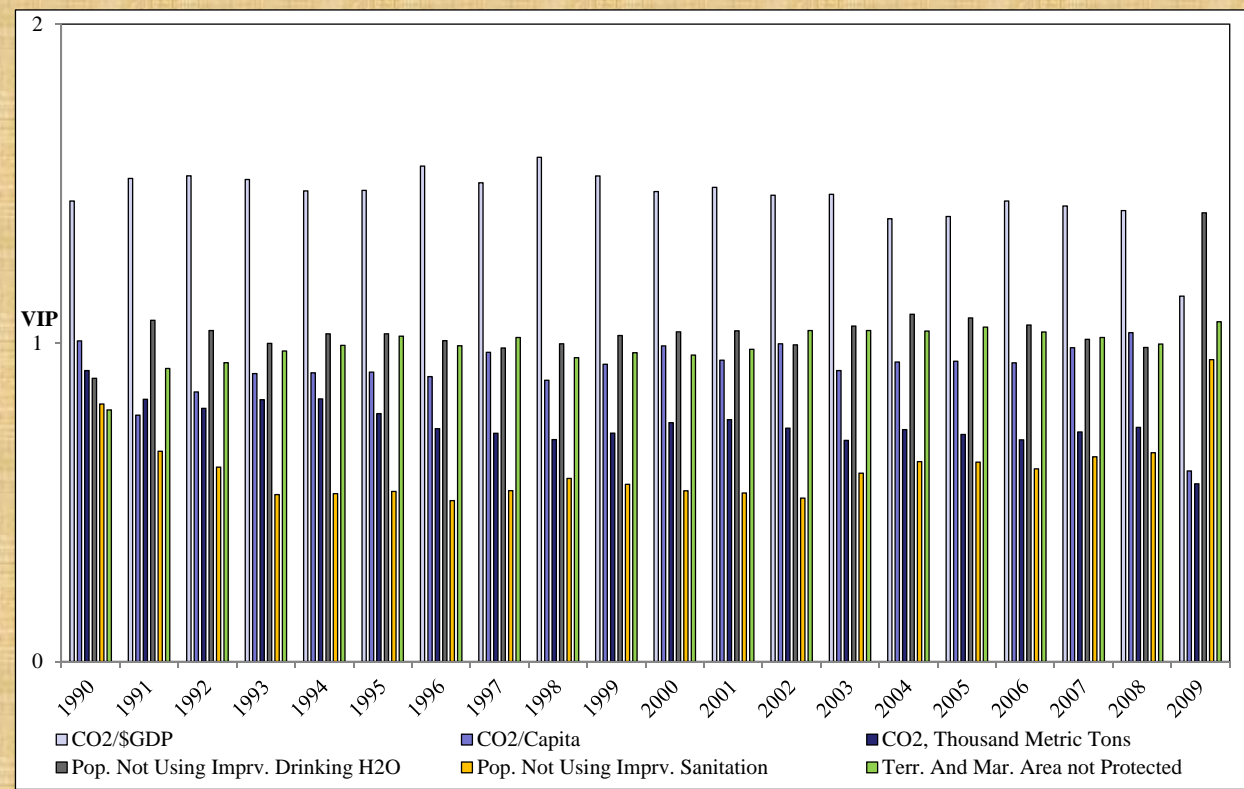

\section{Future Research Needs}

- Needed a Methodology to confirm if all necessary indicators have been chosen for analysis (e.g., cost frequently not included as an indicator but should be)

- A method to determine the sensitivity of Sustainability Footprints $\left(D_{e}\right.$ or $\left.D\right)$ to individual indicators

- Method for identifying which indicators and their underlying variables can be manipulated to make further sustainability advances of systems

- System optimization of Sustainability Footprint with respect to the indicators by process integration techniques 


\section{How to Quantify Sustainability in Construction and Manufacturing, and the Need for Standards}

Subhas Sikdar, US EPA, and

Humberto S. Brandi, INMETRO, Brazil

NIST-ASCE-ASME Sustainability Workshop, Rockville, MD, June 12-13, 2014 


\section{A Systems \\ Approach to \\ Sustainability \\ and Resilience}

\section{Joseph Fiksel}

Executive Director, Center for Resilience The Ohio State University

Special Assistant for Sustainability Office of Research \& Development U.S. Environmental Protection Agency

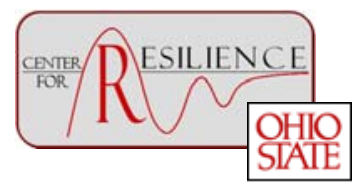

\section{System Resilience}

Resilience is the capacity

for complex, adaptive systems

(e.g., cities, business enterprises)

to survive, adapt, and flourish

in the face of turbulent change...

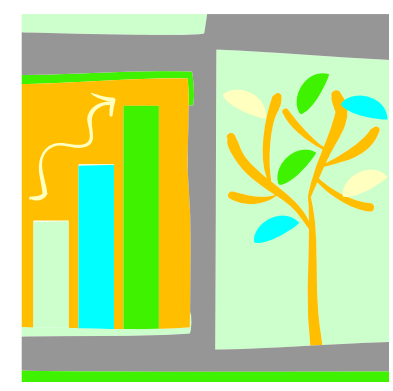

much like living systems

Operational resilience coping with the risk of disruptions that threaten continuity and well being
Strategic resilience sensing and responding to external pressures and opportunities 


\section{Indicators of System Resilience}

\begin{tabular}{|lll|}
\hline Indicators & Urban community & Enterprise supply chain \\
\hline Diversity & $\begin{array}{l}\text { Economic sectors, resource } \\
\text { channels, workforce skills }\end{array}$ & $\begin{array}{l}\text { Markets, suppliers, facilities, and } \\
\text { employee capabilities }\end{array}$ \\
\hline Cohesion & $\begin{array}{l}\text { Community identity, social } \\
\text { networks, local coordination }\end{array}$ & $\begin{array}{l}\text { Corporate identity, stakeholder } \\
\text { relations, collaboration }\end{array}$ \\
\hline $\begin{array}{l}\text { Adaptive } \\
\text { capacity }\end{array}$ & $\begin{array}{l}\text { Ability to rapidly modify urban } \\
\text { services, management practices }\end{array}$ & $\begin{array}{l}\text { Ability to modify products, } \\
\text { technologies, or processes }\end{array}$ \\
\hline $\begin{array}{l}\text { Resource } \\
\text { productivity }\end{array}$ & $\begin{array}{l}\text { Quality of life (security, peace) } \\
\text { relative to ecological footprint }\end{array}$ & $\begin{array}{l}\text { Shareholder value (profits, } \\
\text { assets) vs. ecological footprint }\end{array}$ \\
\hline $\begin{array}{l}\text { Vulnerability } \\
\text { to Change }\end{array}$ & $\begin{array}{l}\text { Disruptive forces that threaten } \\
\text { safety and well being }\end{array}$ & $\begin{array}{l}\text { Disruptive forces that threaten } \\
\text { business continuity }\end{array}$ \\
\hline Stability & $\begin{array}{l}\text { Ability to continue normal } \\
\text { activities if disruptions occur }\end{array}$ & $\begin{array}{l}\text { Ability to continue normal } \\
\text { activities if disruptions occur }\end{array}$ \\
\hline Recoverability & $\begin{array}{l}\text { Ability to overcome disruptions, } \\
\text { restore critical public services }\end{array}$ & $\begin{array}{l}\text { Ability to overcome disruptions, } \\
\text { restore key business operations }\end{array}$ \\
\hline
\end{tabular}

Source: J. Fiksel, I. Goodman, A. Hecht, "Navigating Toward a Sustainable Future,” Solutions, Oct. 2014

\section{Sustainability is the capacity for:}

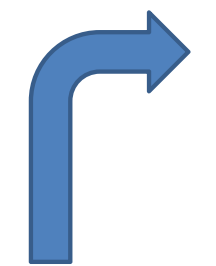

- human health and well being

- economic vitality and prosperity

- environmental resource abundance

\section{continuity}

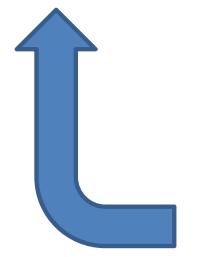

\section{Resilience is the capacity to:}

- overcome unexpected problems

- adapt to change (e.g., sea level rise)

- prepare for and survive catastrophes 


\section{Examples of initiatives aimed at resilience and sustainability}

- Energy systems - smart grid, distributed, renewable, PHEV

- Eco-efficiency-green buildings, local sourcing, waste reuse

- Water systems-rainwater harvesting, green infrastructure

- Mobility-alternative transport, vehicle sharing

- Urban renewal-brownfields, affordable housing

- Smart growth-land use, resource stewardship

- Education-STEM careers, workforce retraining

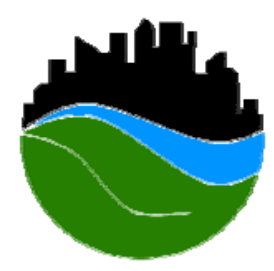

- Economic development-incubators, business clusters

- Emergency preparedness-early detection, evacuation plans

\section{Examples of Synergies and Trade-offs}

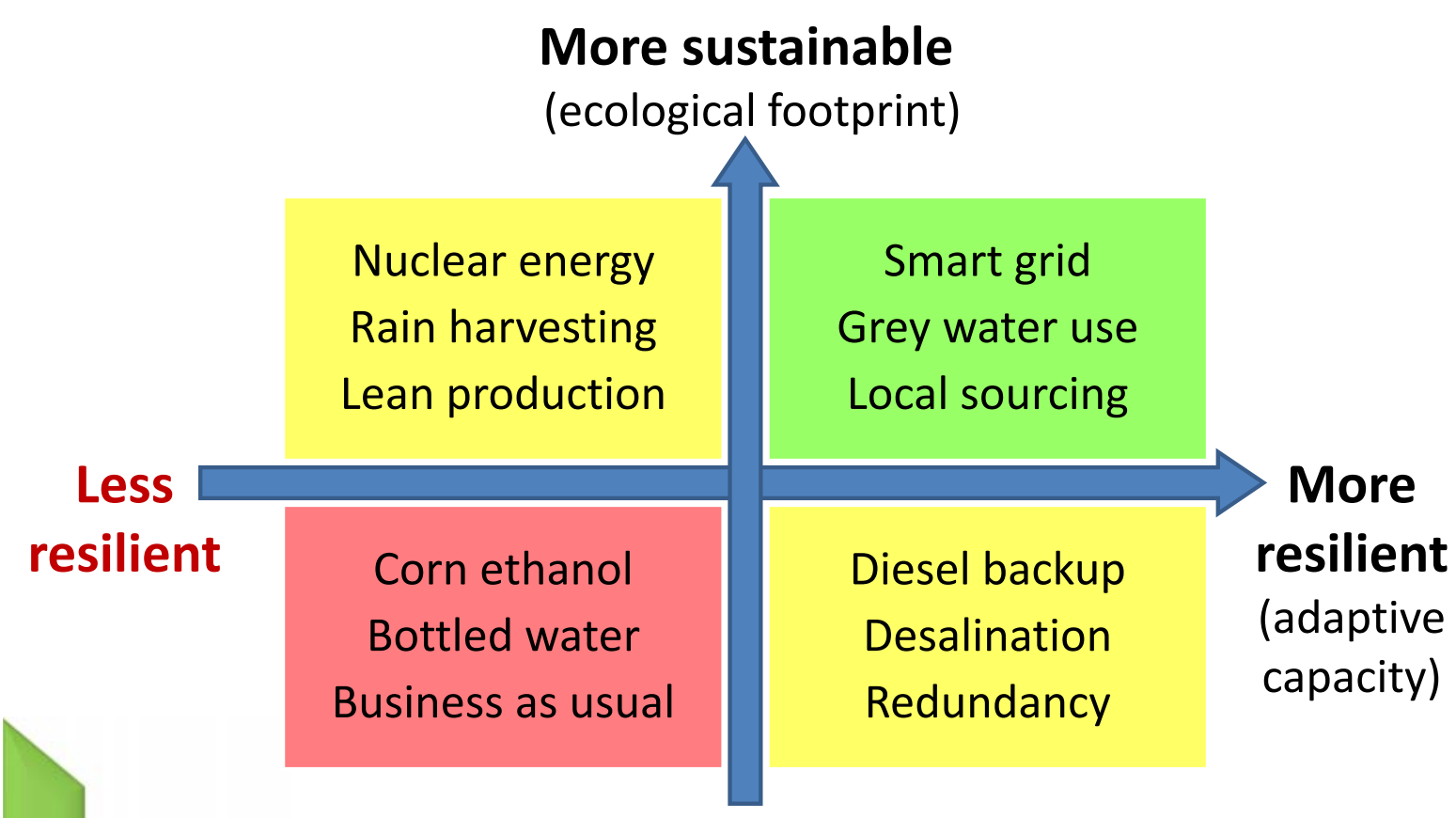

Less sustainable 


\section{What is a Systems Approach?}

- A comprehensive methodology for understanding the interactions and feedback loops among

- Economic systems-companies, supply chains....

- Ecological systems-forests, watersheds....

- Societal systems-cities, networks....

- Reveals consequences (sometimes unintended) of human interventions, such as new policies, technologies, and business practices

- Case in point: Degraded ecosystems threaten the sustainability and resilience of human communities

\section{Triple Value (3V) Framework}

\section{Economy}

(economic capital)

\section{Community}

(human \& social capital)

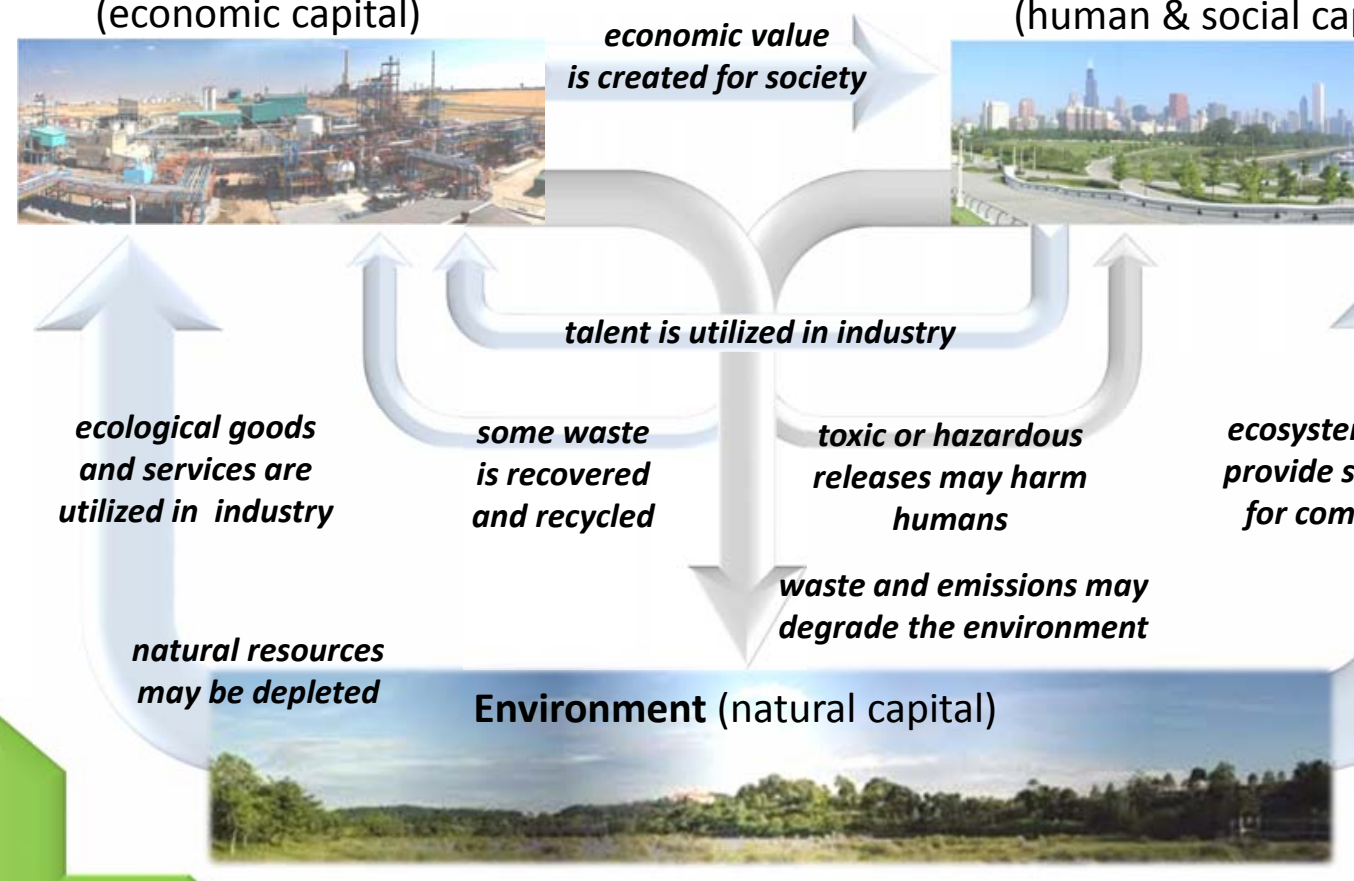




\section{Triple Value (3V) Framework}

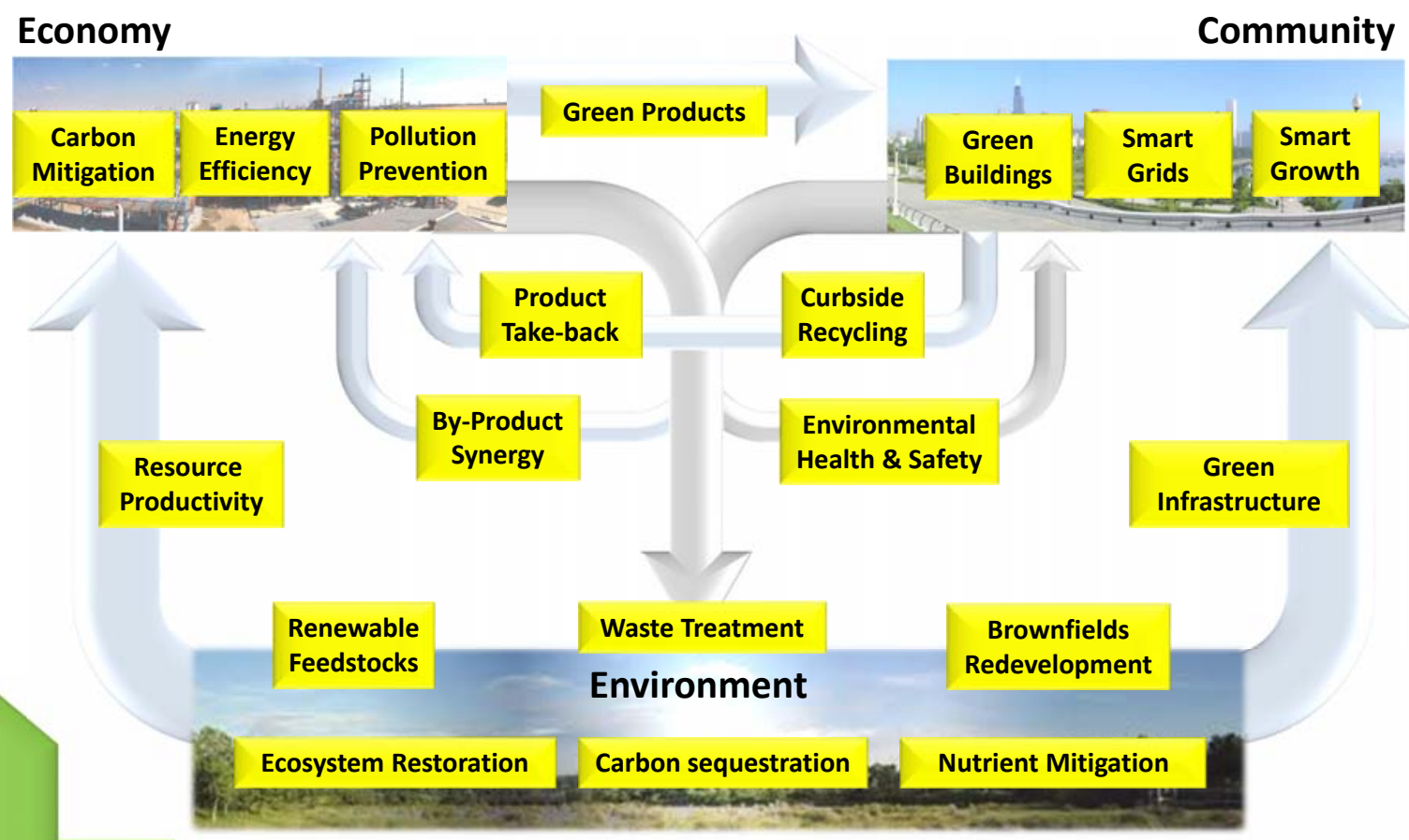

J. Fiksel, "A Systems View of Sustainability: The Triple Value Model," Environmental Development, June 2012.

\section{Example from U.S. EPA}

\section{Narragansett Bay 3VS Project}

\section{Apply "systems thinking" to the problems of nutrient pollution and coastal resilience in New England, working closely with Region 1 stakeholders}
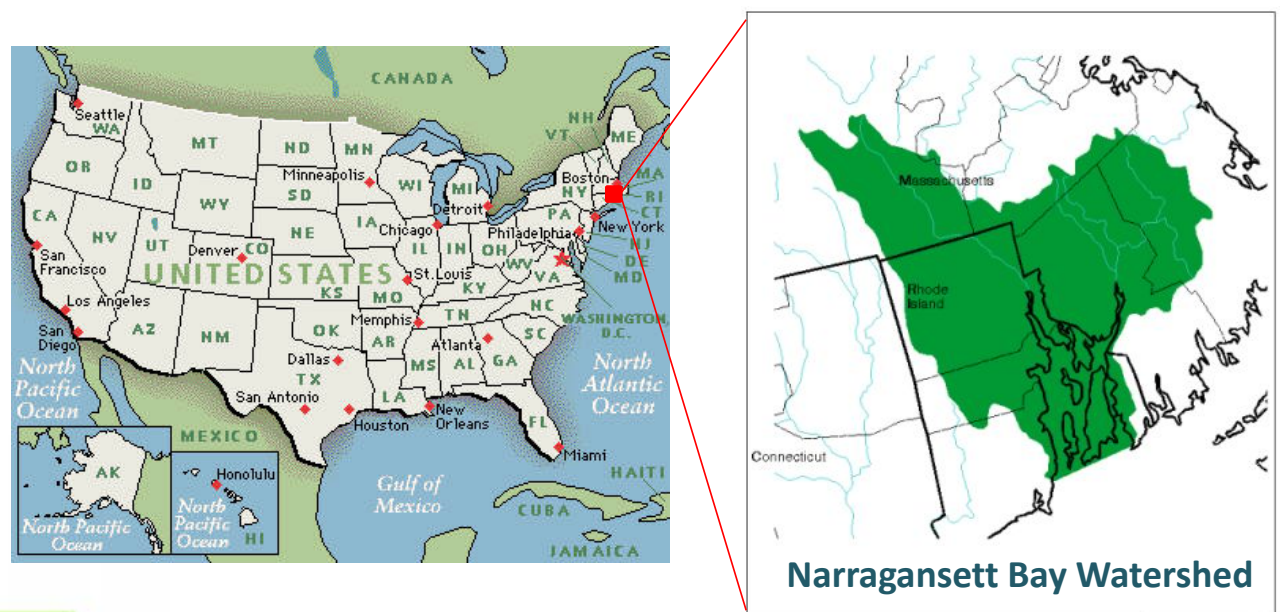


\section{Modeling Coupled Human-Natural Systems at a Watershed Scale Requires Aggregation}

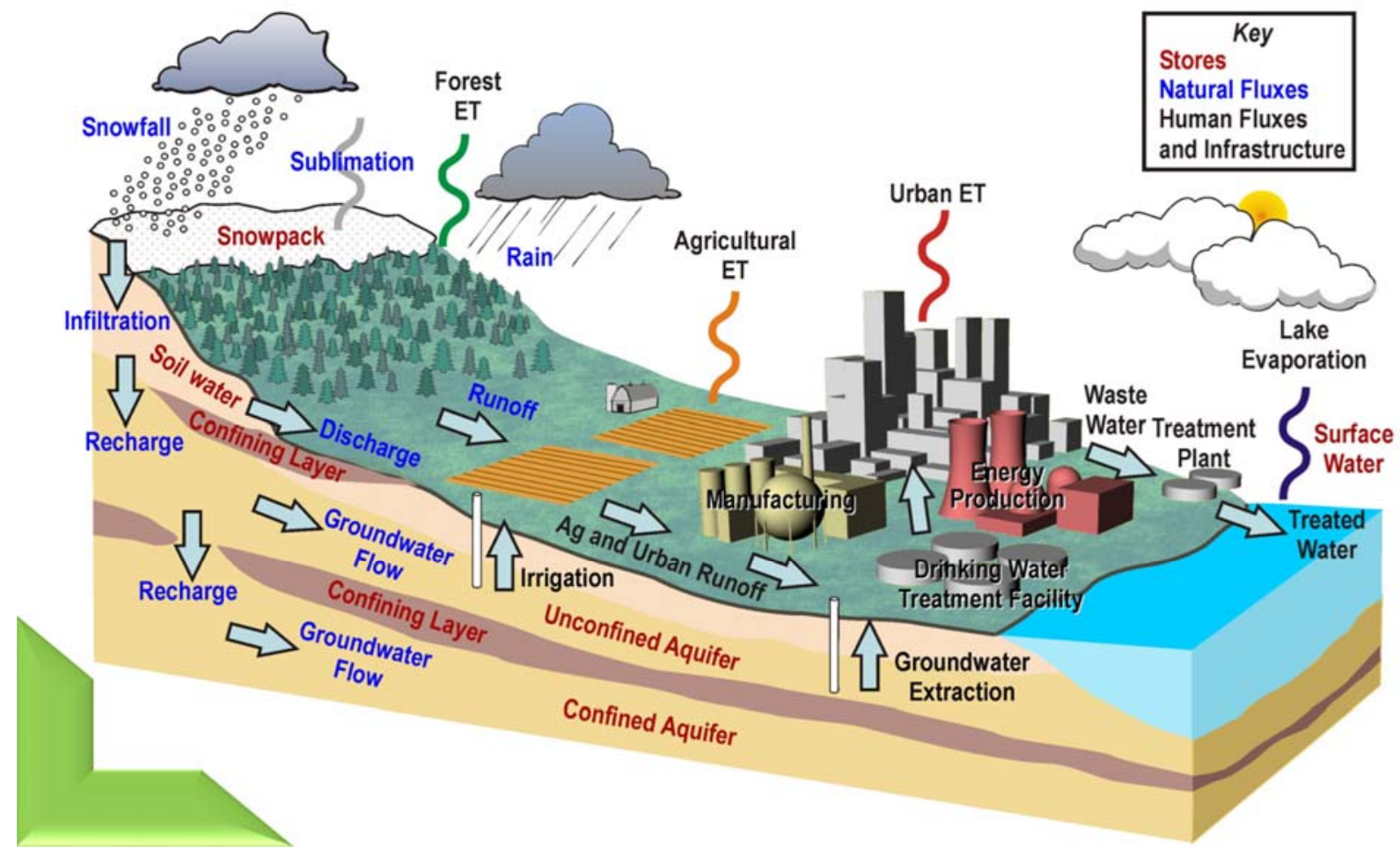

\section{Modeling the Nutrient Cycle}

products \& services

\section{Economic Activities}

- Agriculture

- Commercial Fisheries

- Energy \& Transportation

- Land Development

- Recreation \& Tourism

- Water Treatment

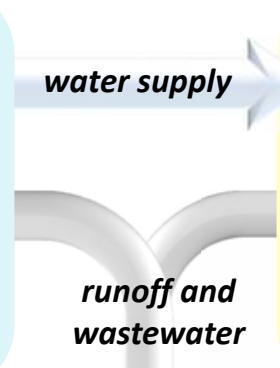

\section{Community Stakeholders}

- Consumers \& residents

- State \& local agencies

- Water \& energy utilities

- Regional businesses

- Septic tank users

- Private well users industrial \& commercial uses
Environmental Resources

- Surface water

- Ground water

- Coastal areas

- Fish \& shellfish

- Regional ecosystems

- Atmosphere \& climate recreational and cultural uses 


\section{Causal Relationships in 3VS Model}

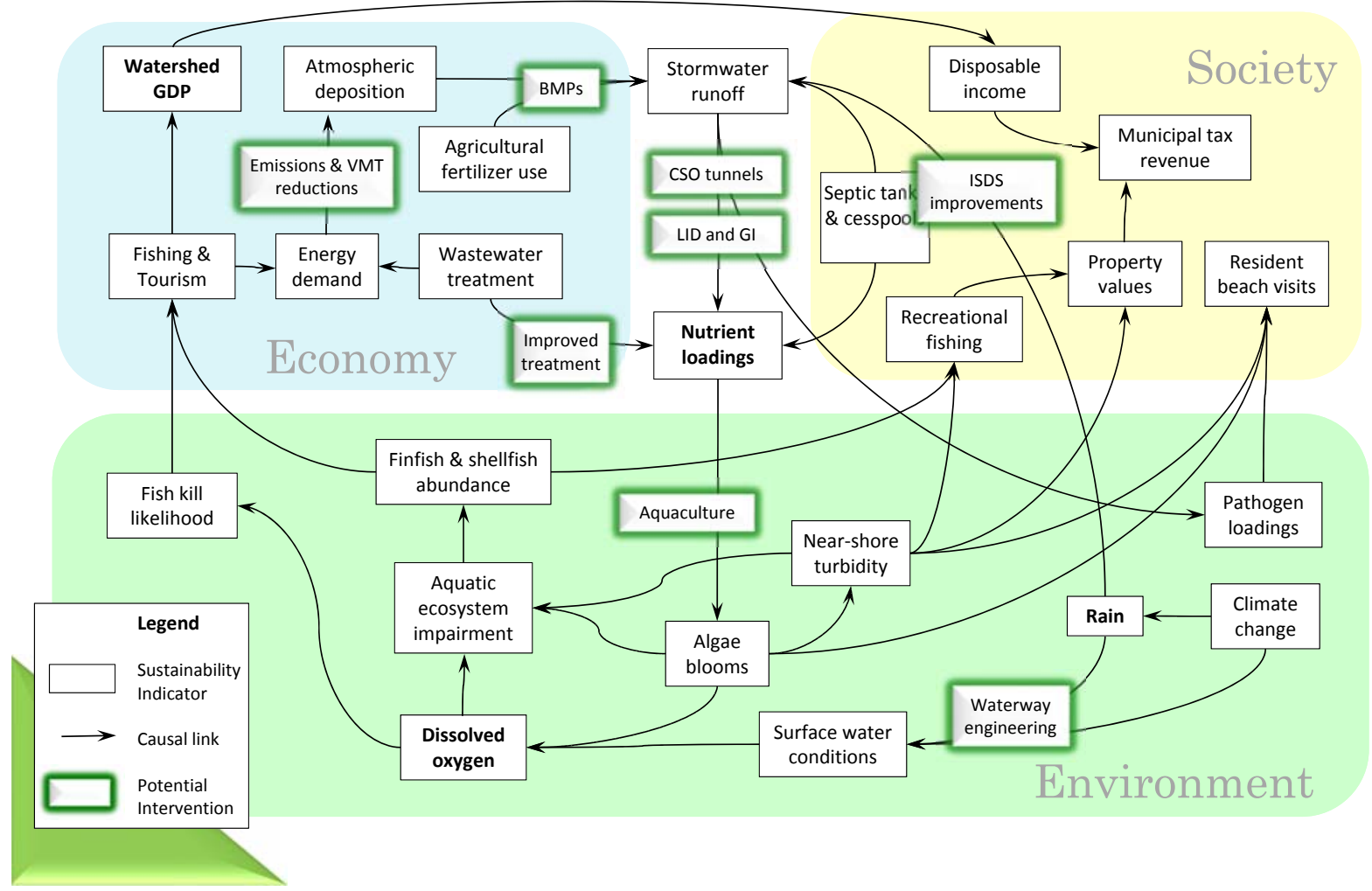

\section{Graphical User Interface}

\section{Define interventions}

Foresee consequences

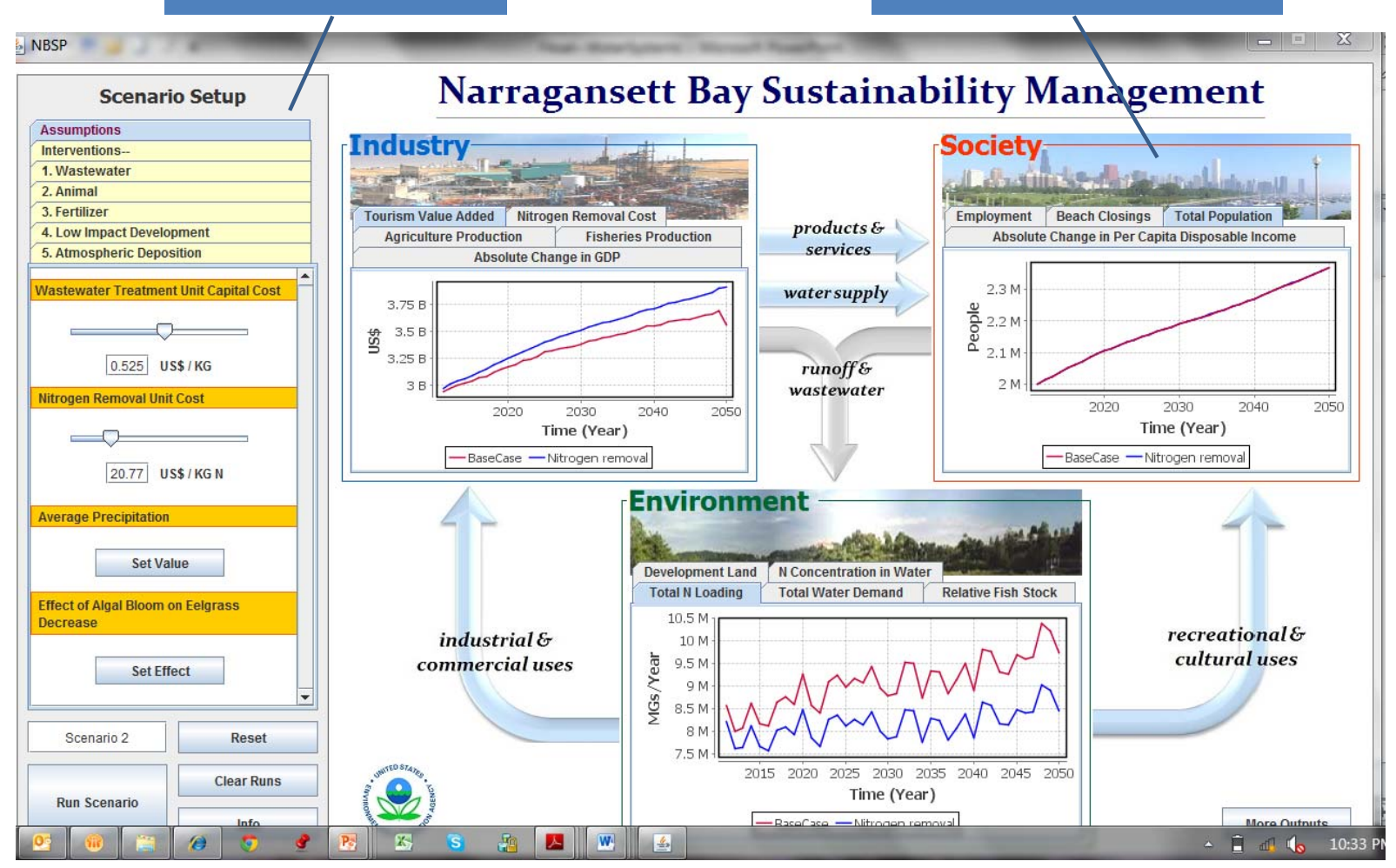




\section{Acknowledgments}

EPA Region 1: Curt Spalding (Regional Administrator), Ira Leighton, Beth Termini, Margherita Pryor, Ken Moraff, Sheryl Rosner, Matt Hoagland, Johanna Hunter, Ellen Weitzler

EPA Office of Research \& Development:

Paul Anastas (Assistant Administrator), Lek Kadeli, Gary Foley, Alan Hecht, Ramona Trovato, Marilyn ten Brink, Nick Ashbolt

Model implementation team:

Eric Ruder and Nadav Tanners, Industrial Economics, Inc. Andrea Bassi, Millennium Institute Chien-Chen Huang, The Ohio State University

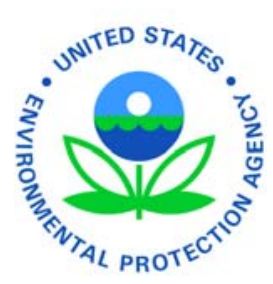




\section{Gül E. Okudan Kremer}

\section{Professor of Industrial Engineering \& Engineering Design}

Summaries of collaborative work with Profs. Karl Haapala, Kyoung-yun Kim, Ratna Chinnam, Leslie Monplaisir, Alper Murat and current and former ADAPS Group Members:

Saraj Gupta, Ming-Chuan Chiu, Wu Hsun Chung, Nirup Philip, Ting Lei and Junfeng Ma

\section{PENNSTATE}

\section{Outline}

- ADAPS Group

- Sustainable Product Collaboratory Project

- Lessons Learned

- Research Directions

PENNSTATE 


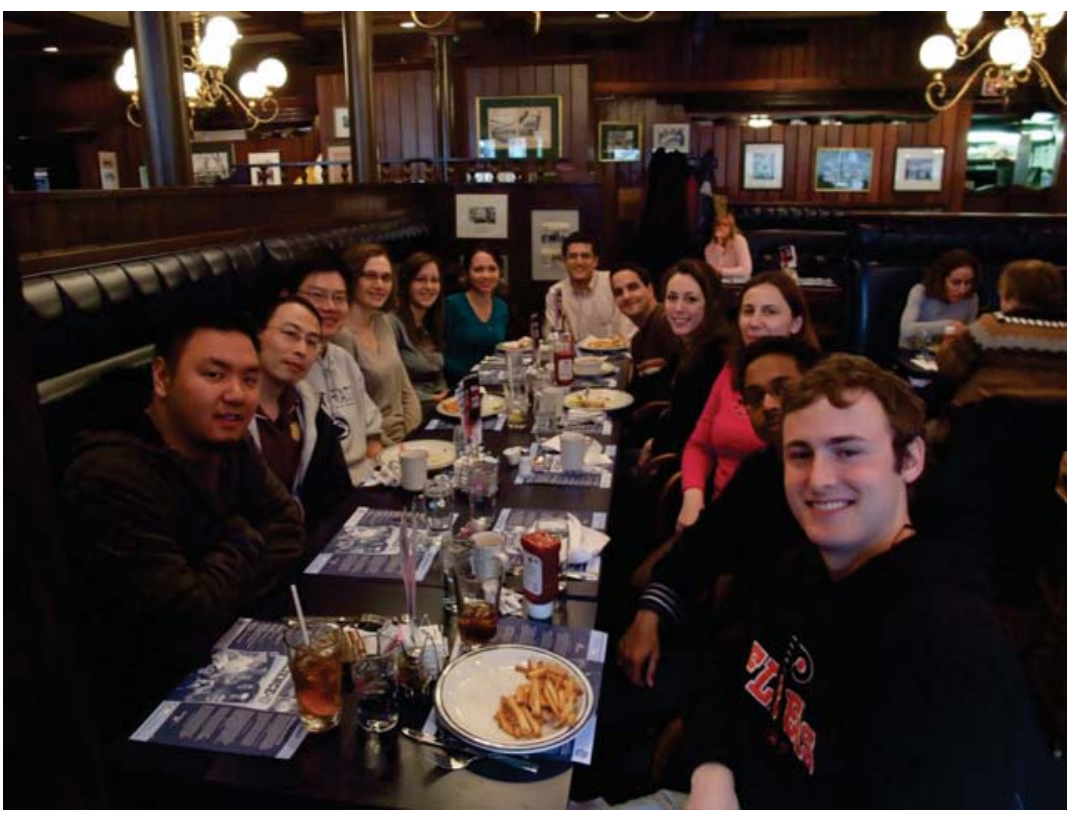

Product Family Design \& Optimization

Design Complexity

Systematic Design Ideation

(TRIZ, SmartPens)

Smart Health (Triage

improvement through MAUT, GT)

\section{Sustainable Product Collaboratory}

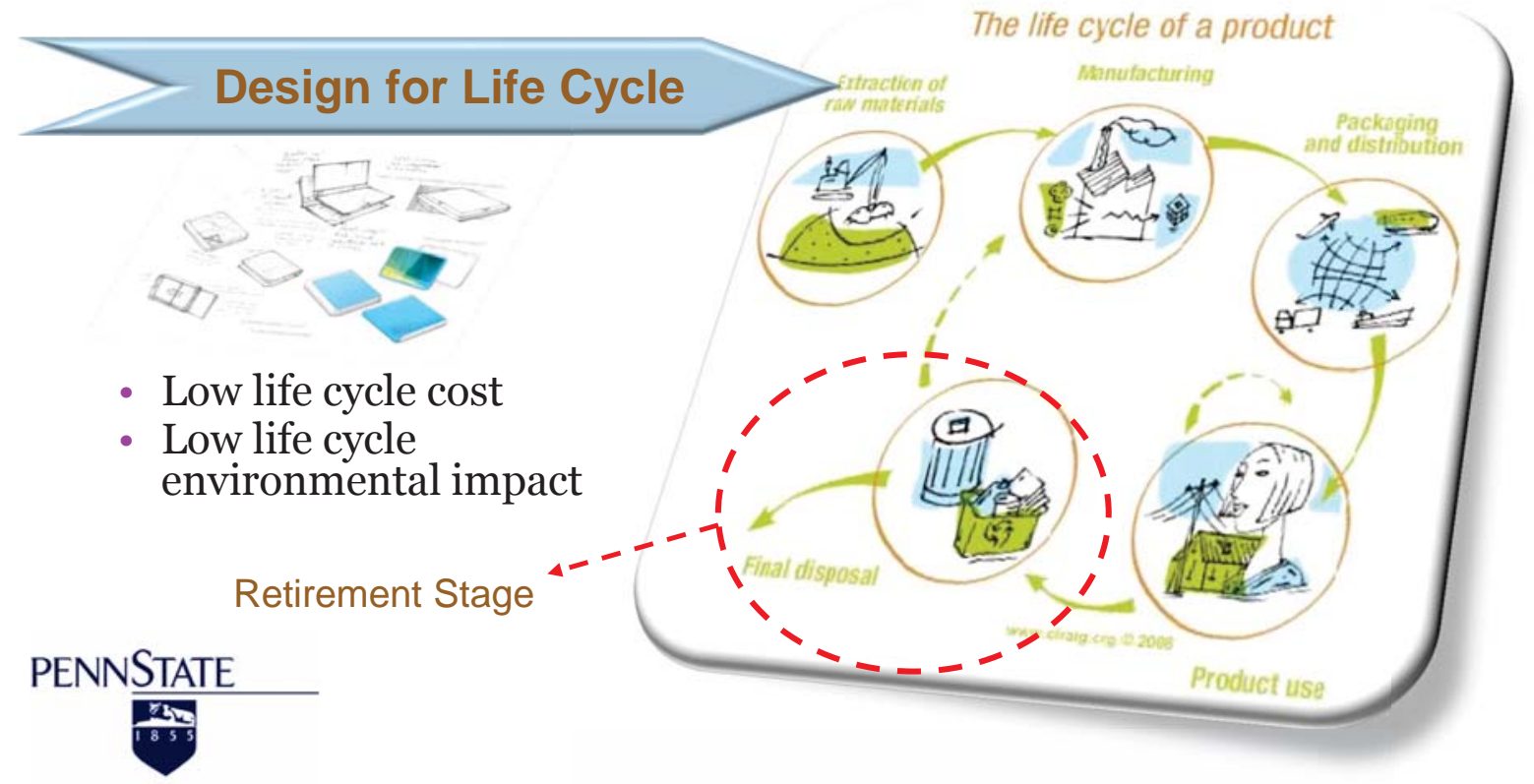


resources that will be needed in the future

International Institute for Sustainable Development (2011)

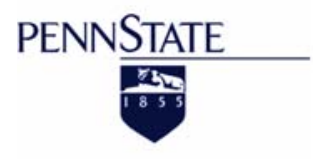

IISD, 2011, "Business Strategies for Sustainable Development,"

International Institute for Sustainable Development, Winnipeg,

Manitoba, CA, www.iisd.org/business/pdf/business_strategy.pdf

\section{Sustainability in the Design Stage}

The design stage determines $70 \%$ of life cycle costs.

It is important that design concurrently considers manufacturing of the product and its supply chain so that a company may gain:

- The ability to reduce waste or increase recyclability of materials

- Supplier selection insight

- Integrated modularity options

- End of life product recovery plans

- Flexibility

- Reduced costs

- Sustainability for profitability

PENNSTATE 
performance of the individual company and its supply chains.

Carter and Rogers (2008)

PENNSTATE

C.R. Carter and D.S. Rogers (2008). "A framework of sustainable supply chain management: moving toward new theory," International J. of Physical

Distribution \& Logistics Management, 38(5) 360 - 387.

\section{Broader Methods for Sustainable Design}

- General goals for sustainability are to eliminate waste, improve energy efficiency, design products for reuse or recycling, conserve natural habitats and move toward zero consumption of non-renewable resources.

- Stakeholders should be considered including the customers, energy and material suppliers, community, waste contractors, trade associations, environmental agency, professional institutions, employers, local council, manufacturers, and end users.

PENNSTATE 


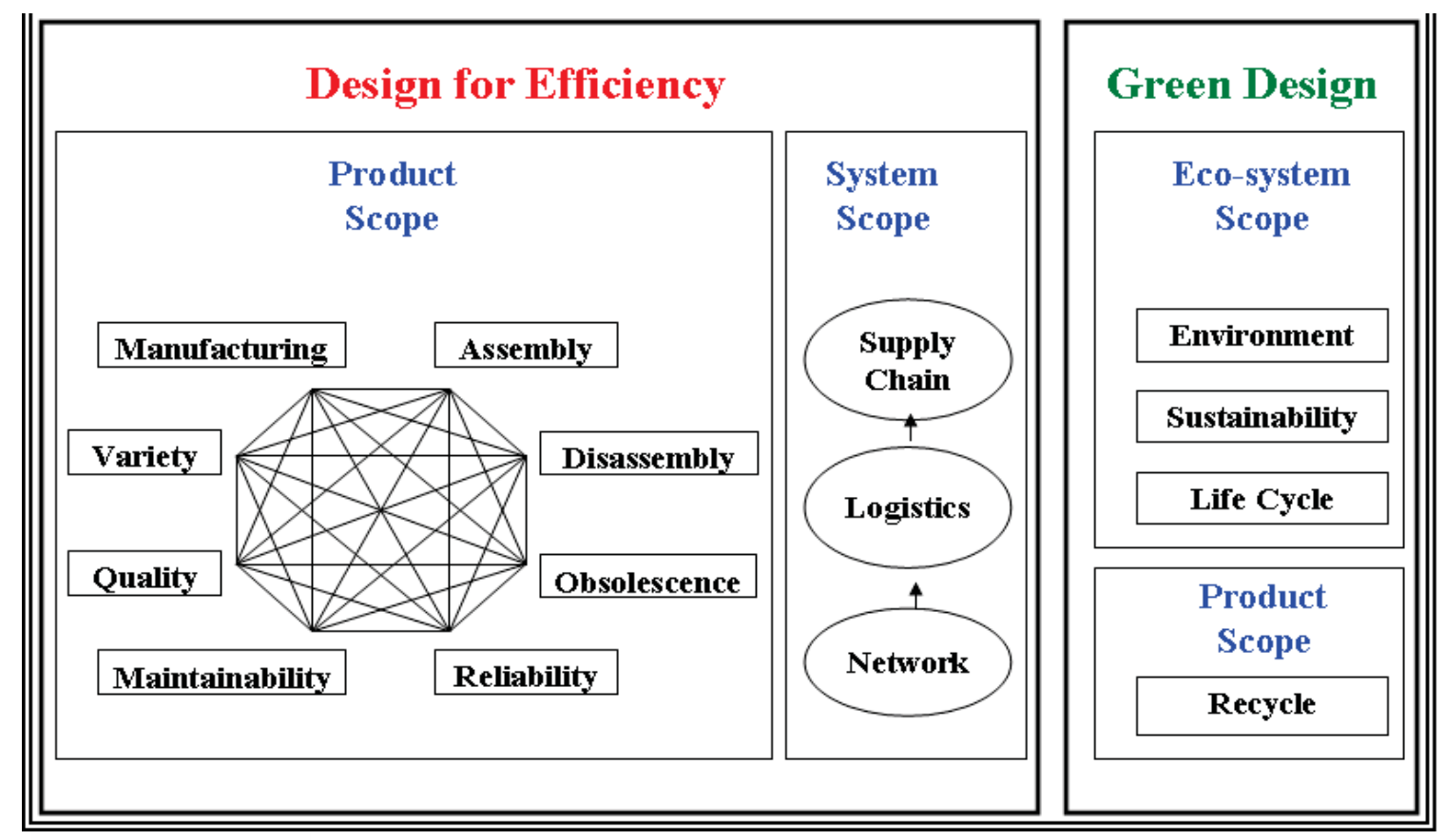

\section{Collaborative R\&D Framework}

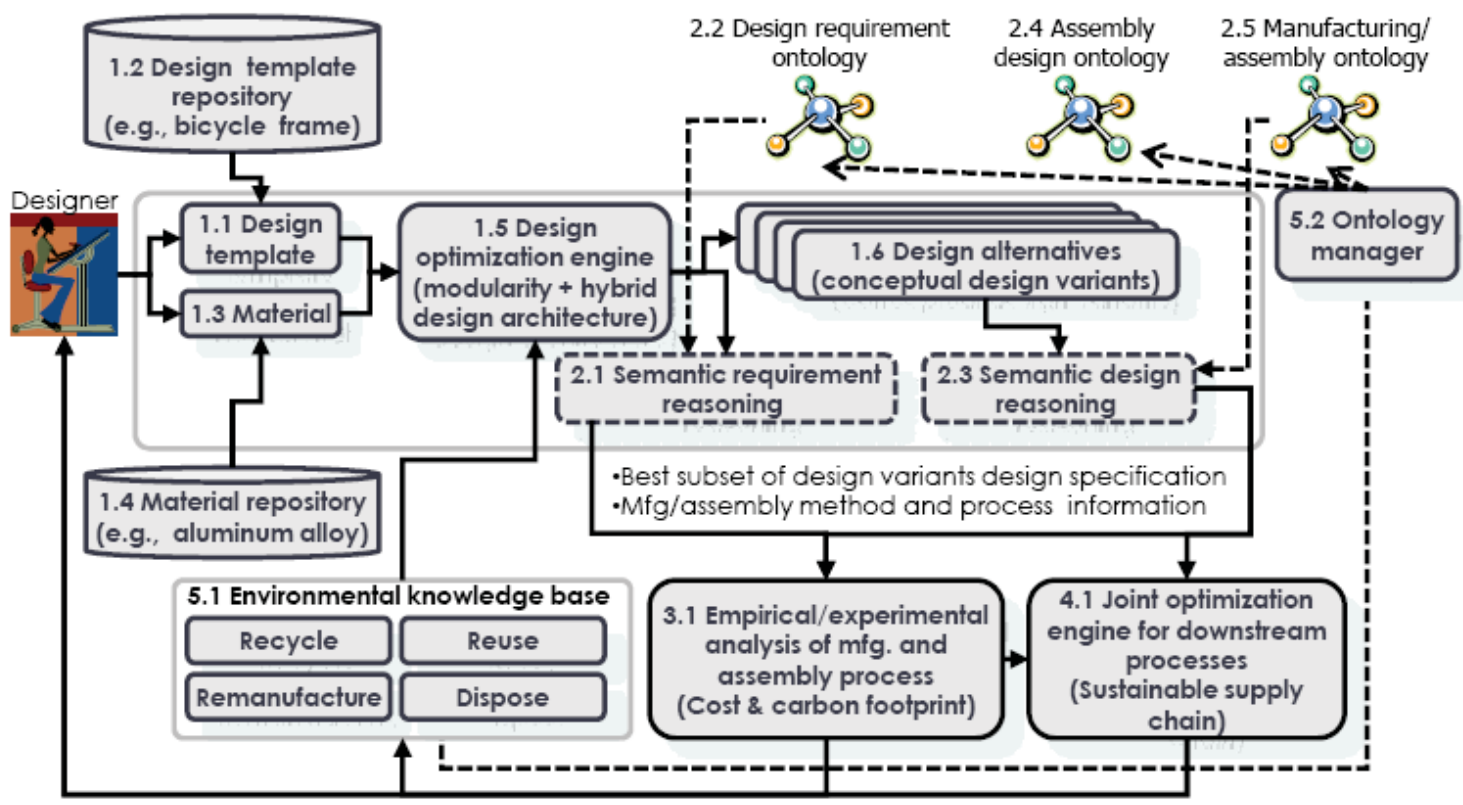

PENNSTATE

Jointly developed R\&D Framework for Sustainable

Product Collaboratory with colleagues from Wayne

State \& Oregon State 
based concept generation to integrate modularity and hybrid design architectures, which enables customization (at the architecture level) to better serve life cycle concerns.

\section{PENNSTATE}
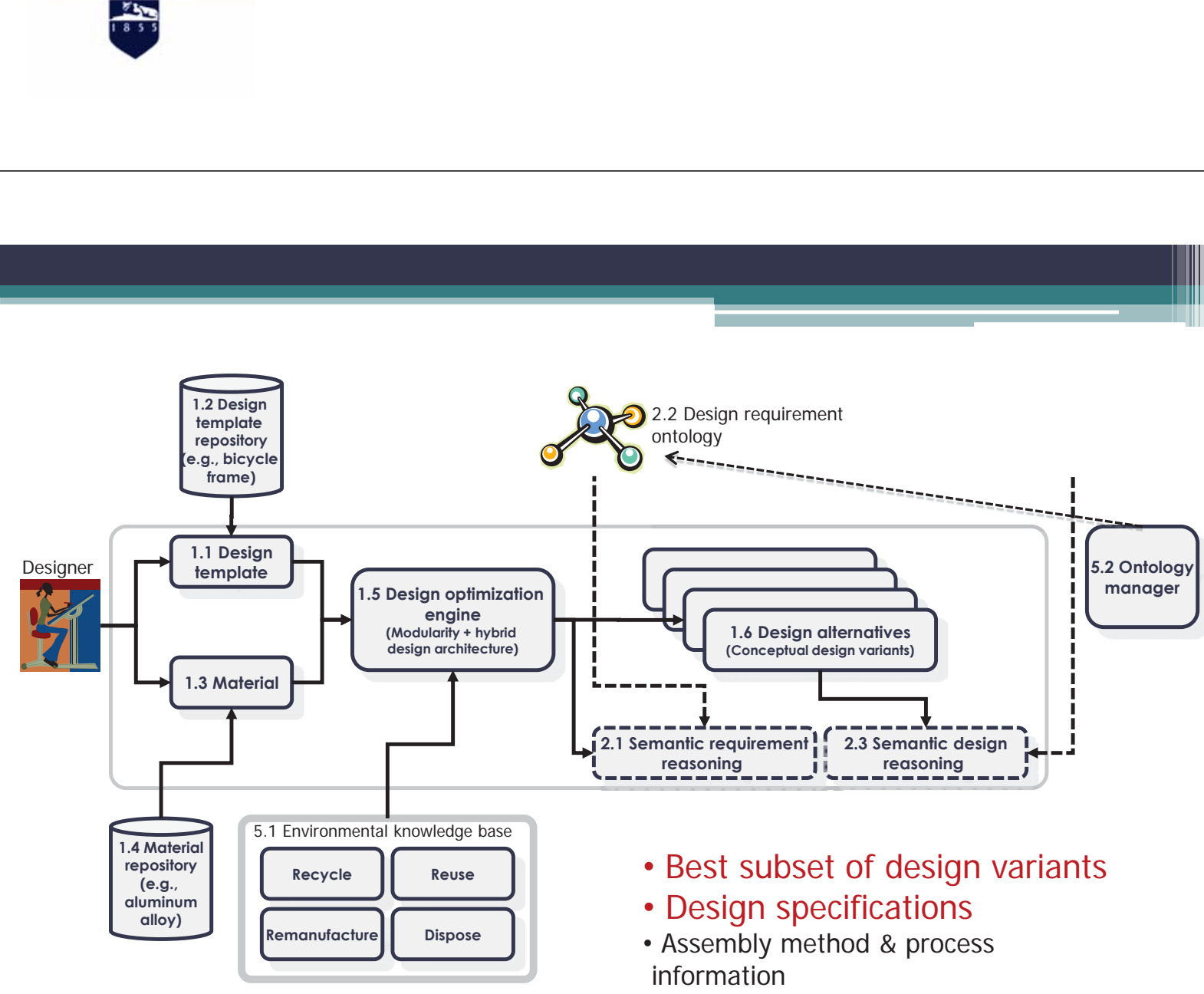

PENNSTATE 
assembly, distribution, sustainment, collection, and disposal.

\section{PENNSTATE}

2no

185

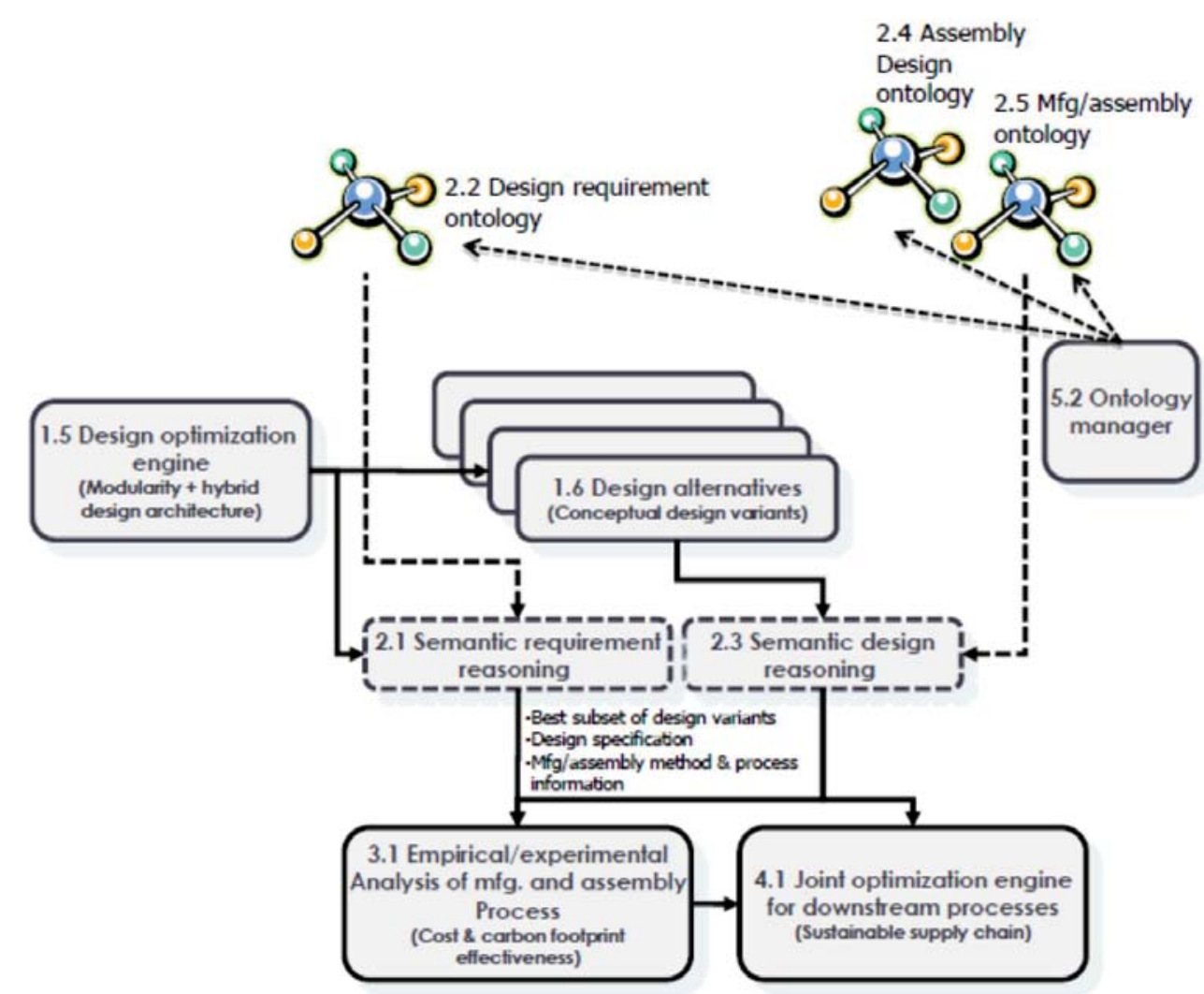




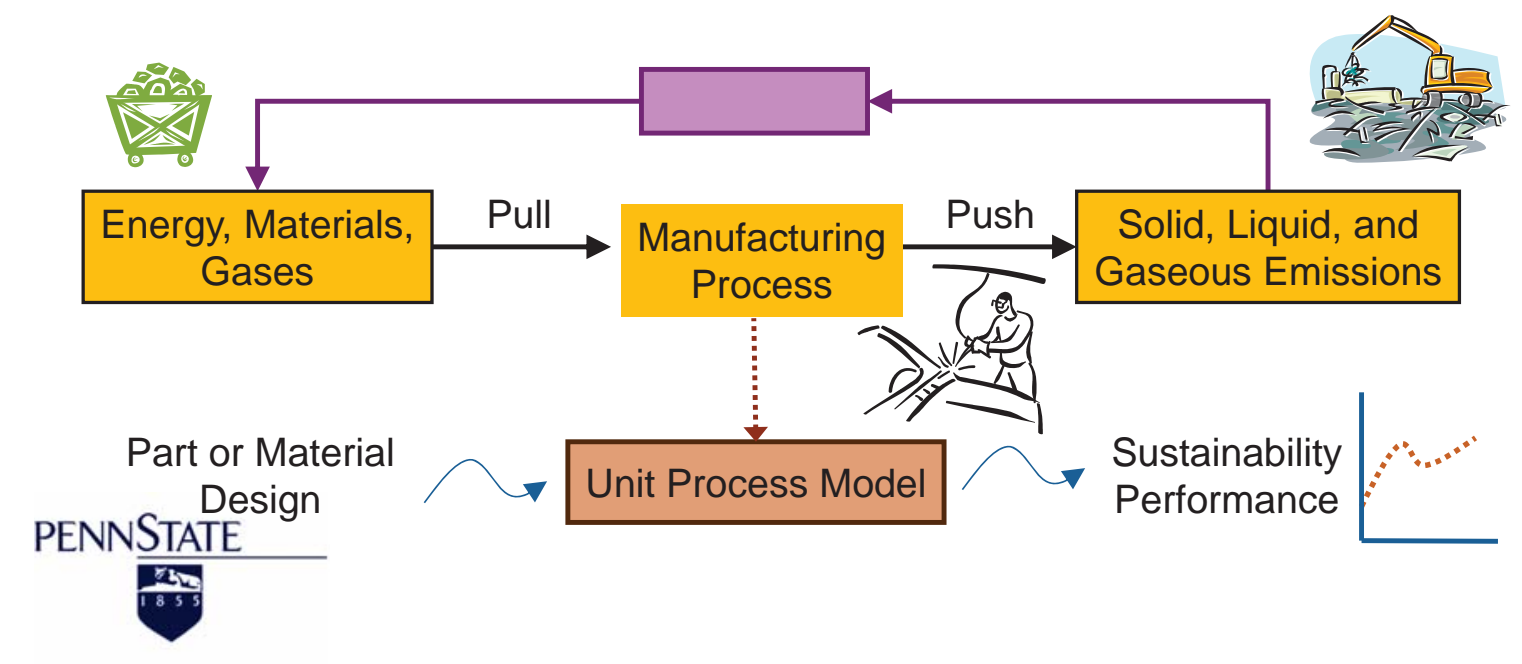

\section{Tasks}

4. Optimization of the product architecture variants while balancing the impact on procurement, manufacturing, distribution, sales/demand, sustainment, collection, and disposal. The algorithms will facilitate joint optimization of the best subset of design variants and configurations with mathematical models of life cycle processes. The research will develop hierarchical optimization models to jointly address the life cycle processes and product architecture 


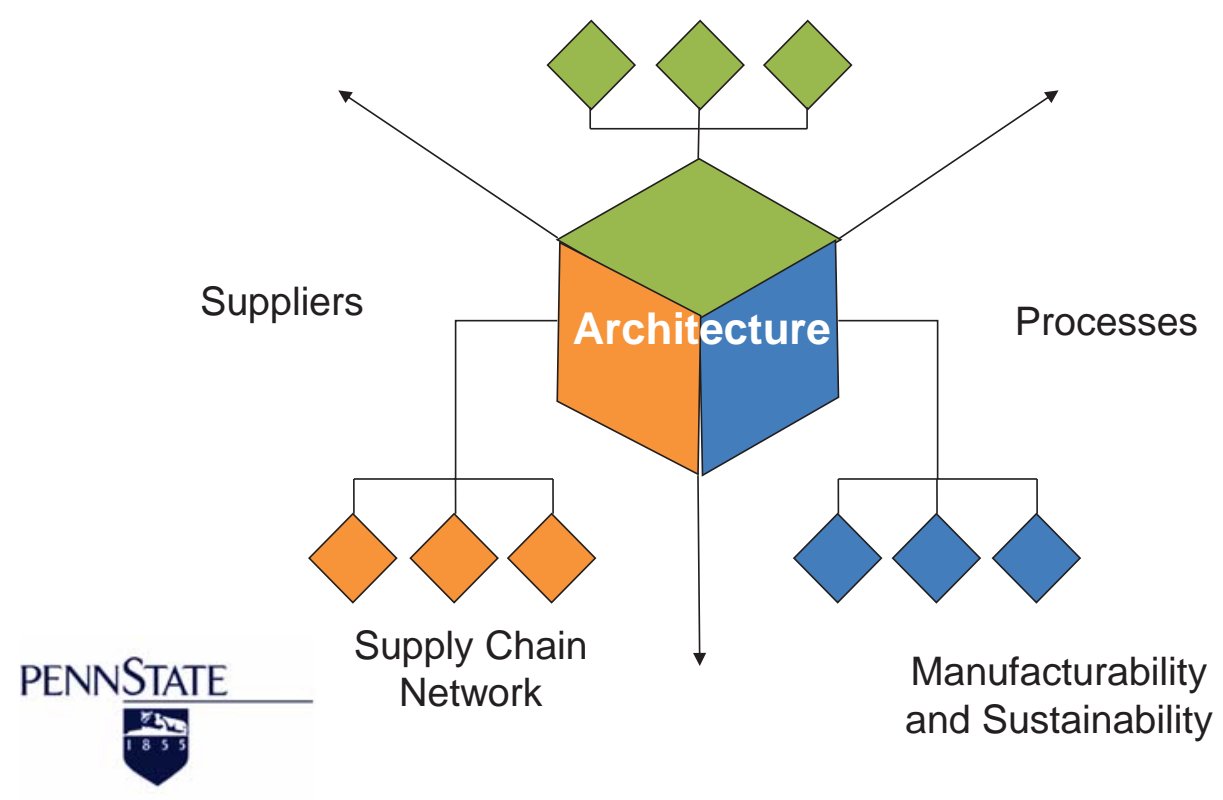

\section{Lessons Learned}

1. Product architecture \& supply chain should be optimized simultaneously

2. Realistic case studies show that cost, lead time and carbon footprint minimization goals favor different type of product architectures

3. Existing modularity methods favor different performance measures

4. Robust modularity methods need to be developed to optimize life cycle costs \& a proposed approach 


\section{conceptual designs}

- Uses functional decomposition of a product to build the product from bottom-up

- Energy-Material-Signal Diagram defines flows

- Generated designs are modularized based on Decomposition Approach, Design for Assembly filtering is used.

\section{PENNSTATE}

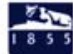

Unbiased experimentation requires automated generation of all design variants. This is accomplished through conceptualizing the product through Energy-Signal-Material modeling and Design for Assembly (DfA) filtering.

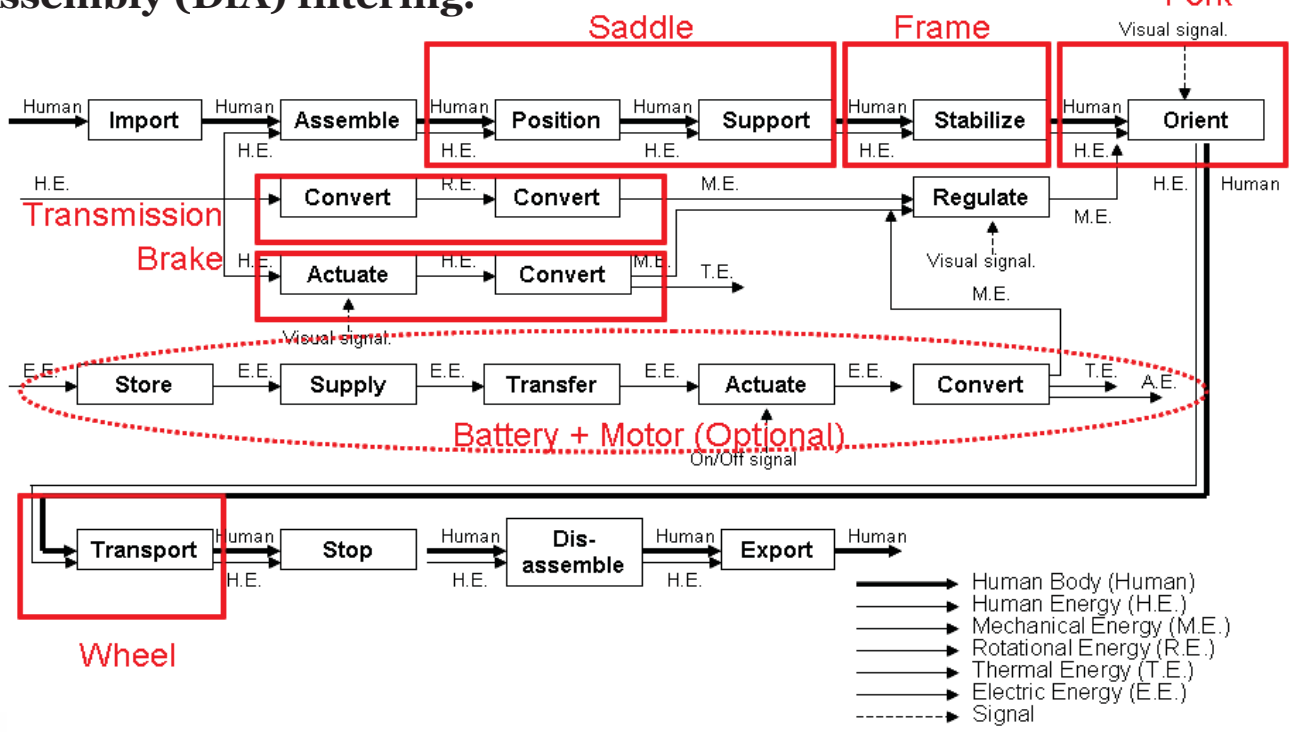

PENNSTATE 
9) composing ment, 10) composition direction, 11) symmetry,

12) alignment, and

13) joining method.

\section{PENNSTATE}

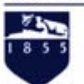

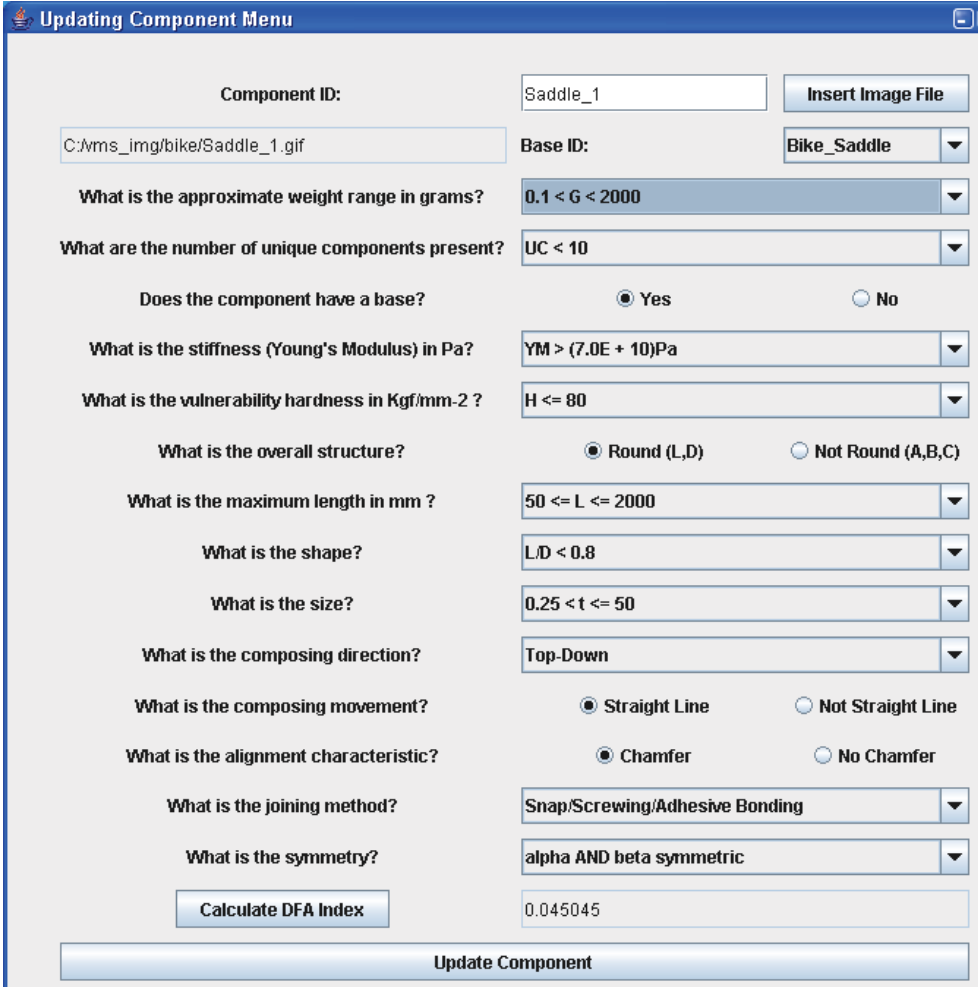

\section{Road Bicycle Design}

- Sample case, medium complexity

- 6 components with two alternatives

- Yields 64 design combinations with various DfA scores

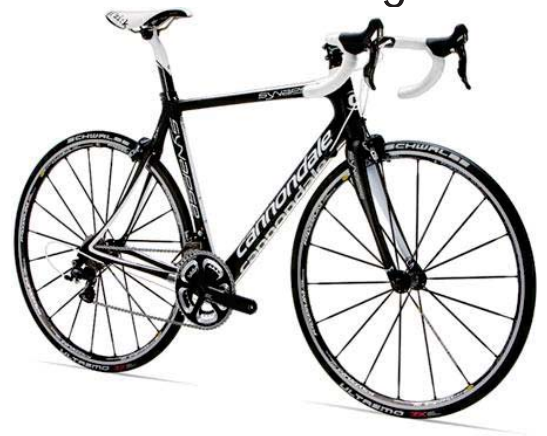

Bike

PENNSTATE
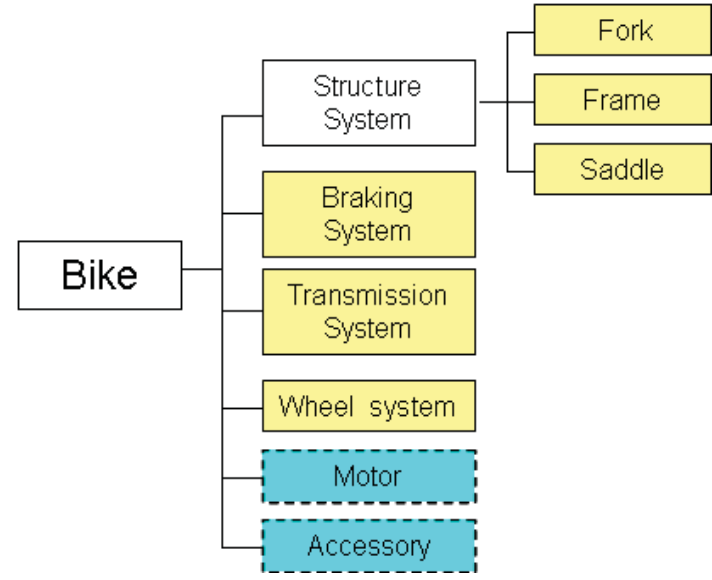

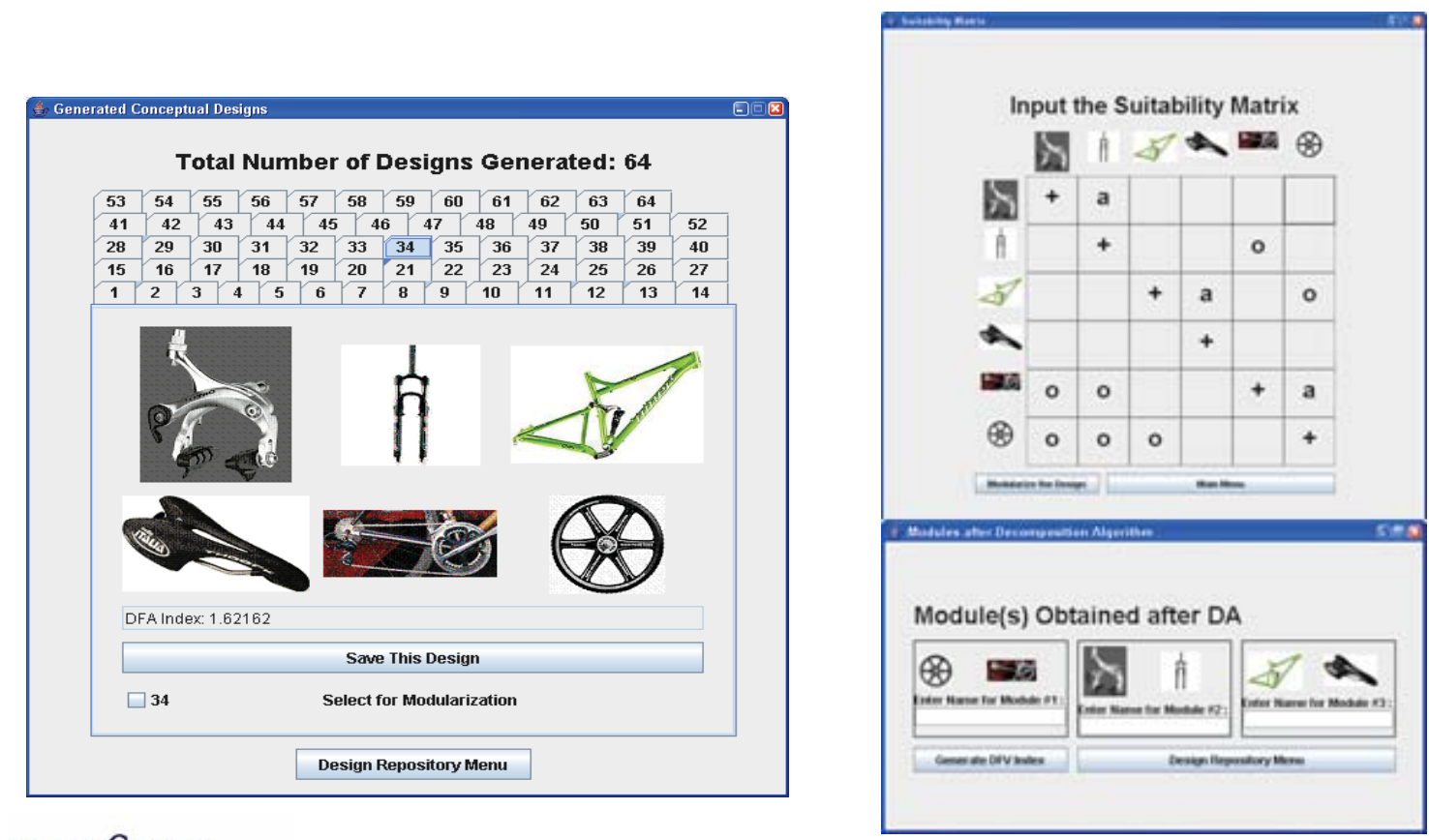

\section{PENNSTATE}

Gupta, S. and Okudan, G. (2008). "Computational Modularized Conceptual Designs with Assembly and Variety Considerations", Journal of Engineering Design, Vol. 19, No. 6, December, pp. 533 - 551.

\section{Sample Design Combinations}
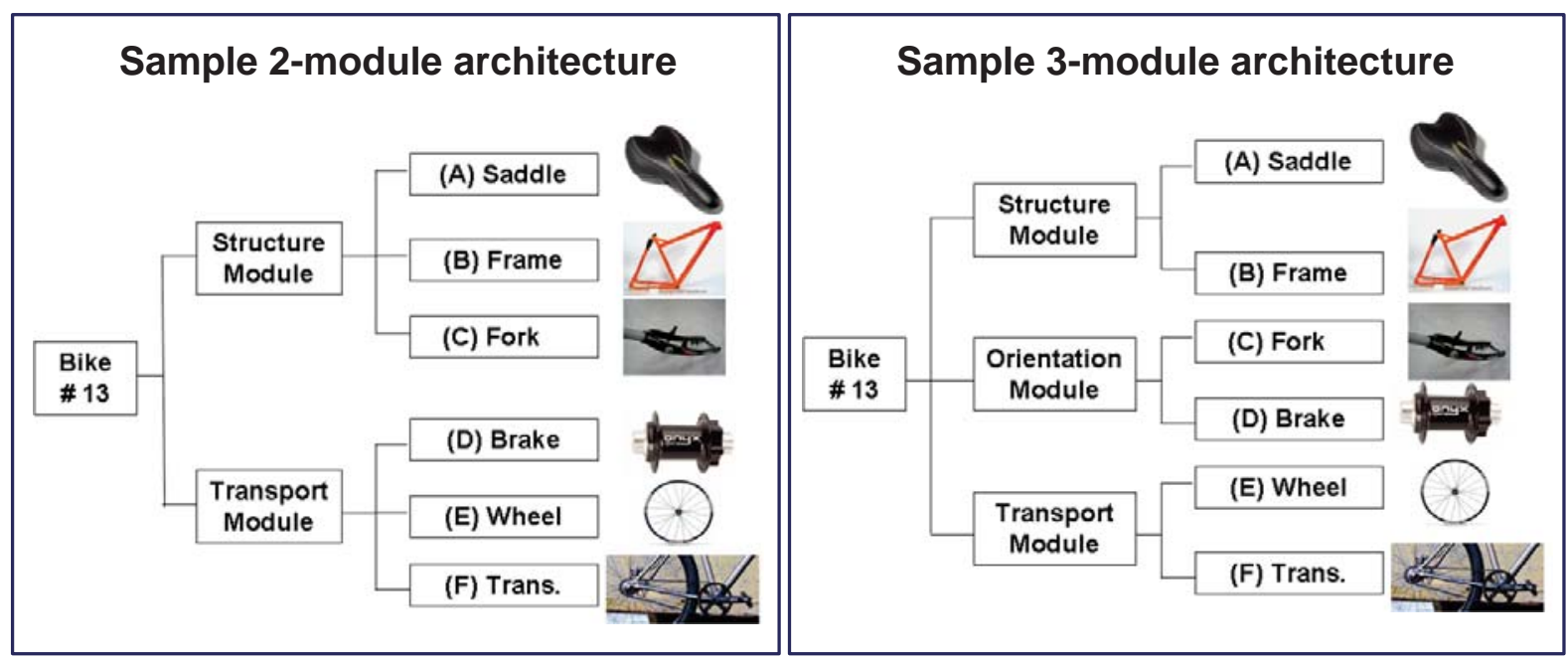

PENNSTATE 


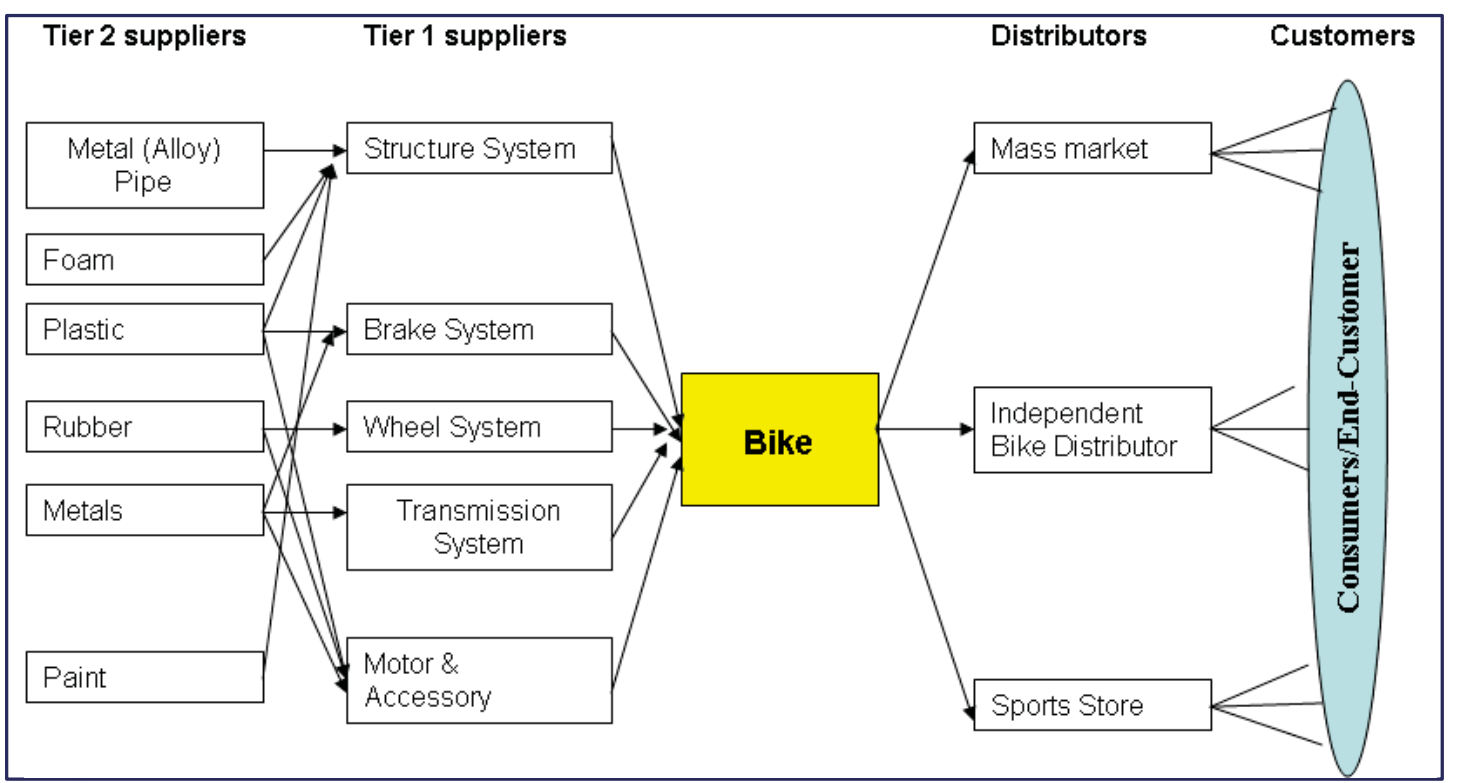

PENNSTATE

$\frac{120}{185}$

\section{Supplier Optimization for Specific Designs}

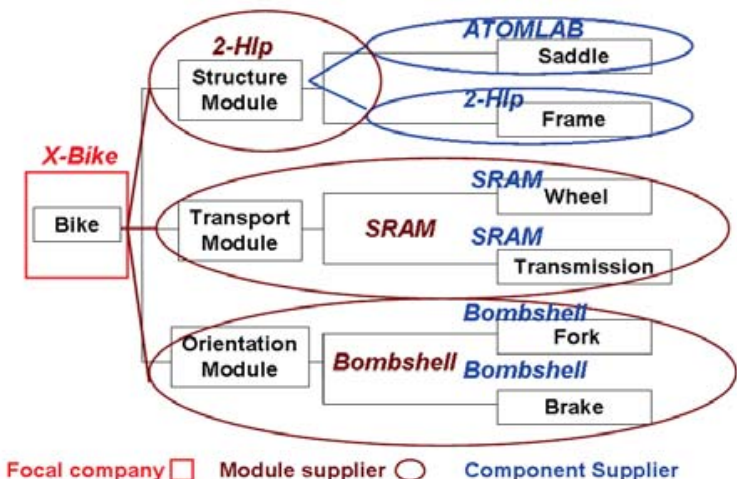

B13

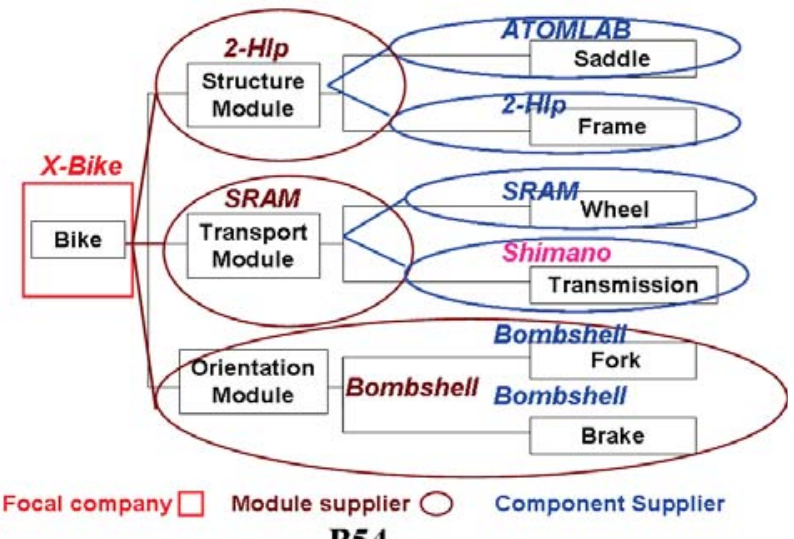

B54

PENNSTATE 
3) For each component, select one component supplier

4) For each module, select one module supplier

5) For final product, select one final supplier

6) Time constraint from decision maker

7) Cost constraints from decision maker

\section{PENNSTATE}

2

$\frac{120}{1853}$

Chiu, M-C. and Okudan, G.E 2011 "An Integrative Methodology for Product and Supply Chain Design Decisions at the Product Design Stage", ASME Journal of Mechanical Design, Vol. 133, pp. 0211008-1-15.

\begin{tabular}{|l|c|c|}
\hline \multicolumn{1}{|c|}{ Measures } & $\begin{array}{l}\text { Ooth Design \& } \\
\text { Only Design is } \\
\text { Considered }\end{array}$ & $\begin{array}{l}\text { Supply Chain are } \\
\text { considered }\end{array}$ \\
\hline Component Cost (\$USD) & 500.60 & 500.60 \\
\hline Assemble Cost (\$USD) & 39.00 & 31.00 \\
\hline Transportation Cost (\$USD) & 53.23 & 34.13 \\
\hline Inventory Cost (\$USD) & 15.42 & 15.19 \\
\hline Total Cost (\$USD) & $\mathbf{6 0 8 . 2 5}$ & $\mathbf{5 8 0 . 9 2}$ \\
\hline Diff & $\mathbf{4 . 7 0 \%}$ & \\
\hline Total Lead Time (days) & 159.5 & 128.2 \\
\hline Diff & $\mathbf{2 4 \%}$ & \\
\hline Number of suppliers & $\mathbf{9}$ & $\mathbf{8}$ \\
\hline
\end{tabular}

PENNSTATE Chiu, M-C. and Okudan, G.E 2011 "An Integrative Methodology for Product and Supply Chain Design Decisions at the Product Design Stage", ASME Journal of Mechanical Design, Vol. 133, pp. 0211008-1-15. 


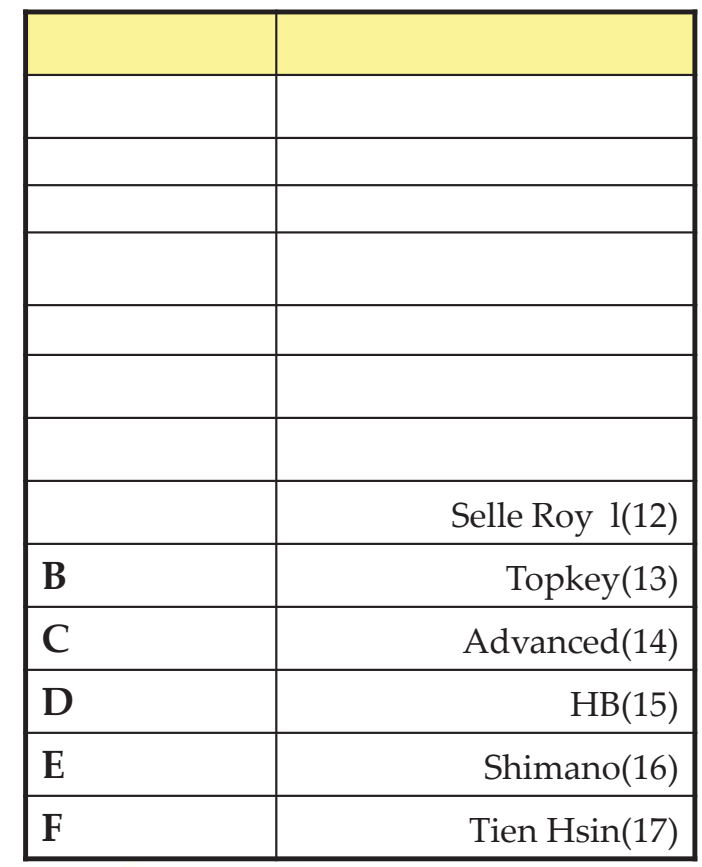

PENNSTATE

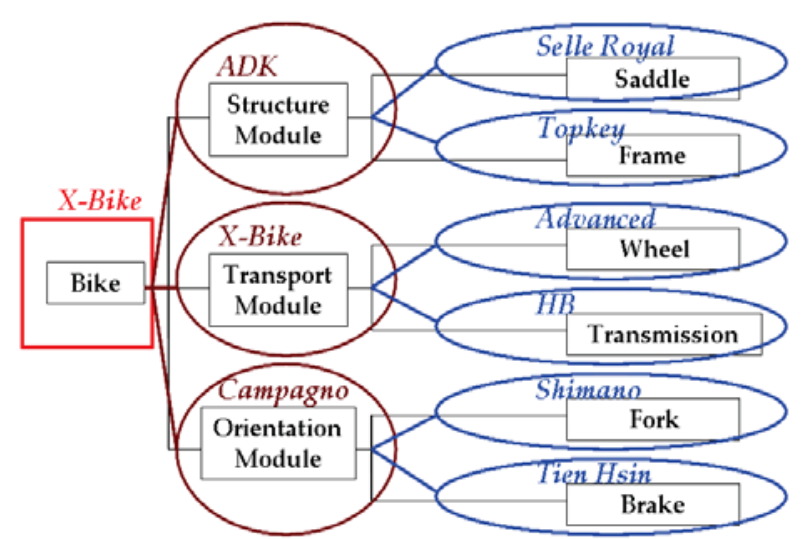

Focal company $\square$ Module supplier $\bigcirc$ Component Supplier

Optimum Solution for the case where only design is considered

20

\begin{tabular}{|l|r|}
\hline Part Type & Supplier (Process \#) \\
\hline ABCDEF & X-bike(1) \\
\hline ABC & Topkey(3) \\
\hline DEF & Sram(4) \\
\hline AB & \\
\hline BC & \\
\hline CD & Selle Royal(12) \\
\hline EF & Topkey(13) \\
\hline A & Advanced(14) \\
\hline B & $\operatorname{HB}(15)$ \\
\hline C & Shimano(16) \\
\hline D & Tien Hsin(17) \\
\hline E & \\
\hline F & \\
\hline
\end{tabular}

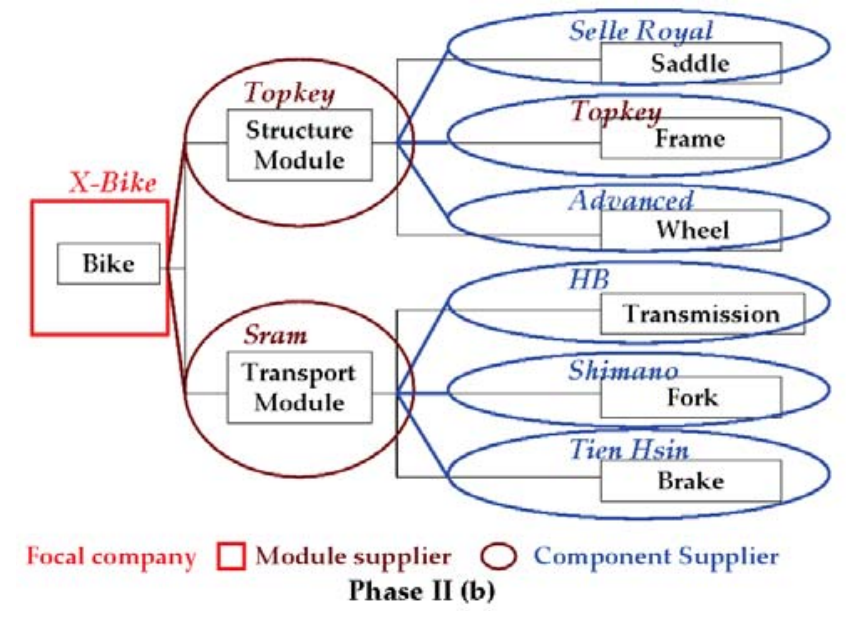

PENNSTATE

Optimum Solution for the case where both design \& supply chain are considered 

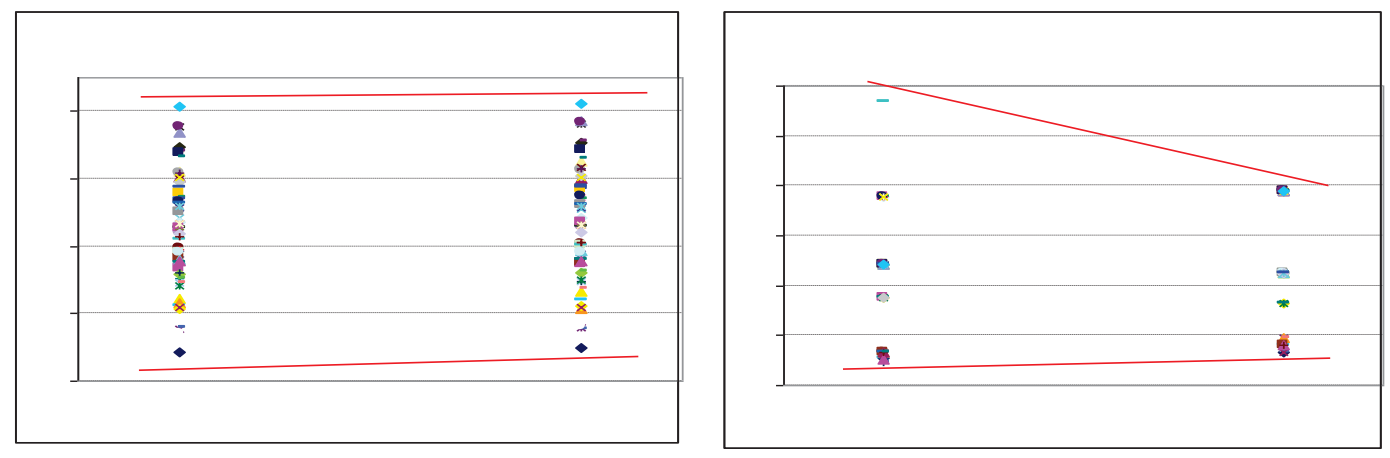

\begin{tabular}{|r|r|r|r|r|}
\hline & \multicolumn{2}{|c|}{ Cost(\$USD) } & \multicolumn{2}{c|}{ Time (Day) } \\
\hline & 2 module_Cost & 3 module_Cost & 2 module_Time & 3 module_Time \\
\hline Avg. & 627.02 & 631.55 & 120.88 & 135.30 \\
\hline Diff & - & $1 \%$ & - & $\mathbf{1 2} \%$ \\
\hline STD & $\mathbf{8 4 . 6 3 0}$ & $\mathbf{8 6 . 3 5 1}$ & $\mathbf{2 1 . 9 8 3}$ & $\mathbf{2 4 . 8 2 3}$ \\
\hline
\end{tabular}

PENNSTATE

$\frac{120}{1853}$

Does modularity level impact the design performance?

2-Module Versus 3-Module Product Architecture in MIP

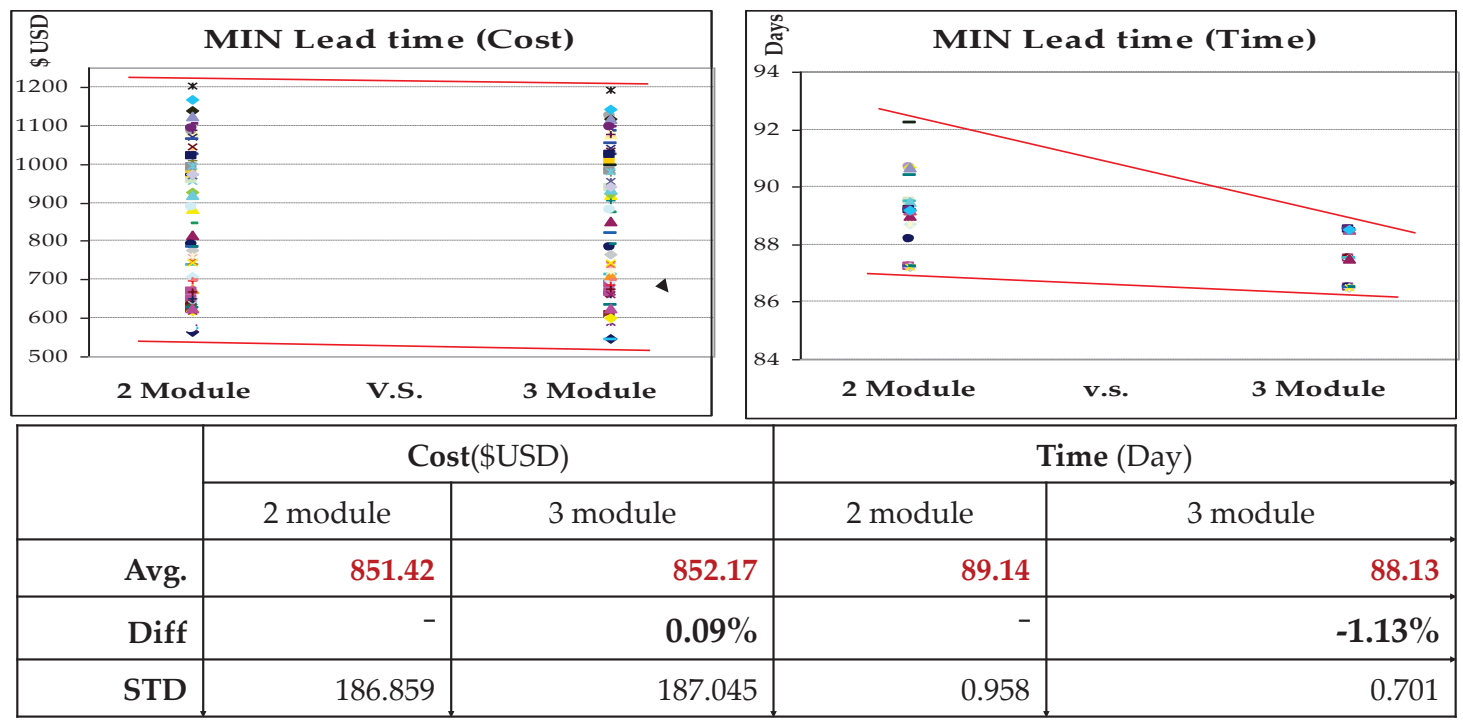

PENNSTATE Chiu, M-C. and Okudan, G.E. 2014 "An Investigation on the Impact of Product Modularity Level on Supply Chain Performance Metrics: An Industrial Case Study", Journal of Intelligent Manufacturing, 25(1), pp. 129-145. 
3-module is superior in time in MIN Lead time condition.

PENNSTATE Chiu, M-C., and Okudan, G.E. (2013). "An Investigation on Centralized and

PENNSTATE Decentralized Supply Chain Scenarios at the Product Design Stage to Increase

Supply Chain Performance", IEEE Engineering Management, in press.

Lesson 2. Cost, lead time and carbon footprint minimization goals favor different type of product architectures

- Previous work

- Included cost and lead time

- Design for Assembly (DfA) rankings

- Product architecture and modularity

- Previous work is expanded to include $\mathrm{kg} \mathrm{CO}_{2}$ equivalent as a sustainability metric accounting for:
- Material extraction
- Material processing
- Transportation

PENNSTATE 

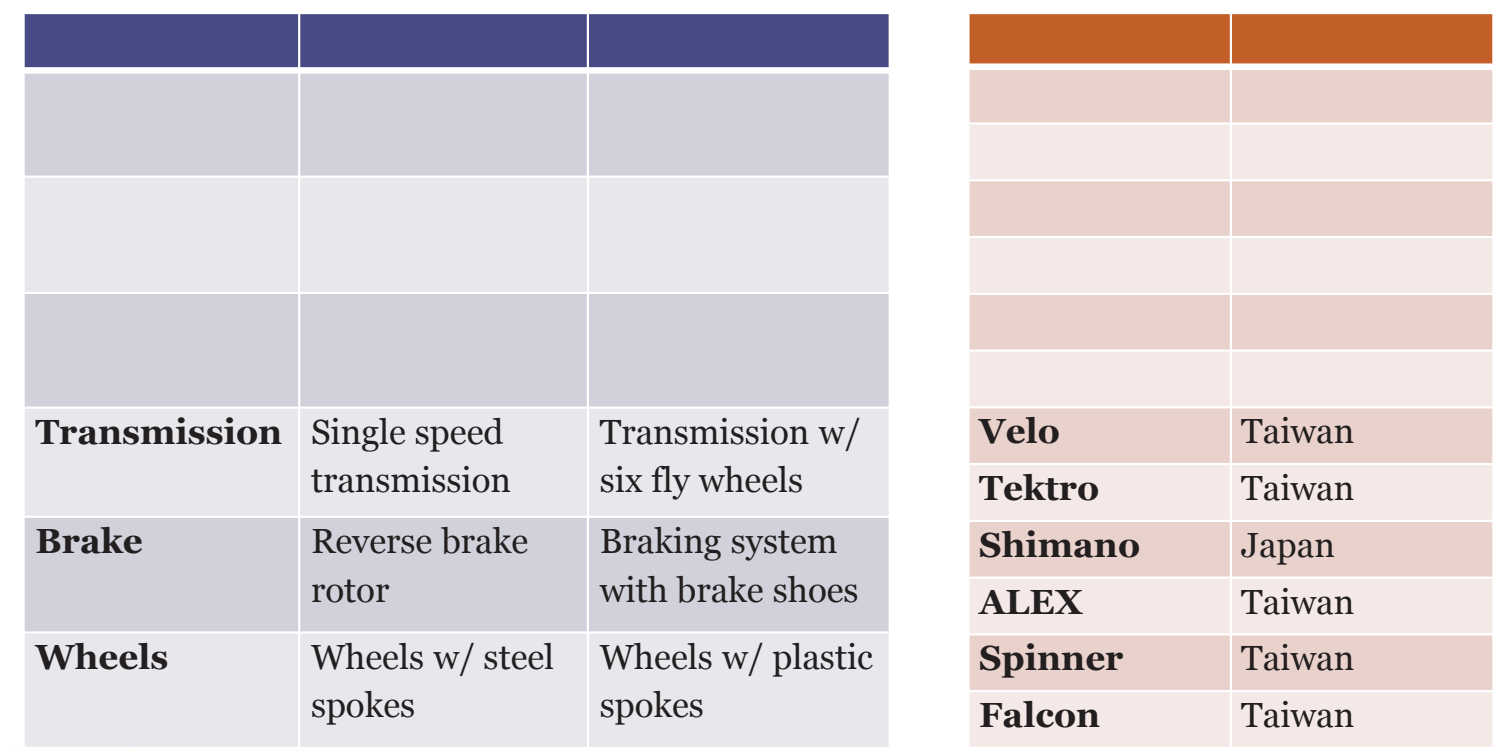

\section{PENNSTATE}

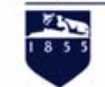

\section{Analysis Tools}

- SimaPro LCA software used to calculate $\mathrm{kg} \mathrm{CO}_{2}$ equiv. for materials, processing, and transportation

- Life cycle inventory: ecoinvent database

- Impact assessment: IPCC 2007 GWP 200 V1.02

- LINGO software used to find the combination of components, suppliers, and product architecture using non-linear programming to optimize:
- Cost
- Lead time
- Sustainability

PENNSTATE 


\begin{tabular}{|c|c|c|c|c|}
\hline No. & \multicolumn{2}{|l|}{ Process } & \multicolumn{2}{|l|}{ Description } \\
\hline 10 & \multicolumn{2}{|c|}{ Pipe cutting } & \multicolumn{2}{|c|}{ Cut the pipes to form the fork blade and steering tube } \\
\hline 20 & \multicolumn{2}{|c|}{$\begin{array}{l}\text { Machining to precise } \\
\text { dimension }\end{array}$} & \multicolumn{2}{|c|}{ For the tips which connect fork and wheel } \\
\hline 30 & \multicolumn{2}{|l|}{ Welding } & \multicolumn{2}{|l|}{ Weld the tubes and tips together } \\
\hline 40 & \multicolumn{2}{|l|}{ Sanding } & \multicolumn{2}{|l|}{ Polish the surface of fork } \\
\hline 50 & \multicolumn{2}{|c|}{ Heat treatment } & \multicolumn{2}{|l|}{ Restore metal to its original condition } \\
\hline 60 & \multicolumn{2}{|l|}{ Painting } & \multicolumn{2}{|c|}{ Create a more finished appearance and protect the fork. } \\
\hline & \multicolumn{4}{|c|}{ Fork Materials and Processes for Life Cycle Inventory } \\
\hline & Part & \multicolumn{2}{|l|}{ Material } & Weight (Kg) \\
\hline & Fork & \multicolumn{2}{|c|}{ Steel, low-alloyed, at plant/RER U } & 1.105 \\
\hline & & \multicolumn{2}{|c|}{ Alkyd paint, white, $60 \%$ in $\mathrm{H} 2 \mathrm{O}$, at plant/RER $\mathrm{U}$} & 0.05 \\
\hline & Part & \multicolumn{2}{|l|}{ SimaPro } & Weight (Kg) \\
\hline & Fork & \multicolumn{2}{|c|}{ Drawing of pipes, steel/RER U } & 1.095 \\
\hline & & \multicolumn{2}{|c|}{ Steel product manufacturing, average metal working/RER U } & 1.105 \\
\hline & & \multicolumn{2}{|c|}{ Sheet rolling, steel/RER U } & 0.01 \\
\hline
\end{tabular}

\section{Sustainability: Material Compositions}

\begin{tabular}{|c|c|c|c|}
\hline Material mass (kg) & B13 & B54 & SimaPro Process (ecoinvent database) \\
\hline $\begin{array}{l}\text { Medium carbon steel components } \\
\text { (e.g., frame, fork) }\end{array}$ & 7.5294 & 5.3464 & Steel, low-alloyed, at plant/RER U \\
\hline $\begin{array}{l}\text { Alloy and stainless steel components } \\
\text { (e.g., bearings) }\end{array}$ & 2.47 & 2.784 & Steel, electric, chromium steel 18/8, at plant/RER U \\
\hline Composite nylon wheels & & 1.88 & Nylon 66, glass-filled, at plant/RER U \\
\hline $\begin{array}{l}\text { Rubber components (e.g., tires and } \\
\text { brake pads) }\end{array}$ & 1.52 & 1.554 & Synthetic rubber, at plant/RER U \\
\hline Saddle support structure (shell) & 0.41 & 0.4 & Polypropylene, granulate, at plant/RER U \\
\hline Saddle cover & 0.08 & 0.07 & $\begin{array}{l}\text { Polyvinylchloride, suspension polymerised, at } \\
\text { plant/RER U }\end{array}$ \\
\hline Saddle padding & 0.033 & 0.024 & Polyurethane, flexible foam, at plant/RER U \\
\hline Saddle thread & 0.006 & 0.006 & Viscose fibres, at plant/GLO U \\
\hline Paint & 0.06 & & Alkyd paint, white, $60 \%$ in $\mathrm{H} 2 \mathrm{O}$, at plant/RER U \\
\hline PFadid STIATE & 0.02 & & Acrylic binder, 34\% in $\mathrm{H} 2 \mathrm{O}$, at plant/RER U \\
\hline
\end{tabular}




\begin{tabular}{|l|l|l|l|}
\hline & & & \\
\hline & & & \\
\hline & & & \\
\hline & & & \\
\hline $\begin{array}{l}\text { Forming of medium carbon steel flat } \\
\text { stock (e.g., for brackets) }\end{array}$ & 1.044 & 0.546 & Sheet rolling, steel/RER U \\
\hline $\begin{array}{l}\text { Forming of alloy/stainless steel flat stock } \\
\text { (e.g., for sprockets) }\end{array}$ & 1.38 & 0.035 & Sheet rolling, chromium steel/RER U \\
\hline $\begin{array}{l}\text { Welding of frame (estimated overall } \\
\text { weld length) }\end{array}$ & $1(\mathrm{~m})$ & $1(\mathrm{~m})$ & Welding, gas, steel/RER U \\
\hline
\end{tabular}

PENNSTATE

$\frac{120}{1853}$

Sustainability - Comparison of carbon footprint

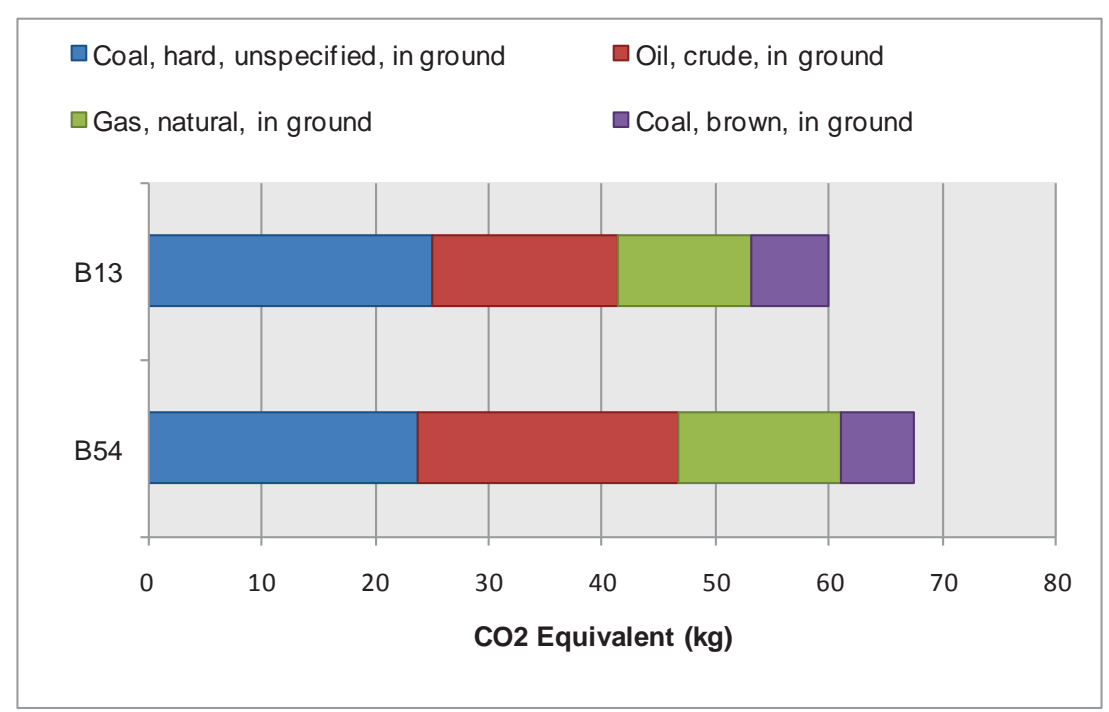

PENNSTATE

Graph shows the carbon footprint difference of two design variants 


\section{Decision Variables}

MPCF - Carbon footprint for manufacturing and processing the chosen components

$\mathrm{TCF}$ - The total carbon footprint for transporting the chosen components, modules and assembly parameters

MPXpi - The carbon footprint value for process $\mathrm{p}$ and supplier $\mathrm{i}$

TLDpi - The distance travelled on land for process $p$ and supplier $i$

TSDpi - The distance travelled by sea for process $p$ and supplier $i$

TLDI - The carbon footprint per ton-mile travelled on land

TSDI -The carbon footprint per ton-mile travelled by sea

$\mathrm{CWpi}$ - The fraction of a ton for each component or module from process $\mathrm{p}$ and supplier $\mathrm{i}$

\section{Optimization Results}

\section{NUMERICAL RESULTS}

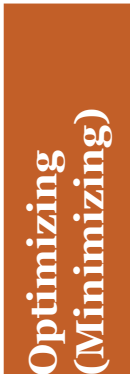

Cost

Lead

Time

Carbon Footprint

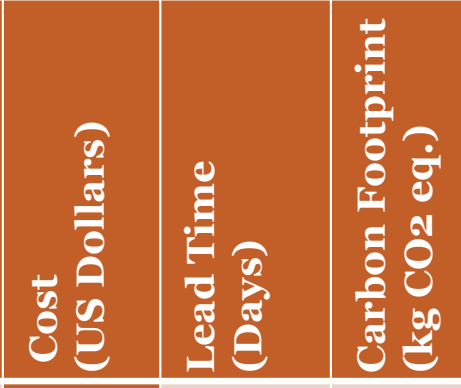

\begin{tabular}{|r|r|r|}
\hline $\mathbf{8 3 . 7 4}$ & 54.20 & 60.48 \\
\hline 109.3 & $\mathbf{3 8 . 8 0}$ & 65.85 \\
\hline 99.94 & 172.80 & 44.18 \\
\hline
\end{tabular}

COST: Product Architecture

\begin{tabular}{|l|l|l|}
\multicolumn{1}{|c|}{$\begin{array}{c}\text { Part or } \\
\text { Module }\end{array}$} & \multicolumn{1}{c|}{ Supplier } & Location \\
\hline ABCDEF & X-Bike & PA, USA \\
\hline AB & 2 Hip & CA, USA \\
\hline CD & SRAM & IL, USA \\
\hline EF & BBB & Holland \\
\hline (A) Saddle & ATOM LAB & CA, USA \\
\hline (B) Frame & 2 Hip & CA, USA \\
\hline (C) Fork & X-Bike & PA, USA \\
\hline (D) Brake & SRAM & IL, USA \\
\hline (E) Wheel & BBB & Holland \\
\hline (F) Trans. & BBB & Holland \\
\hline
\end{tabular}



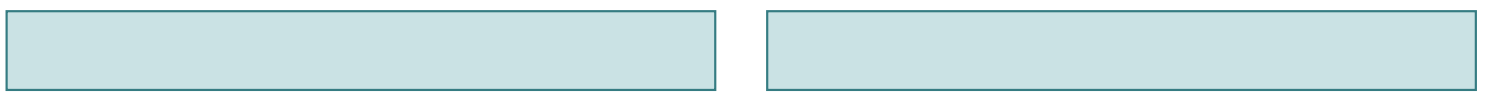

\begin{tabular}{l|l|l} 
& & \\
& & \\
& & \\
\hline DEF & ATOM LAB & CA, USA \\
\hline EF & Shimano & JAPAN \\
\hline (A) Saddle & ATOM LAB & CA, USA \\
\hline (B) Frame & Axxis & CA, USA \\
\hline (C) Fork & X-Bike & PA, USA \\
\hline (D) Brake & SRAM & IL, USA \\
\hline (E) Wheel & Shimano & Japan \\
\hline (F) Trans. & BBB & Holland \\
\hline
\end{tabular}

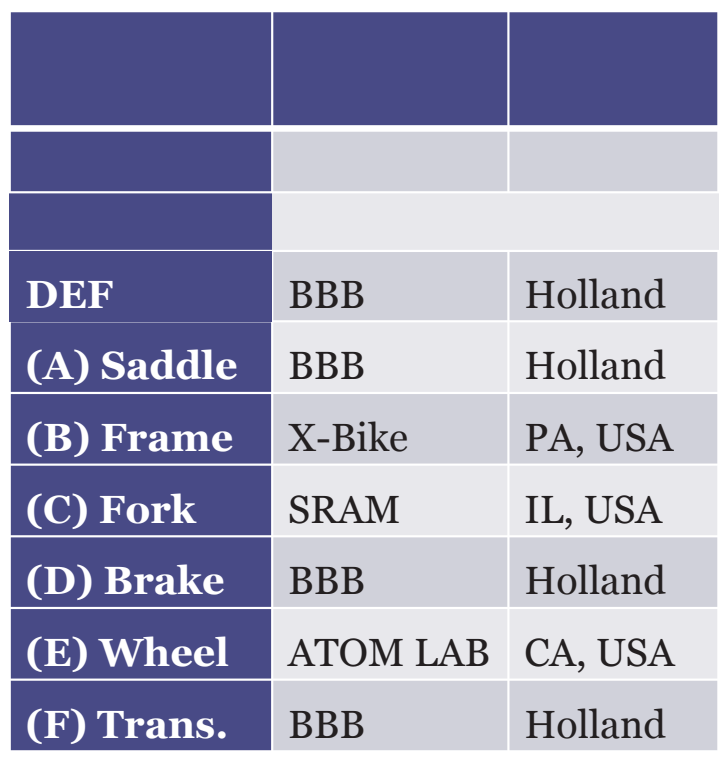

\section{Lesson 2. Cost, lead time and carbon footprint minimization goals favor different type of product architectures}

- Optimization results point to different product architectures for cost, lead time and CF

- Development of computational artificial intelligence is needed to:

\section{- Analyze more complex products \\ - Exploit objective tradeoffs \\ - Improve customization for products}

Olson, E., Okudan, G. E., Chiu, M-C., Haapala, K. R. (2011) "Positioning Product Architecture As the Driver for Carbon Footprint \& Efficiency Trade-offs in A Global Supply Chain", 4th International Conference on Industrial Engineering and Systems Management (IESM 2011), Metz, France.

Olson, E., Haapala, K. and Okudan, G.E. "Integration of Sustainability Issues during Early Design Stages in a Global Supply Chain Context", AAAI Spring Symposium Series, March 21-23, 2011, at Stanford University, Stanford, CA. 


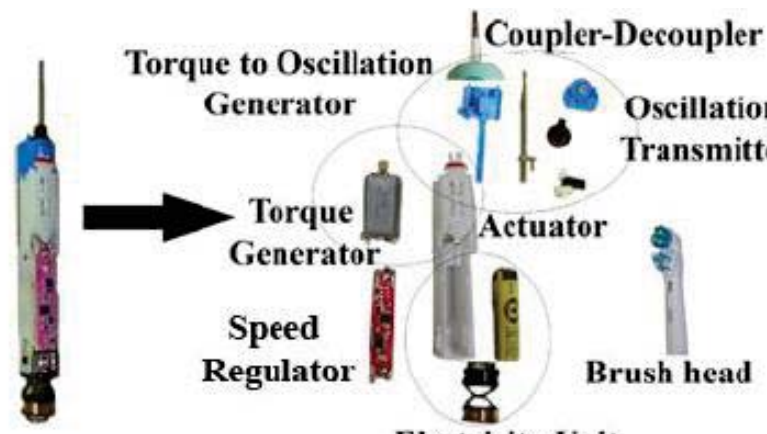

Electricity Unit

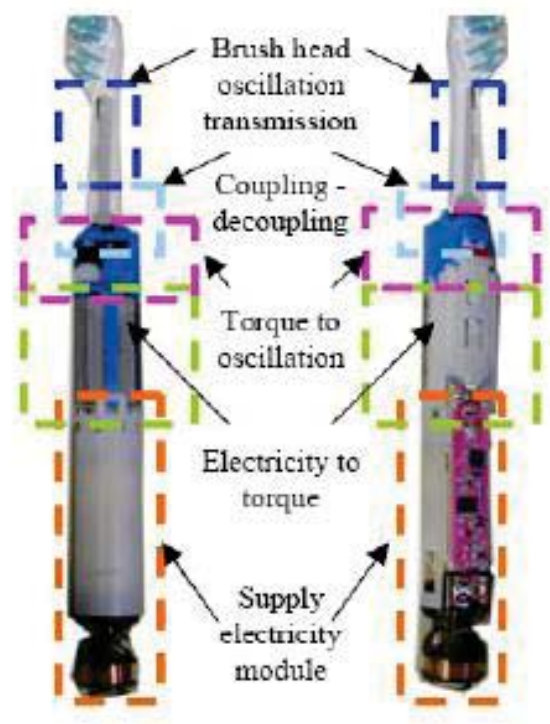

PENNSTATE

geve

1853

\section{Coupler-Decoupler}




\begin{tabular}{|c|c|c|c|c|c|c|}
\hline \multicolumn{7}{|c|}{ Stone et al.'s approach } \\
\hline Modules & $\begin{array}{c}\text { Supply } \\
\text { electricity }\end{array}$ & $\begin{array}{l}\text { Electricity to } \\
\text { torque }\end{array}$ & $\begin{array}{l}\text { Torque to } \\
\text { oscillation } \\
\text { converter }\end{array}$ & $\begin{array}{l}\text { Coupli } \\
\text { decoup }\end{array}$ & & $\begin{array}{c}\text { Brush-head Oscillation } \\
\text { transmission }\end{array}$ \\
\hline \multirow{3}{*}{ Units } & Electricity unit & Torque generator & \multirow{3}{*}{$\begin{array}{l}\text { Oscillation } \\
\text { generator }\end{array}$} & \multirow{2}{*}{\multicolumn{2}{|c|}{$\begin{array}{c}\text { Coupling - decoupling } \\
\text { unit }\end{array}$}} & \multirow[t]{3}{*}{ Oscillation transmitter } \\
\hline & Actuator & & & & & \\
\hline & Speed regulator & & & & & \\
\hline \multicolumn{7}{|c|}{ Zhang et al.'s approach } \\
\hline Modules & \multicolumn{2}{|c|}{ Electricity - actuation } & \multicolumn{2}{|c|}{$\begin{array}{l}\text { Electricity to oscillation } \\
\text { transmission }\end{array}$} & \multicolumn{2}{|c|}{ Brush head coupling } \\
\hline \multirow{5}{*}{ Units } & \multirow{3}{*}{\multicolumn{2}{|c|}{ Electricity unit }} & Speed & lator & \multirow{5}{*}{\multicolumn{2}{|c|}{ Coupling-decoupling unit }} \\
\hline & & & Electricity to & ue converter & & \\
\hline & & & \multirow{2}{*}{\multicolumn{2}{|c|}{$\begin{array}{c}\text { Torque to Oscillation } \\
\text { converter }\end{array}$}} & & \\
\hline & \multirow{2}{*}{\multicolumn{2}{|c|}{ Actuator }} & & & & \\
\hline & & & \multicolumn{2}{|c|}{ Oscillation transmitter } & & \\
\hline \multicolumn{7}{|c|}{ Huang and Kusiak's approach } \\
\hline Modules & \multicolumn{3}{|c|}{ Electricity - Oscillation } & \multicolumn{3}{|c|}{ Brush head oscillation transmission } \\
\hline \multirow{4}{*}{ Units } & \multirow{2}{*}{\multicolumn{3}{|c|}{$\begin{array}{c}\text { Electricity unit } \\
\text { Actuator }\end{array}$}} & \multirow{2}{*}{\multicolumn{3}{|c|}{ Oscillation generator }} \\
\hline & & & & & & \\
\hline & \multirow{2}{*}{\multicolumn{2}{|c|}{$\begin{array}{c}\text { Speed regulator } \\
\text { Electricity to Torque conve }\end{array}$}} & & \multicolumn{3}{|c|}{ Coupler-Decoupler } \\
\hline & & & Electricity to Torque converter & \multicolumn{3}{|c|}{ Oscillation transmitter } \\
\hline
\end{tabular}

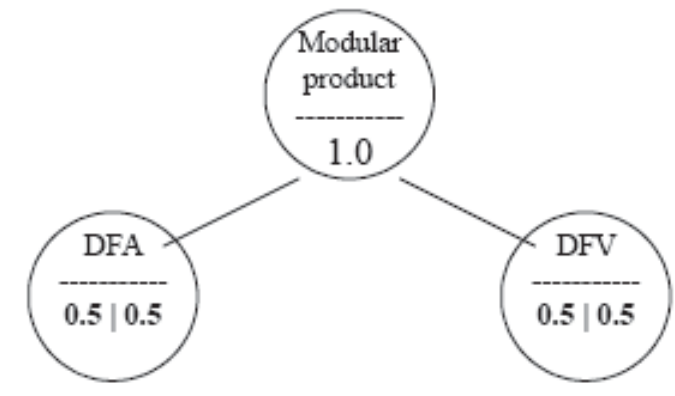

\begin{tabular}{|l|c|c|}
\hline & $\begin{array}{c}\text { Electricity/ } \\
\text { Oscillation }\end{array}$ & $\begin{array}{c}\text { Brush Head / Oscillation } \\
\text { transmission }\end{array}$ \\
\hline Weight $(\mathrm{g})$ & 1 & 1 \\
\hline Cost $(\mathrm{S})$ & 3 & 3 \\
\hline $\begin{array}{l}\text { Battery Life } \\
\text { (weeks) }\end{array}$ & 3 & \\
\hline $\begin{array}{l}\text { Decibels } \\
\text { (dB) }\end{array}$ & 1 & 1 \\
\hline Compatibility & & 3 \\
\hline
\end{tabular}

\begin{tabular}{|l|c|}
\hline Alternative & DFA Index \\
\hline FHM & 17.82 \\
\hline B-FES & 10.8 \\
\hline DA & 8.64 \\
\hline
\end{tabular}

The final values for the three concepts are: 12.32 for DA, 14.40 for B-FES, and 23.41 for FHM.

Based on these results, we observe that the DA is better in comparison to B-FES and FHM approaches with regards to DfA and DfV index values.

PENNSTATE Okudan, G.E. and Gupta, S. (2013). "Analysis of Modularity Implementation Methods from an Assembly and Variety Viewpoint", International Journal of Advanced Manufacturing Technology, 6(9), pp. 1959-1976. 


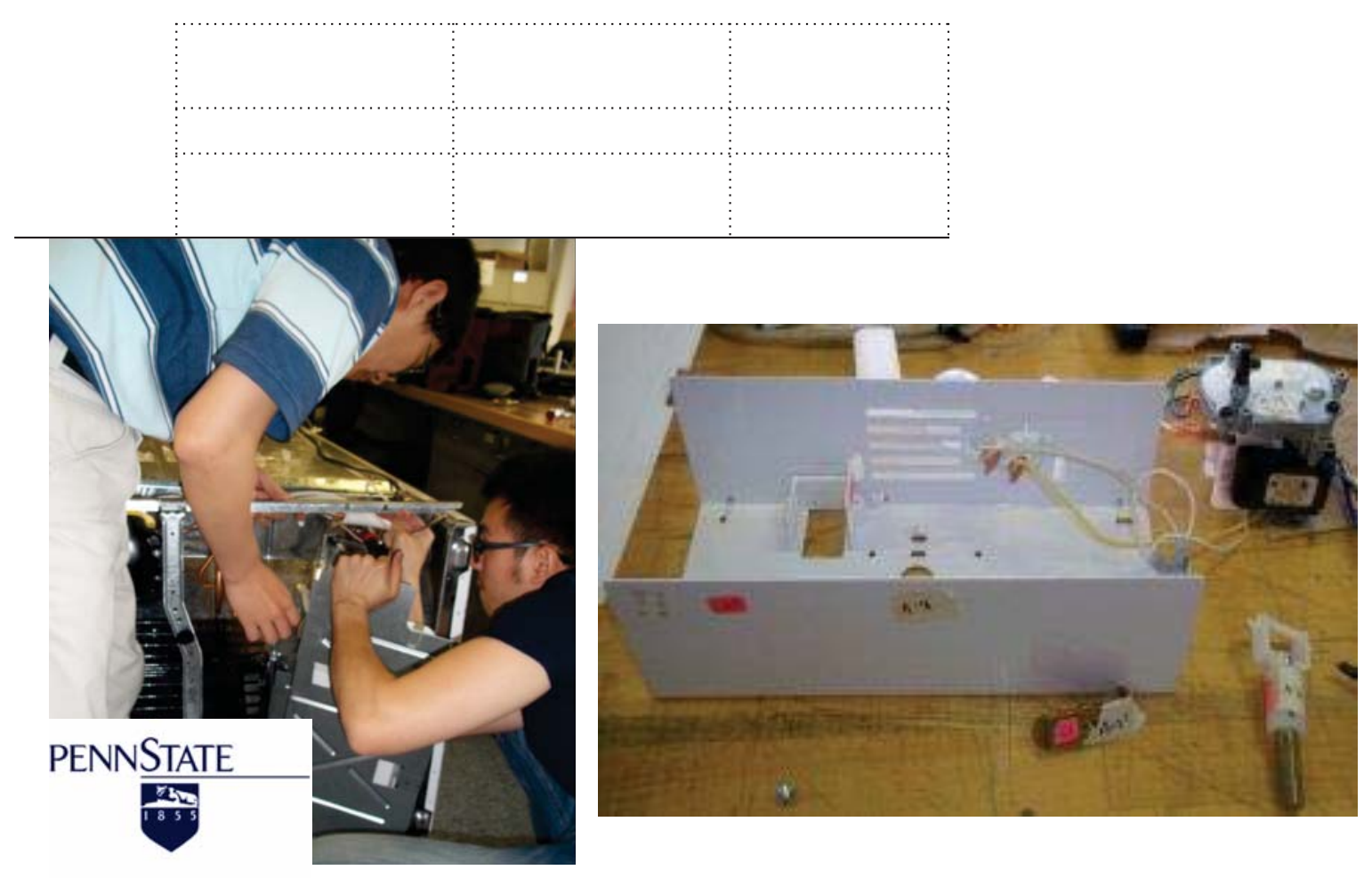

\section{Comparison of DA \& Multivariate Clustering}

\begin{tabular}{clclclc}
\hline Module & $\begin{array}{l}\text { DA } \\
\text { (component } \\
\text { numbers } \\
\text { within module) }\end{array}$ & $\begin{array}{l}\text { Carbon } \\
\text { Footprint } \\
\text { (465.66 kg } \\
\text { CO2 eq.) }\end{array}$ & $\begin{array}{l}\text { MC(I) } \\
\text { Interaction weight } \\
\begin{array}{l}\text { weight 0.65 } \\
\text { weight }\end{array}\end{array}$ & $\begin{array}{l}\text { Carbon } \\
\text { Footprint } \\
\text { (461.53 kg } \\
\text { CO2 eq.) }\end{array}$ & $\begin{array}{l}\text { MC(II) } \\
\text { Interaction weight } \\
0.65 ; \text { End of life } \\
\text { weight 0.35 }\end{array}$ & $\begin{array}{l}\text { Carbon } \\
\text { Footprint } \\
\text { (466.16 kg } \\
\text { CO2 eq.) }\end{array}$ \\
\hline 1 & $1,2,3,4,5,6$ & 25.2 & $1,2,3,4,6$ & 21.2 & $1,2,3,4,5,6$ & 25.2 \\
2 & $7,8,9,10,11$ & 30.8 & 5,10 & 0.01 & $7,8,9,10,11$ & 30.8 \\
3 & $12,13,26$ & 323 & $7,8,9,11$ & 30.5 & 12,13, & 321 \\
4 & 14 & 13.6 & $12,13,14,20,21$, & 352.6 & $14,21,22$ & 24.3 \\
5 & $15,16,17,18$ & 40.3 & $15,16,17,23$ & 40.3 & $15,16,17$ & 37.7 \\
6 & 20 & 6.07 & 18 & 1.72 & 18 & 1.72 \\
7 & 21,22 & 9.03 & $19,24,25$ & 15.2 & $19,23,24,25$ & 17.7 \\
8 & 23,24 & 3.26 & & & 20,26 & 7.74 \\
9 & 19,25 & 14.4 & & & & \\
\hline
\end{tabular}

PENNSTATE 


\begin{tabular}{clclllc}
5 & $15,16,17,18$ & Recycle/Reuse & $15,16,17,23$ & Reuse & $15,16,17$ & Reuse \\
6 & 20 & Recycle & 18 & Recycle & 18 & Recycle \\
7 & 21,22 & Recycle & $19,24,25$ & Recycle & $19,23,24,25$ & Recycle/Reuse \\
8 & 23,24 & Recycle/Reuse & & 20,26 & Recycle \\
9 & 19,25 & Recycle & & & \\
\hline
\end{tabular}

PENNSTATE $\frac{120}{1853}$

Results show easy to separate subassemblies for disposal and recycle.

Input the Suitability Matrix for Regular DA or choose the Green DA approach

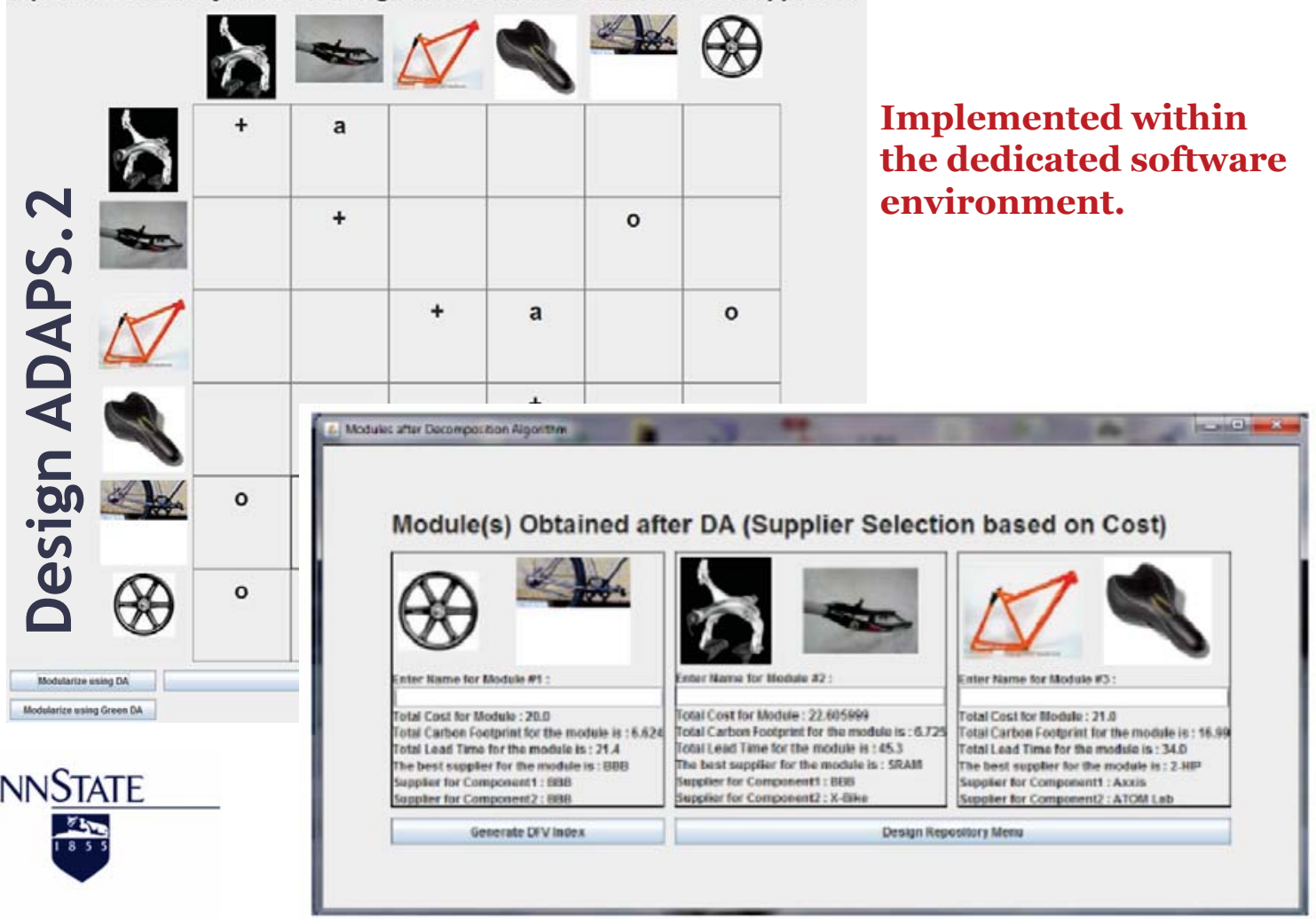




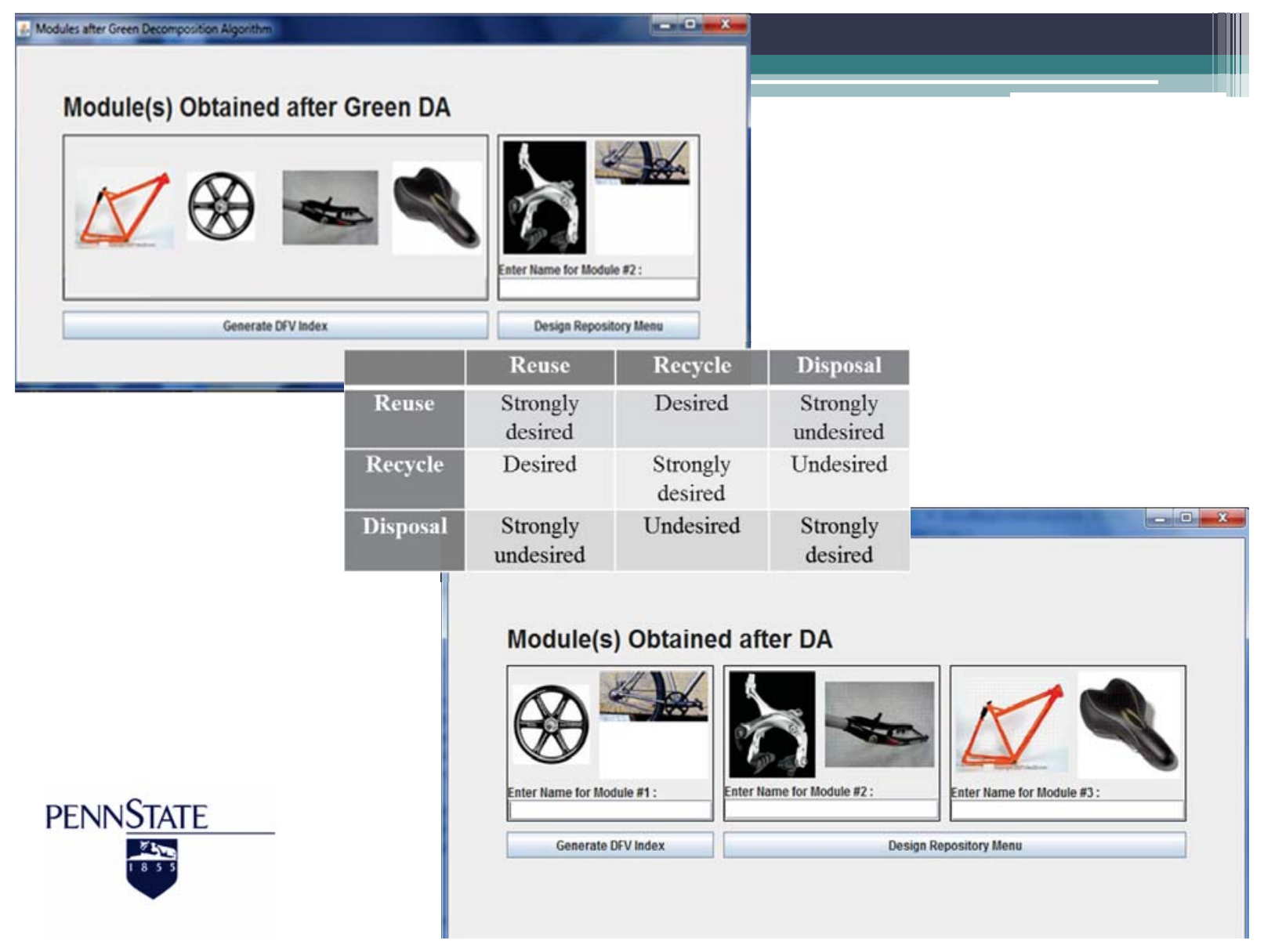

\section{Lesson 4. Robust modularity methods need to be developed to optimize life cycle costs \& a proposed approach}

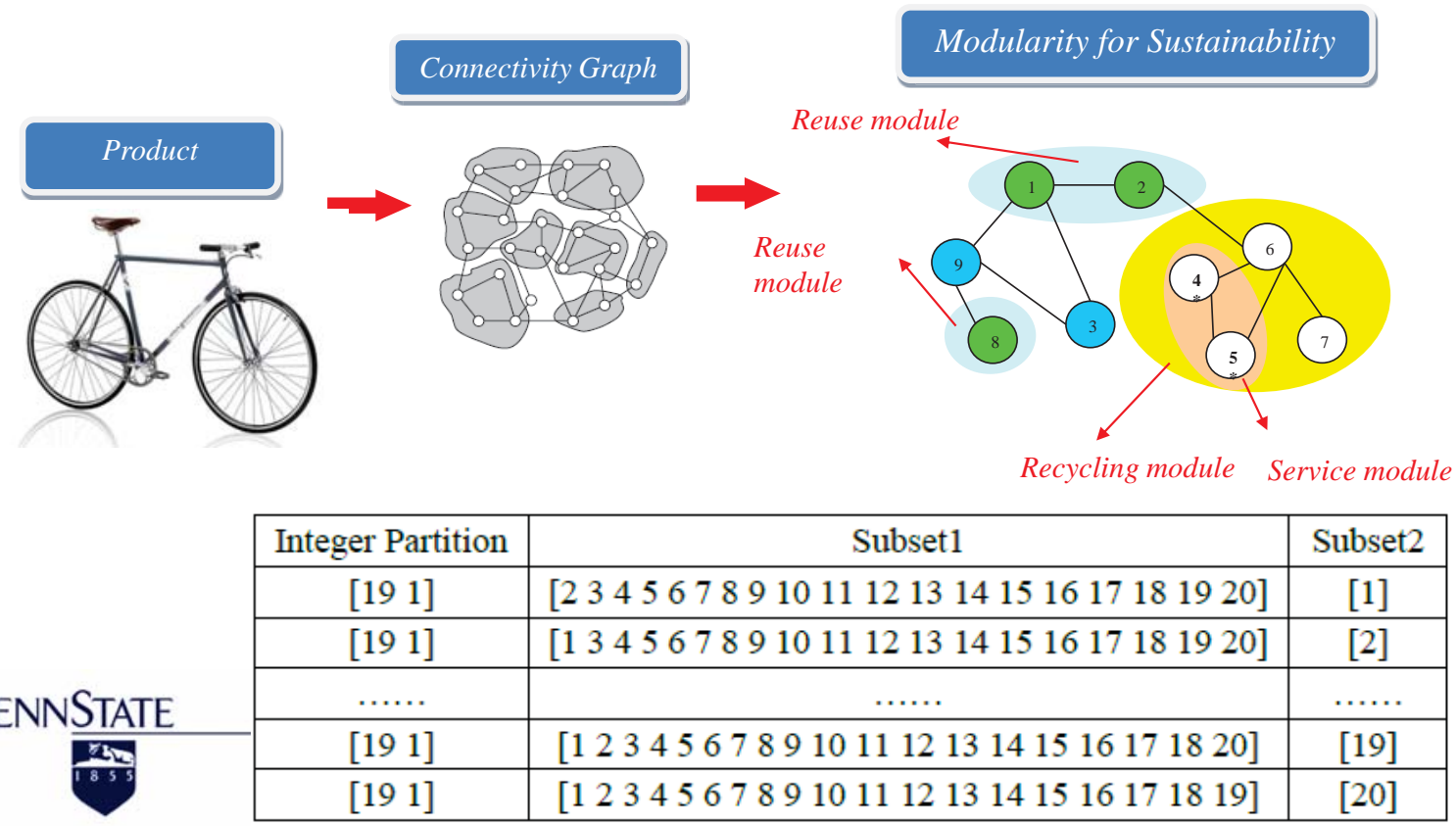




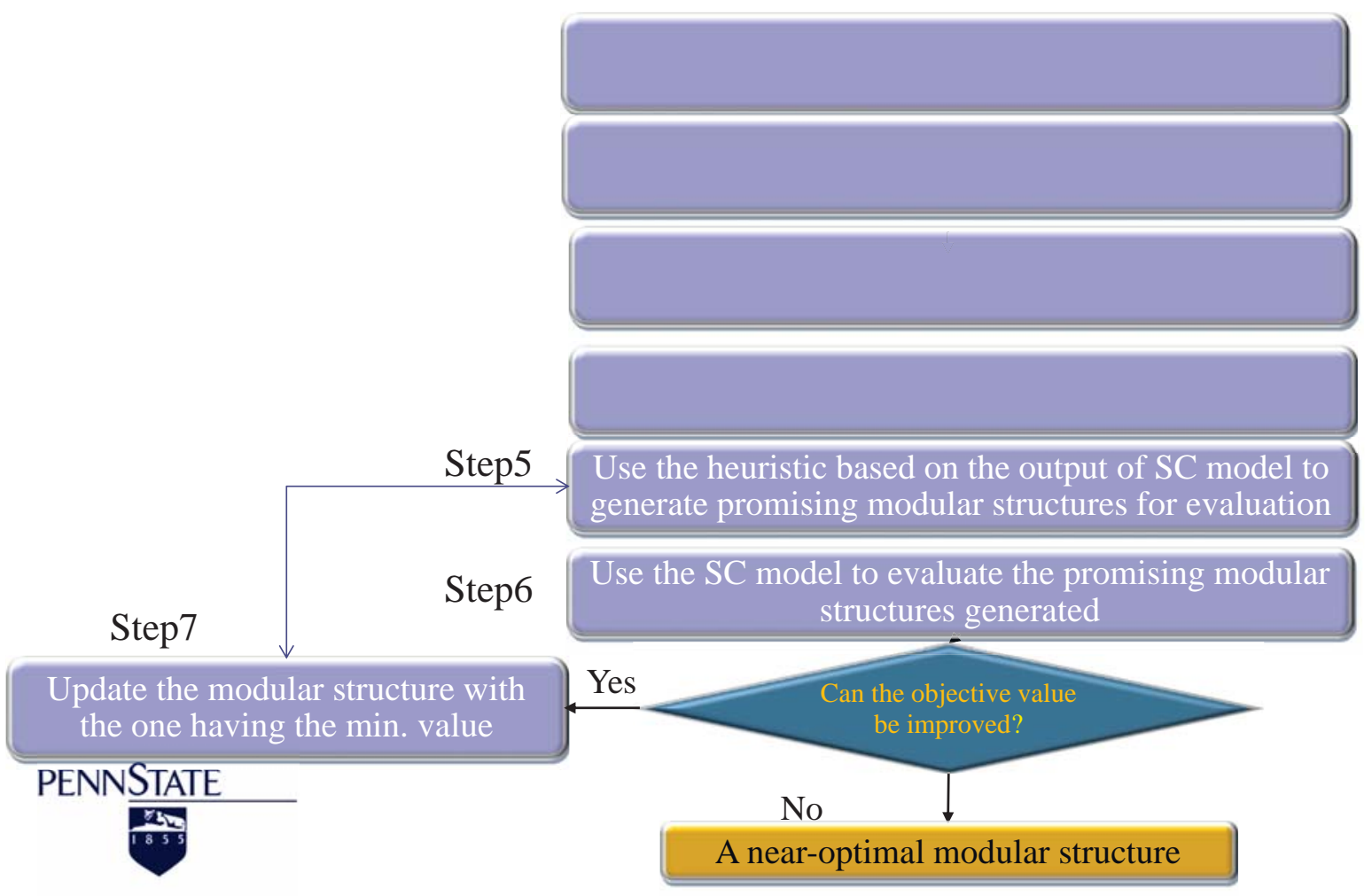

Connectivity Graph

\begin{tabular}{|c|c|c|c|c|c|c|c|c||c|}
\hline Product & $\begin{array}{c}\text { Vertex/ } \\
\text { Compont }\end{array}$ & $\begin{array}{c}\text { Mfg. } \\
\text { cost } \\
(\$)\end{array}$ & $\begin{array}{c}\text { Mfg. } \\
\text { energy } \\
(\mathrm{kWh})\end{array}$ & $\begin{array}{c}\text { Weight } \\
(\mathrm{g})\end{array}$ & $\begin{array}{c}\text { MTBF } \\
(\text { month) }\end{array}$ & $\begin{array}{c}\text { Reuse } \\
\text { value } \\
(\$)\end{array}$ & $\begin{array}{c}\text { Recycli } \\
\text { ng value } \\
(\$)\end{array}$ & $\begin{array}{c}\text { End-of- } \\
\text { life } \\
\text { option }\end{array}$ & $\begin{array}{c}\text { Service } \\
\text { intent }\end{array}$ \\
\hline
\end{tabular}




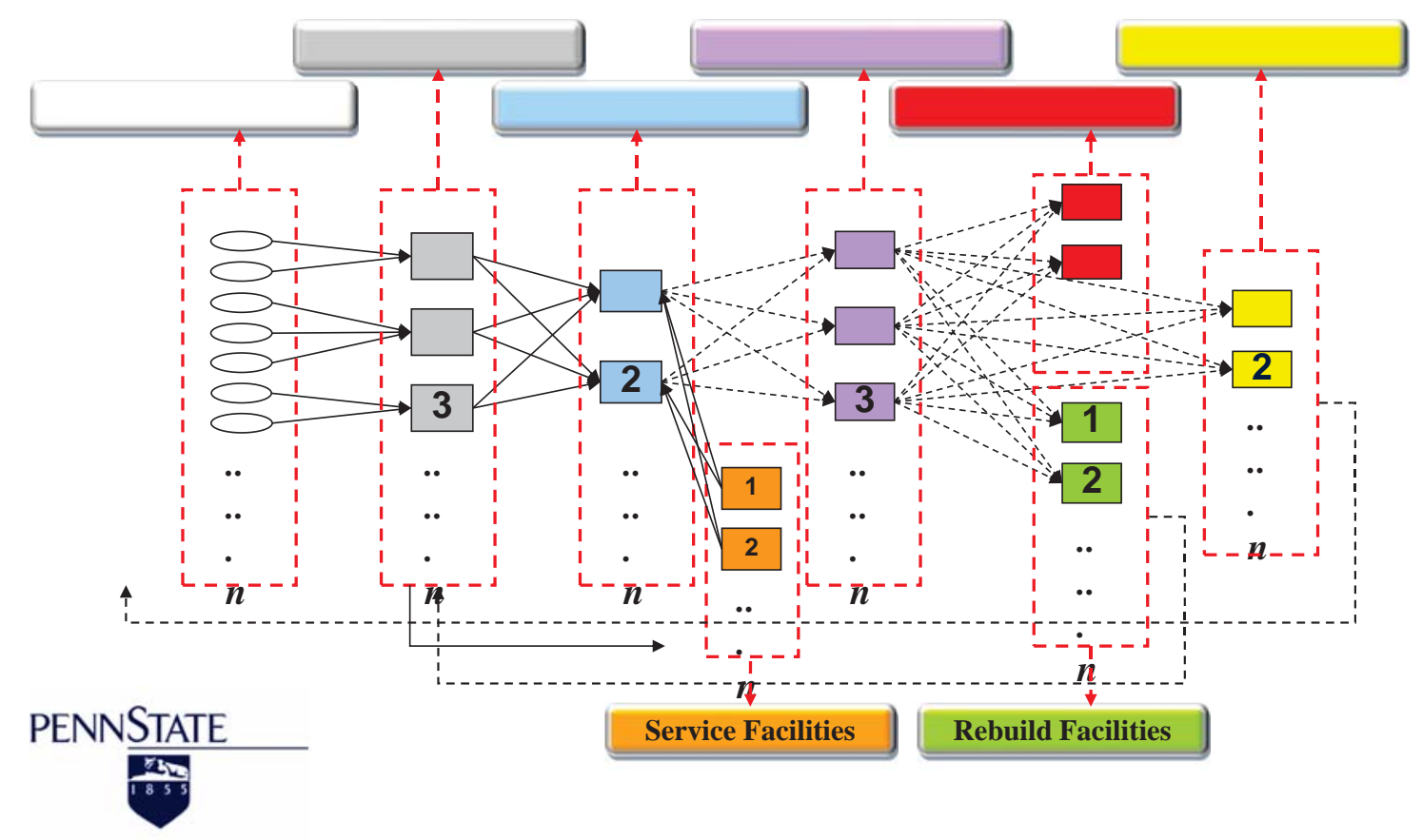

\title{
Formulation of the Supply Chain Optimization Model
}

\author{
Objective Min $Z_{L C C}$ \\ Min $Z_{L C E C}$ \\ where
}

$Z_{L C C}$ the life cycle cost in the supply chain (\$)

$Z_{L C E C}$ the life cycle energy consumption in the supply chain

\section{Constraints} $(k W h)$

\section{Forward Logistics Balance (Pull)}

Soutbound product/module flow from the facilities in the forward flows= 乏inbound component/module/product flow to the facilities in the forward flows

\section{Reverse Logistics Balance (Push)}

¿outbound module flow from the facilities in the reverse flows $=\Sigma$ inbound component/module/product flow to the facilities in the reverse flows

\section{PENNSTATE}




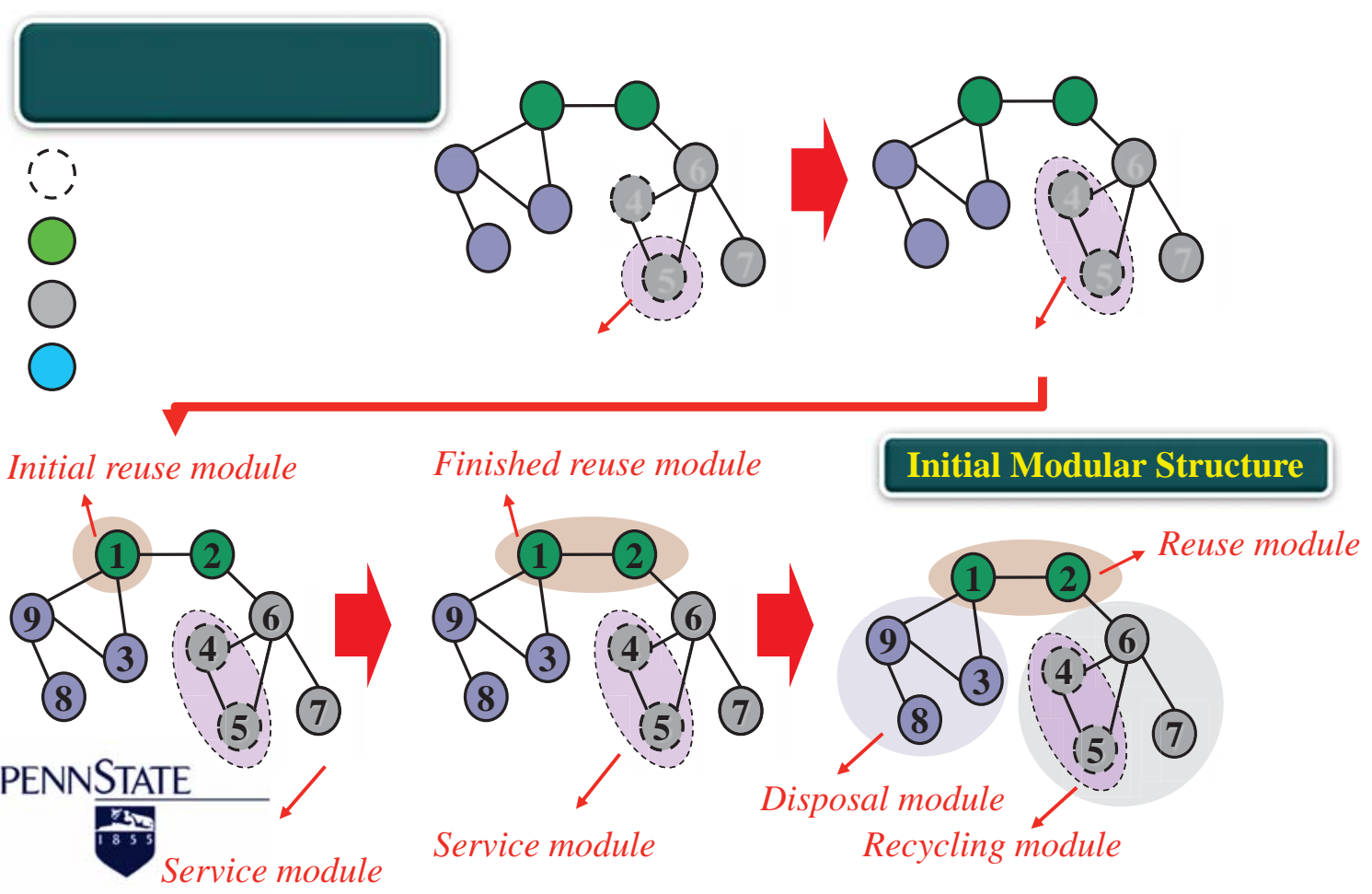

\section{The Criteria for Evaluating Potential Modular Structures in Costs}

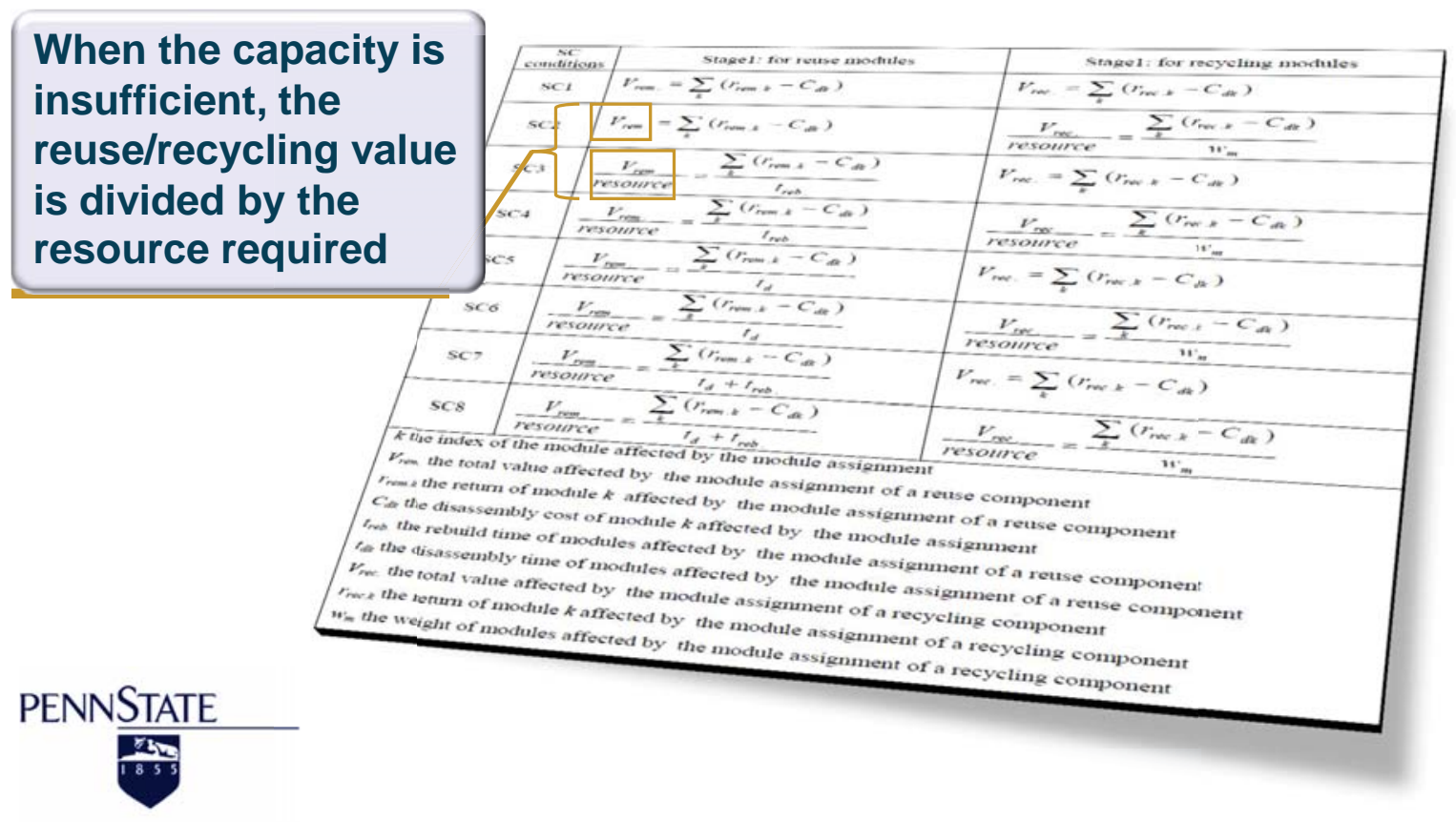




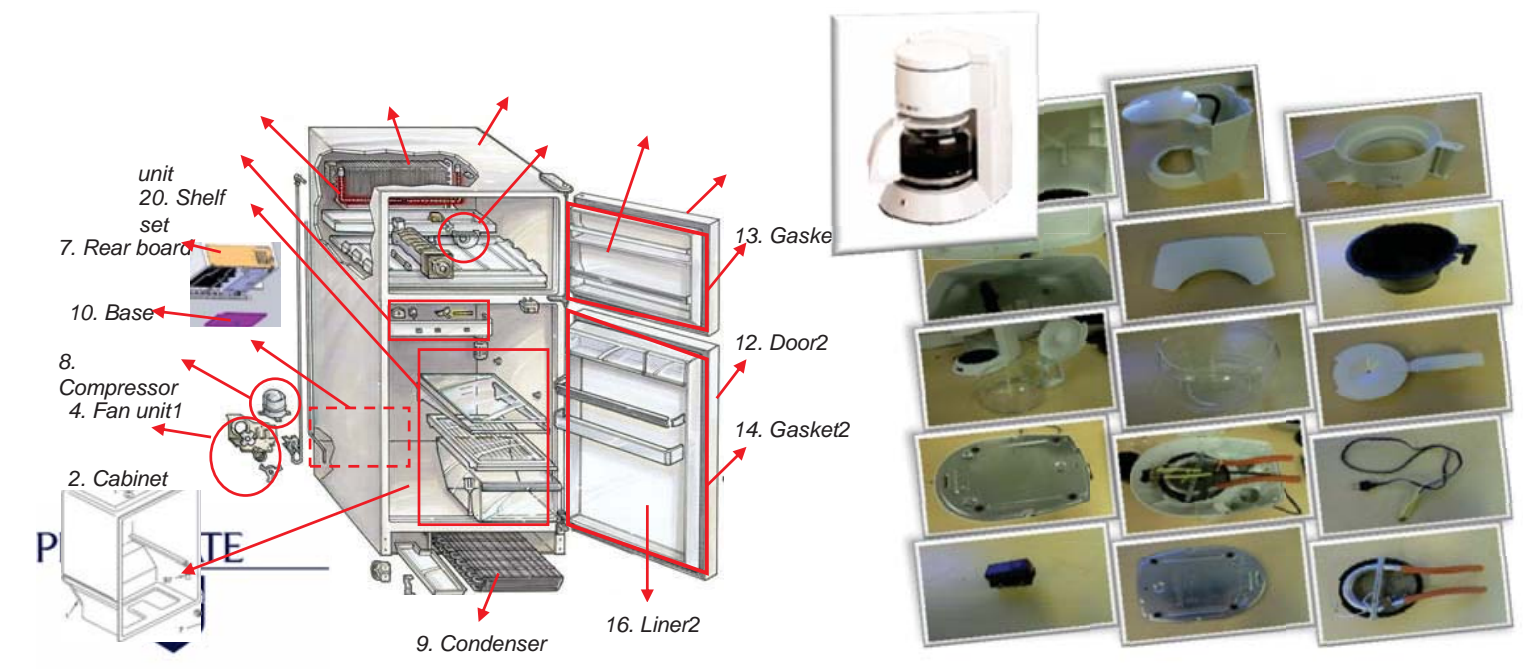

\section{Connectivity Graph of the Refrigerator}

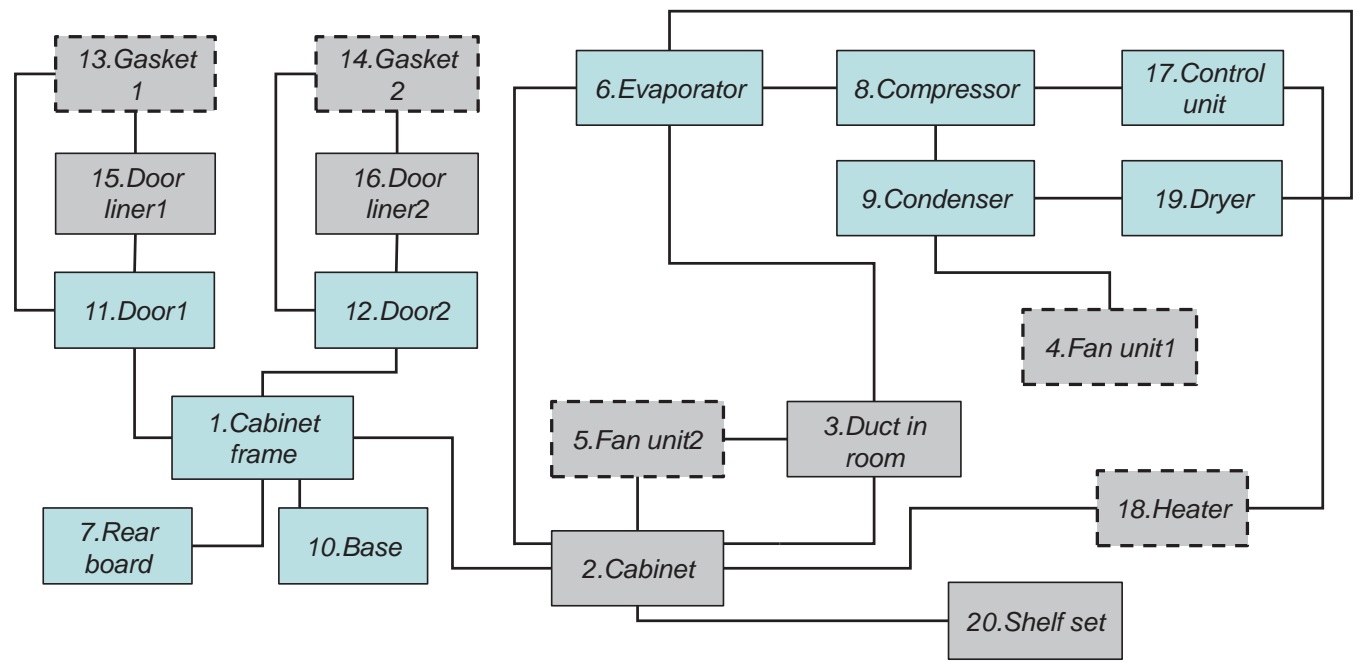

PENNSTATE 


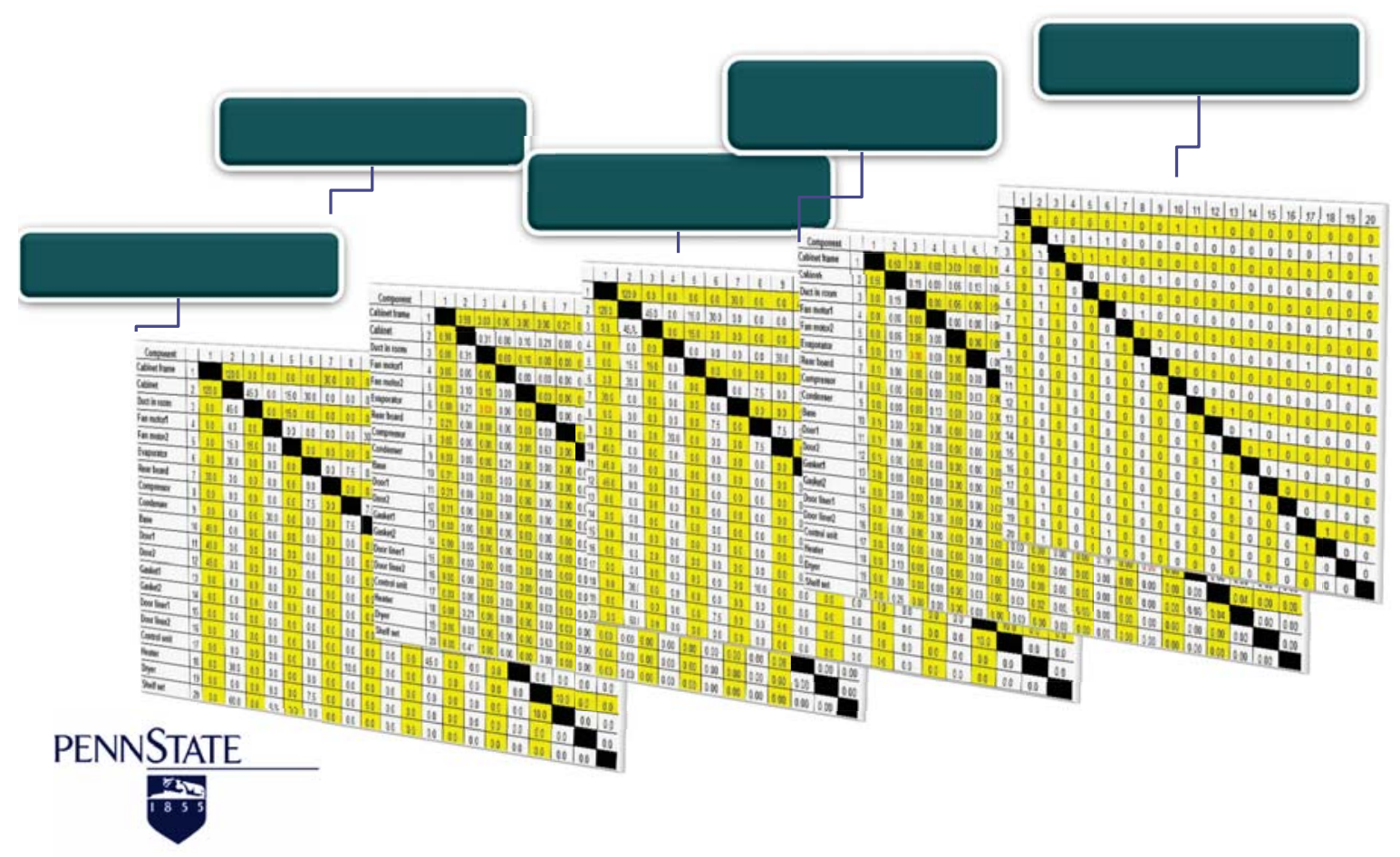

\section{Processing Facilities}

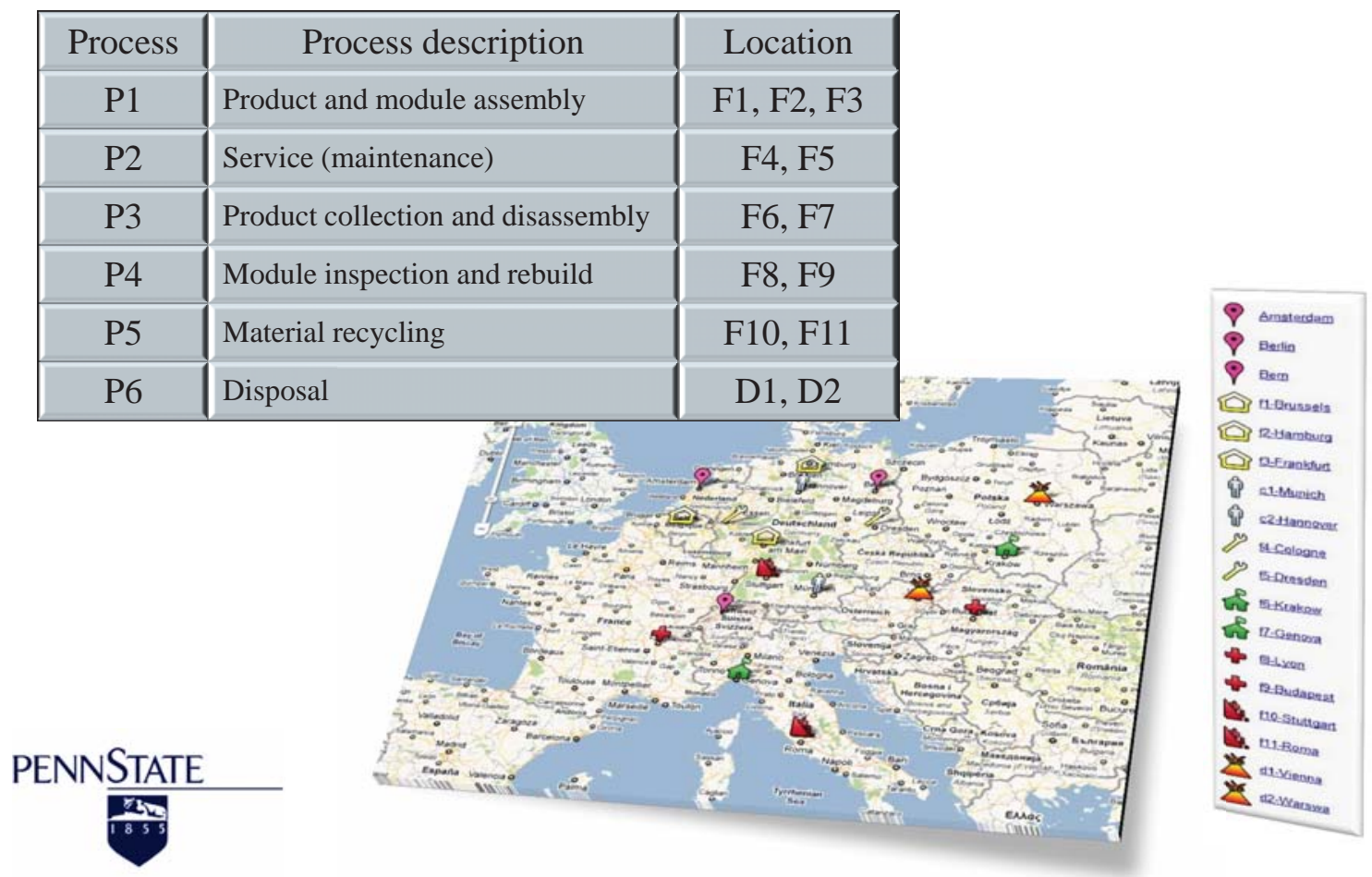



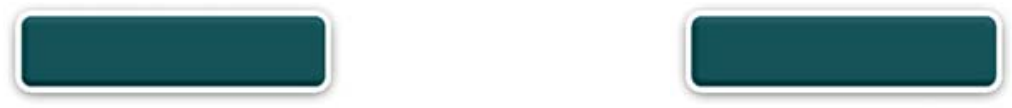

optimal modular structure, and is modular structure. measured by LCC or LCEC difference in percentage.

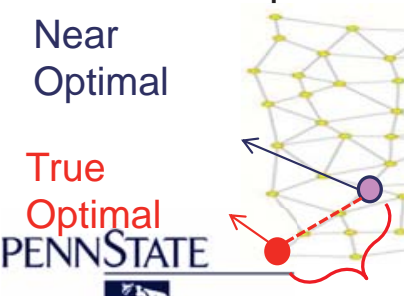

$\frac{22}{185}$
Initial Initial

Distance
Near

Optimal

True Optimal

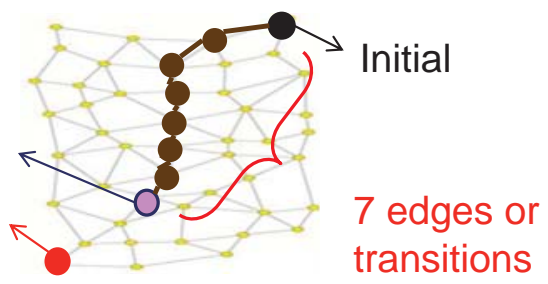
transitions

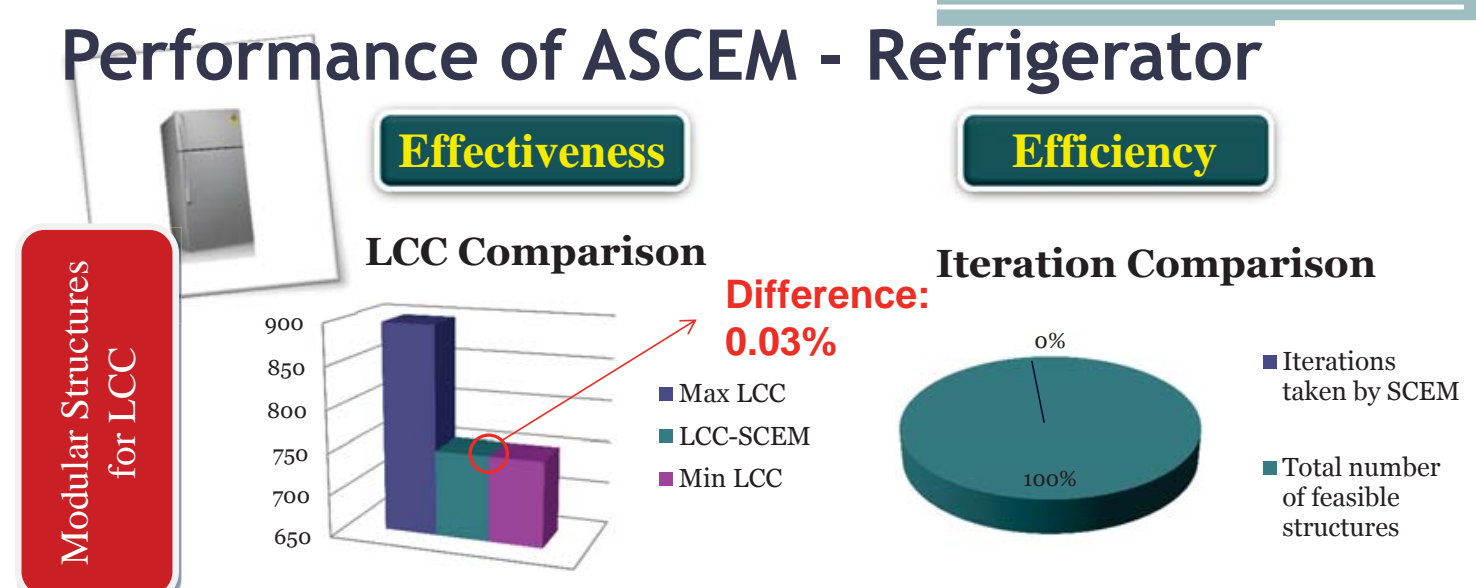

LCEC Comparison Difference:

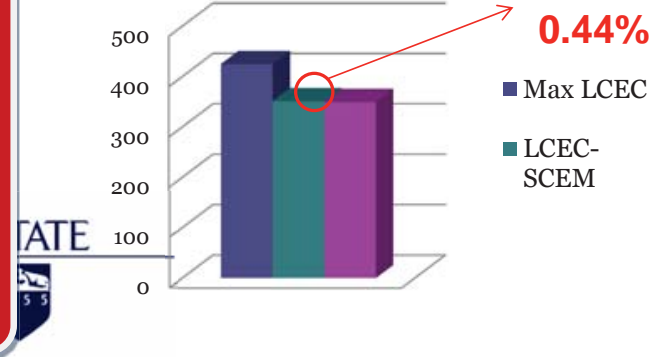

Iteration Comparison

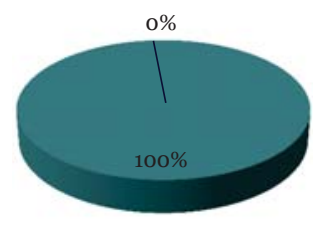

- Iterations taken by SCEM

Total number of feasible 

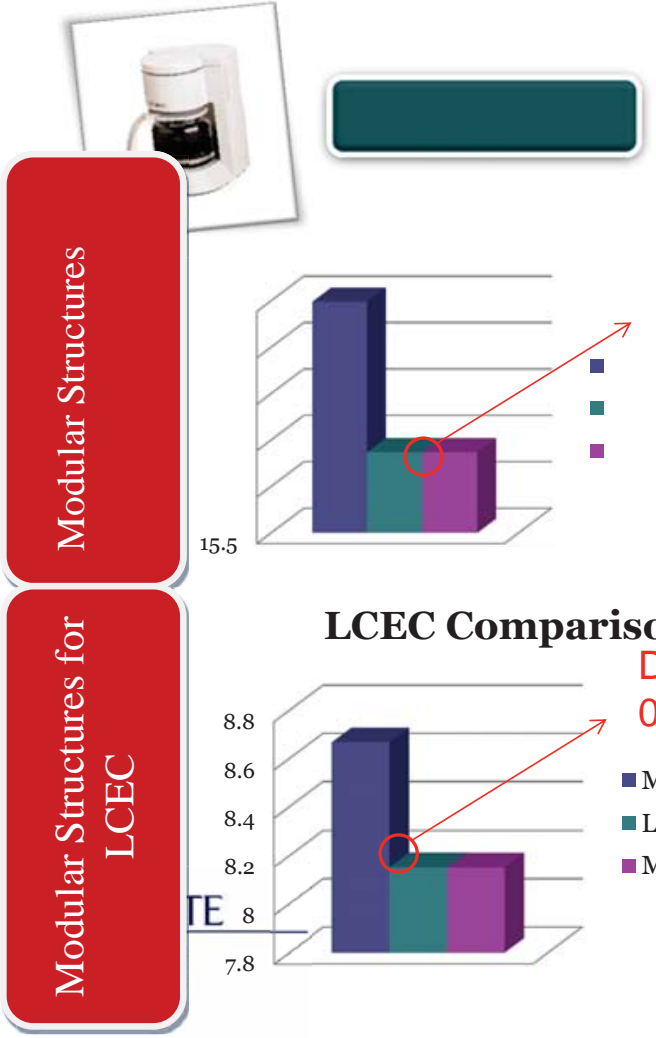

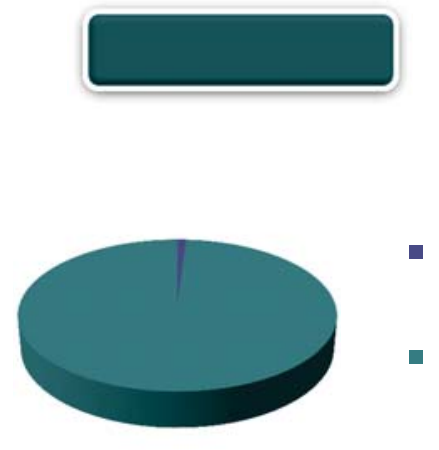

Iteration Comparison

Difference:

$0.02 \%$

- Max LCEC

- LCEC-SCEM

- Min LCEC

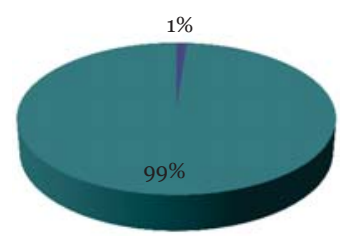

- Iterations taken by SCEM

- Total number of

feasible

structures

\section{Lesson 4. Robust modularity methods should be developed to optimize life cycle costs}

\begin{tabular}{|l|c|c|}
\hline Category & Small products & Large product \\
\hline Tested product & Coffee maker & Refrigerator \\
\hline Number of vertices (components) & 11 & 20 \\
\hline Number of edges (interactions) & 13 & 25 \\
\hline \hline LCC-ASCEM & 16.37 & 751.72 \\
\hline Min LCC & 16.37 & 751.48 \\
\hline Effectiveness: Difference\% & $0 \%$ & $0.03 \%$ \\
\hline Max LCC & 17.99 & 896.28 \\
\hline Efficiency: Iterations used & 26 & 55 \\
\hline Total number of feasible structures & 2,583 & $4,173,557$ \\
\hline \hline LCEC-ASCEM & 8.1544 & 351.66 \\
\hline Min LCEC & 8.1533 & 350.12 \\
\hline Effectiveness: Difference\% & $0.014 \%$ & $0.44 \%$ \\
\hline Max LCEC & 8.67 & 425.2 \\
\hline Efficiency: Iterations used & 31 & 86 \\
\hline Total number of feasible structures & 2,583 & $4,173,557$ \\
\hline
\end{tabular}




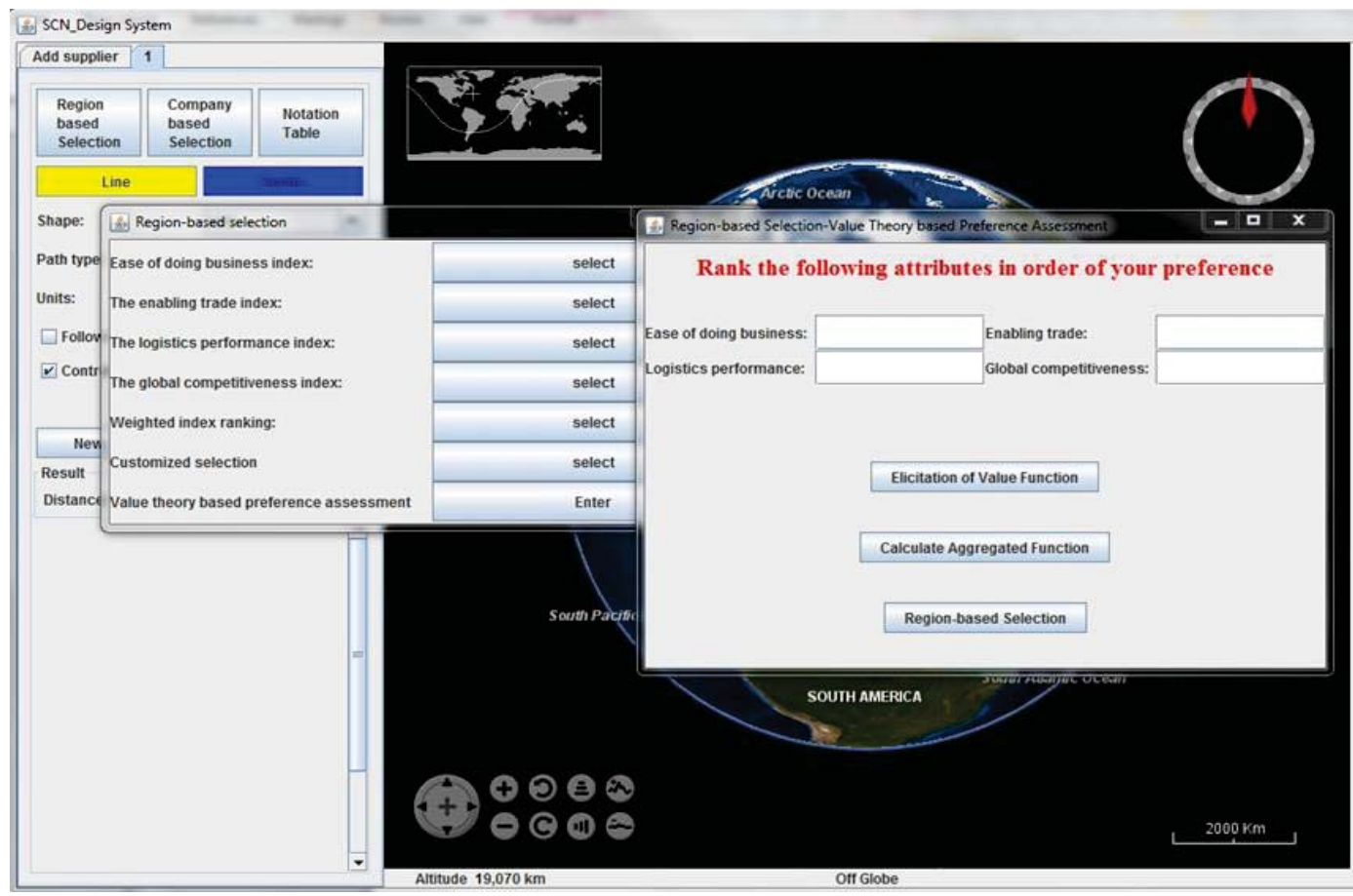

Goal is to seamlessly infuse data sources into decision making (e.g., World Bank data on countries' capabilities in manufacturing, logistics, and business operations.

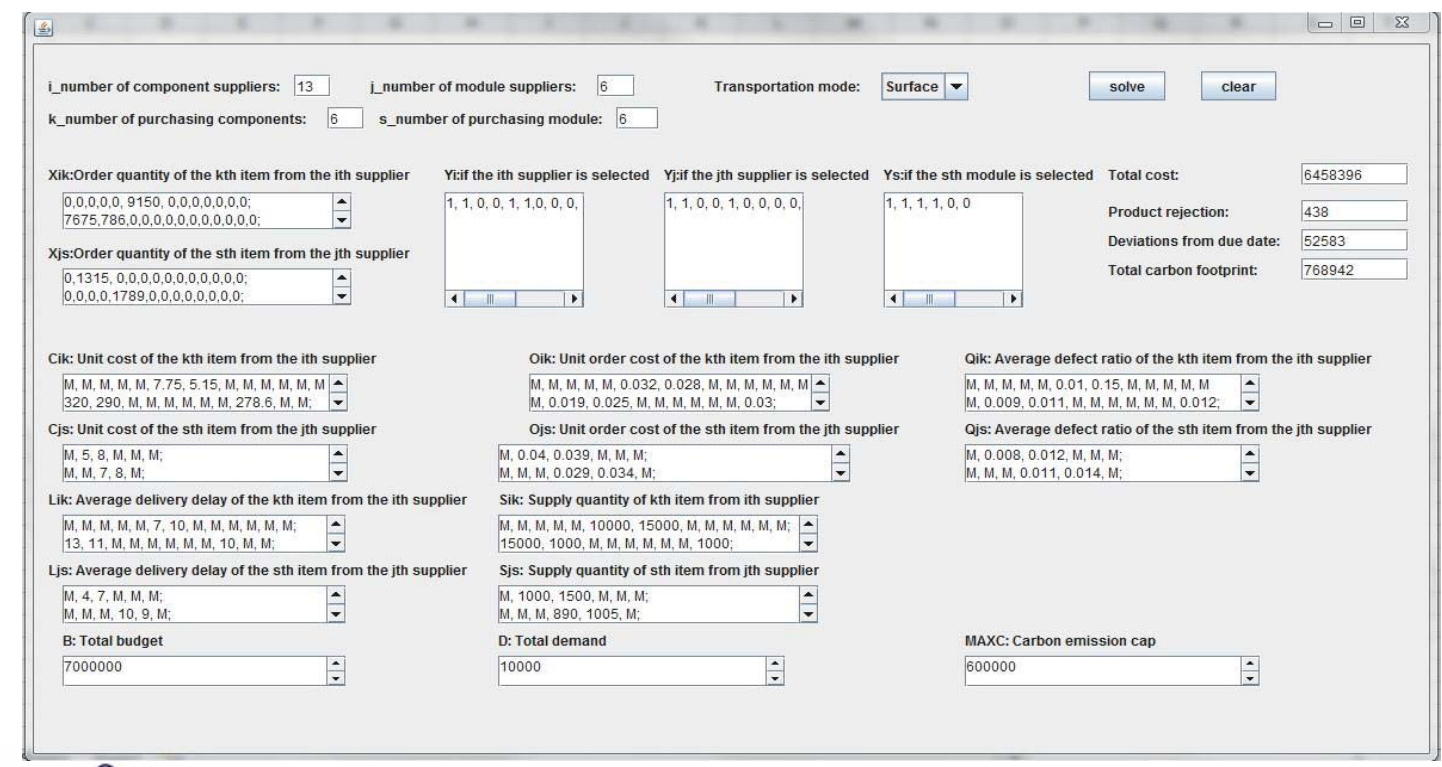

\section{PENNSTATE}

Lei, T. and Okudan Kremer, G.E. "GIS-Based Hierarchical Multi-Objective Supply Chain Network Design: A Proposed Tool \& Case Study", Industrial and Systems Engineering Conference (ISERC 2013), May 18-22, San Juan, Puerto Rico. 
The Pennsylvania State University

University Park, PA 16802

Tel: 8148631530

Email: gkremer@psu.edu

\section{PENNSTATE}

$\frac{1250}{1853}$ 


\title{
Measurement Science for Sustainable Construction and Manufacturing
}

\author{
Breakout 4 \\ Economic, Environmental, \\ and Social Aspects
}

\section{Cliff I. Davidson}

Thomas \& Colleen Wilmot Professor of Engineering

Director, Center for Sustainable Engineering

Syracuse University

ASCE, Reston, Virginia

J une 12, 2014

\section{Outline}

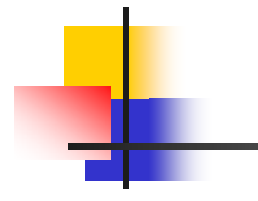

Economic, Environmental, and Social I ssues summarized from papers by participants of

Breakout 4:

- I ndividual buildings

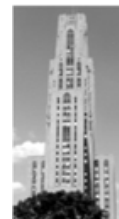

- Infrastructure projects

- Entire urban areas

- Overarching issue: Changing Human Behavior 


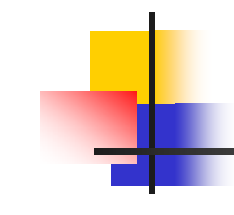

\section{Individual Buildings}

Design $\rightarrow$ Construction $\rightarrow$ Operation \& Use $\rightarrow$ Demolition

- Ability to incorporate sustainability decreases as we move forward

- Previously: cost dominated design considerations. New software includes sustainability, but not used much (Athena Sust. Materials I nst.)

- Could apply current knowledge of sustainable product manufacturing to buildings (RFI D tags to track logistics)

\section{Individual Buildings}

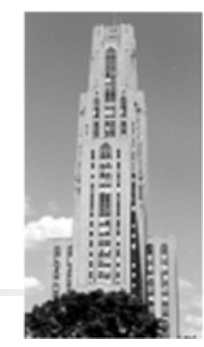

- Data collection during construction

-- Energy, materials, water, social issues

-- Embedded energy and water in materials

- Data collection during use phase

-- Sensors for microclimate, HVAC, lighting, electricity, appliance use, flow of people

-- Personal monitors - air quality, noise, vibrations

-- Monitors for interaction with natural environment - wind, temp, humidity, rain runoff, vegetation growth 

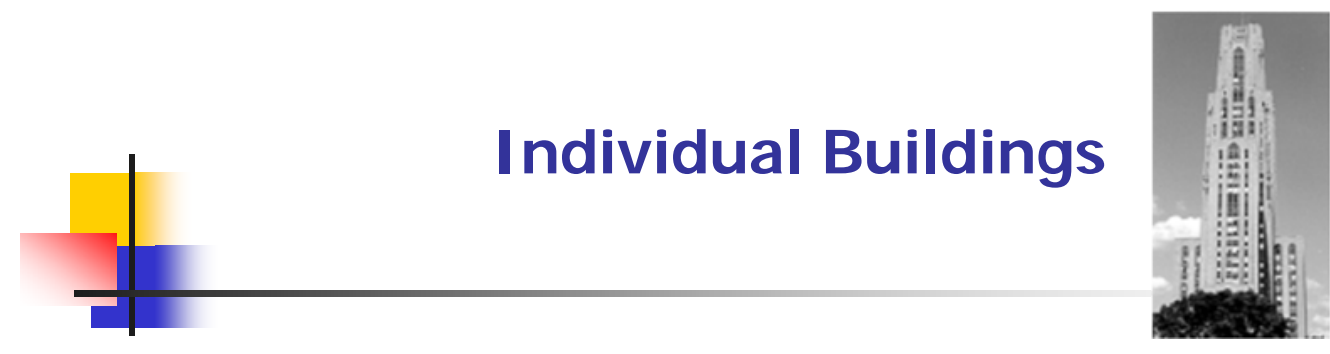

- Data collection during demolition

-- Degradation of building envelope over time

-- Differences in degradation for different parts of the building

-- Re-use, recycle building components

I nfrastructure Projects

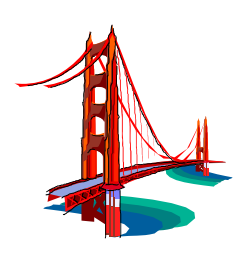

Design $\rightarrow$ Construction $\rightarrow$ Operation \& Use $\rightarrow$ Demolition

- As with individual buildings, ability to incorporate sustainability decreases as we move forward

- Indicators of safety are well-established - need the equivalent for sustainability

- Need for quantifiable social sustainability metrics 


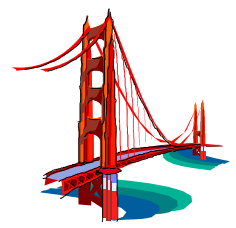

Design $\rightarrow$ Construction $\rightarrow$ Operation \& Use $\rightarrow$ Demolition

- Need to make infrastructure more resilient

-- Performance of infrastructure during disasters such as severe storms, terrorist attacks, evacuation

-- Avoiding increase in vulnerability due to human development close by - buildings adjacent to a major roadway

-- Avoiding increase in vulnerability by not accounting for natural processes - beach erosion

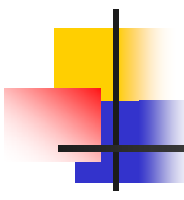

\section{Urban areas}

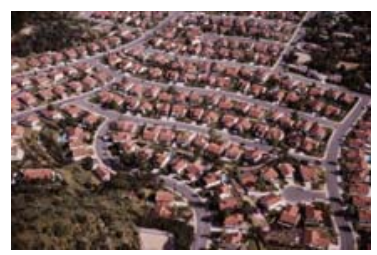

- Establish ability to obtain large data sets for metabolism of a city

-- Flows of energy, materials, water, people, information

- Can we use such data to improve Quality of Life and resilience?

-- Energy balance, material balance, water balance

-- How people are spending their time in cities: Performing services, engaged in recreation, engaged with family, etc.

-- Health monitoring of people in cities 


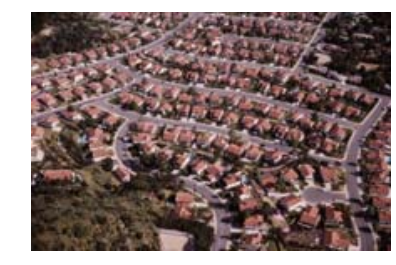

\section{Reduce social inequity}

- Low income and minority residents in cities are generally under-represented in decision making

-- distrust of government

-- language problems

-- previously marginalized

- Necessary for engineers to make special effort to bring these people into discussion

\section{Changing Human Behavior}

Habits are difficult to break

- Change requires several steps: first step is the desire to change

- Do most people understand the impact of their dayto-day activities?

- To explore the answer for one example situation, survey was conducted

- Questions involved estimating the energy consumption for normal household activities. 


\section{Changing Human Behavior}

\section{Question 1:}

“A 100-watt incandescent light bulb uses 100 units of energy in one hour. How many units of energy do you think each of the following devices typically uses in one hour?"

- A compact fluorescent light bulb that is as bright as a 100-watt incandescent light bulb

- An electric clothes dryer

- A portable heater

- A room air conditioner

- A central air conditioner

- A dishwasher

\section{Changing Human Behavior}

\section{Question 2:}

"Turning off a 100-watt incandescent light bulb for one hour saves $\mathbf{1 0 0}$ units of energy. How many units of energy do you think each of the following changes will save?"

- Replacing one 100-watt incandescent bulb with equally bright compact fluorescent bulb that is used for one hour

- Replacing one 100-watt kitchen bulb with a 75-watt bulb that is used for one hour

- Drying clothes on a clothes line for one load

- Turning up the thermostat on your air conditioner by $5^{\circ} \mathrm{F}$ in summer 
Human perceptions of home energy use

Attari, Dekay, Davidson, Bruine de Bruin (PNAS, 2010)

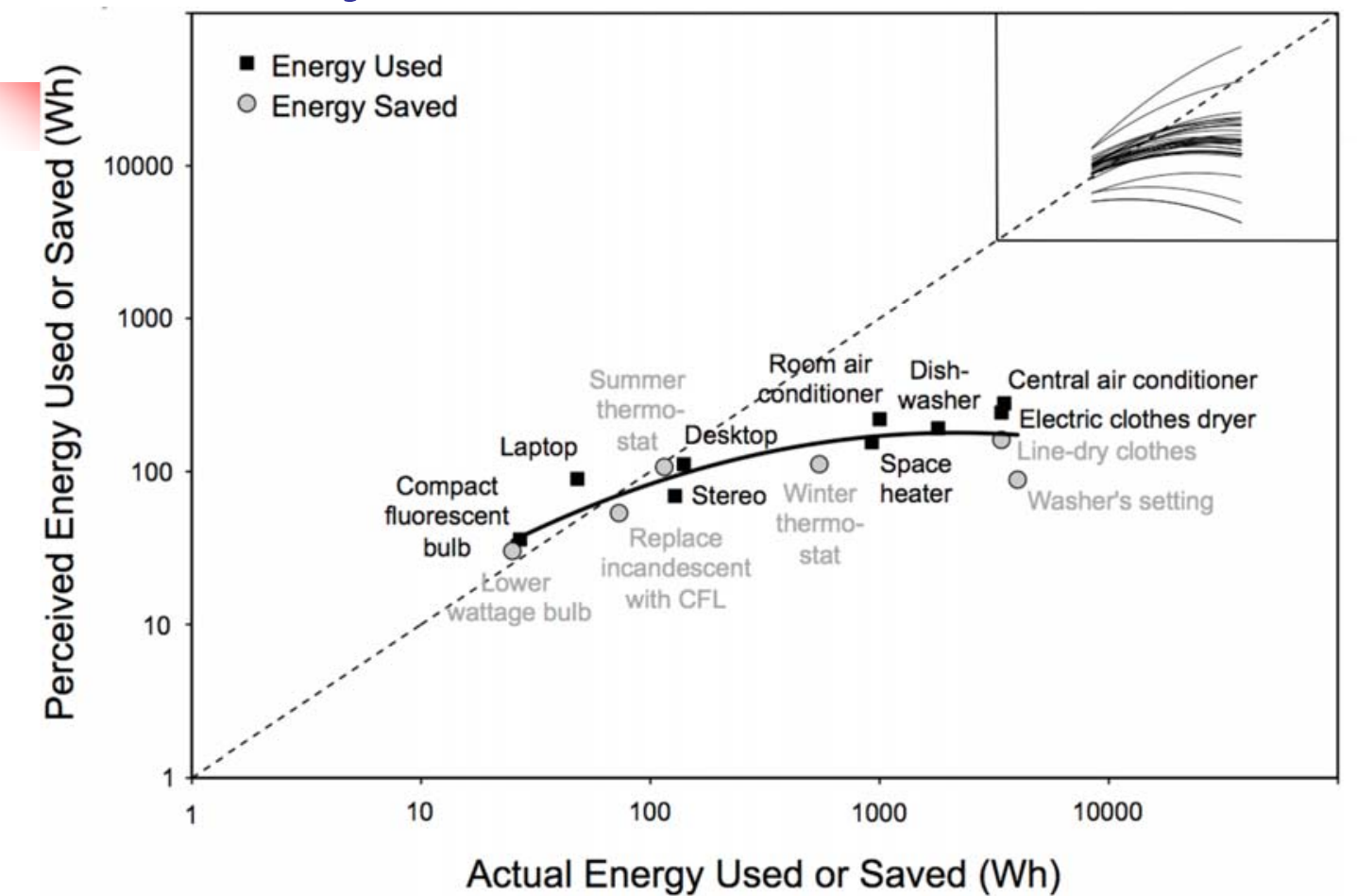

\section{Human perceptions of home energy use}

- Perception curve is relatively flat

- Slight overestimate for low energy appliances

- Large underestimate for high energy appliances where perceptions are most important

- Overall perceptions show an underestimate of a factor of $\mathbf{2 . 8}$ 


\section{Conclusions}

-We have the capability to collect large quantities of technical data, but we need to determine which technical data are most important for understanding sustainability in manufacturing and infrastructure development.

- It is much more difficult to collect data to quantify social sustainability and assess our progress.

- Achieving change in human behavior in the correct direction will require educational efforts for people understand the impacts of their activities and how to reduce them. 


\section{The Quantified Community: Measuring, Modeling, and Understanding the Urban Environment}

NIST-ASCE-ASME

June 12, 2014

Dr. Constantine E. Kontokosta, PE, AICP, LEED AP, FRICS

Deputy Director, NYU-CUSP

Director, NYU Center for the Sustainable Built Environment Associate Research Professor, NYU-Polytechnic School of Engineering Head, Quantified Community Research Initiative

\section{The CUSP vision includes New York City as its laboratory}

The Center for Urban Science and Progress (CUSP) is a unique public-private research center that uses New York City as its laboratory and classroom to help cities around the world become more productive, livable, equitable, and resilient. CUSP observes, analyzes, and models cities to optimize outcomes, prototype new solutions, formalize new tools and processes, and develop new expertise/experts. These activities will make CUSP the world's leading authority in the emerging field of "Urban Informatics."

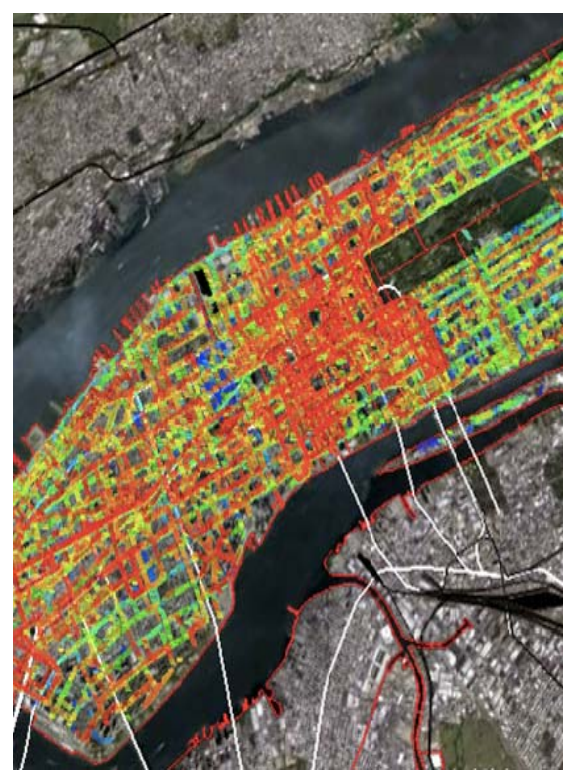




\section{The CUSP Partnership}

University Partners

- NYU/ NYU-Poly

- The City University of New York

- Carnegie Mellon University

- University of Toronto

- University of Warwick

- IIT-Bombay

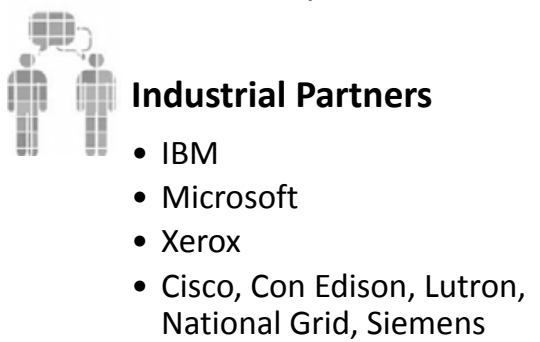

- AECOM, Arup, IDEO

\section{National Laboratories}

- Brookhaven

- Lawrence Livermore

- Los Alamos

- Sandia

\section{City \& State Agency Partners}

- The City of New York

- Buildings

- City Planning

- Fire Department

- Citywide Administrative Services

- Design and Construction

- Economic Development

- Environmental Protection

- Finance

- Metropolitan Transportation Authority

- Port Authority of NY \& NJ

Parks and Recreation

- Police Department

A diverse set of other organizations have expressed interest in joining the partnership.

Mental Hygiene

\section{Urban Data Sources}

- Organic data flows

- Administrative records (census, permits, ...)

- Transactions (sales, communications, ...)

- Operational (traffic, transit, utilities, health system, ...)

- Twitter feeds, blog posts, Facebook, ...

- Sensors

- Personal (location, activity, physiological)

- Fixed in situ sensors

- Crowd sourcing (mobile phones, ...)

- Choke points (people, vehicles)

- Opportunities for "novel" sensor technologies

- Visible, infrared and spectral imagery

- RADAR, LIDAR

- Gravity and magnetic

- Seismic, acoustic

- Ionizing radiation, biological, chemical

$-\ldots$ 


\section{What can cities do with the data?}

- Optimize operations

- traffic flow, utility loads, services delivery, ...

- Monitor infrastructure conditions

- bridges, potholes, leaks, ...

- Infrastructure planning

- zoning, public transit, utilities

- Model the dynamics of land use and neighborhood change

- Public health

- Nutrition, epidemiology, environmental impacts

- Identify and respond to abnormal conditions and shocks

- Hazard detection, emergency management

- Data-driven formulation of performance-based policies

- Energy use, road pricing and congestion charging, etc.

- Improve regulatory compliance ("nudges", efficient enforcement)

- Inform, empower, and engage residents

\section{The Quantified Community (QC)}

\section{Understanding the Patterns of Urban Life}

The CUSP "Quantified Community" (QC) will be a fully instrumented urban neighborhood that uses an integrated, expandable sensor network and citizen engagement to support the measurement, integration, and analysis of neighborhood conditions. Through an informatics overlay, data on physical and environmental conditions and use patterns will be processed in real-time to maximize operational efficiencies, improve quality of life for residents and visitors, and drive evidence-based planning. 


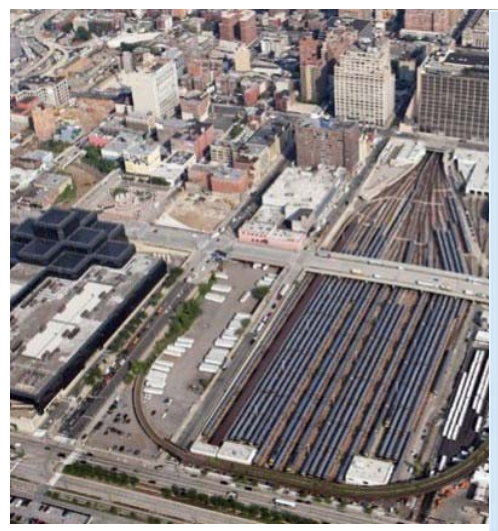

Images: Related Companies

Ehe Nieu Hork Eimes
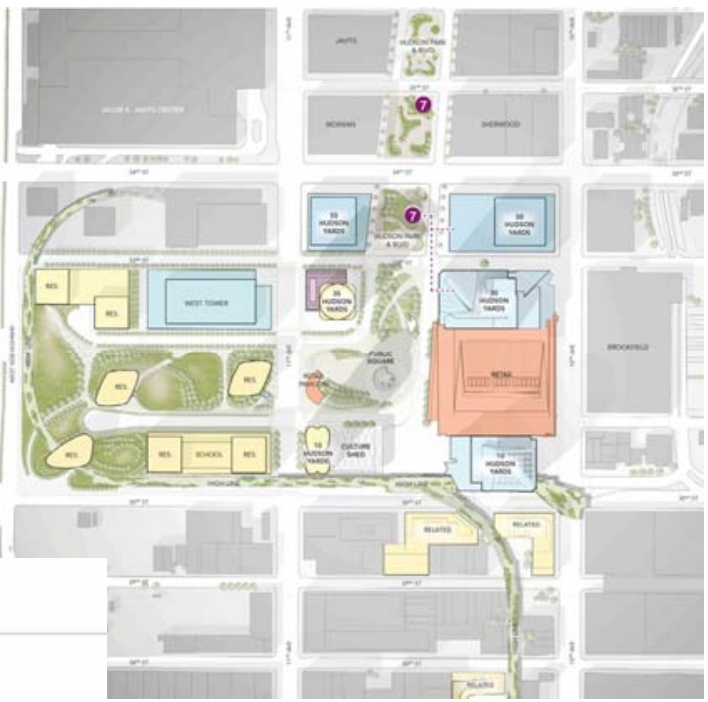

\section{Huge New York Development Project Becomes a}

\section{Data Science Lab}

By STEVE LOHR

April 14, 2014, 7:00 am

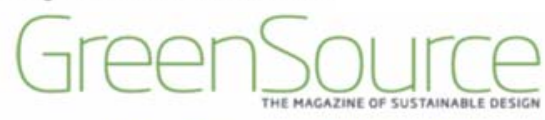

home news projects best green houses continuing education features Video NEWS

NYU's CUSP to Turn Hudson Yards into New York City's First Smart Development

\section{By David Sokol}

KONTOKOSTA 2014 - NOT FOR

DISTRIBUTION
Buildings

Resource consumption;

indoor air quality;

productivity, health

measures

Safety and Security

Network Security,

Situational Awareness,

Emergency Management

Integration, Event

Forecasting

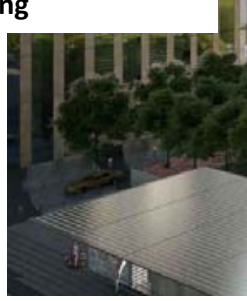

Environment

carbon emissions; air pollution and particulates; noise; climate

Infrastructure

Solid waste, storm-water management, power generation/distribution 


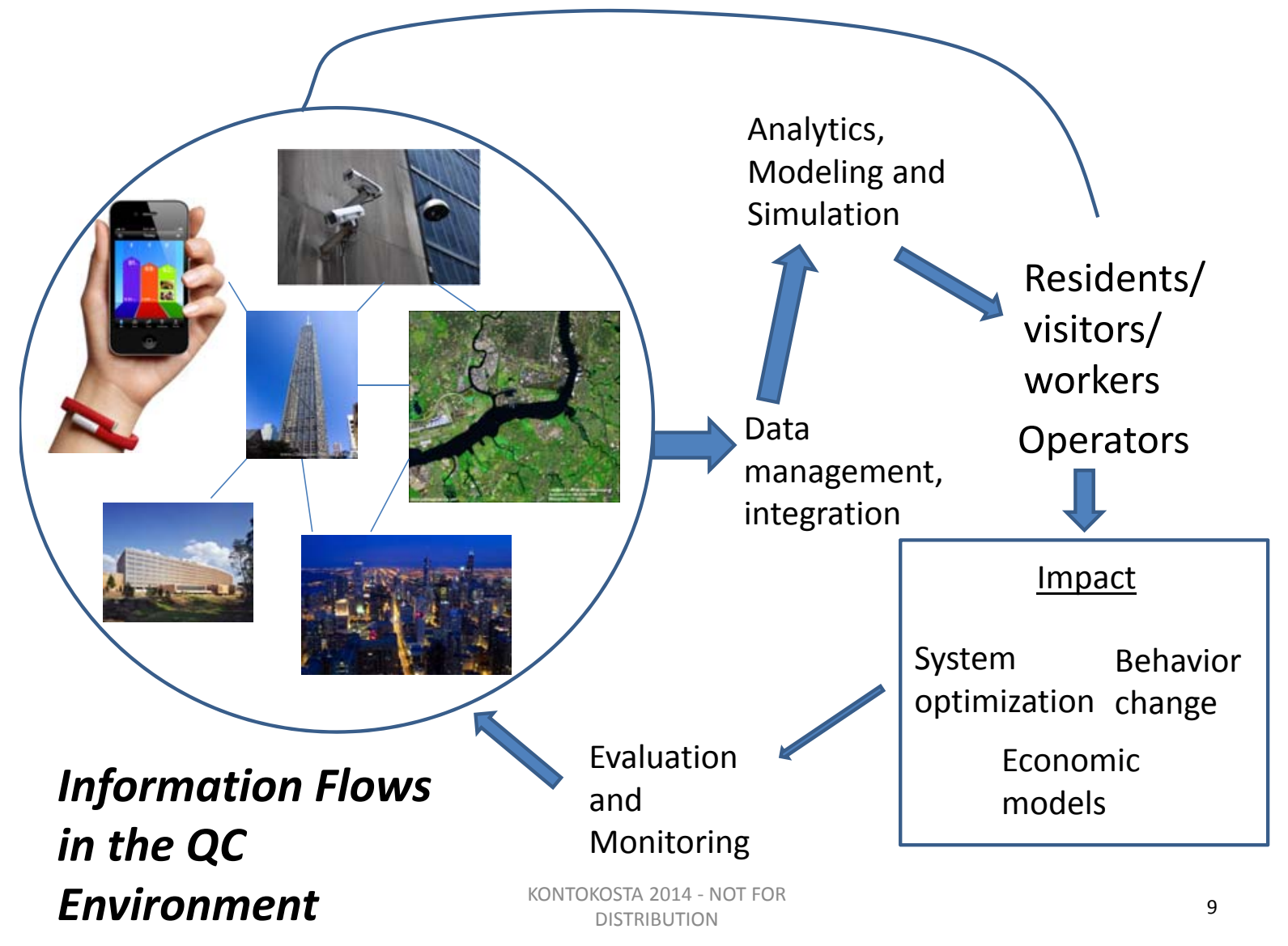

\section{Next Steps}

- Pilot project underway

- Initial data by Fall 2014; simulation and modeling by early Spring 2015

- Planning of "informatics overlay" at Hudson Yards underway

- Focus on district infrastructure and first building to be completed

- Data-driven construction safety, mobility, and logistics optimization project In development

- Hiring postdocs/research scientists 


\section{들

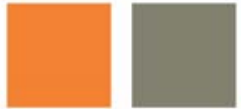

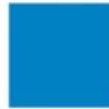 \\ CENTER FOR URBAN \\ SCIENCE+PROGRESS \\ Thank you ckontokosta@nyu.edu}

cusp.nyu.edu

f NYUCUSP

y @NYU-CUSP 


\title{
Population and Carrying Capacity: Metrics for Sustainability
}

\author{
Eugenia Kalnay ${ }^{1}$, Jorge Rivas², \\ and Safa Motesharrei ${ }^{1,3}$ \\ ${ }^{1}$ University of Maryland; ' 2 University of Minnesota; \\ ${ }^{3}$ National Socio-Environmental Synthesis Center (SEYSNC)
}

Presentation at the NIST-UMD Workshop on Measurement Science for Sustainable Construction and Manufacturing June 12, 2014

Growth of Population and GDP/Capita: Consumption of Resources is their Product!

\begin{tabular}{|l|l|}
\hline 1 AD & $0.3 \mathrm{~b}$ \\
\hline 1650 & $0.5 \mathrm{~b}$ \\
\hline 1804 & $1.0 \mathrm{~b}$ \\
\hline 1927 & $2.0 \mathrm{~b}$ \\
\hline 1960 & $3.0 \mathrm{~b}$ \\
\hline 1975 & $4.0 \mathrm{~b}$ \\
\hline 1987 & $5.0 \mathrm{~b}$ \\
\hline 1998 & $6.0 \mathrm{~b}$ \\
\hline 2011 & $7.0 \mathrm{~b}$ \\
\hline
\end{tabular}

World Population and GDP per Capita, 0 to 2000 A.D.

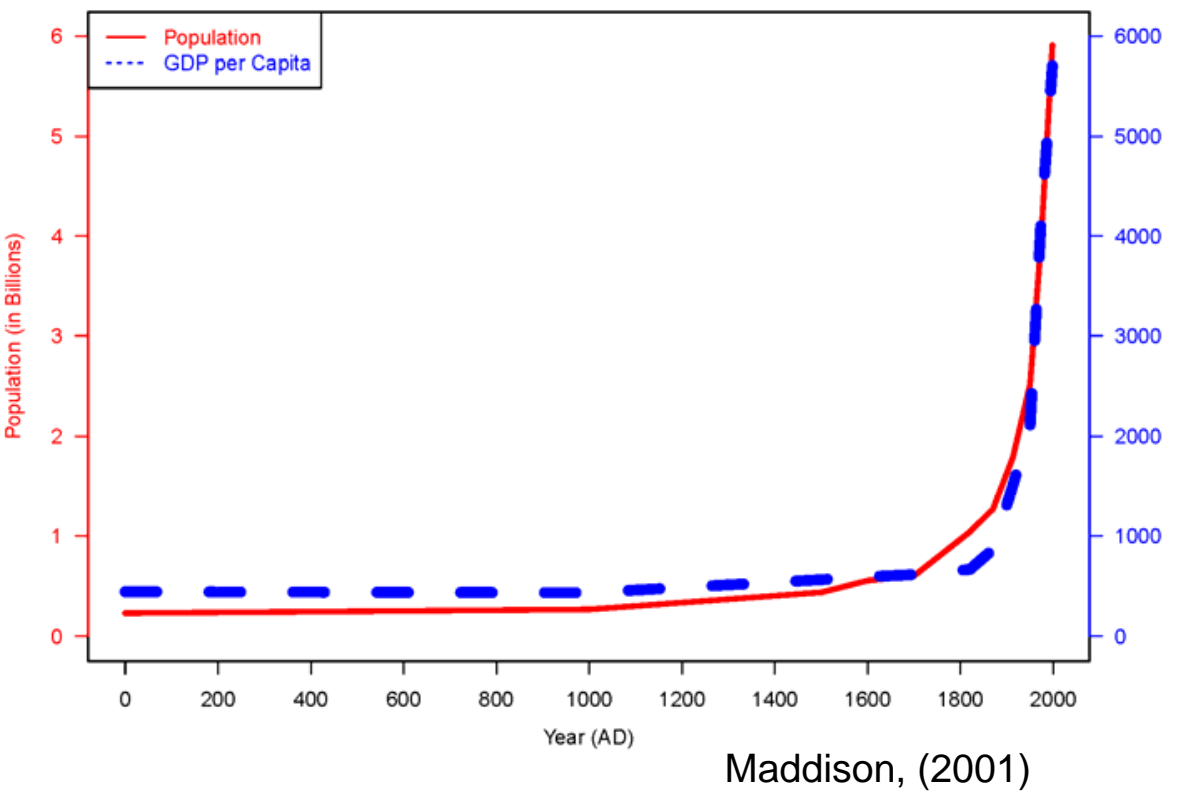




\section{Why was the population able to grow so fast since the 1950's?}

Two reasons:

1) Sanitation and Antibiotics (Public Health $\rightarrow$ living longer)

2) Use of fossil fuels in agriculture starting in the 1950' s:

- fertilizers, pesticides, irrigation, mechanization (Green Revolution).

1950 to 1984: production of grains increased by $250 \%$ and the population doubled

Without fossil fuels population would be much smaller!

- Growth in grain production is now flattening out

- Industrial farming is destroying forests, soil

- Urban and suburban sprawl is overrunning best farmland

This is not sustainable: "We are drawing down the stock of natural capital as if it was infinite" (Herman Daly)

\section{Standard Neoclassical Economic Model}

As Herman Daly, Robert Costanza, and other scholars in the field of Ecological Economics describe,

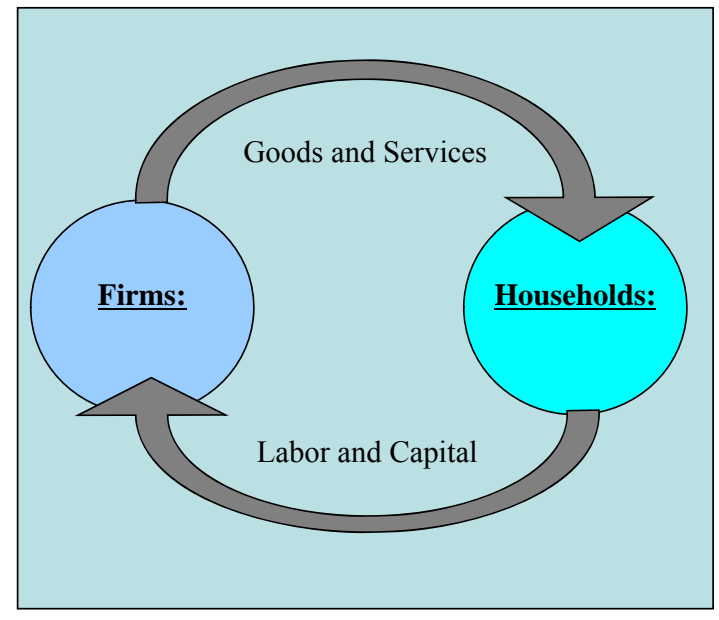

The standard Neoclassical Economic Model does not account for:

- Inputs (resources)

- Outputs (pollution)

- Stocks of Natural Capital

- Dissipation of Energy (i.e., a Perpetual Motion Machine)

- Depletion, Destruction or Transformation of Matter

Therefore, no effects on the Earth System, and No Limits to Growth. 


\section{Realistic Ecological Economic Model (Herman Daly)}

- Incorporates INPUTS, including DEPLETION of SOURCES

- Incorporates OUTPUTS, including POLLUTION of SINKS

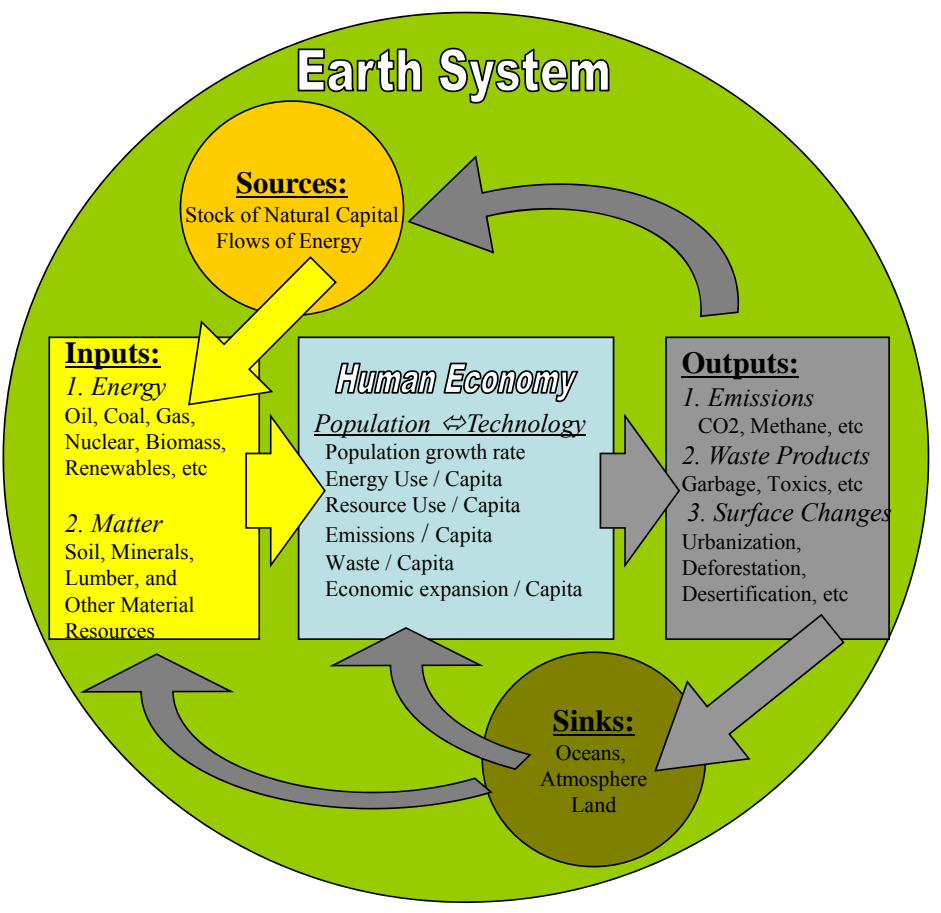

\section{“Empty World" Model}

- Throughout most of human history, the Human Economy was so small relative to the Earth System, that it had little impact on the Sources and Sinks.

- In this scenario, the standard isolated economic model might have made sense.

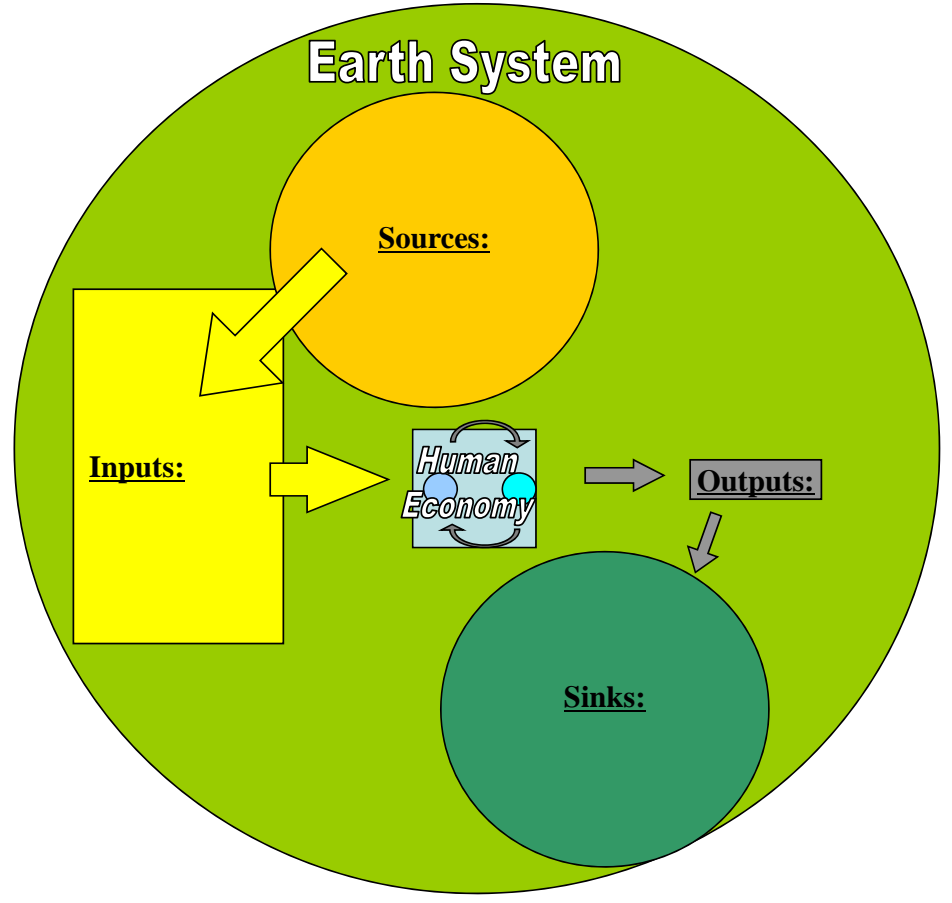




\section{"Full World" Ecological Economic Model}

- Today, the Human Economy has grown so large, it has very large Effects on the Earth System, Depleting the Sources and Filling the Sinks. It is clear that growth cannot continue forever.

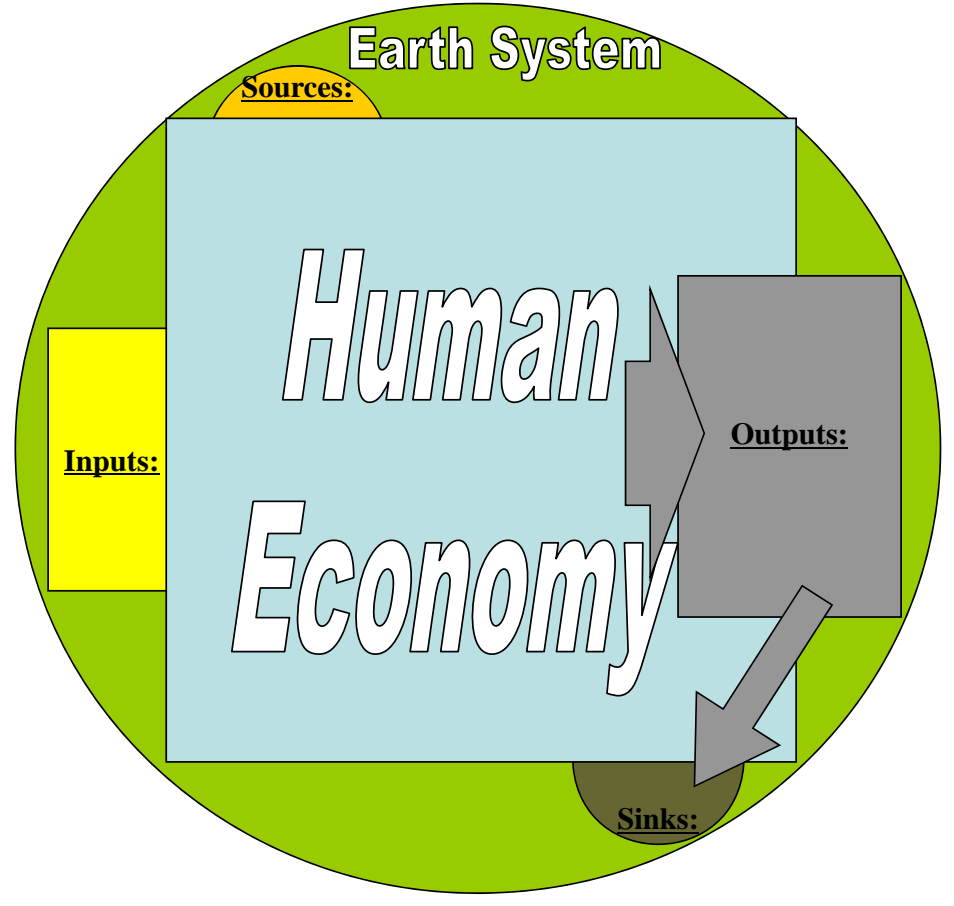

\section{Prototype Earth System - Human System Feedbacks}

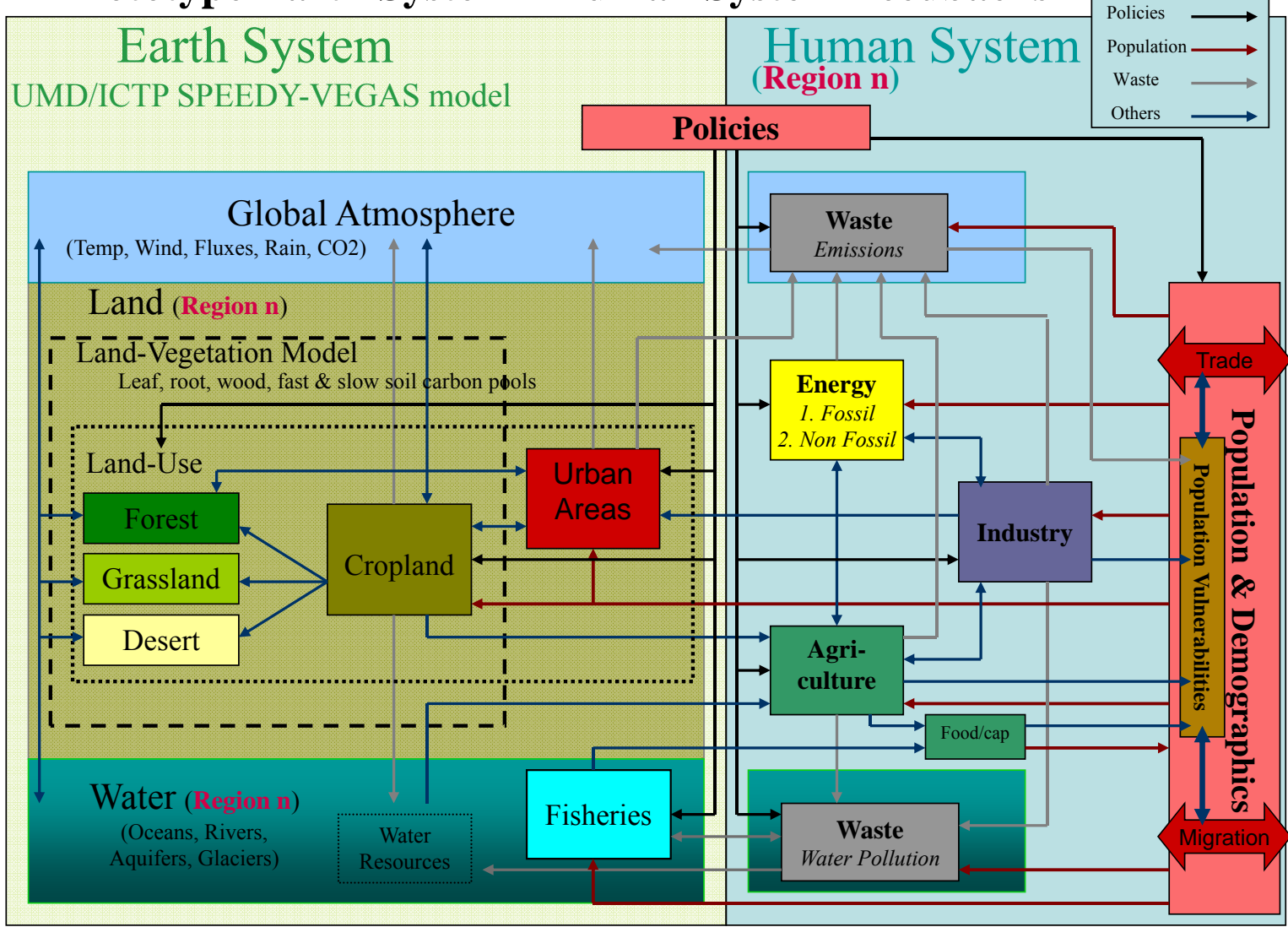




\section{Could an advanced society like ours collapse?}

- Collapses of many advanced societies have taken place in the last $\mathbf{5 0 0 0}$ years!

- A recent study of the many collapses that took place in Europe has excluded climate forcing, war, and disease as the root cause of such collapses, so that it concluded:

- $\quad$ The collapses were due to overrunning the Carrying Capacity

- We developed a "Human and Nature Dynamical model" (HANDY) to start understanding the nonlinear feedbacks between the Earth and the Human System.

HANDY: Human and Nature Dynamical model with Rich and Poor: for Thought Experiments

Commoner Population

Elite Population

Nature

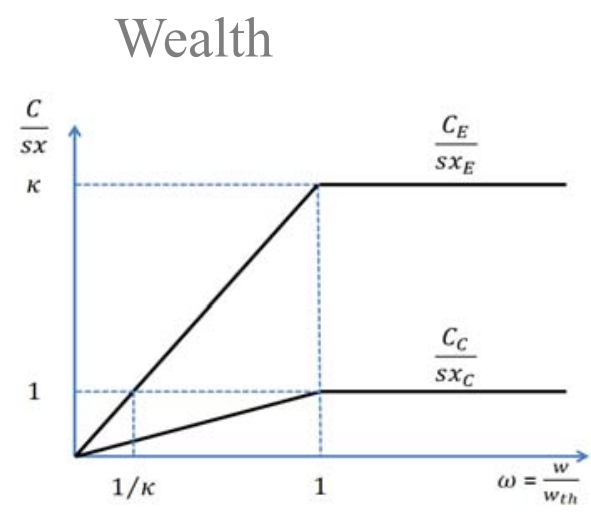

$$
\dot{x}_{C}=\beta_{C} x_{C}-\alpha_{C} x_{C}
$$

$$
\dot{x}_{E}=\beta_{E} x_{E}-\alpha_{E} x_{E}
$$

$$
\dot{y}=\gamma y(\lambda-y)-\delta x_{C} y
$$$$
\dot{w}=\delta x_{C} y-C_{C}-C_{E}
$$ 


\section{State Variables (Stocks) and Flows in HANDY1}
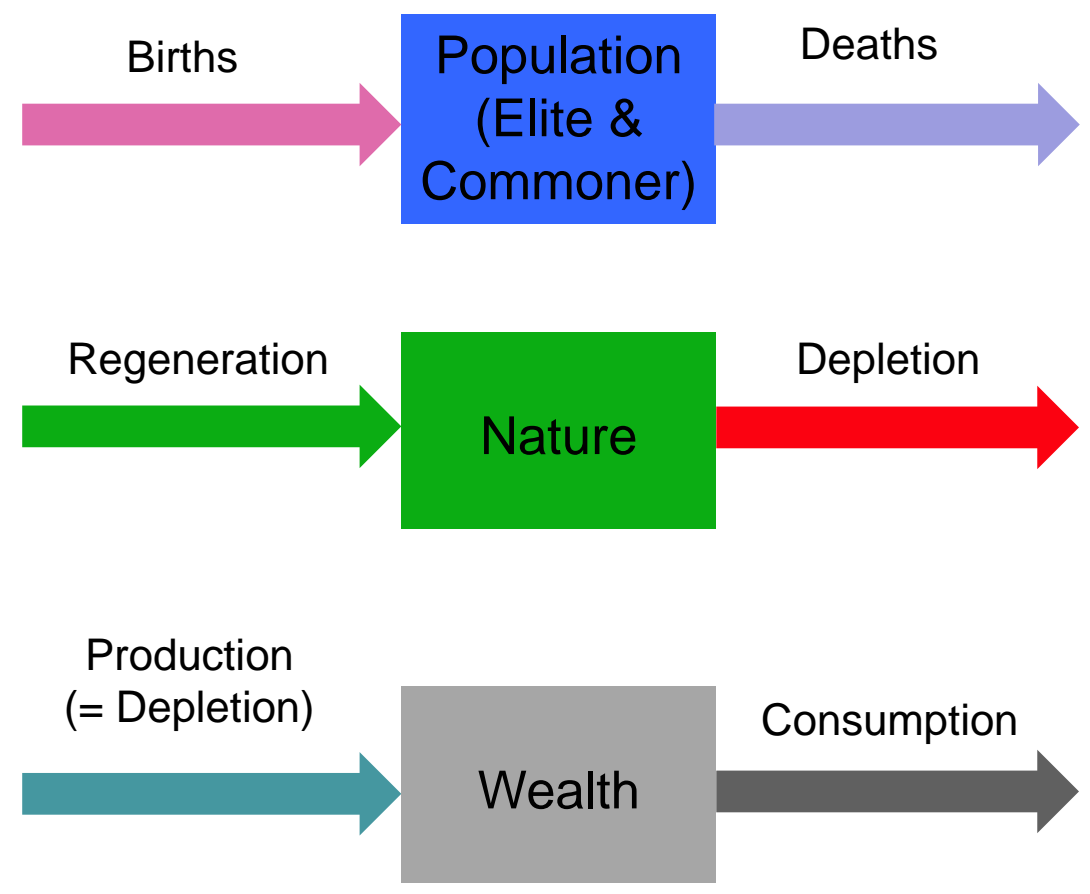

\section{Carrying Capacity}

- Carrying Capacity: The population level that the resources of a particular environment can sustain over the long term

Carrying Capacity in HANDY

$$
\chi=\frac{\gamma}{\delta}\left(\lambda-\eta \frac{s}{\delta}\right)
$$

Maximum Carrying Capacity $\quad \chi_{M}=\frac{\gamma}{\eta s}\left(\frac{\lambda}{2}\right)^{2}$ 


\section{Experiments for an Egalitarian Society}
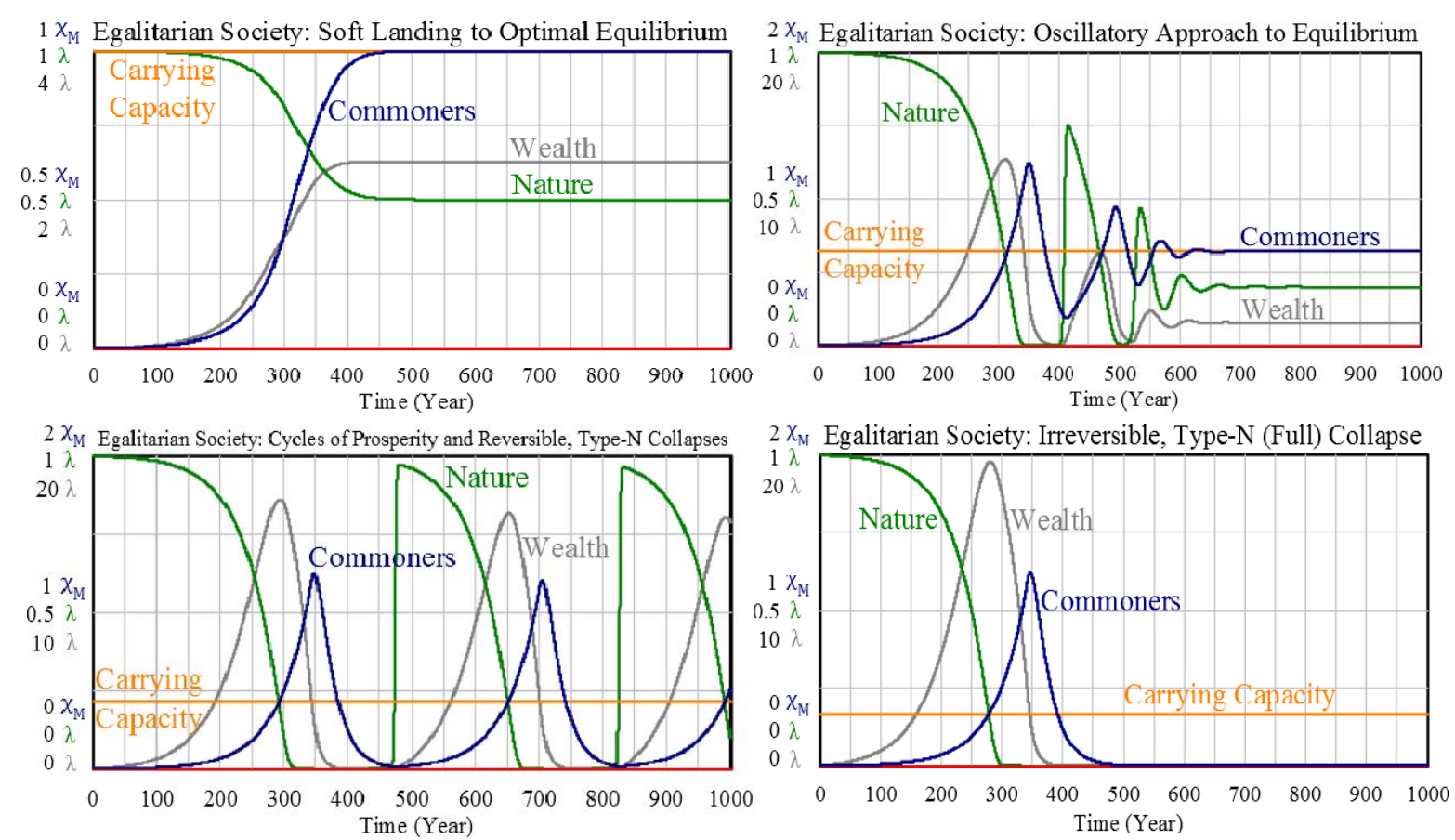

High depletion rate can lead to collapse.

\section{What if we introduce Inequality?}
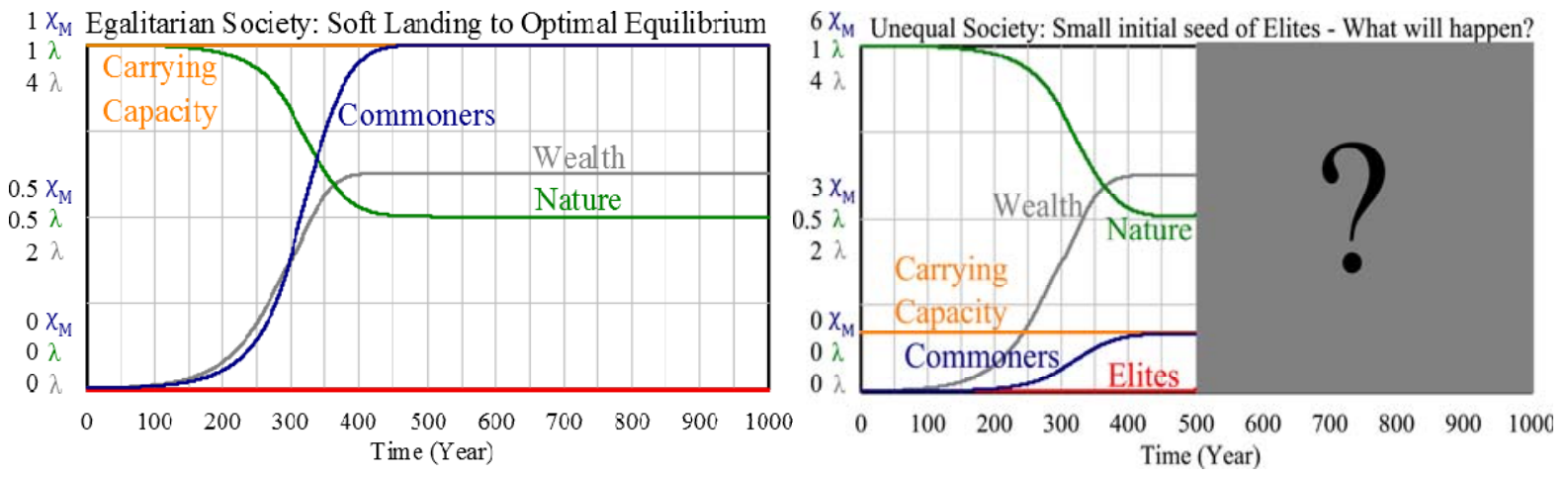

Up until $\mathrm{t}=500$,

both scenarios show the exact same dynamics. 


\section{An otherwise sustainable society could collapse if there is high inequality $(\kappa=100)$.}

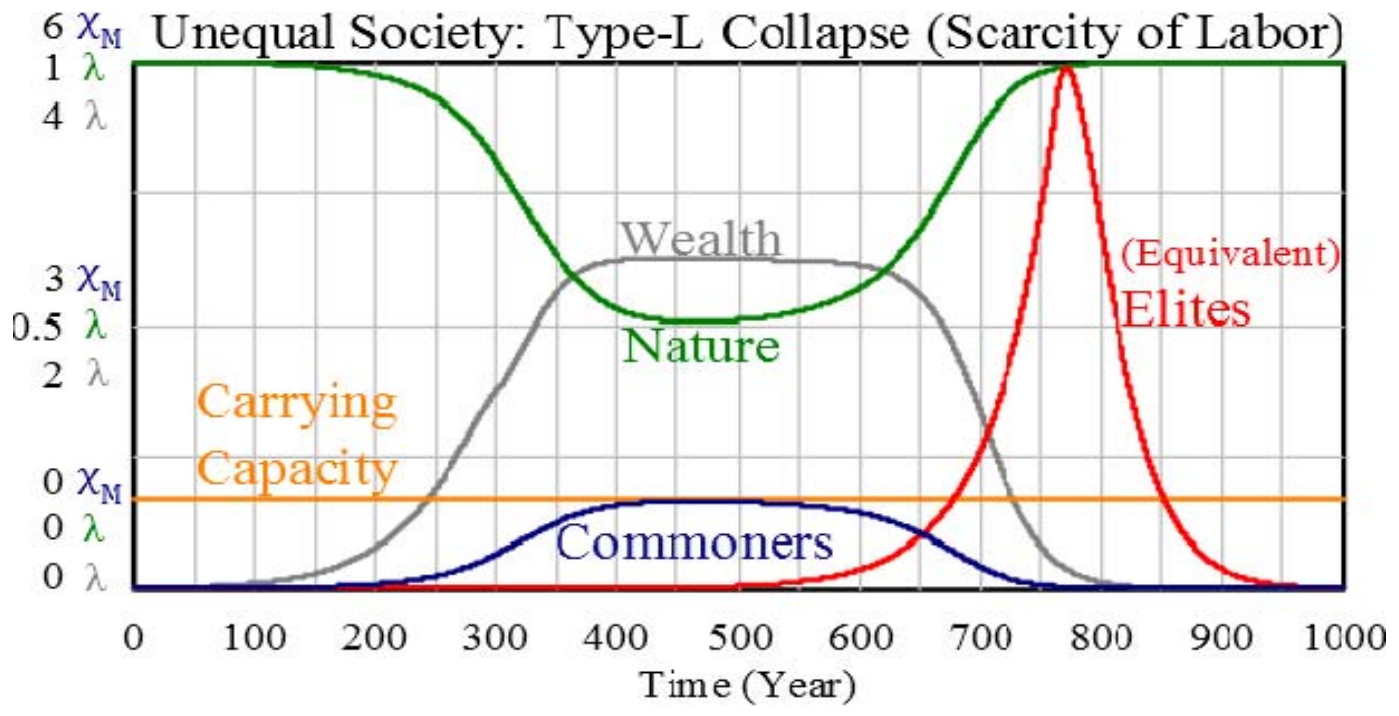

What happens if we have both high inequality and high depletion rate?

Typical Collapse: High Depletion Rates and High Inequality at the same time

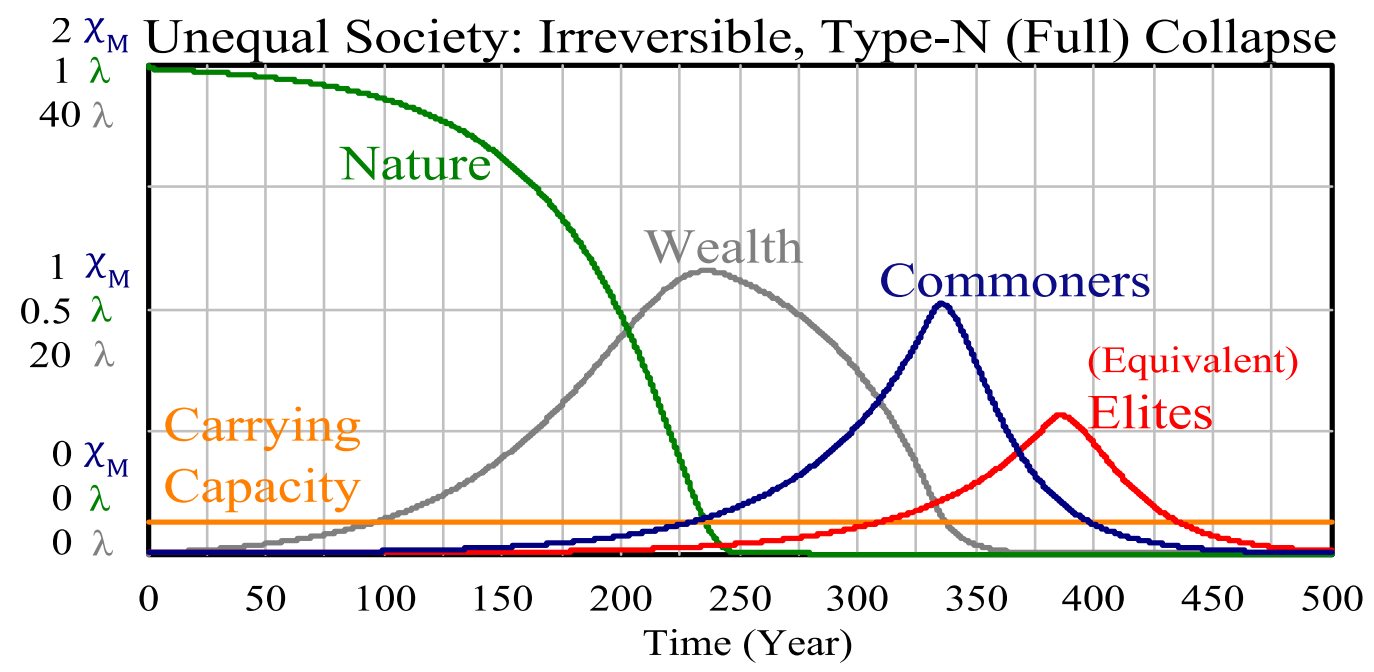

Is there any hope for an unequal society to survive? 
If we reduce the depletion per capita and inequality, and slow down the population growth, it is possible to reach a steady state and survive well.
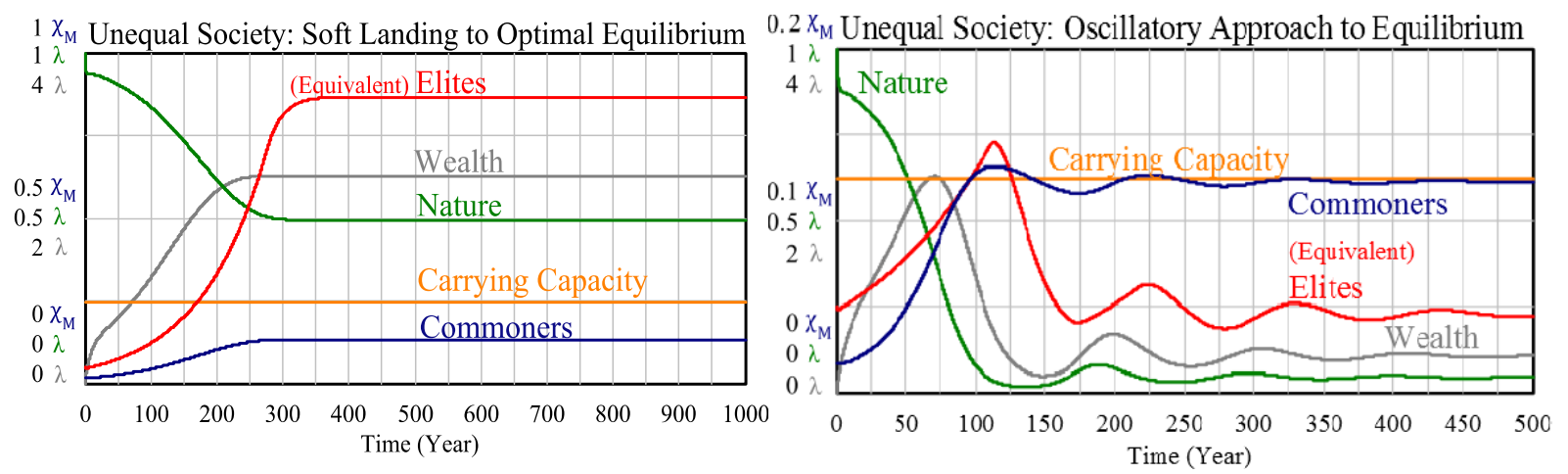

Reaching this equilibrium requires changes in policies:

- Reduce depletion per capita

- Reduce inequality $(\kappa=10)$

- Reduce population growth

\section{Could a collapse be prevented if we have large stocks of Nonrenewable Energy?}

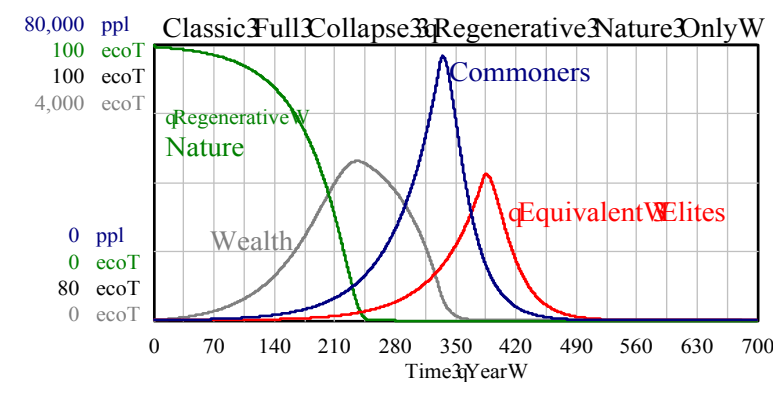

This is the classic HANDY1 full collapse scenario, with only regenerating Nature

\author{
What happens \\ when we add \\ fossil fuels?
}

We then add to the regenerating Nature a nonrenewable Nature 


\section{Impact of adding fossil fuels (nonrenewable energy resources)}

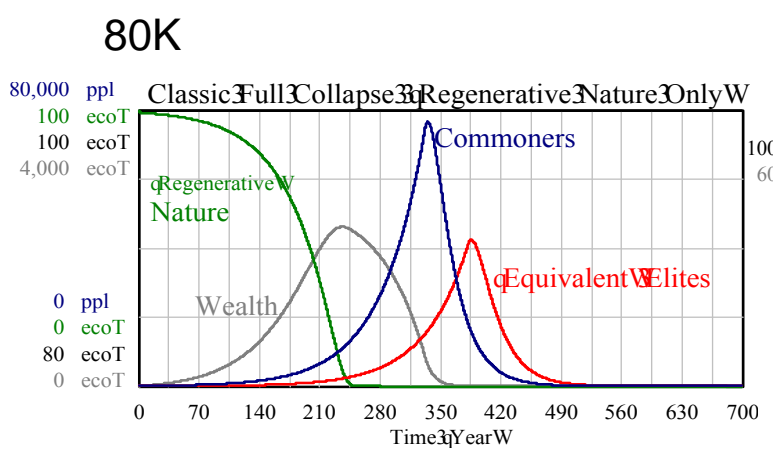

Regenerating Nature Only
4Million

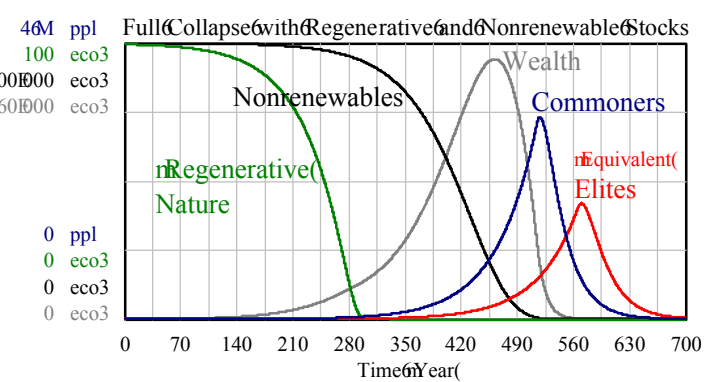

Both Regenerating and

Nonrenewable

Resources

The collapse is postponed by $\sim 250$ years and the peak population increases by a factor of $\sim 25$ !

\section{State Variables (Stocks) and Flows in HANDY1}
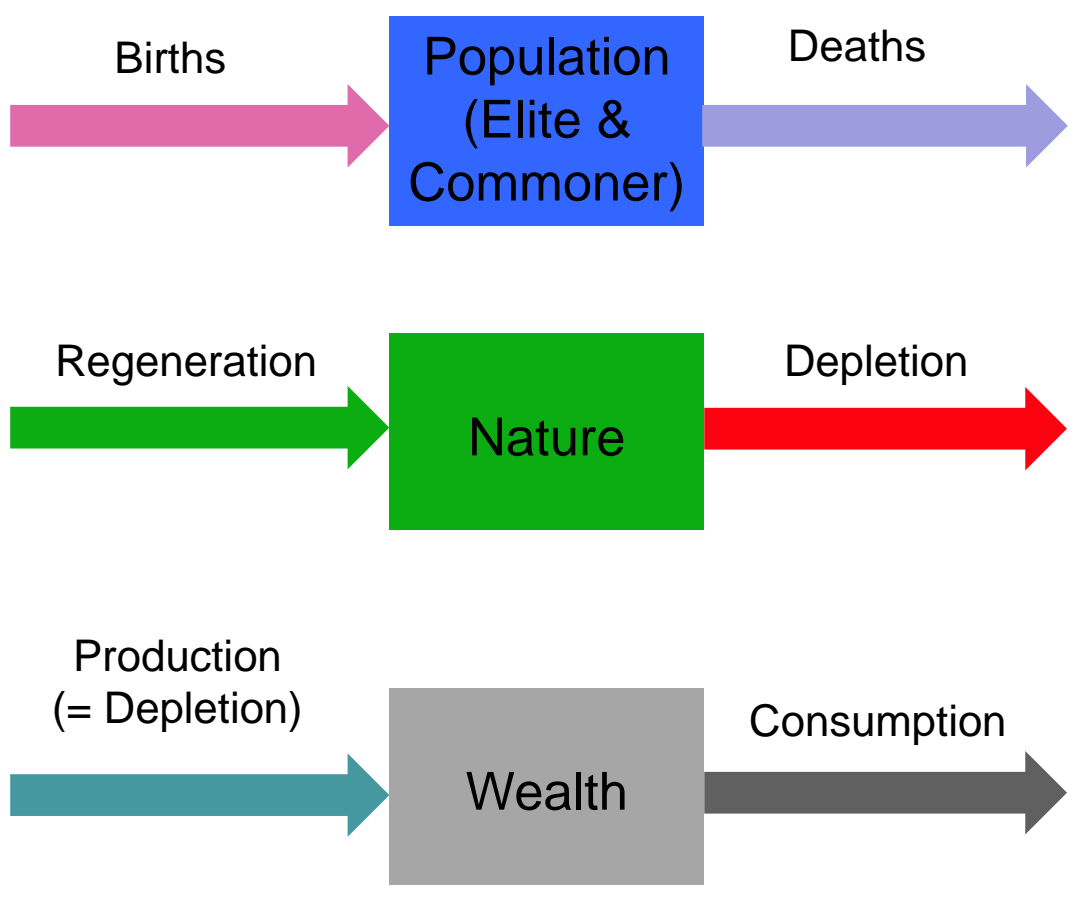


\section{Metrics for Sustainability}

The conditions for sustainability of resources depend on their type:

1. Regenerating resources (e.g., forests, fisheries, herds):

Total Depletion Rate $\leq$ Regeneration Rate

2. Renewable resources (e.g., Flows of solar and wind):

Sustainable by definition, since the total extraction rate is always smaller than the flow rate.

Also, consumption of Accumulated Wealth must be sustainable to ensure societal sustainability, therefore:

\section{Total Consumption $\leq$ Total Production}

But what about Nonrenewables? Could their extraction be sustainable?

\section{A Metric for Sustainability of Nonrenewables}

We define a new metric Time to Depletion, $T_{N}(t)$, for

Nonrenewable resources (e.g., fossil fuels, aquifers, minerals):

$$
T_{N}(t)=\text { Time to Depletion }=\frac{\text { Total Nonrenewalbe Stock }}{\text { Depletion rate of Nonrenewables }}=\frac{y_{N}(t)}{D_{N}(t)}
$$

For extraction of nonrenewables to be sustainable, Time to Depletion has to increase with time:

$$
T_{N}(t+d t) \geq T_{N}(t)
$$

It can be shown that this is equivalent to:

$$
\frac{d^{2}}{d t^{2}}\left(\log y_{N}(t)\right) \geq 0
$$

This also means that the net depletion rate of nonrenewables must decrease with time if their extraction is to be sustainable. 


\section{CONCLUSIONS}

- The Human System has dominated the Earth System.

- In order to assess Societal Sustainability and issues like Climate Change, we need to couple the Earth System with Population, include bidirectional (two-way) feedbacks, and take into account the impact of policies on longer time scales (>50 years, $>2$ generations).

- Carrying Capacity is a widely applicable measure for societal sustainability.

- Additional sustainability metrics are also derived for all three types of resources.

- For Regenerating resources, net depletion must be within net regrowth rate of the resource.

- Extraction of Renewables is inherently sustainable.

- For Nonrenewables, Time to Depletion must increase with time.

- Therefore, net depletion of Nonrenewables has to decrease.

- This means if population is relatively steady, depletion per capita of nonrenewables must decrease with time. 
National Institute of Standards and Technology

Measurement Science for Sustainable Construction and Manufacturing

\section{Challenges and Metrics in Public Buildings and Infrastructure}

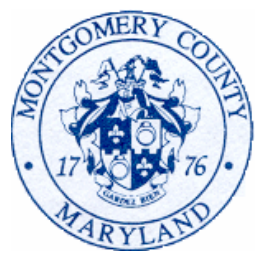

David Dise, Director

Department of General Services

david.dise@montgomerycountymd.gov

\section{DEPARTMENT OF GENERAL SERVICES}

- Completed over 50 capital projects since 2007

- $\$ 1.2$ billion in planning, design and construction costs

- Project range from $\$ 1 \mathrm{M}$ to $\$ 100 \mathrm{M}+$

- More than 50 active projects in design or construction

- Custodian of 412 buildings, 9.5 million square feet

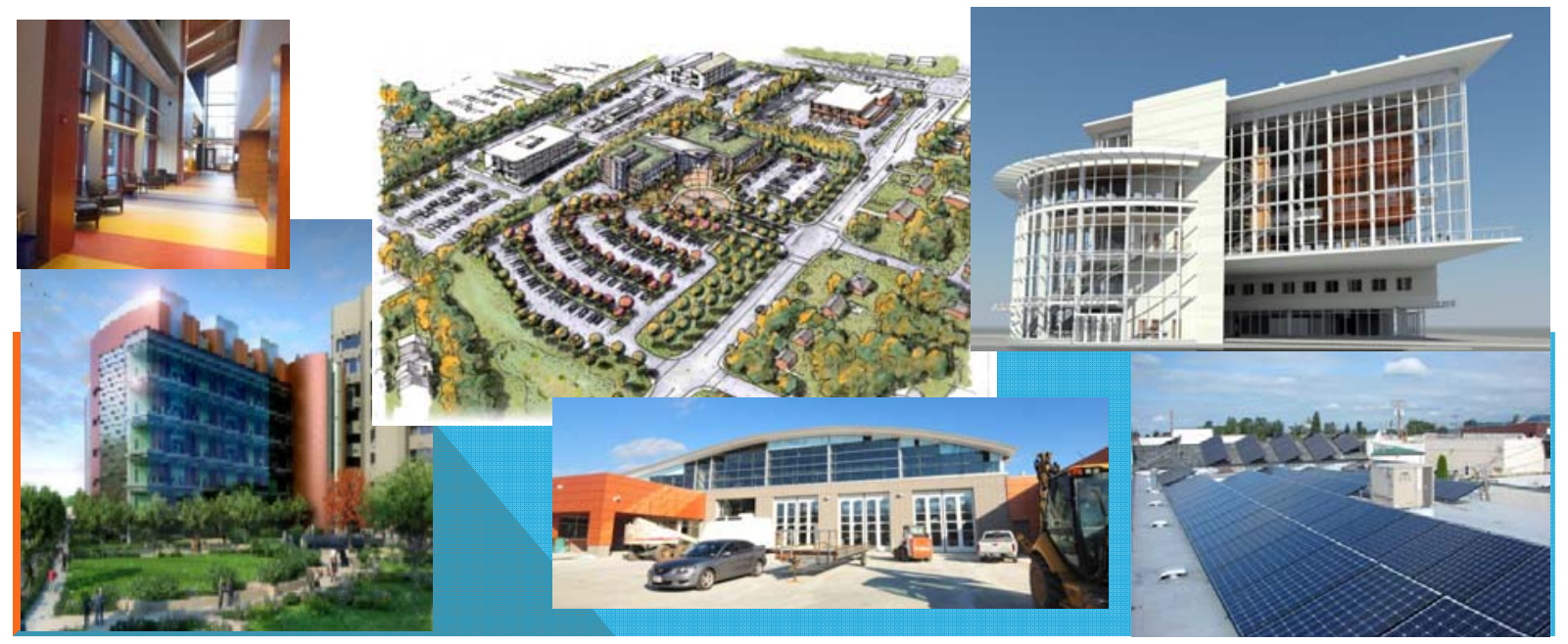




\section{DEPARTMENT OF GENERAL SERVICES}

Priorities for facility performance:

- Low environmental impact

- Durability

- Low, long-term O\&M

- Long operating hours

- Flexibility for varying uses

- Resiliency

\section{DEPARTMENT OF GENERAL SERVICES}

Sustainability priorities in new capital projects:

- Passive solar design

- Daylight harvesting

- Geothermal

- Designed for future active solar

- Water capture/reuse

- Reduced impervious surface

- Use of rapidly renewable/recycled materials 


\section{Example Projects:}

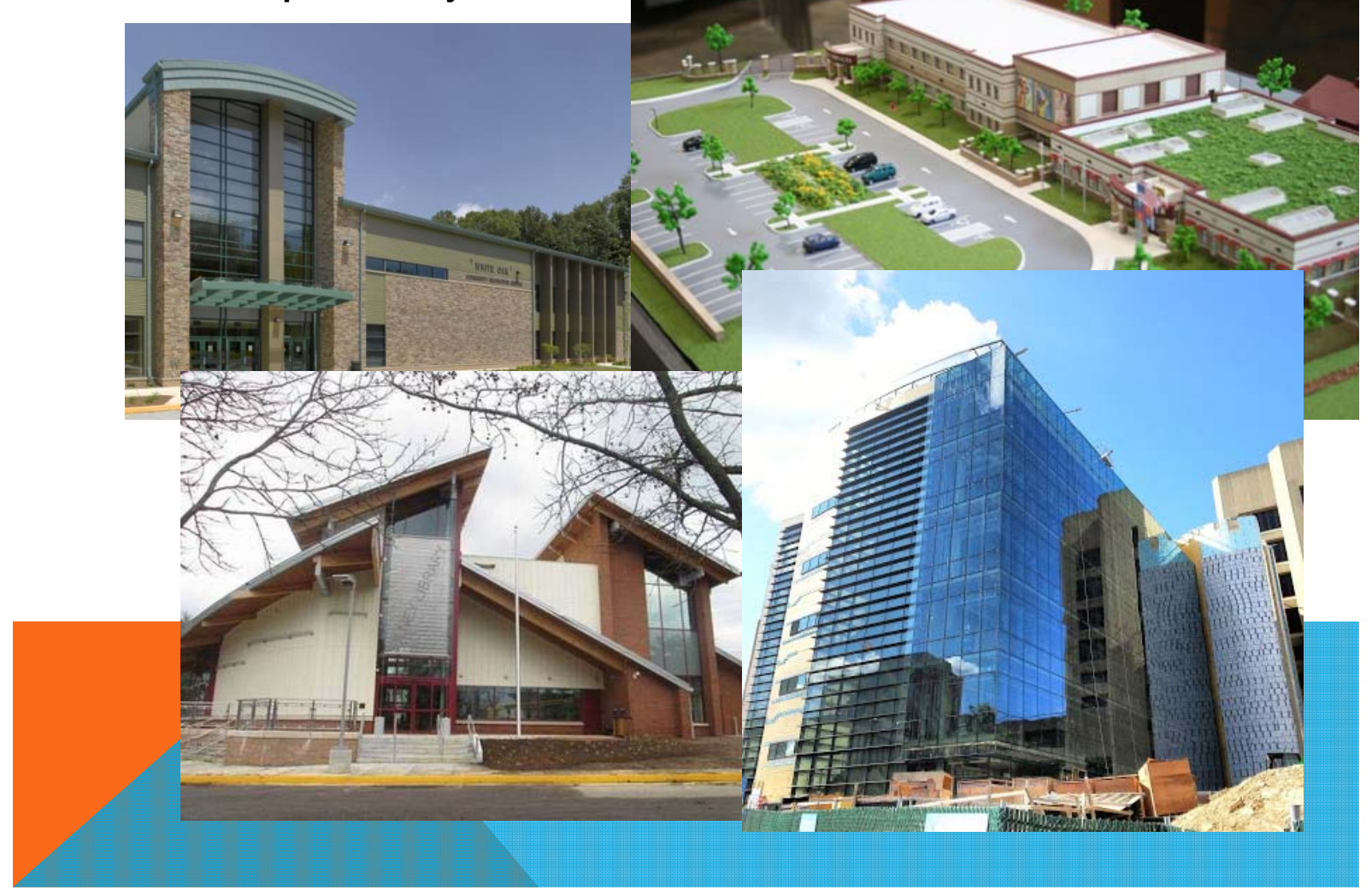

\section{CHALLENGES}

- Competing priorities

- Budget vs. ROI

-Environmental Impact

- Durability

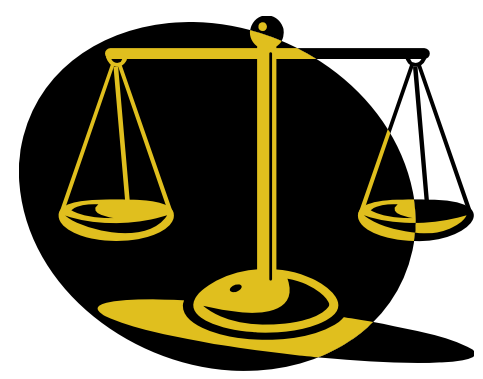

- Community concerns and interests

- Regulatory requirements

- Internal client expectations 


\section{Equipment Maintenance and Transit Operations Center}

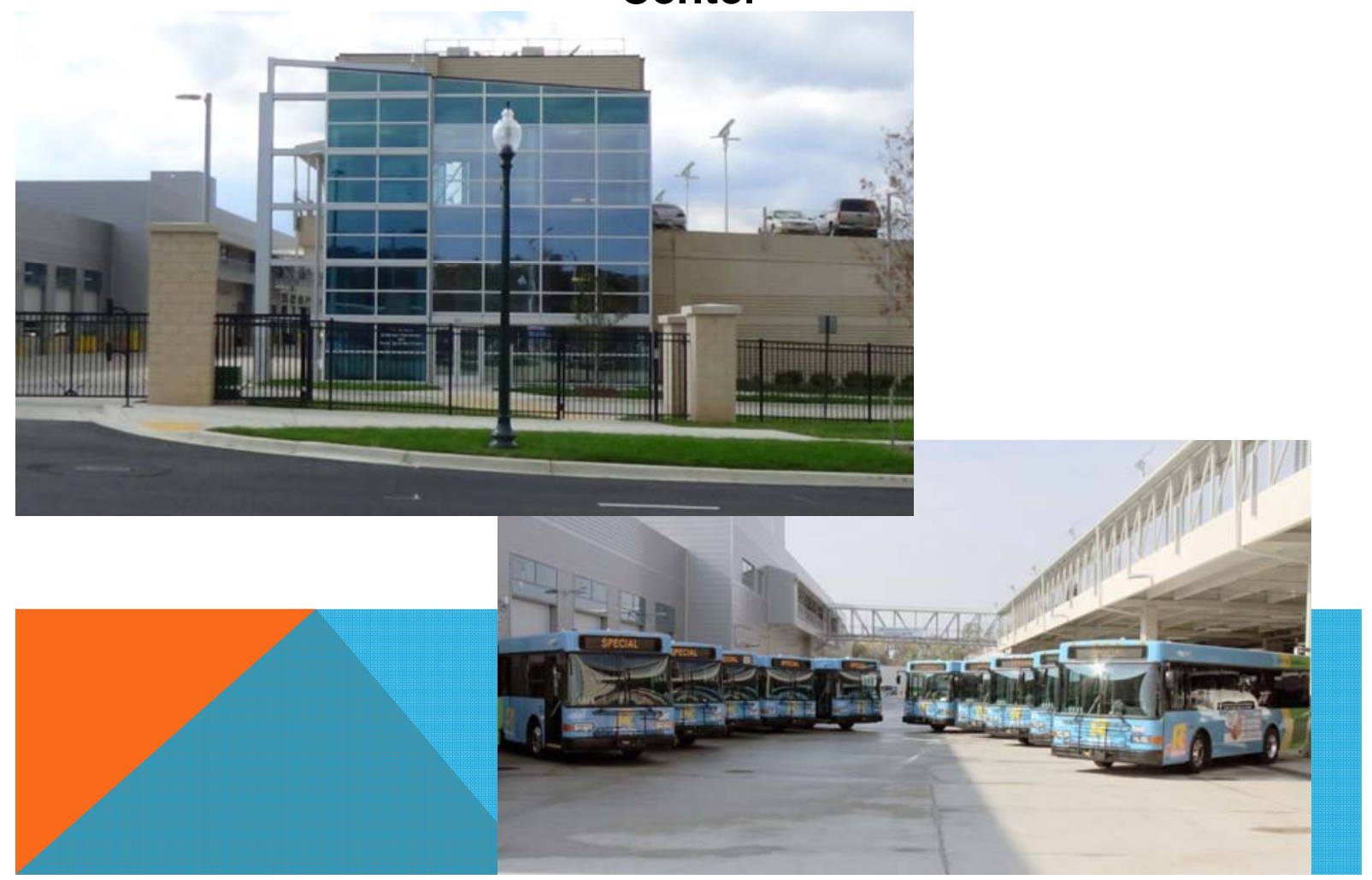

\section{Case Study: Equipment Maintenance and}

Transit Operations Center

- Multiple buildings

- 200+ transit buses, highway trucks and equipment, and some light duty fleet

- Fueling facility

- LEED Gold

- Tight site conditions

- Plan for future capacity
- Energy efficiency

- Light harvesting

- $400 \mathrm{~kW}$ of Onsite Solar potential for expansion.

- 4 acres of vegetative roof

- Continuing measurement and verification

- On-site compressed natural gas 

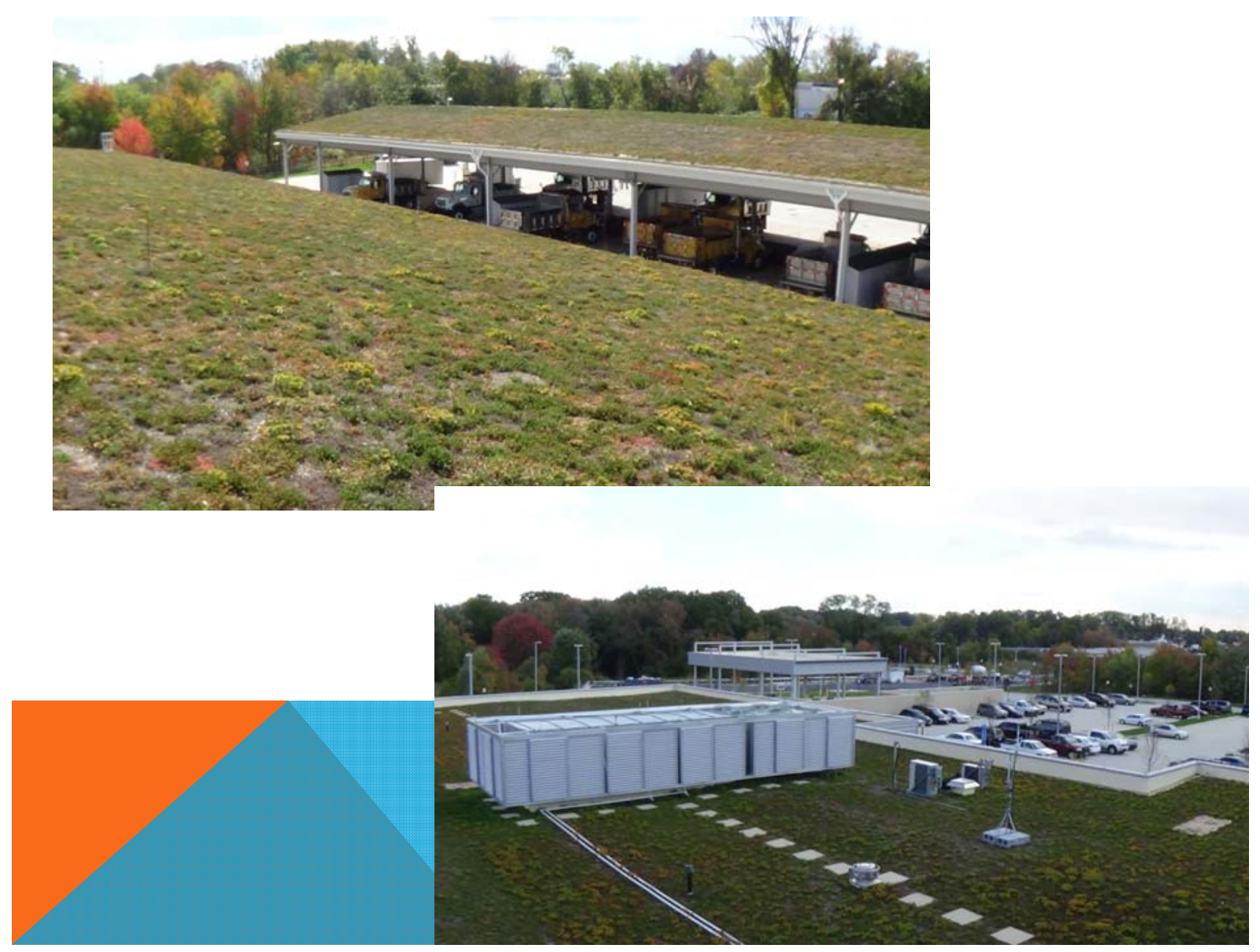

\section{Future Efforts}

- More aggressive solar photovoltaic/thermal

- Combined Heat and Power/Microgrids

- Expanded occupant education/engagement

- Innovative P3 opportunities

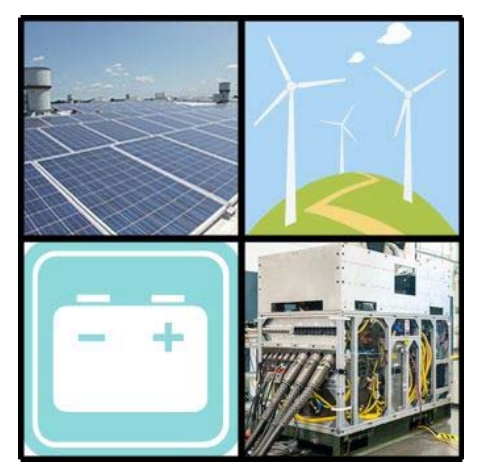


Needed Metrics to Facilitate Sustainable Construction

Contacts:

David E. Dise, Director, Department of General Services David.Dise@montgomerycountymd.gov

Eric R. Coffman, Chief, Office of Energy and Sustainability Eric.Coffman@montgomerycountymd.gov

Rassa Davoodpour, Manager, Office of Special Projects Rassa.Davoodpour@montgomerycountymd.gov 


\section{Measuring Sustainable Construction}
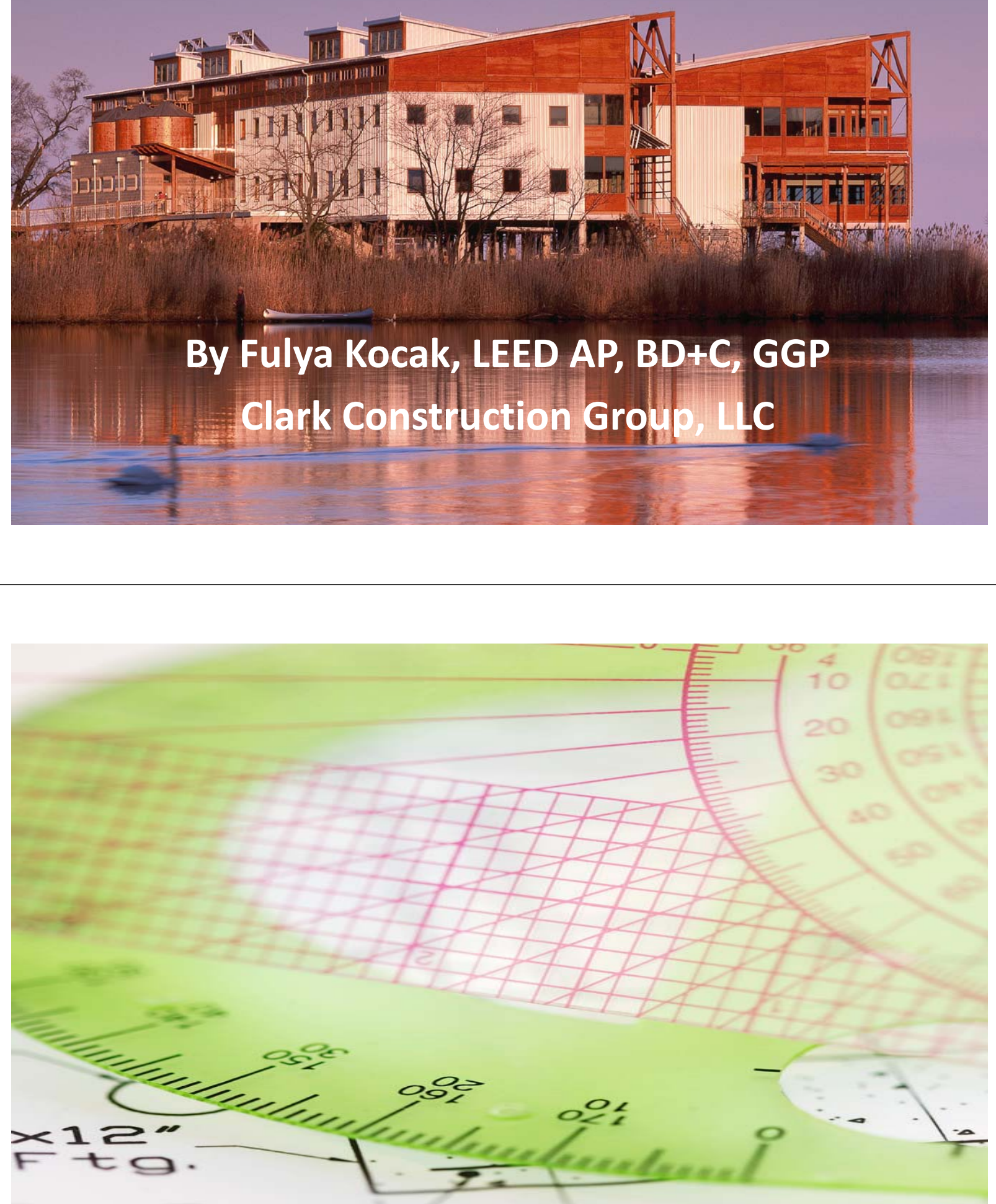

\section{How do we measure Sustainability in Construction Industry?}




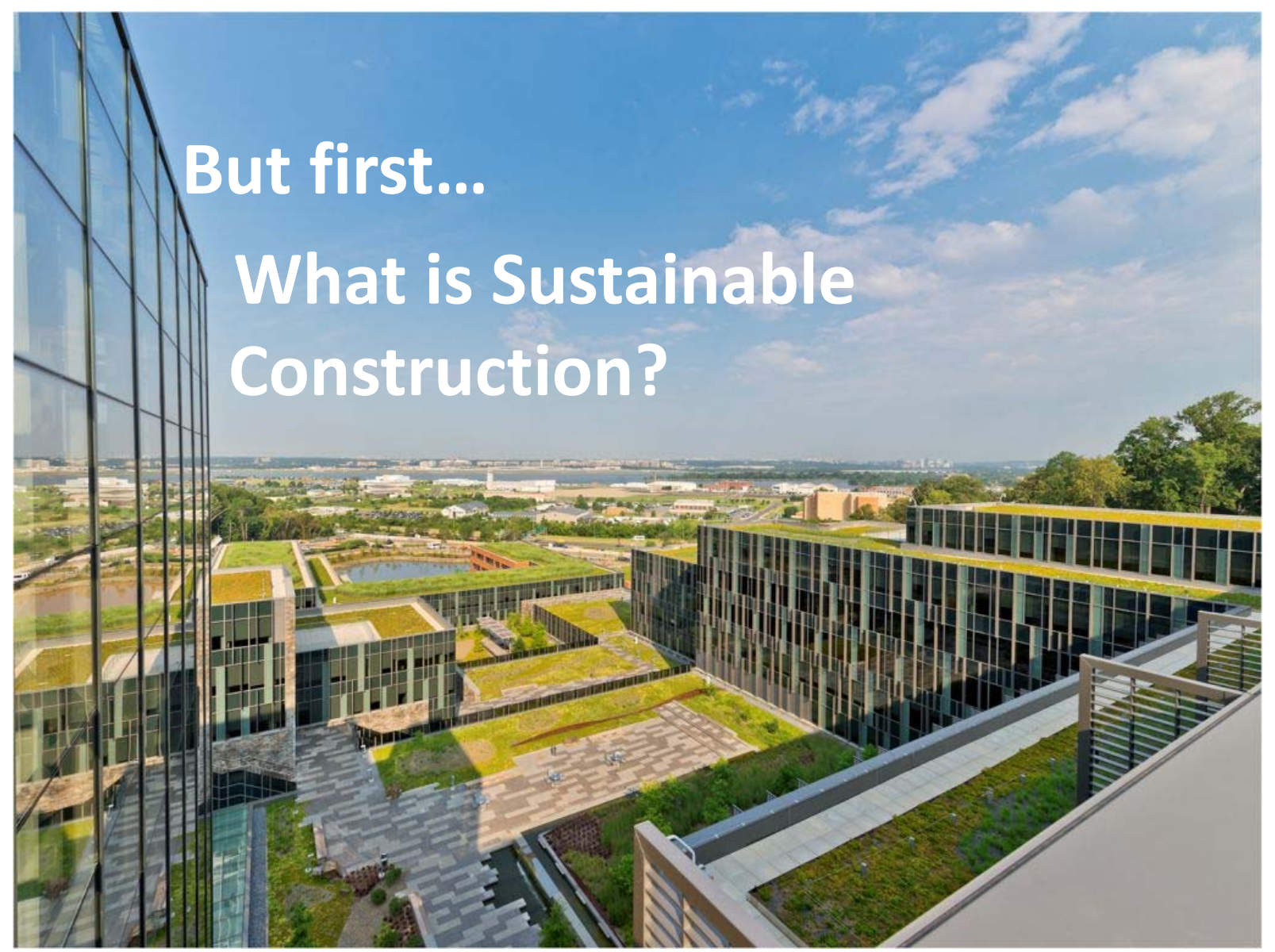

\section{Constructing Green Buildings?}

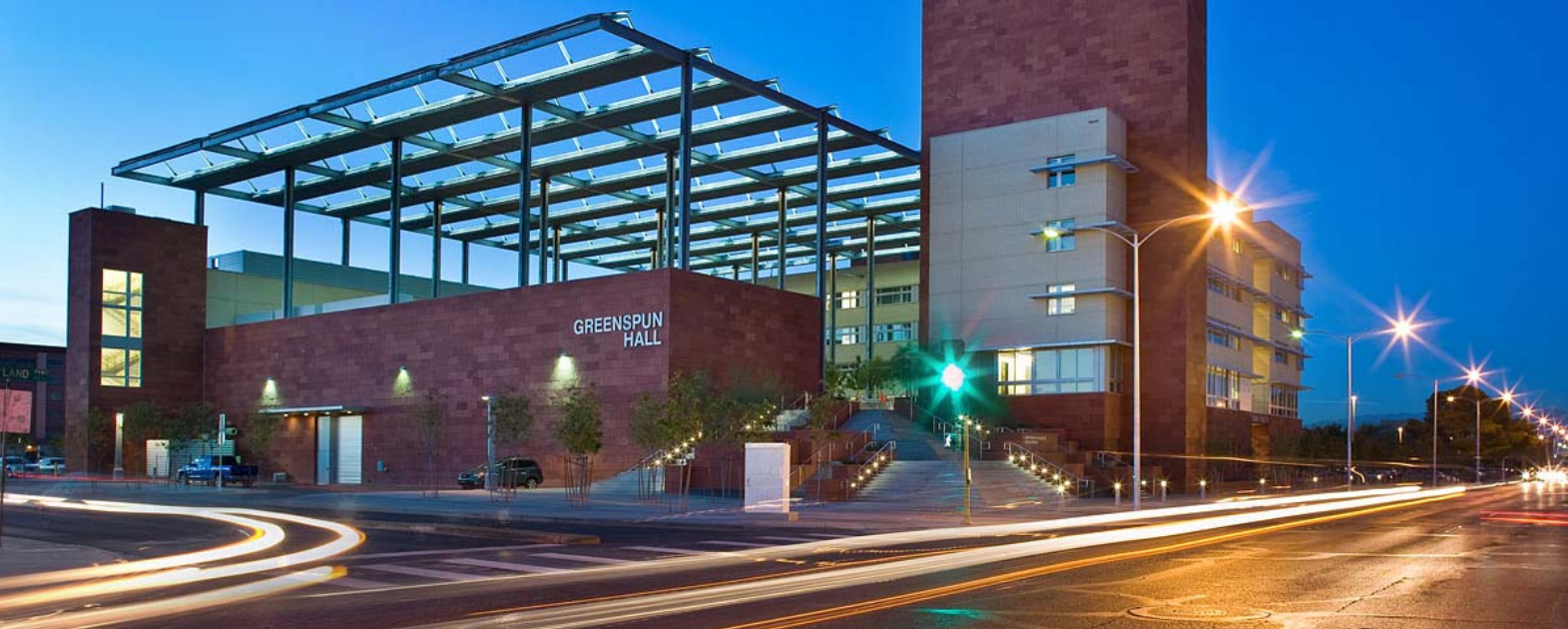




\section{Capabilities in LEED Certification?}

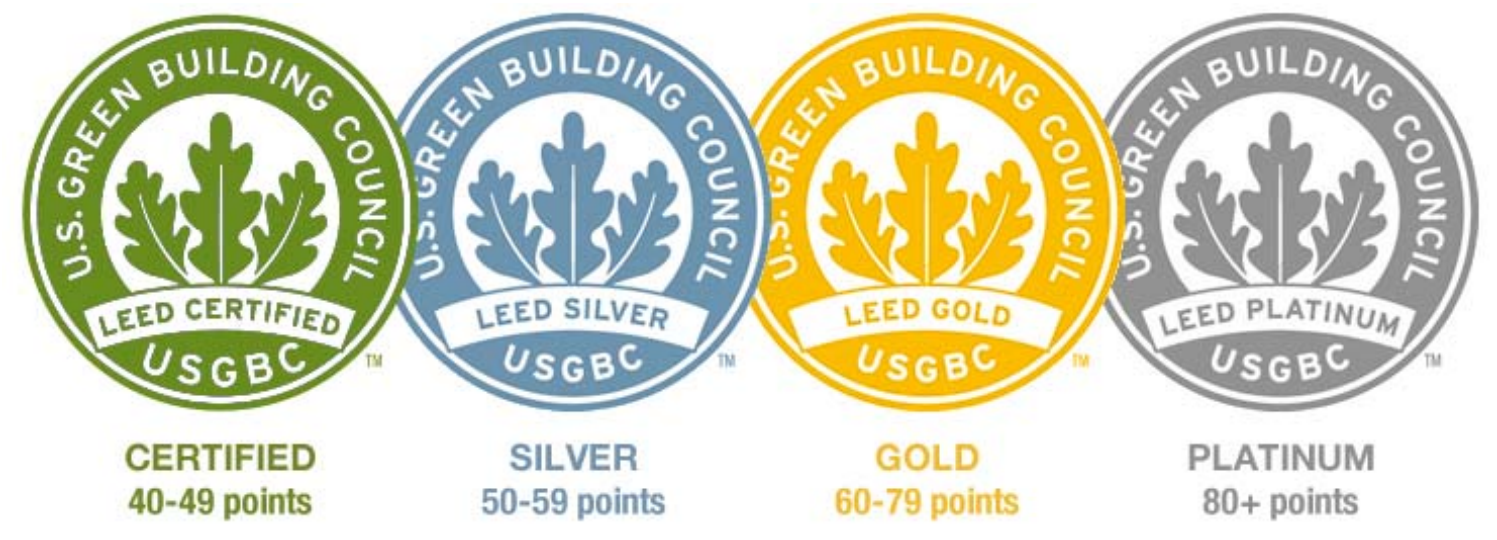

\section{Health \& Well Being ?}

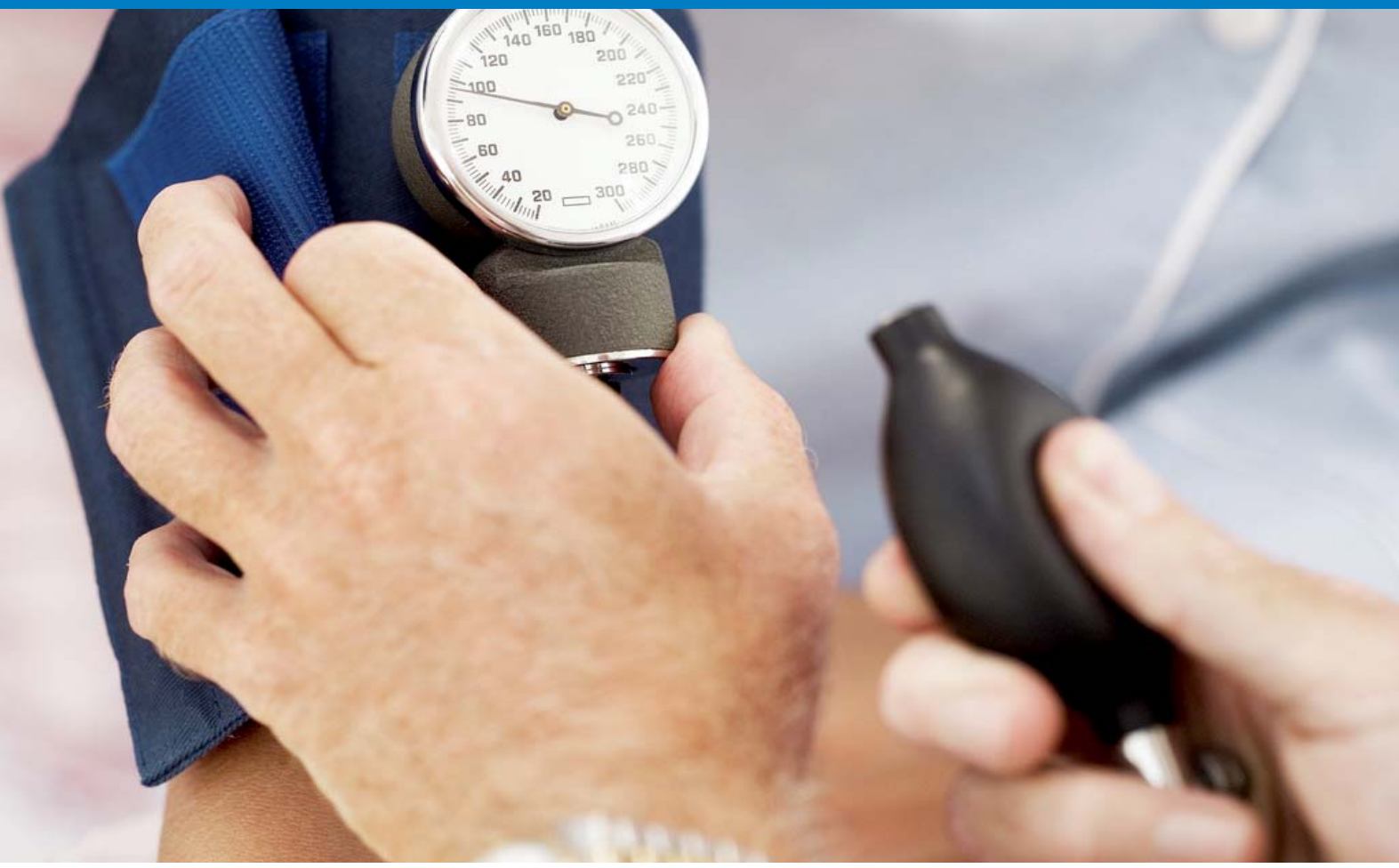




\section{Environmental Compliance?}

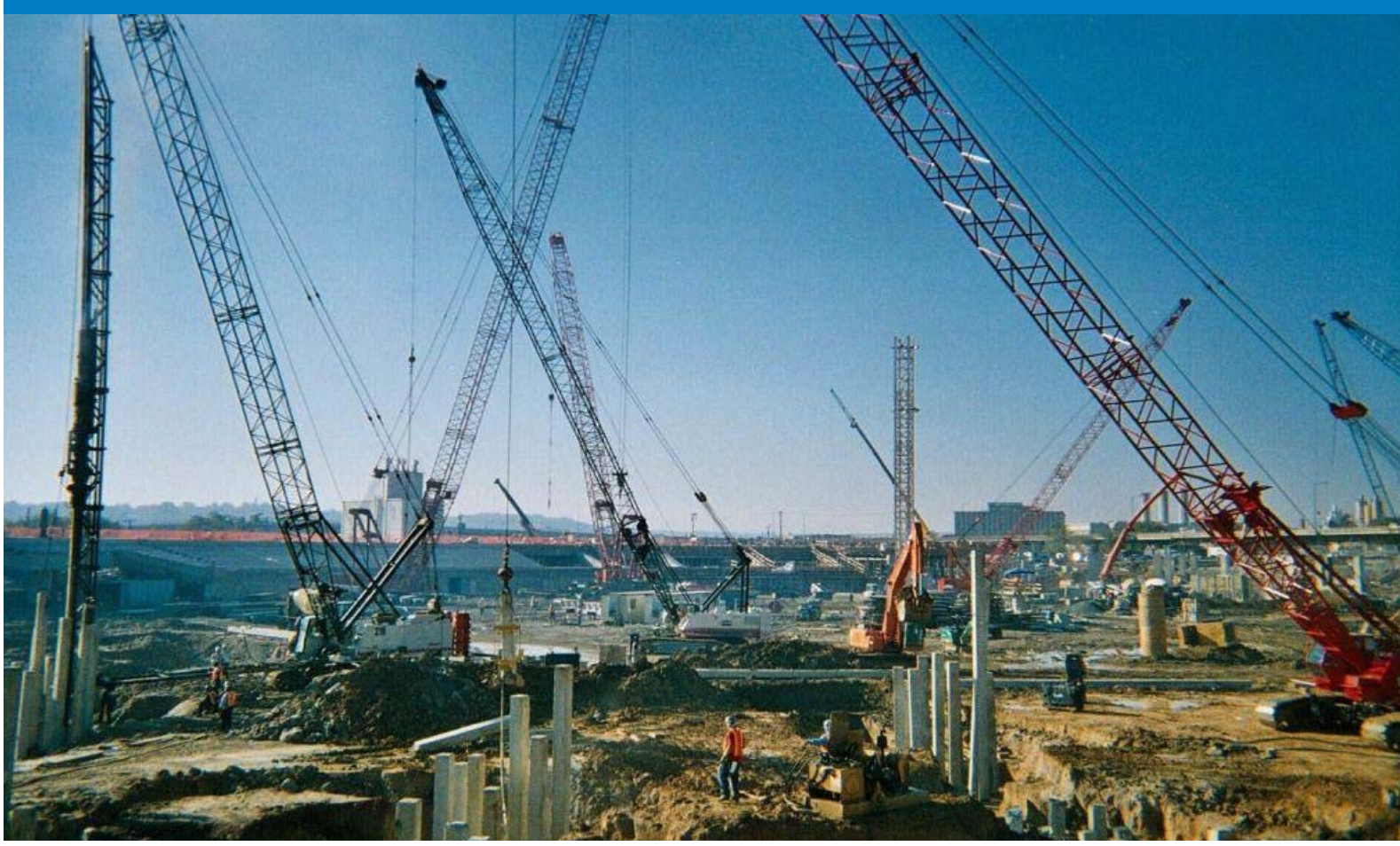

Environmental Management Systems?

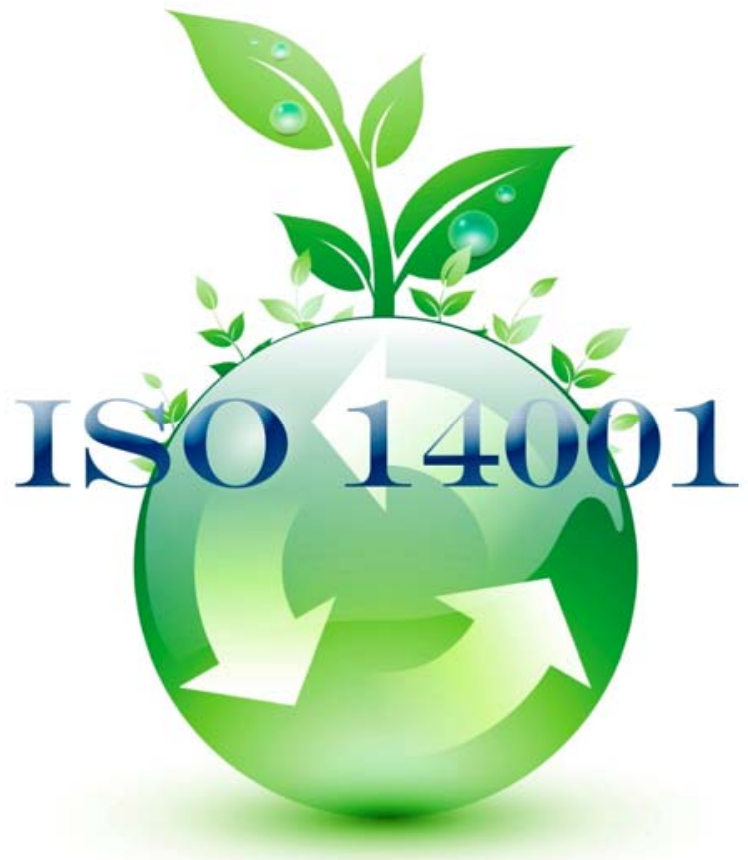




\section{Greening the Supply Chain?}

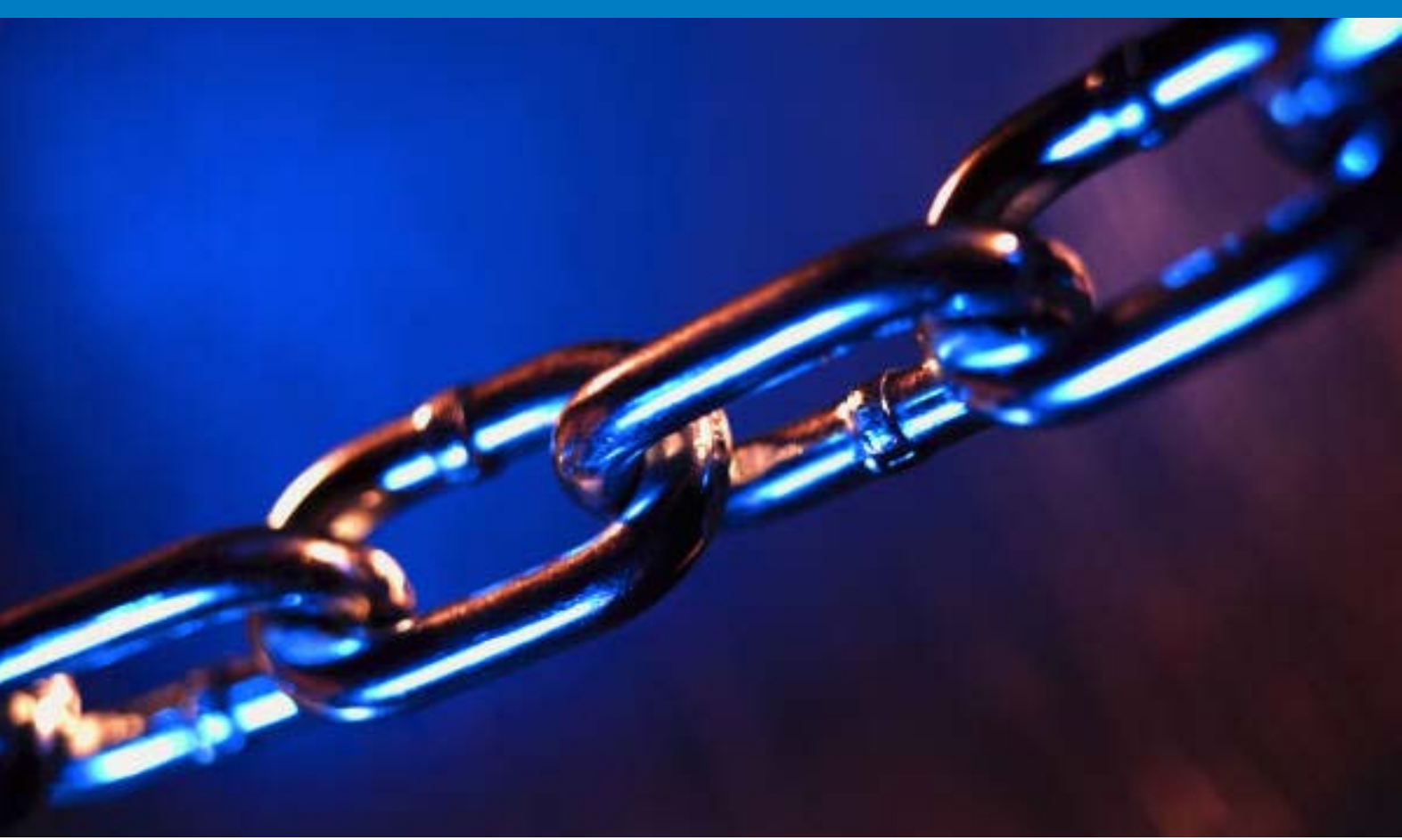

\section{Research and Innovation}

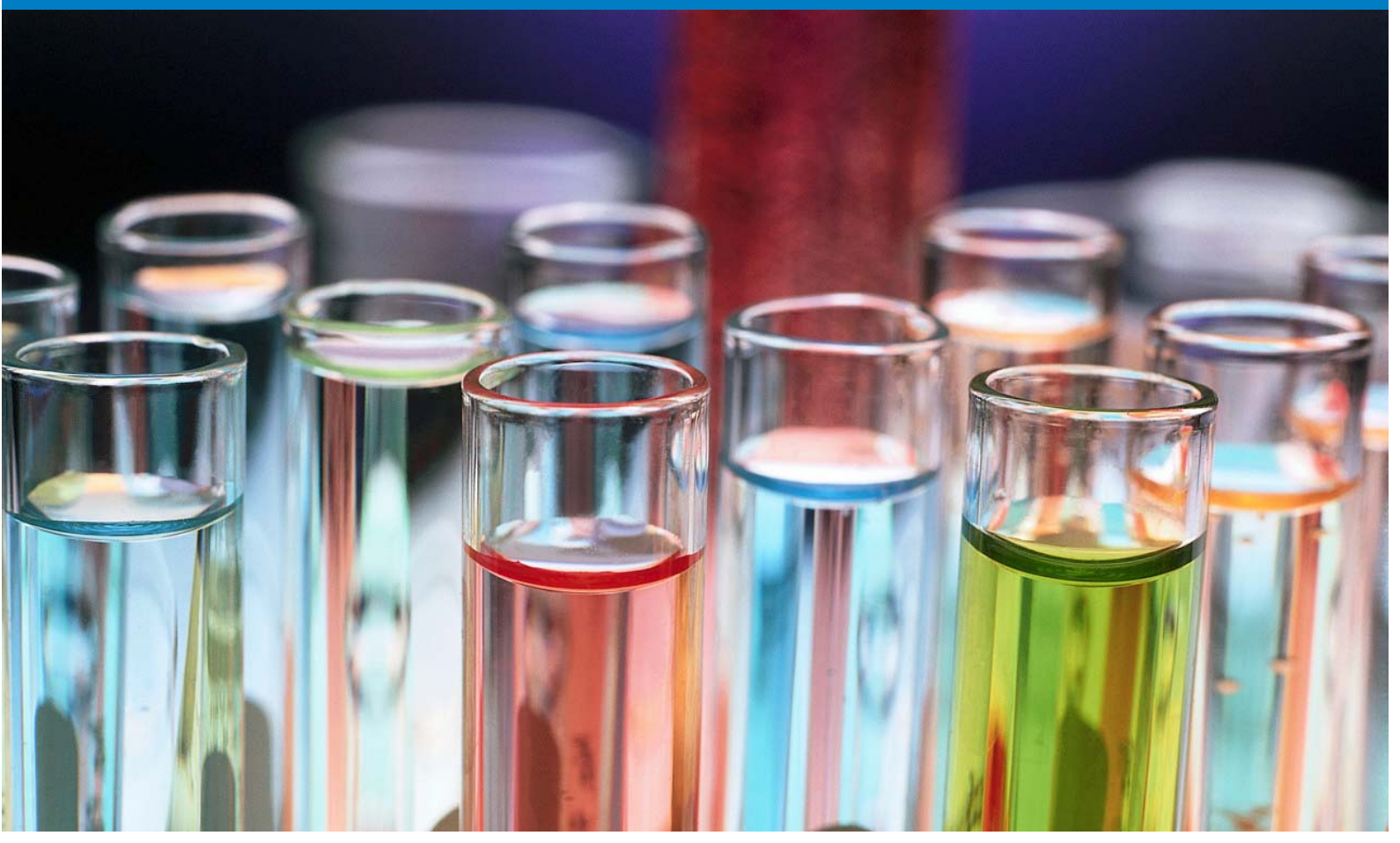




\section{Education and Awareness?}

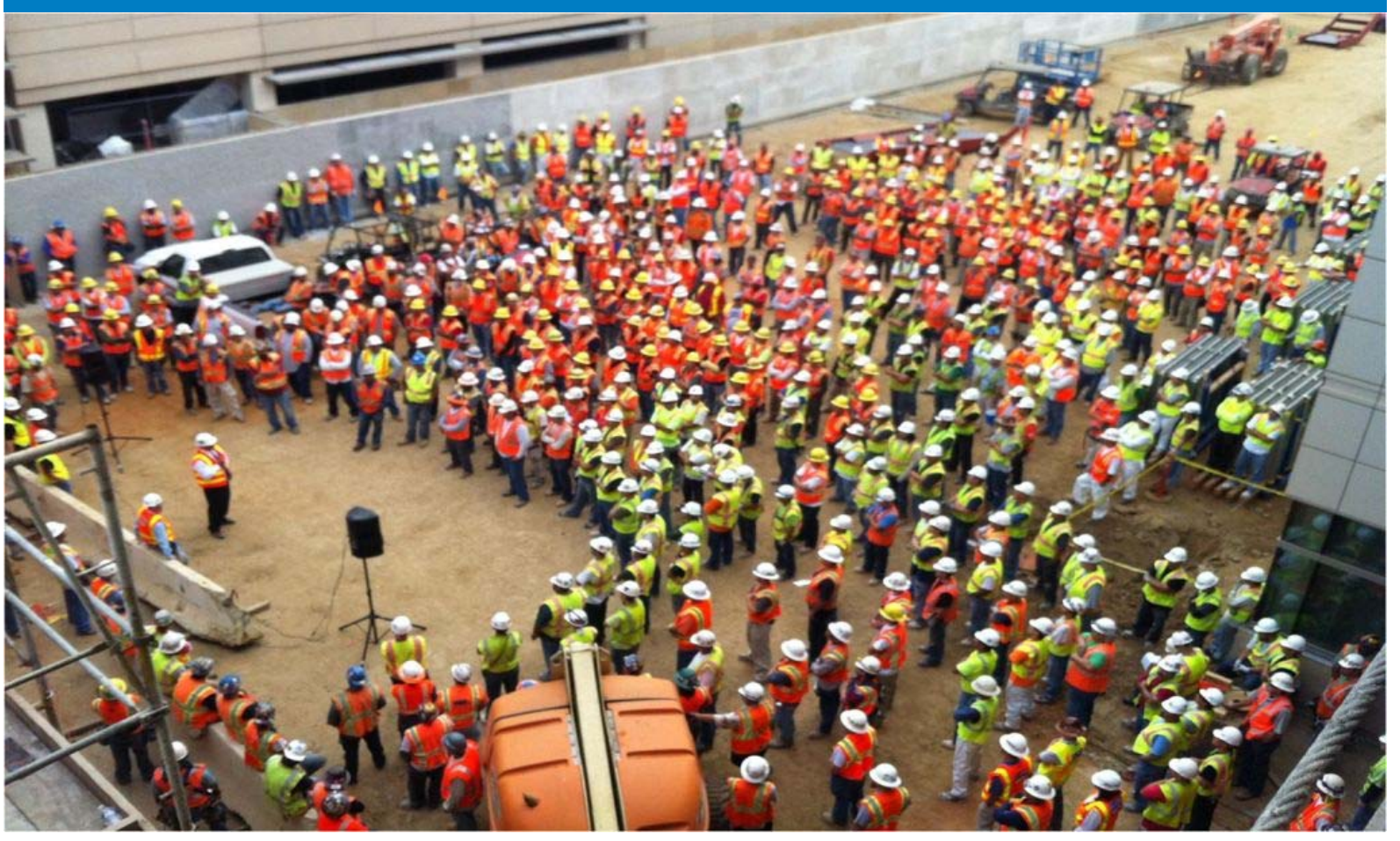

\section{Reducing disruption to land \& habitats?}

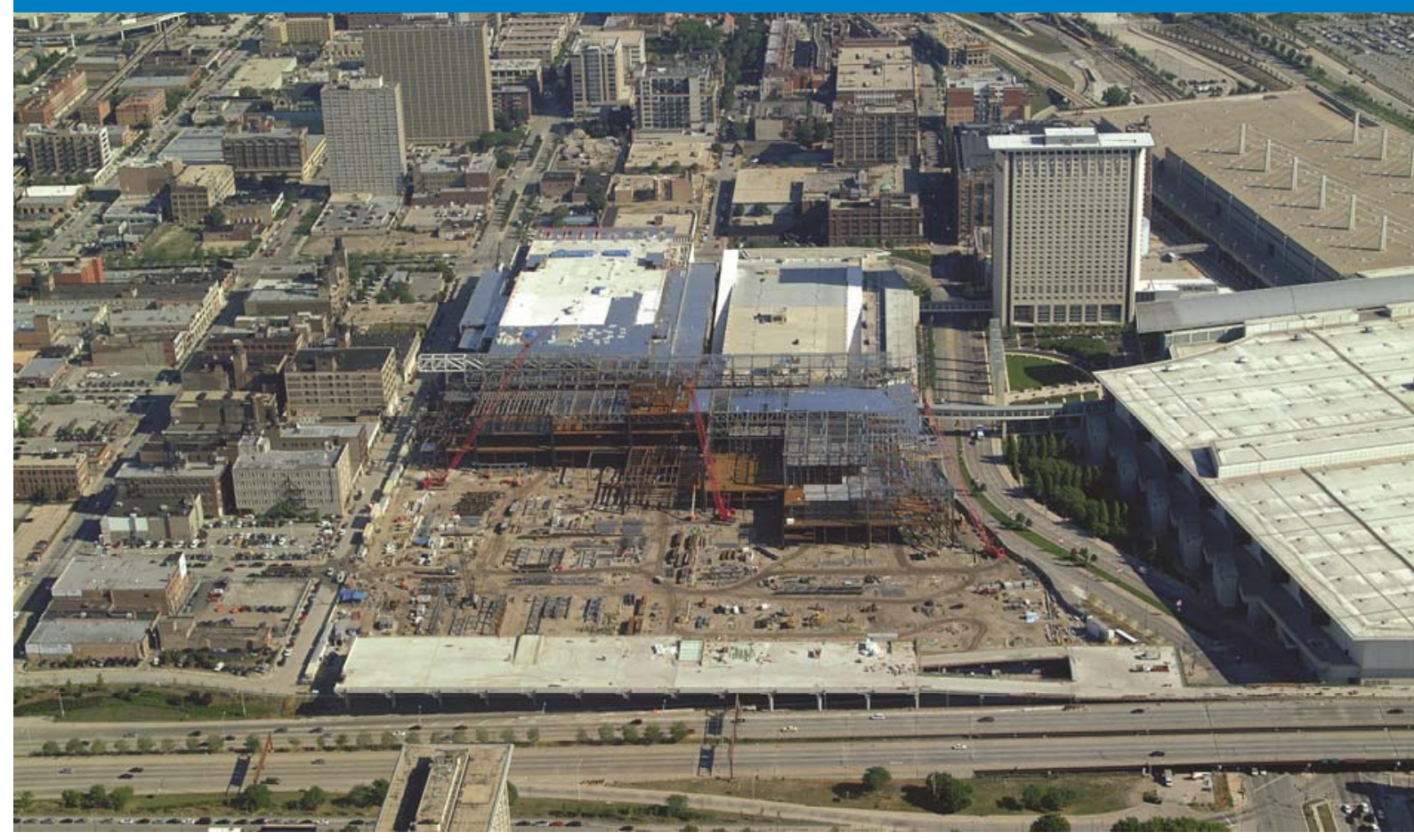




\section{Minimized transportation?}

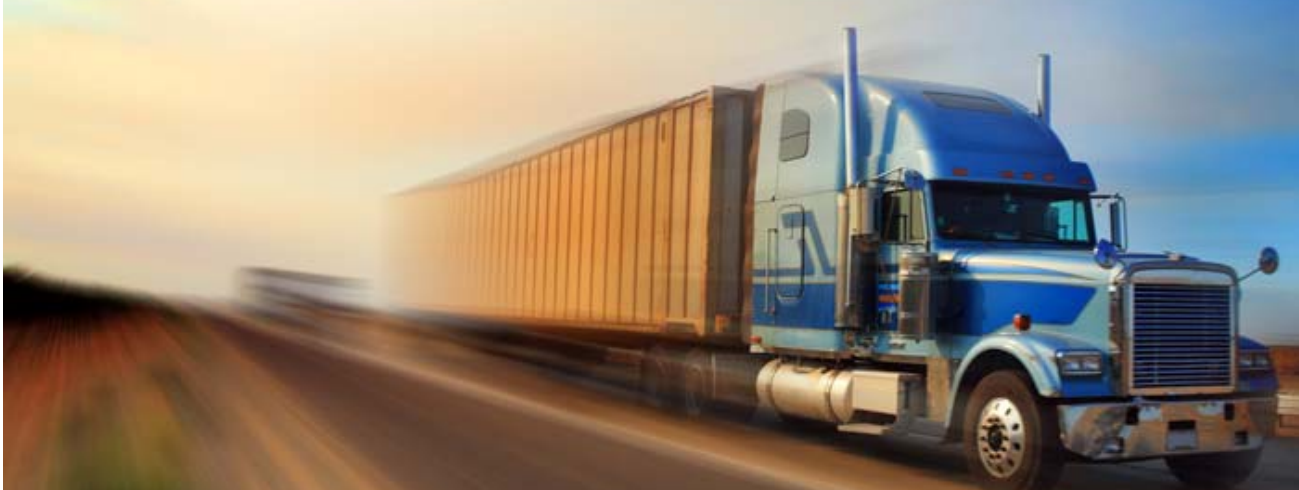

\section{Progress in new green technologies \& products?}

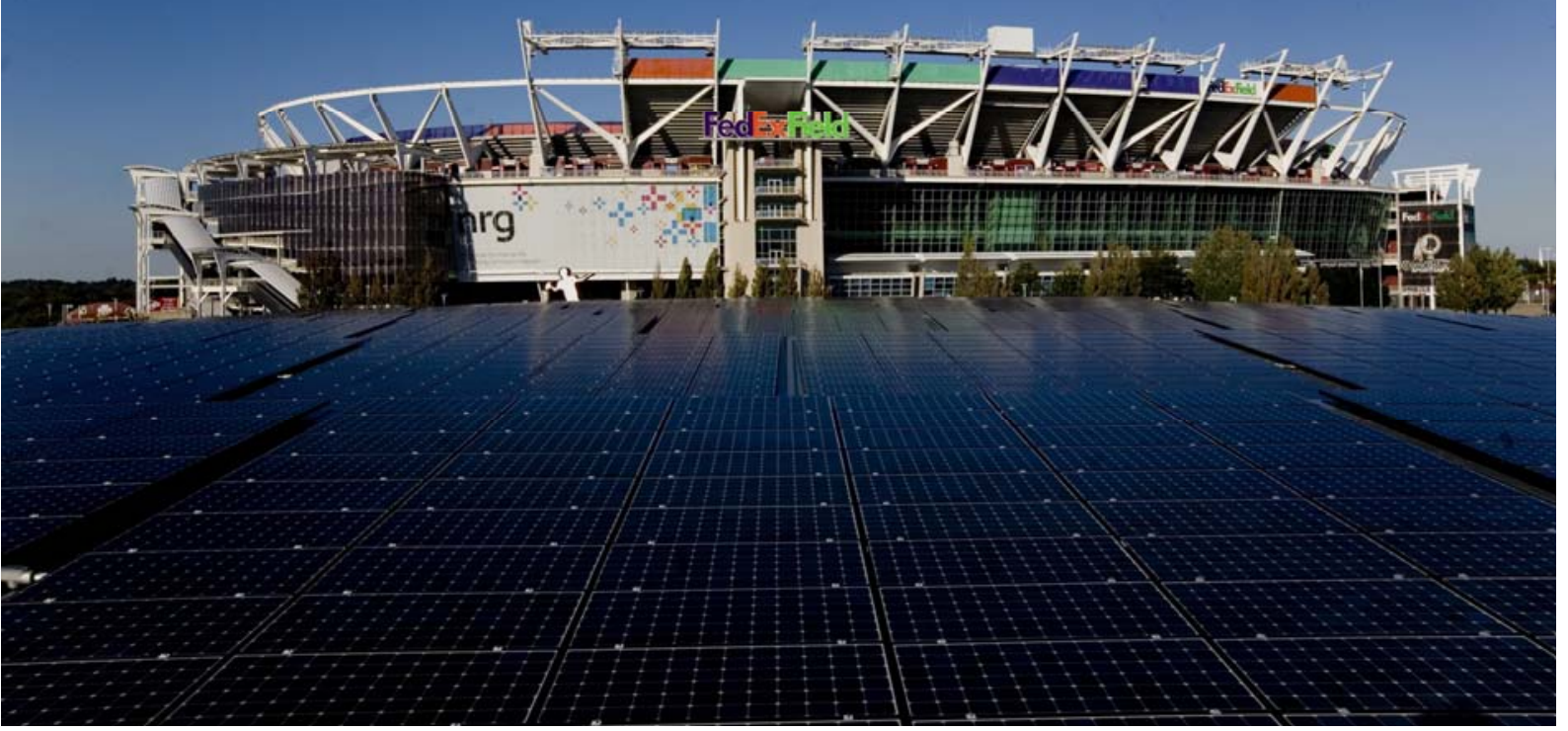




\section{Minimizing pollution during construction operations?}

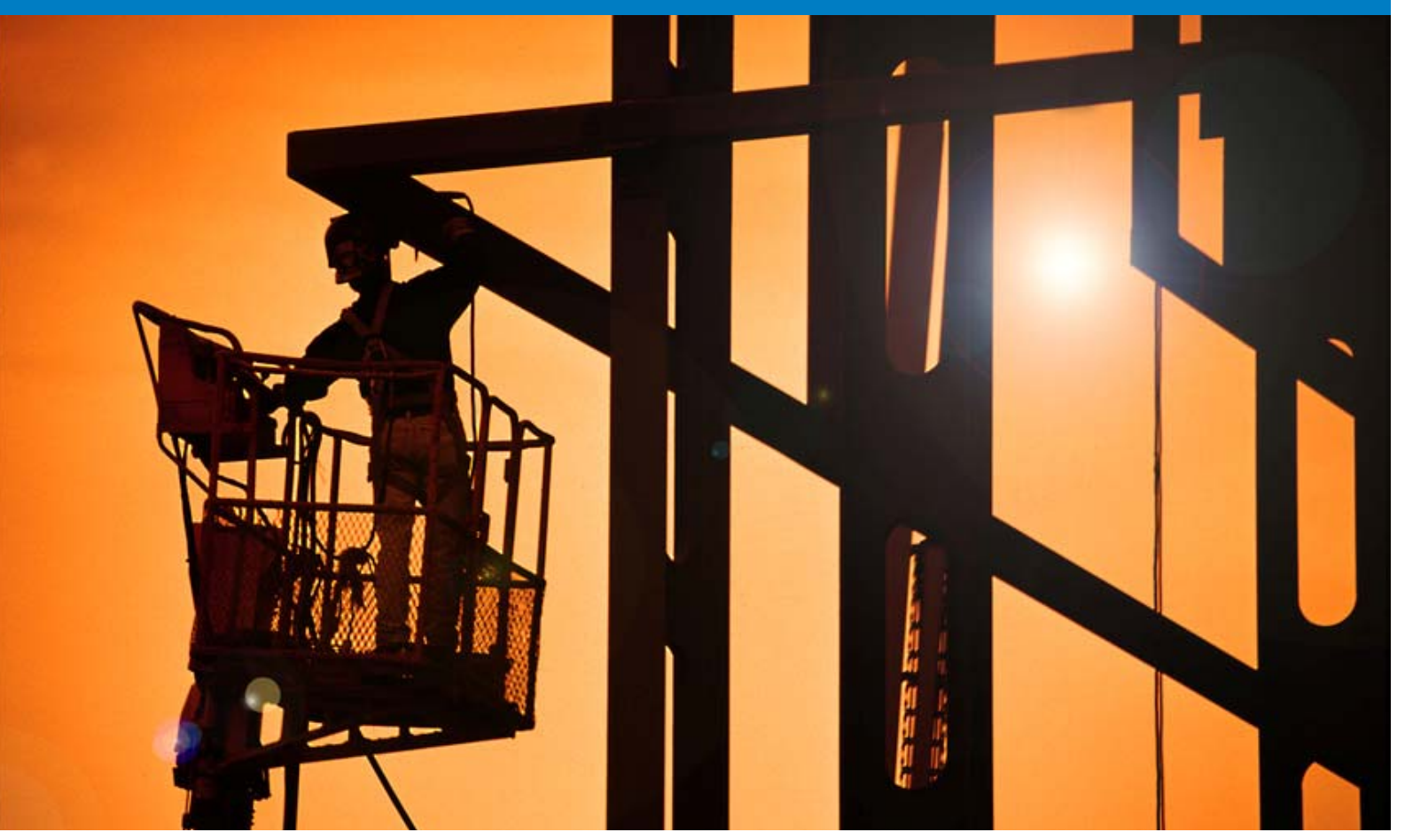

\section{Reduce, Reuse, Recycle Construction Waste?}

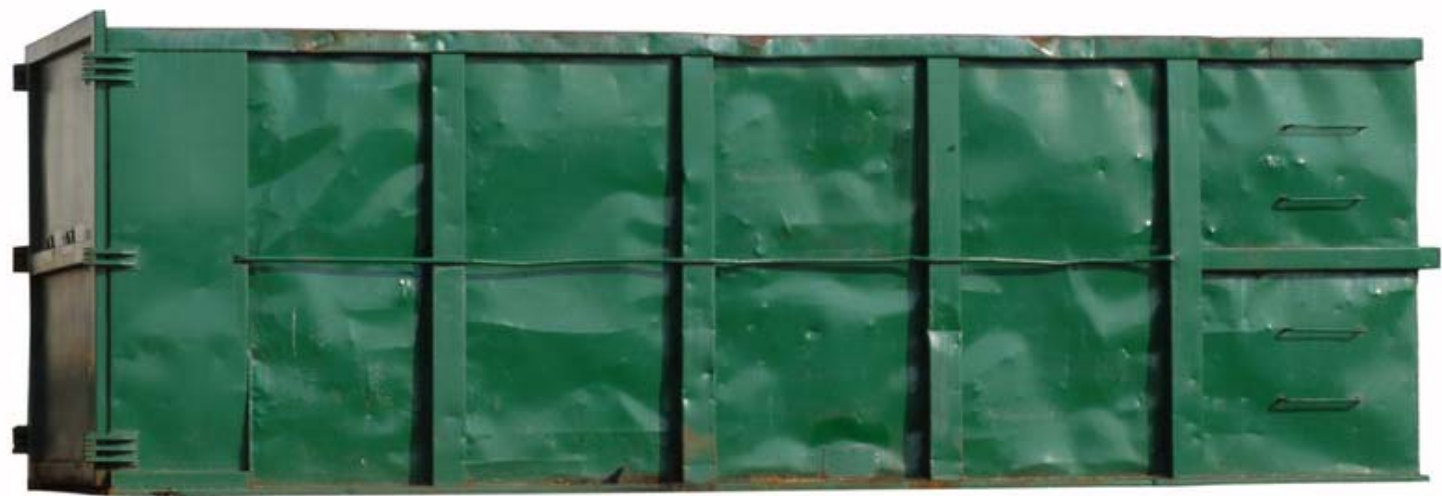


Making green buildings cost effective?

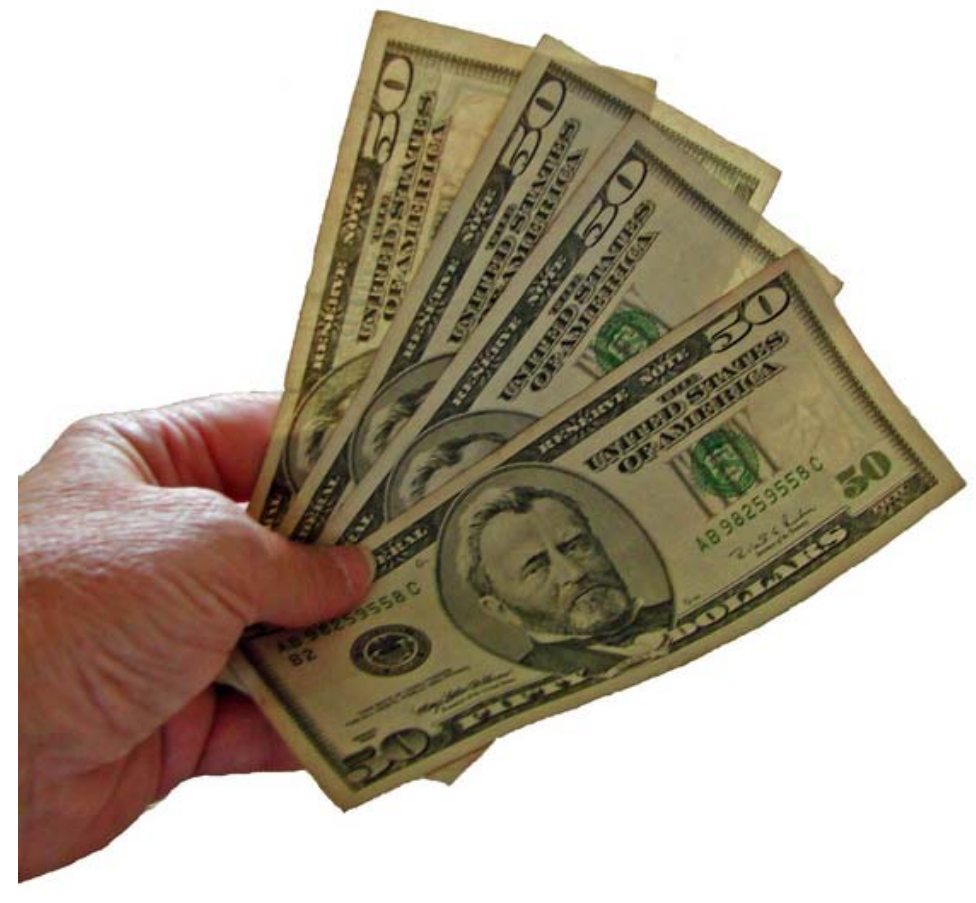

Assisting the clients build green?

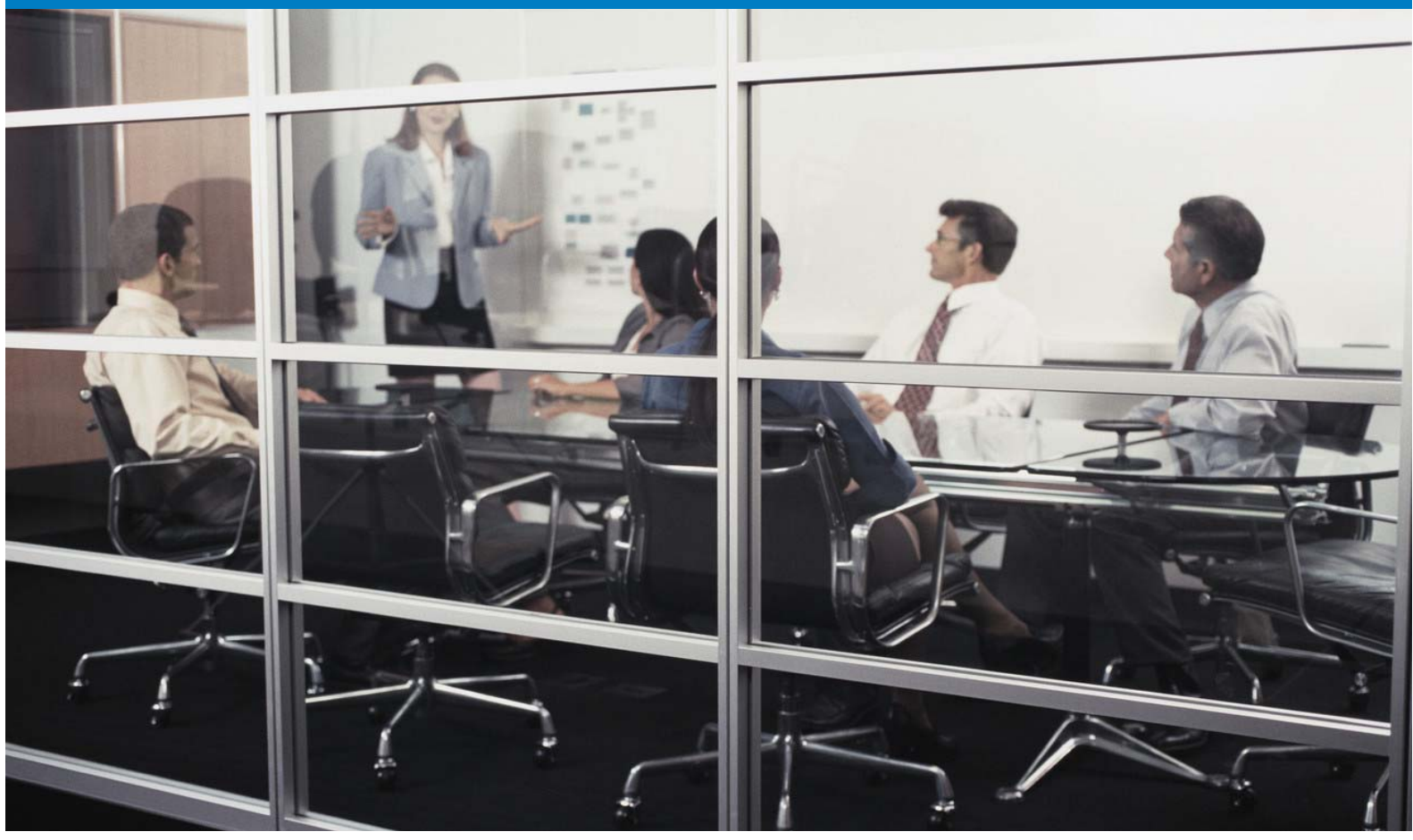


Supporting local communities \&

\section{businesses?}

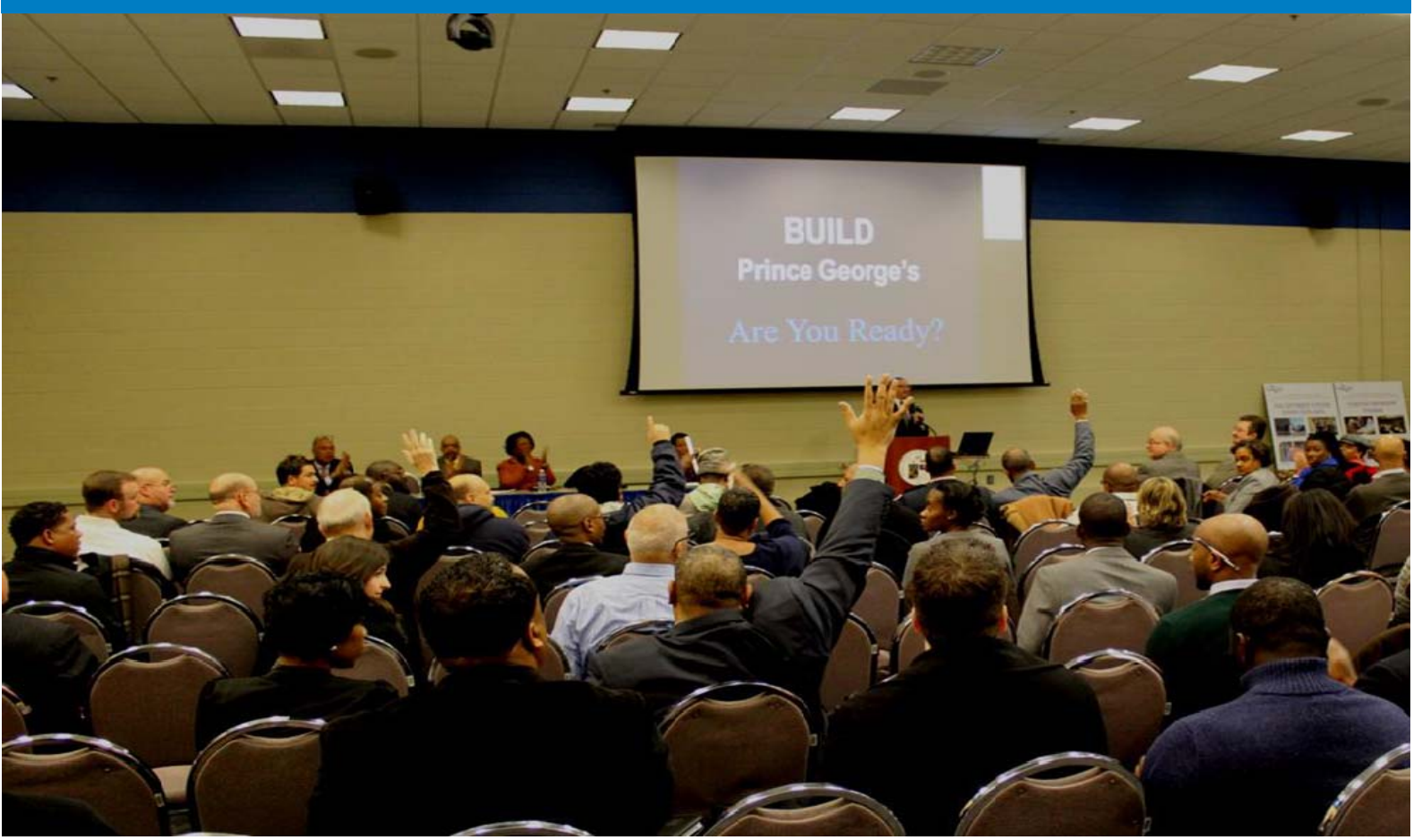

Tracking carbon emissions from construction operations?

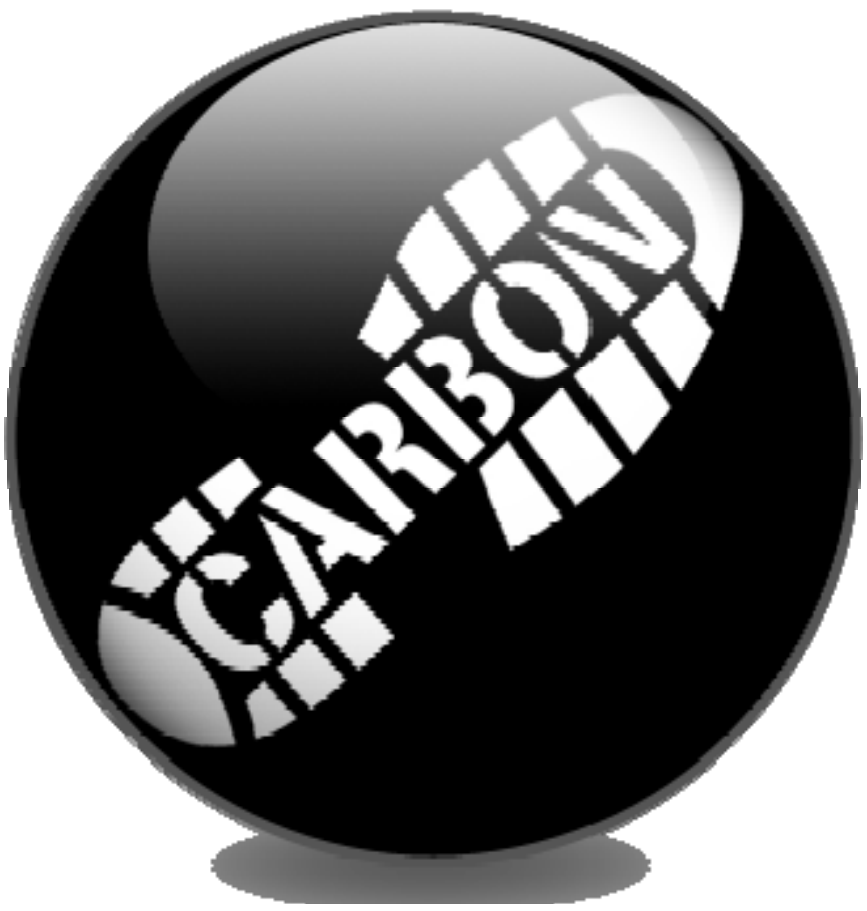




\section{Walking the Talk?}

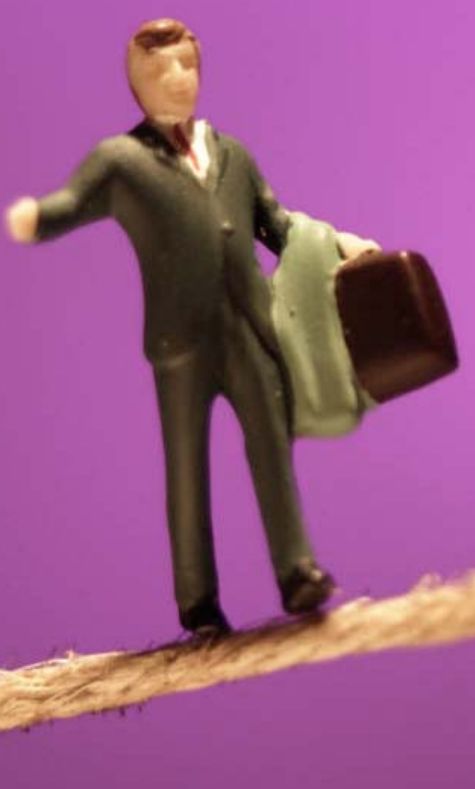

Competitive Advantage?

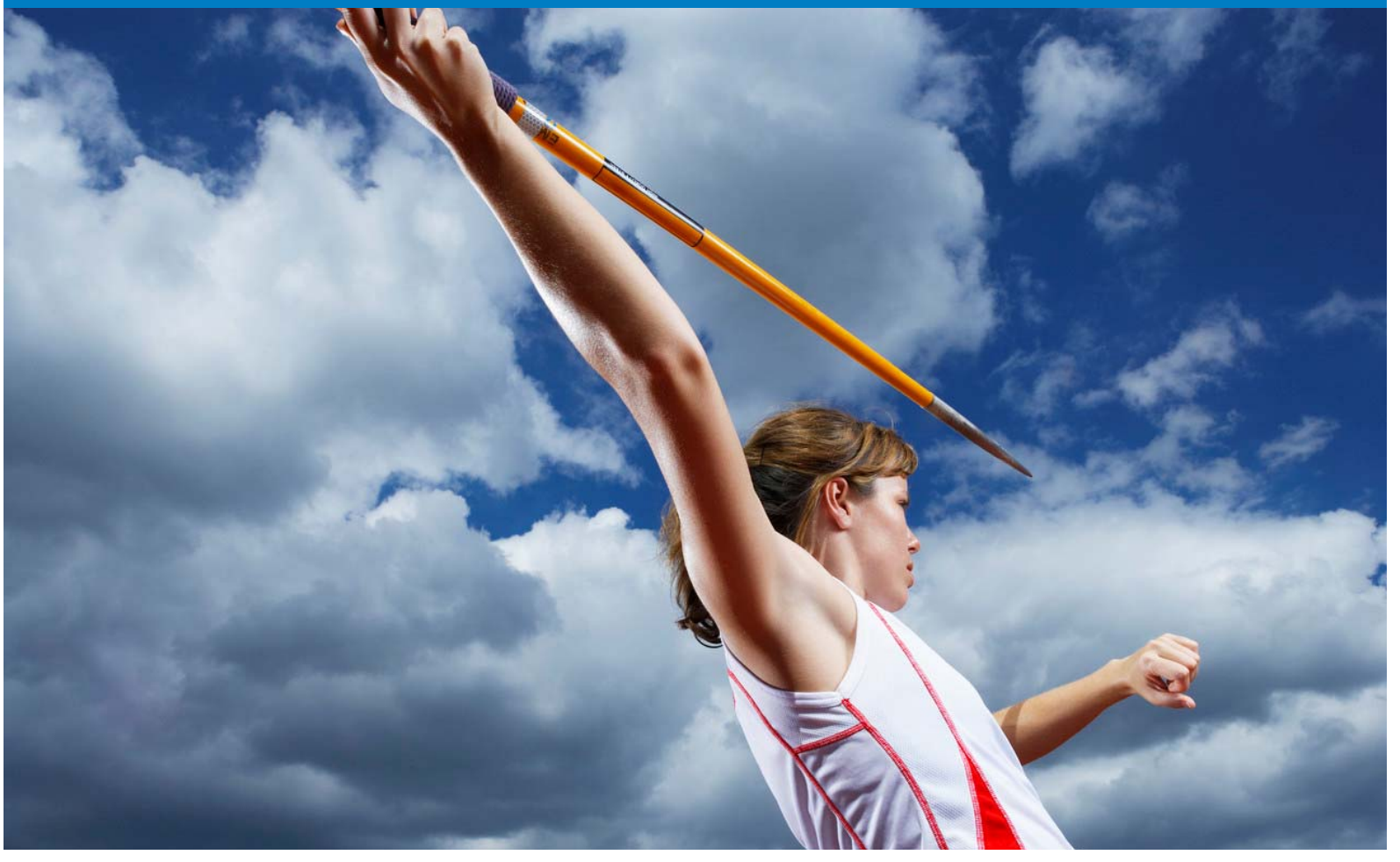




\section{Marketing?}
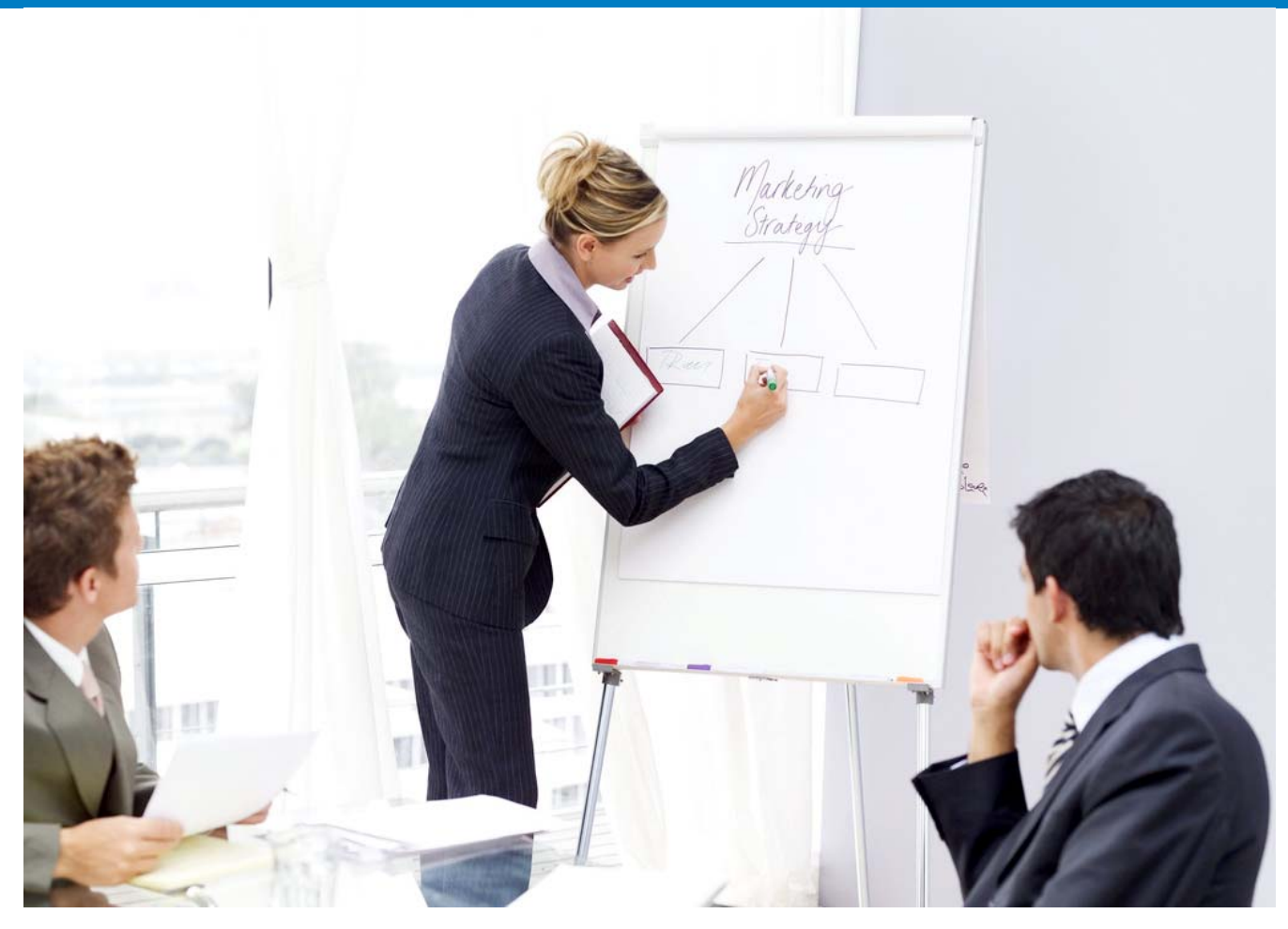

\section{Profitability?}

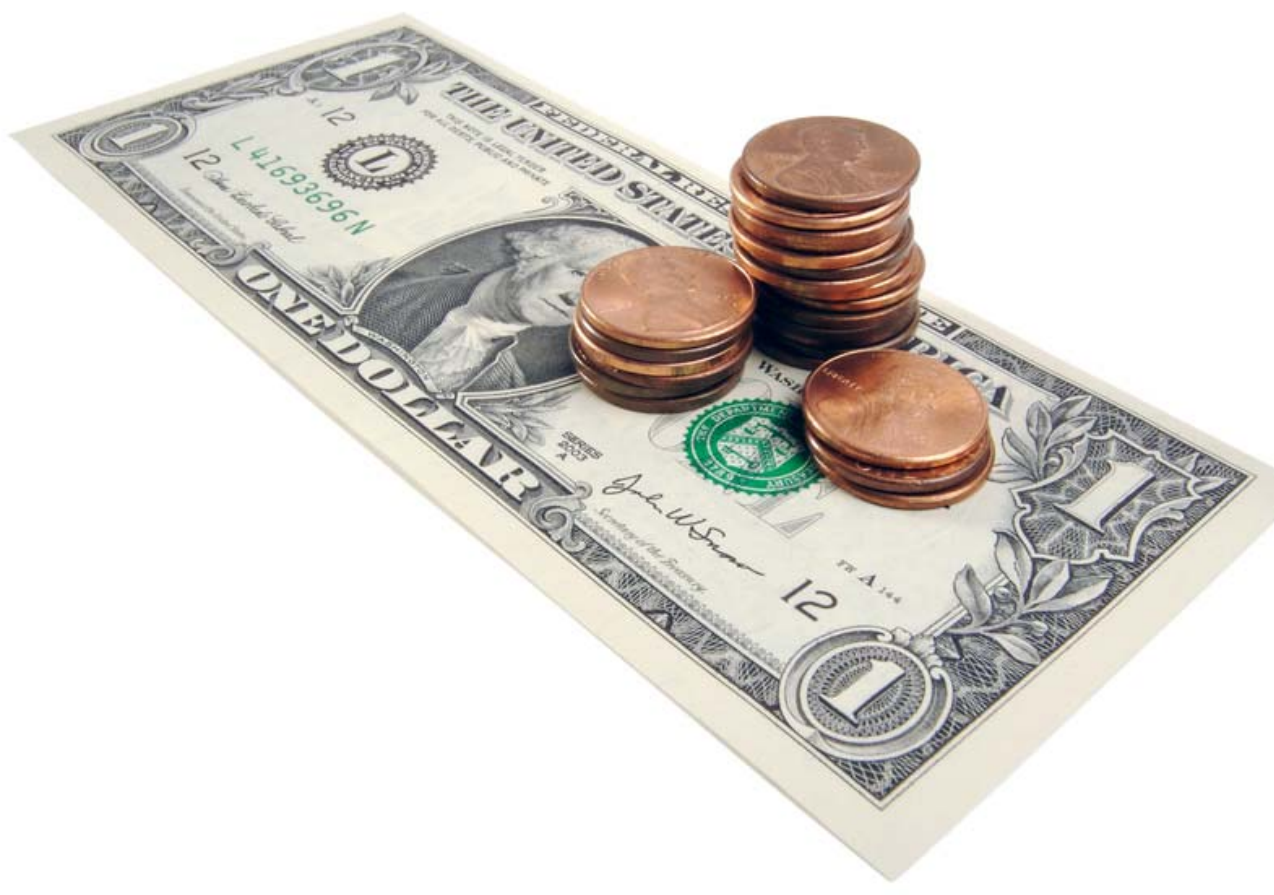




\section{All of the above?}

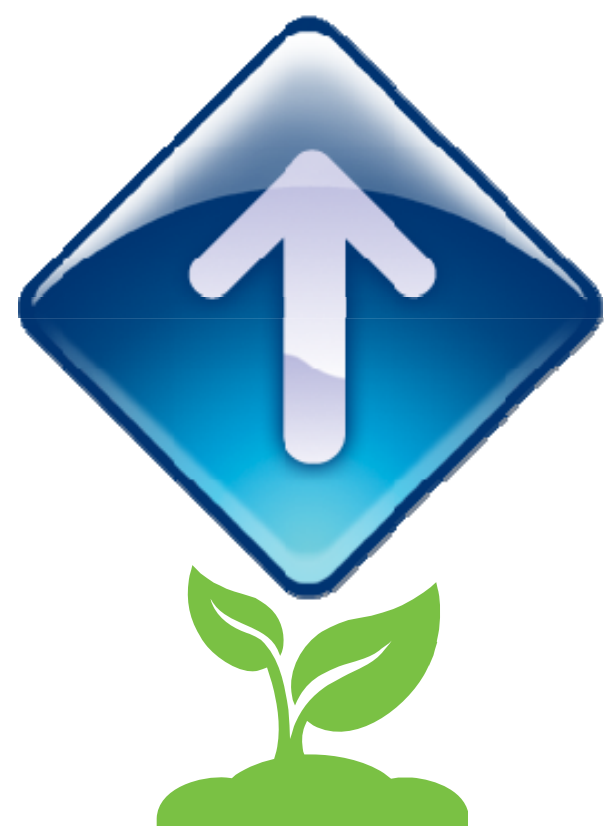

\section{What metrics exist today?}

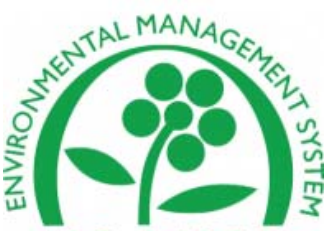

ISO 14001

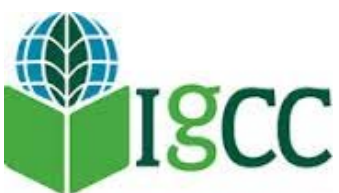

SAFE \& SUSTAINABLE BY THE BOOK

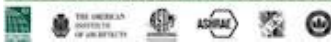

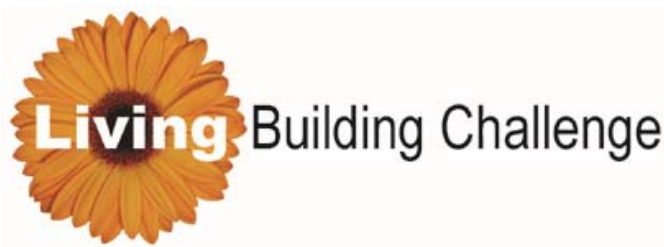

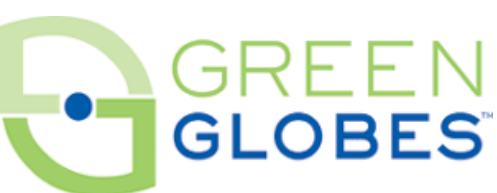
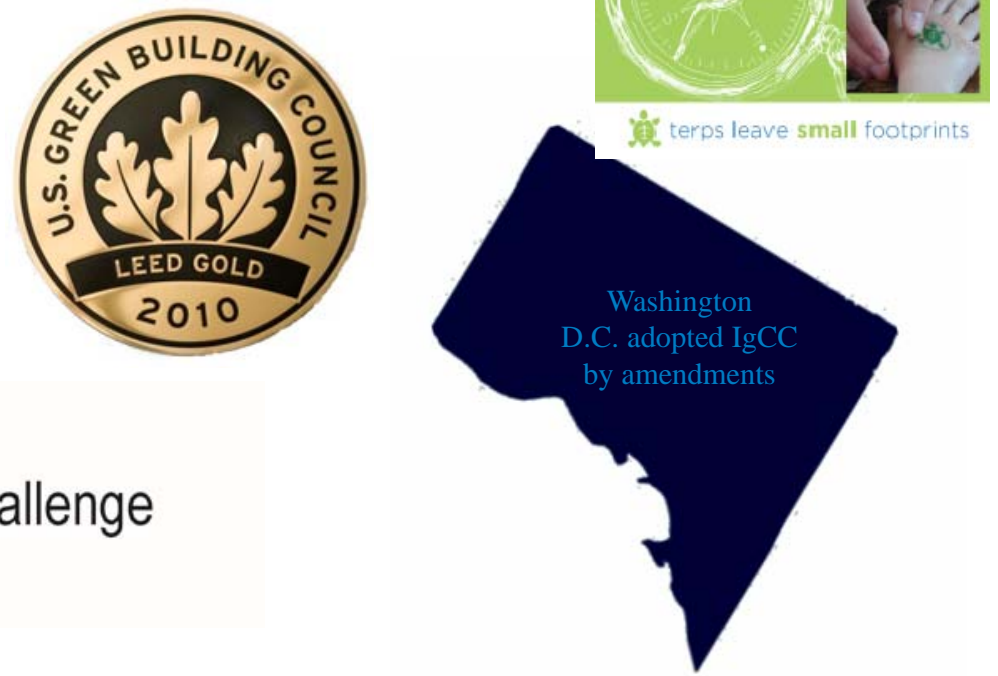


\title{
Challenges?
}

Various meanings and priorities for sustainability

Lack of client demand

High cost, low tangible benefits

Lack of awareness

Limited resources

Long-term commitment

Slow progress

\section{Opportunities}

\author{
Profitability,
}

Competitive Advantage,

Reduced liability and risk,

Employee satisfaction. 


\section{Questions?}

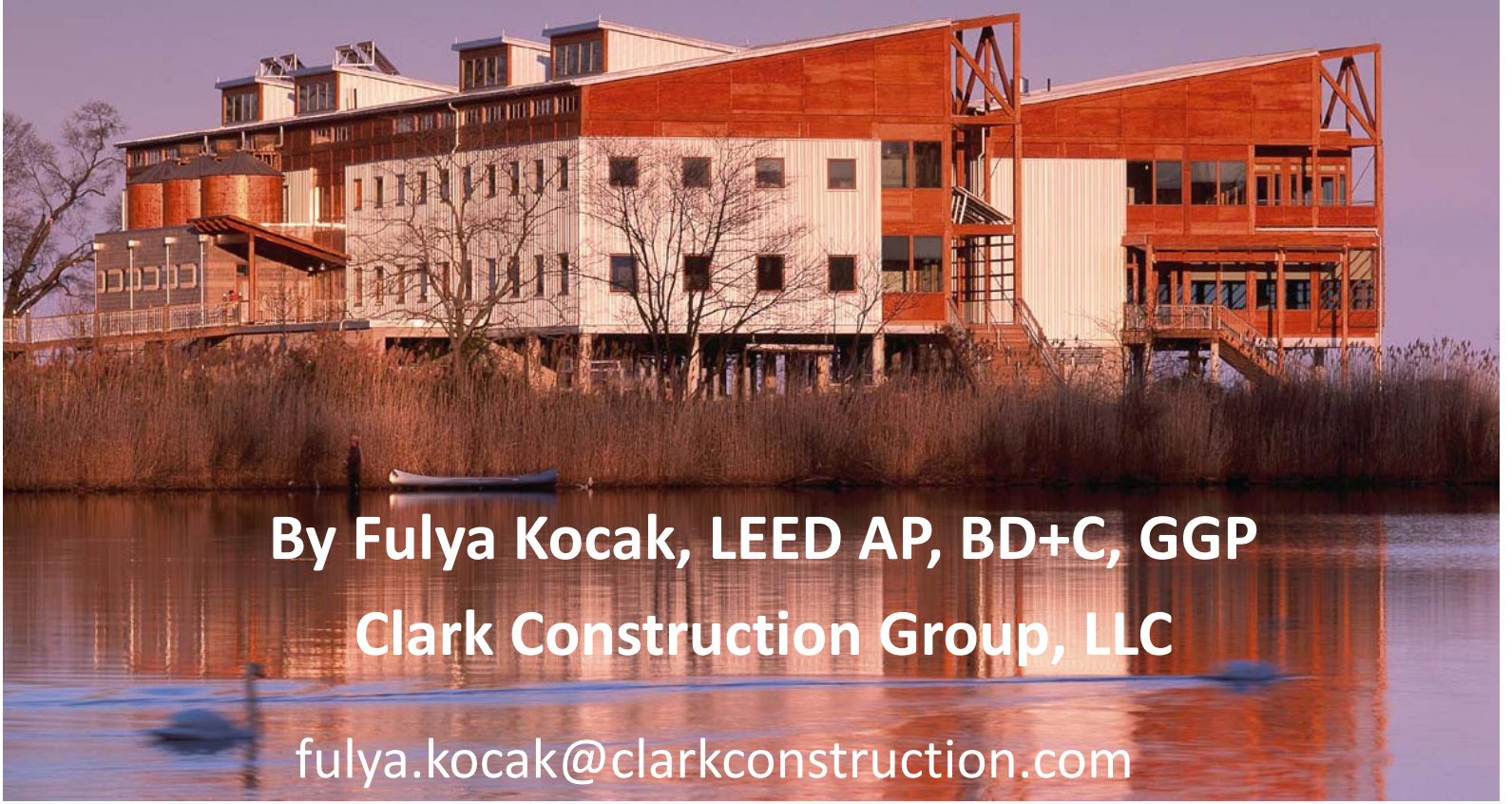




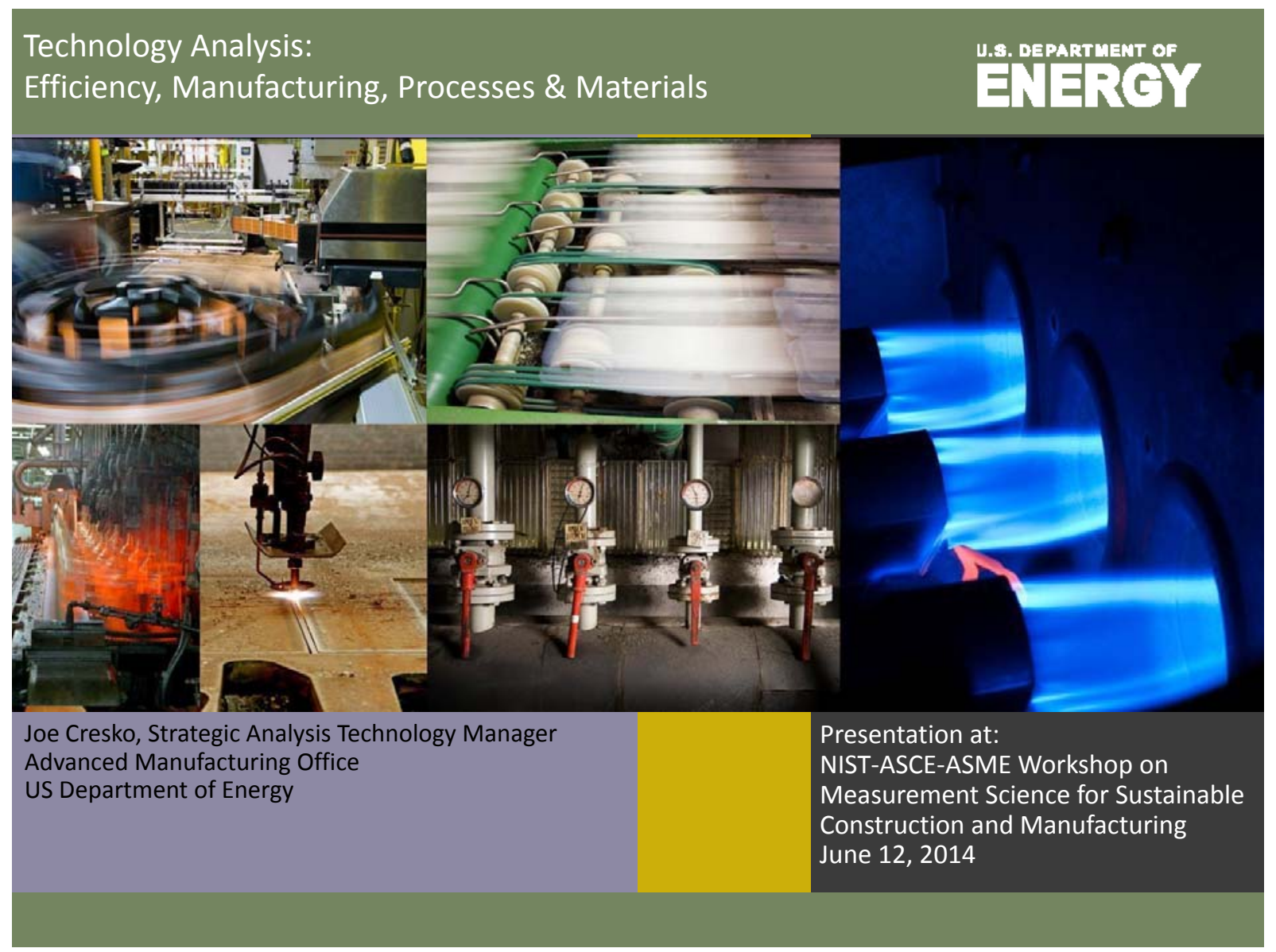

\section{United States Manufacturing Industry}

\section{Manufacturing industry}

- Constitutes $11 \%$ of GDP

- Employs 12 million people

- Employs $60 \%$ of engineers and scientists

- Accounts for $\sim 30 \%$ of primary energy consumption in the United States ${ }^{1}$

\section{AMO programs target:}

Primary TBtus per year of energy use

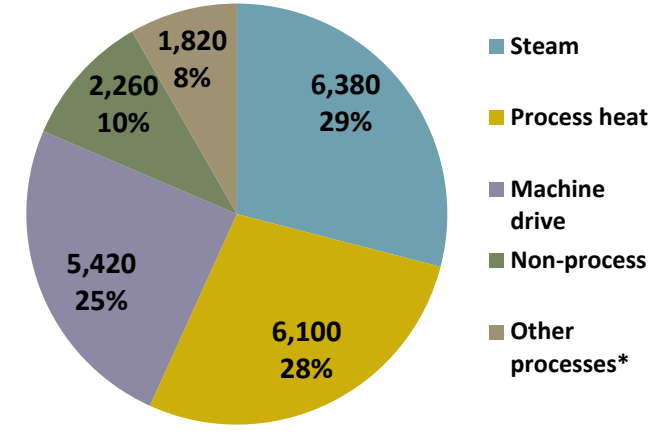

Source: Manufacturing Energy and Carbon Footprint, derived from 2006 MECS

- Research, Development and Demonstration of new, advanced processes and materials technologies that reduce energy consumption for manufactured products and enable life-cycle energy savings

- Efficiency opportunities through deployment of known technologies to existing manufacturing practices, especially for energy-intensive steam, process heating, and machine drive end-uses 


\section{Manufacturing and Advanced Manufacturing}

"The economic evidence is increasingly clear that a strong manufacturing sector creates spillover benefits to the broader economy, making manufacturing an essential component of a competitive and innovative economy."

Gene Sperling, Director of the National Economic Council

Remarks at the Conference on the Renaissance of American Manufacturing, March 27, 2012

"There is a close connection between R\&D and manufacturing in many of the emerging sectors $R \& D$ engineers may have to stay close to manufacturing to develop new strategies for making processes more efficient. The tighter integration of innovation and production may also present opportunities to bring design closer to end users, as advanced manufacturing technologies make it possible to produce higher-value goods at lower volume."

Professor Suzanne Berger, co-chair of MIT's Production in the Innovation Economy (PIE)

"Advanced Manufacturing involves both: new ways to manufacture existing products, and especially the manufacture of new products emerging from new advanced technologies."

President's Council of Advisors on Science and Technology,

"Report to the President on Ensuring America's Leadership in Advanced Manufacturing," June 2011

\section{Advanced Manufacturing and Clean Energy at DOE}

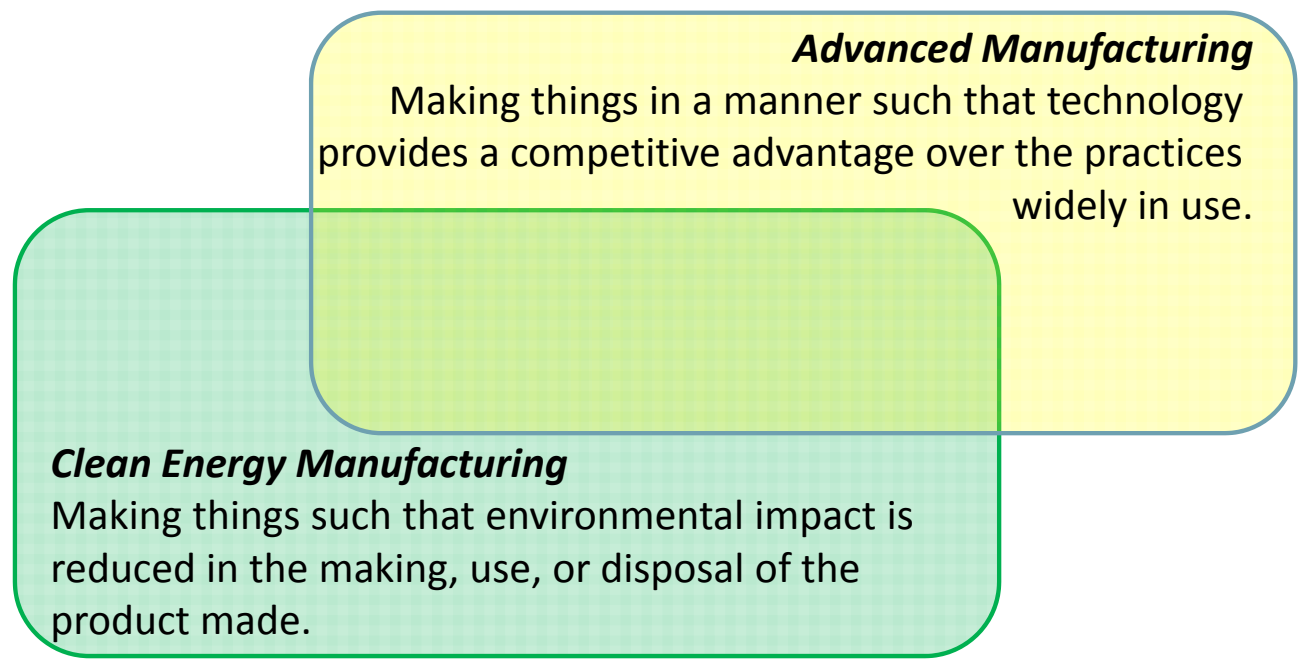


The "Missing Middle"

Target: Reduce life-cycle energy consumption of select manufactured products by $50 \%$ within 10 years of the start of each development effort

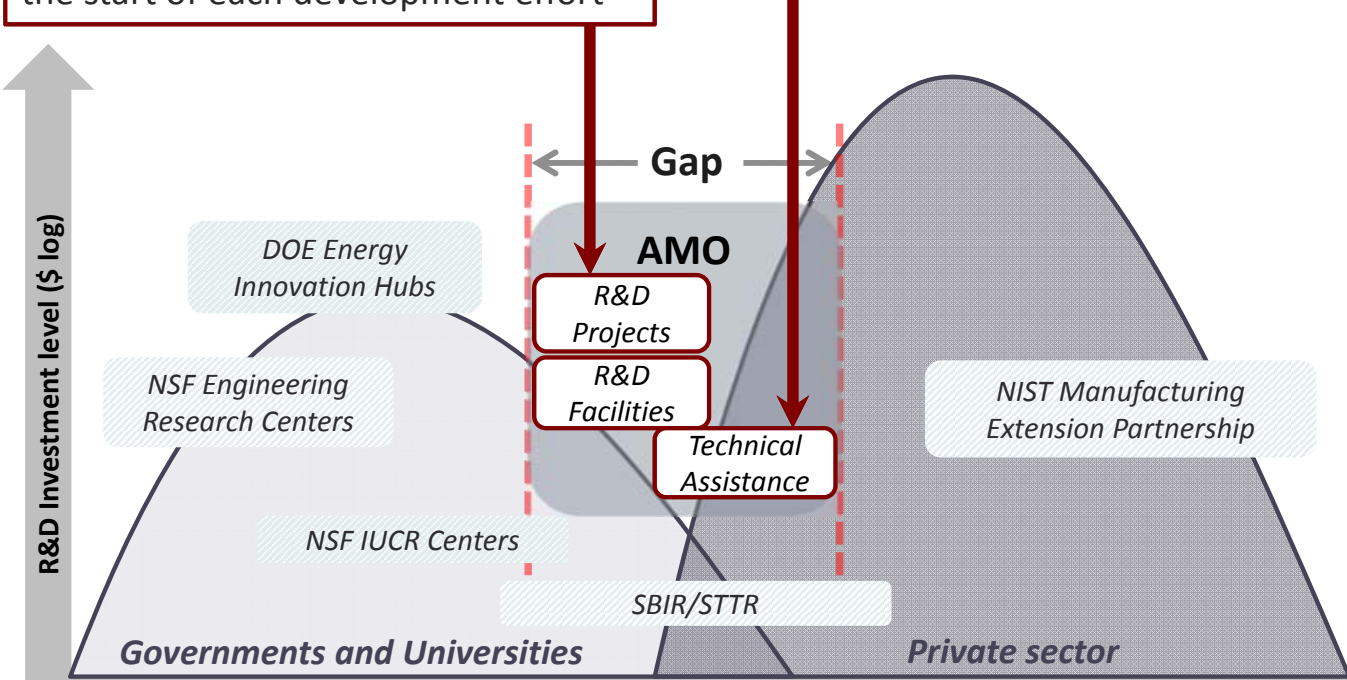

Technology Maturity (TRL; MRL; etc.)

Concept $\rightarrow$ Proof of Concept $\rightarrow$ Lab scale development $\rightarrow$ Demonstration and scale-up $\rightarrow$ Product Commercialization

- Leverage Federal support of basic research

-Partner with the private sector to accelerate commercialization

\section{Advanced Manufacturing Office - focus on Technologies}

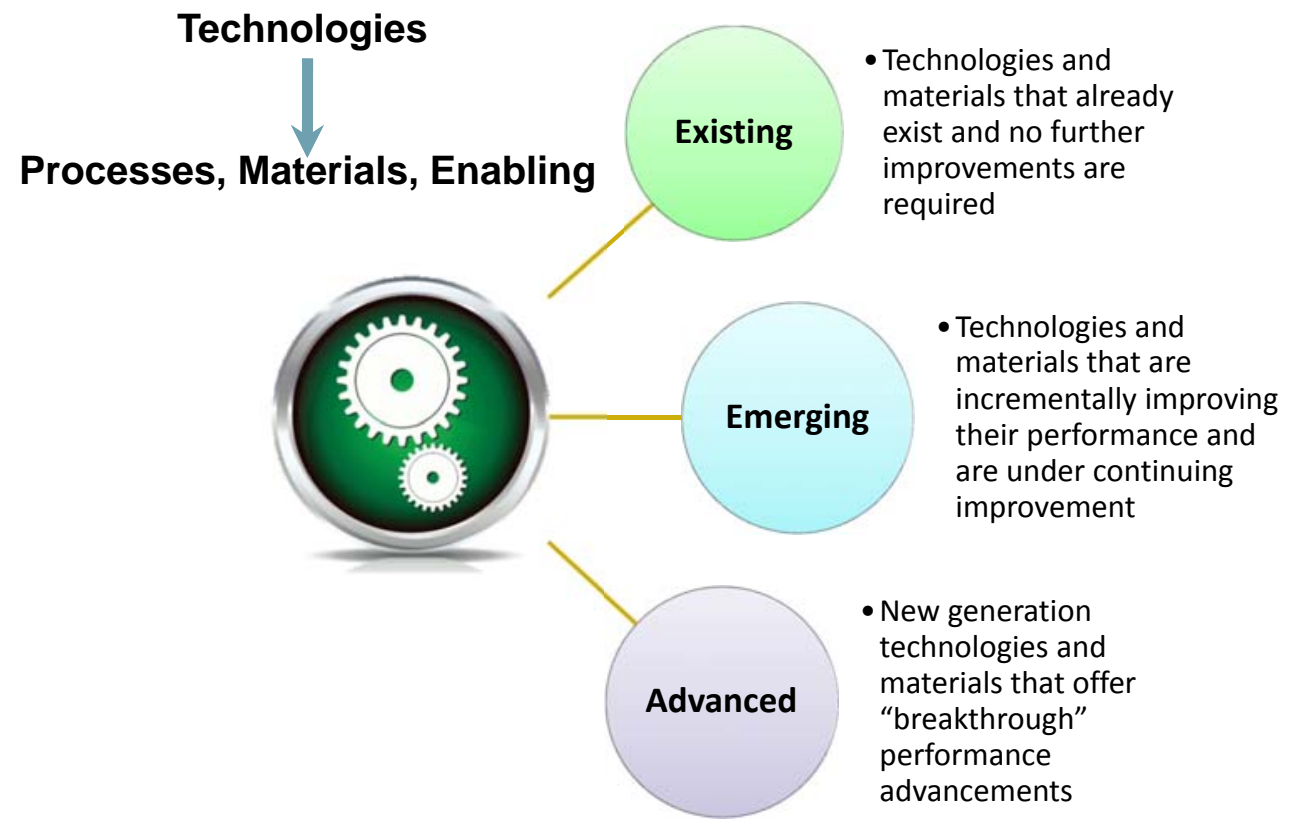




\section{Advanced manufacturing and supply chains}

What is Advanced Manufacturing?
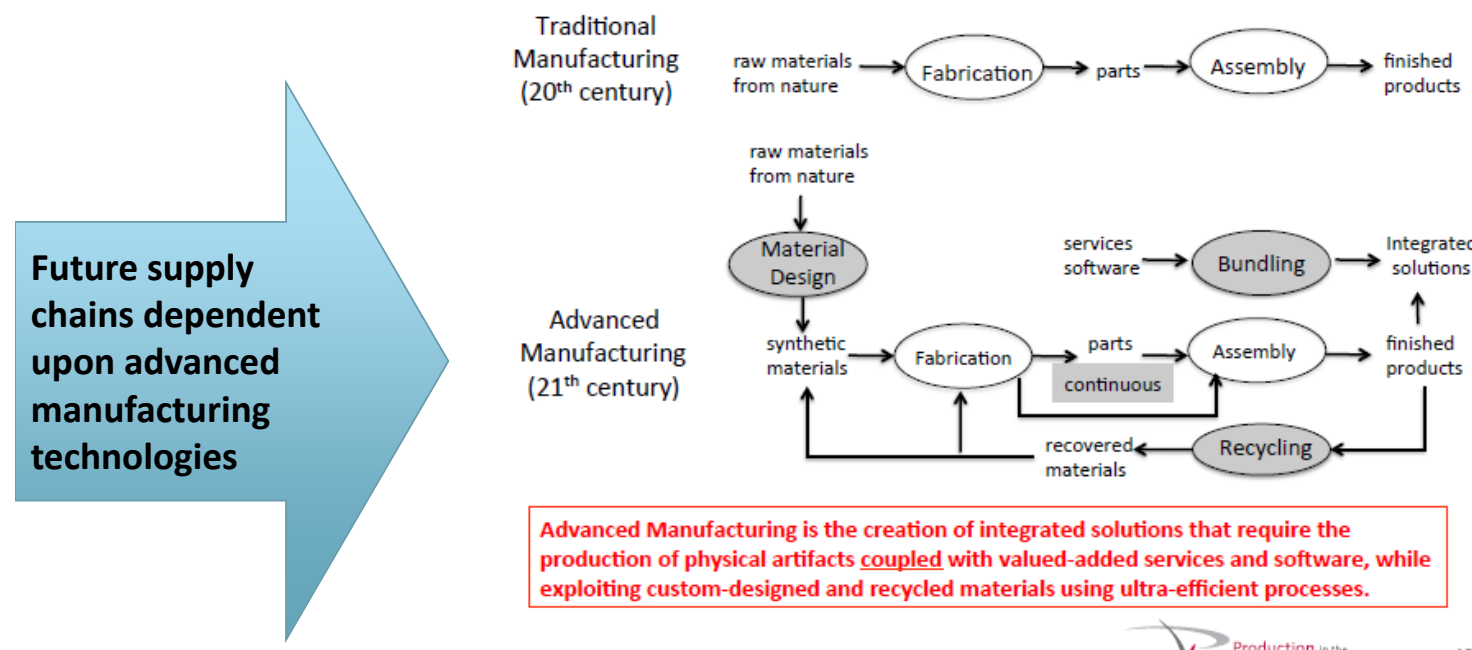

Manufacturing (21 $1^{\text {th }}$ century)

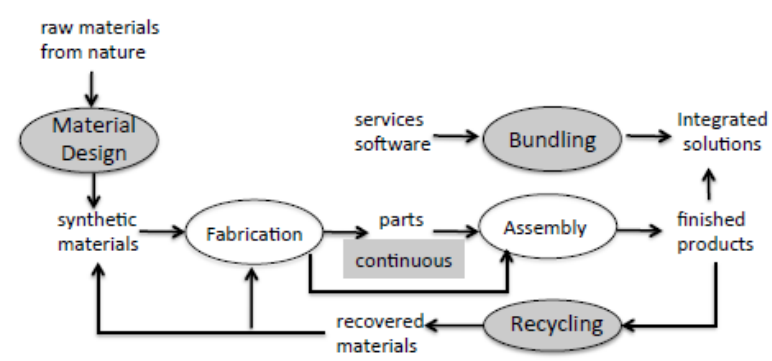

Advanced Manufacturing is the creation of integrated solutions that require the

production of physical artifacts coupled with valued-added services and software, while exploiting custom-designed and recycled materials using ultra-efficient processes.

Production inche

\section{Supply chains and U.S. manufacturing competitiveness}

\section{EERE's Clean Energy Manufacturing Initiative (CEMI):}

1. Increase U.S. competitiveness in the production of clean energy products

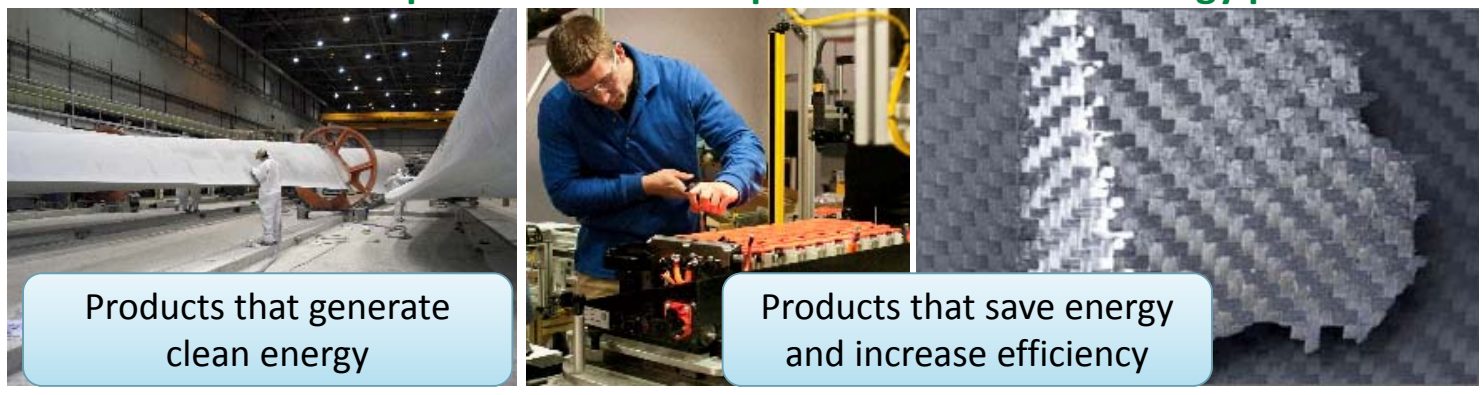

2. Increase U.S. manufacturing competitiveness across the board by increasing energy productivity and use of clean and low-cost fuels and feedstocks

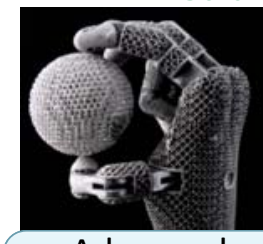

Advanced Manufacturing Technologies

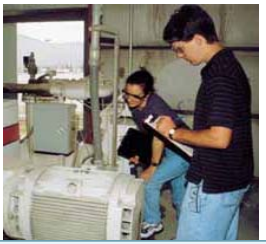

Industrial Energy Efficiency

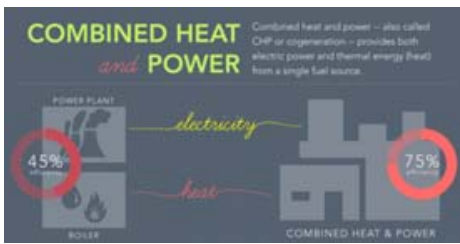

Combined Heat \& Power

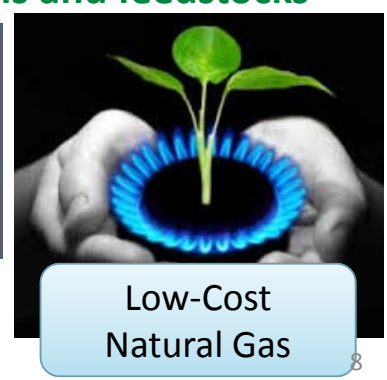




\section{Drivers affecting US Manufacturing}

“.......natural gas is likely to remain 50 to 70 percent cheaper in the U.S. than in Europe and Japan ..."

Boston Consulting Group analysis

Shale gas production has more than doubled since January 2010.

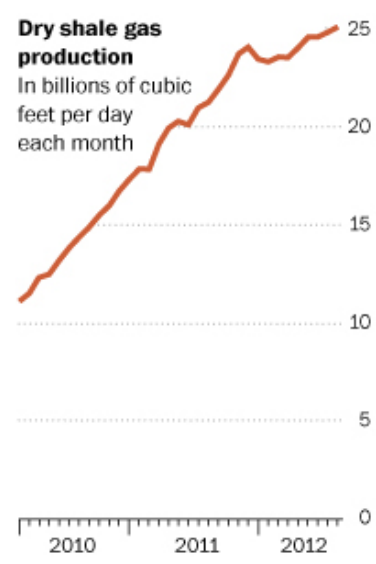

0

This has helped increase overall U.S. natural gas production, despite flat to declining production in traditional gas fields. In the future, shale gas is expected to play an even bigger role.

U.S. natural gas production

In trillions of cubic feet per year by type of gas*
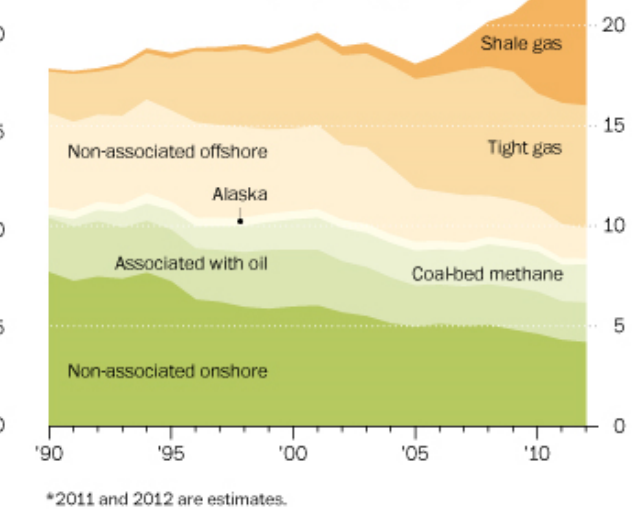

Natural gas wellhead prices crashed in April. They have recovered somewhat but remain near the lowest level in the past decade.

\section{U.S. natural gas}

wellhead prices

In dollars per thousand

cubic feet

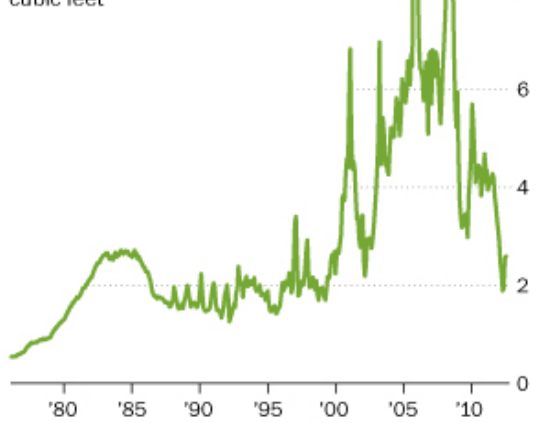

\section{Evaluating US Manufacturing competitiveness}

\section{Solar, wind batteries, carbon fiber, WBG semiconductors}

1. Characterize the current industry structure (develop a benchmark)

2. Map the value stream

3. Develop a high-level understanding of manufacturing cost drivers

4. Identify areas where the United States has (or may have) viable manufacturing opportunities

5. Select technologies for analytical "deep dive"

- Refine market analysis

- Develop cost models

- Assess qualitative factors driving factory location decisions

Regional carbon fiber reinforced plastics market values (billion \$/\# mfg. sites)

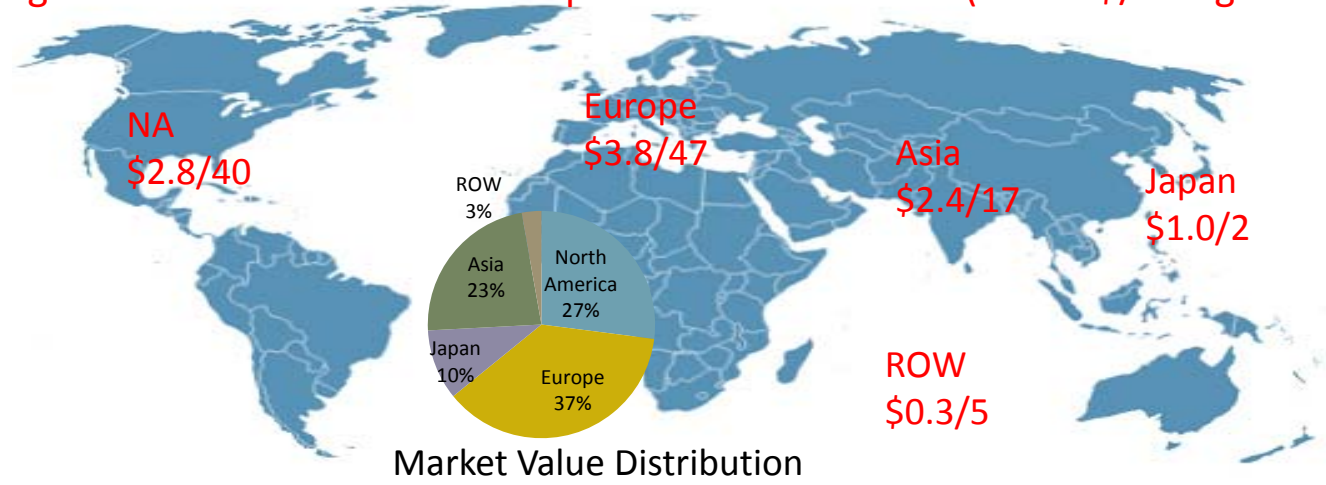




\section{Evaluating competitiveness starts with technologies}

\section{AMO targets investments in high impact technologies}

- Transformative: Results in significant change in the life-cycle impact (energetic or economic) of manufactured products

- Pervasive: Creates value in multiple supply chains, diversifies the end use/markets, applies to many industrial/use domains in both existing and new products and markets

- Globally Competitive: Represents a competitive/strategic capability for the United States

- $\quad$ Significant in Clean Energy Industry: Has a quantifiable energetic or economic value (increase in value-added, increase in export value, increase in jobs created)

\section{Wide range of metrics}

\begin{tabular}{|c|c|c|c|c|}
\hline $\begin{array}{c}\text { Relevant } \\
\text { Technology } \\
\text { Characteristics }\end{array}$ & $\begin{array}{l}\text { High level drivers: } \\
\text { Enabling? } \\
\text { Add-value? } \\
\text { Add quality? } \\
\text { Reduce energy use? } \\
\text { Reduce materials waste? } \\
\text { Improve production speed? } \\
\text { Others? }\end{array}$ & \multicolumn{3}{|c|}{$\begin{array}{l}\text { More detailed metrics: } \\
\text { Production volume (units per year) } \\
\text { Process cycle time (time per unit) } \\
\text { Percent cost reduction (relative to current) } \\
\text { Percent weight reduction (relative to current) } \\
\text { Energy cost savings target? } \\
\text { Others? }\end{array}$} \\
\hline Barriers & \multicolumn{3}{|c|}{$\begin{array}{l}\text { Technology risks/uncertainties } \\
\text { Availability of verifiable testing capabilities } \\
\text { High capital cost } \\
\text { High material cost } \\
\text { Material supply chain insecurity } \\
\text { Lack of customer demand }\end{array}$} & $\begin{array}{l}\text { Technical limitations } \\
\text { Lack of knowledge } \\
\text { Insufficient tools } \\
\text { Workforce availability } \\
\text { Other? }\end{array}$ \\
\hline $\begin{array}{c}\text { Existing } \\
\text { Approaches }\end{array}$ & \multicolumn{2}{|c|}{$\begin{array}{l}\text { Internal assets (R\&D; technology } \\
\text { experts, etc.) } \\
\text { Consultants } \\
\text { Commercial labs } \\
\text { Technology vendors }\end{array}$} & \multicolumn{2}{|c|}{$\begin{array}{l}\text { Universities } \\
\text { Shared R\&D facility (capable of } \\
\text { precompetitive and protected work) } \\
\text { Other? }\end{array}$} \\
\hline
\end{tabular}




\section{Life cycle approach to better understand system-wide impacts}

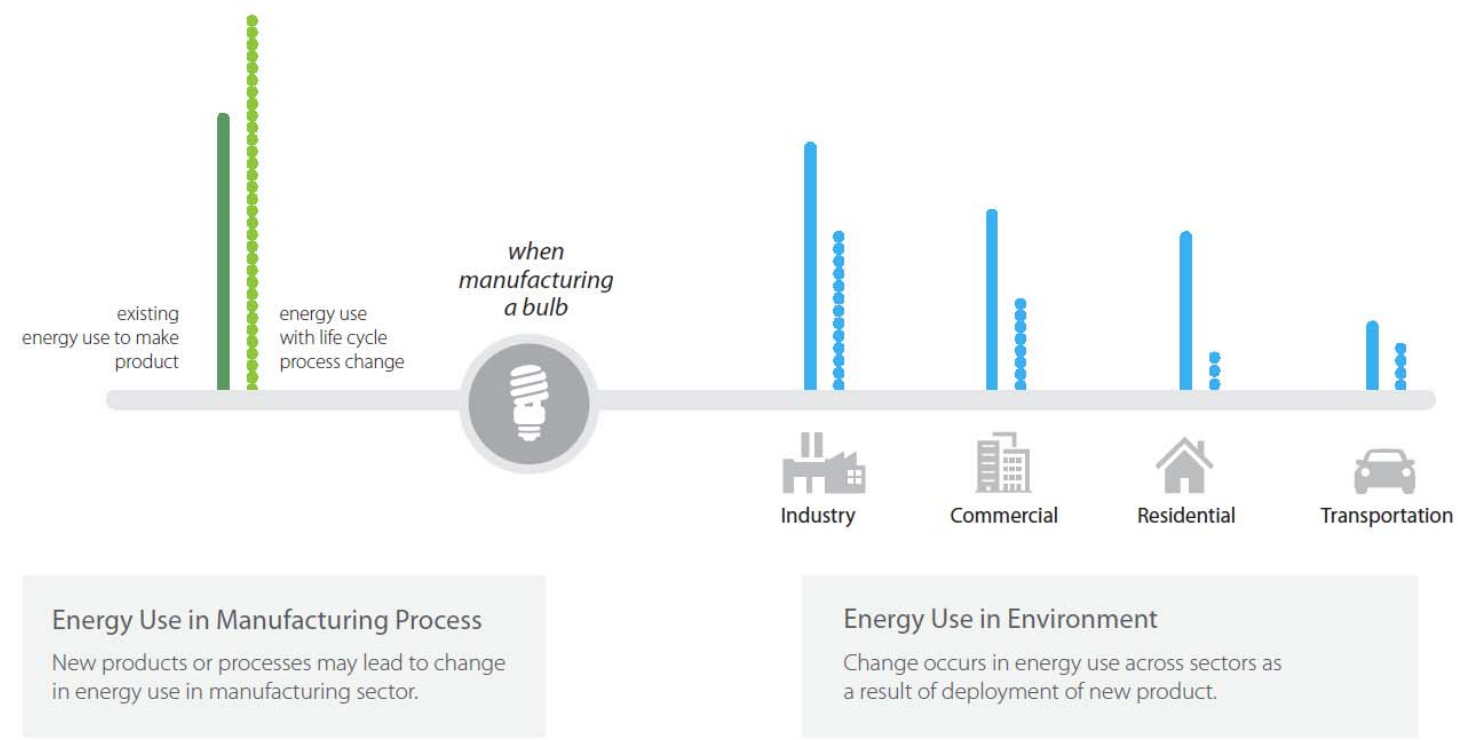

\section{Flow of Energy through the U.S. Economy}

Estimated U.S. Energy Use in 2012: 95.1 Quads

Lawrence Livermore National Laboratory

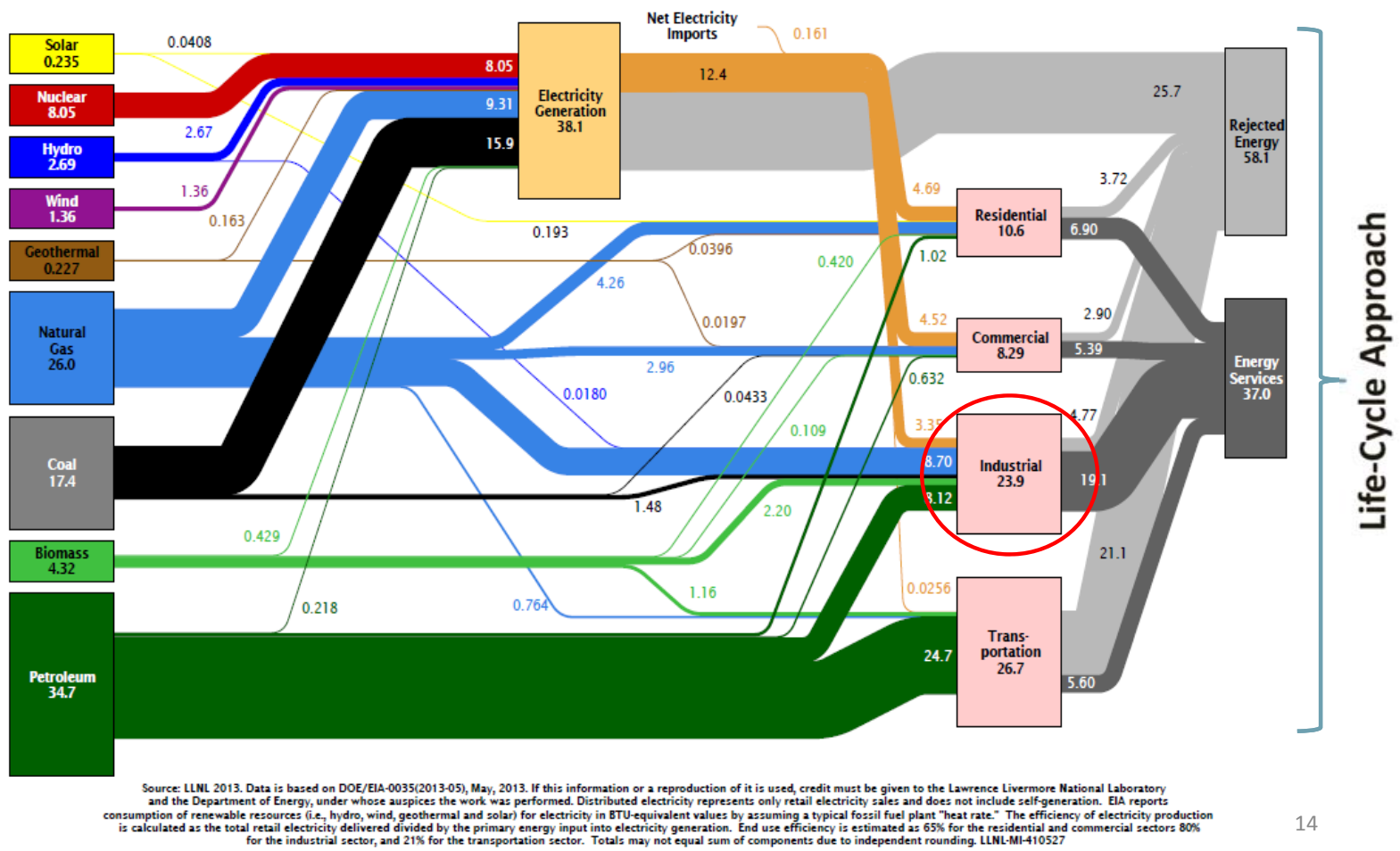




\section{The opportunity space: economy-wide energy impacts resulting from clean energy manufacturing.}

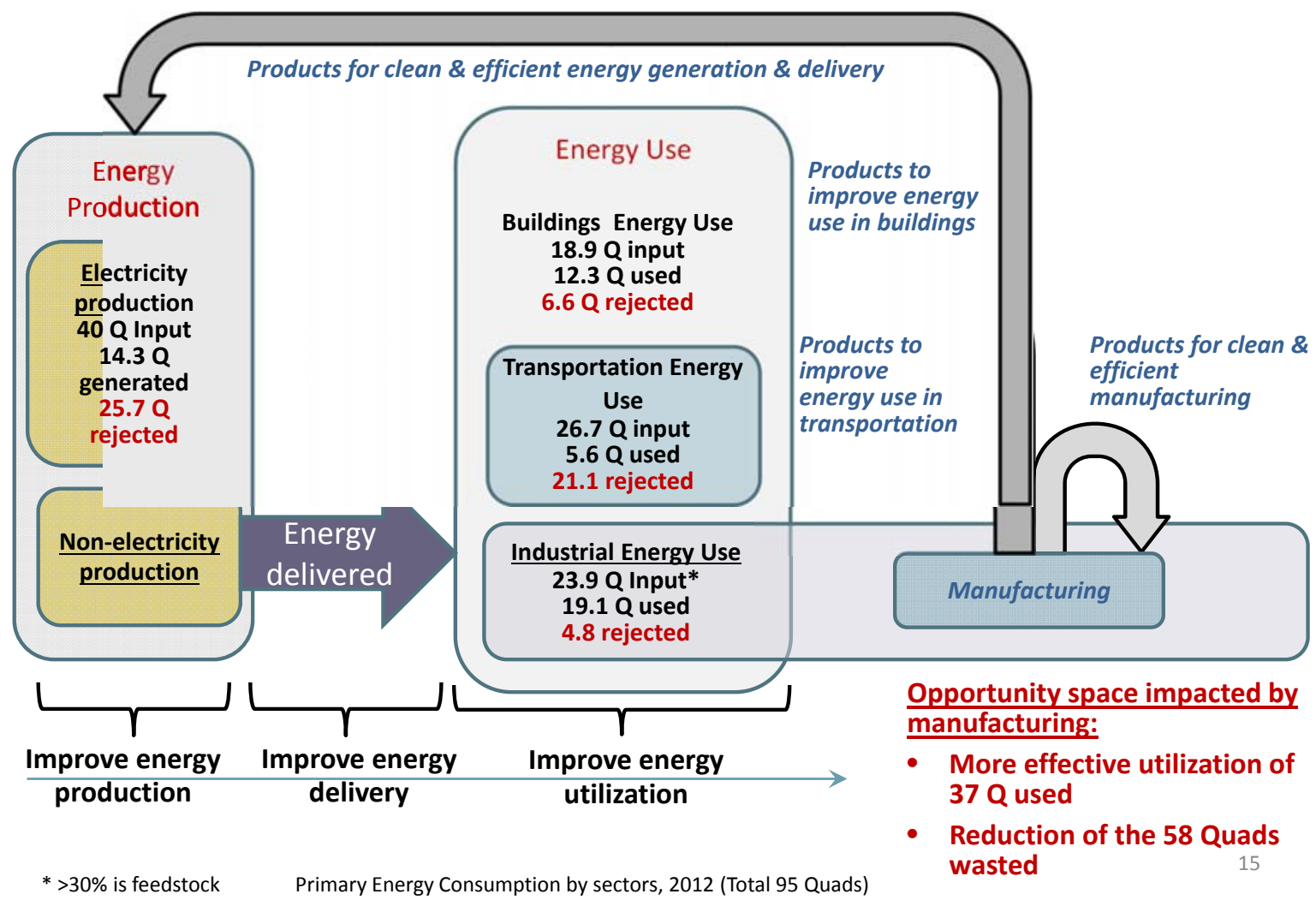

\section{Systems Approach - What affects the system?}

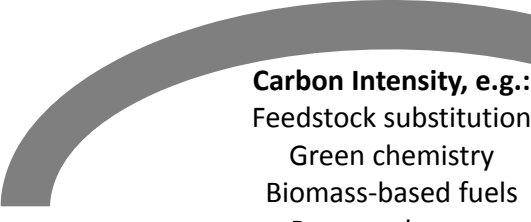

Process changes

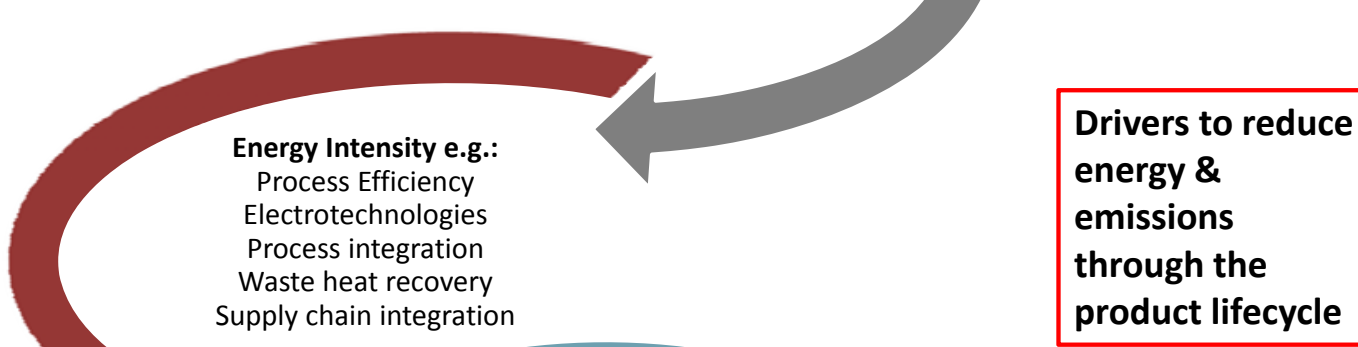

Use Intensity e.g.:

Recycling

Reuse and remanufacturing Material efficiency and substitution

By-products

Behavioral change

Product-Service-Systems 


\section{Where do we start? Energy data...}

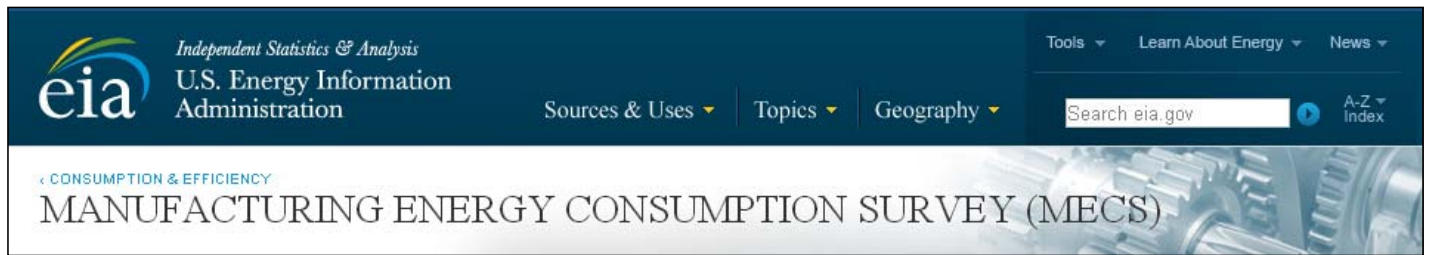

- National sample survey that collects information on the stock of U.S. manufacturing establishment, their energy-related building characteristics, and their energy consumption and expenditures.

- 250,000 U.S. manufacturing plants

- Statistical sample of approximately 15,500 establishments are surveyed representing $97 \%$ - $98 \%$ of U.S. manufacturing payroll and energy consumption

- MECS data released every four years

- Past footprints $(1998,2002,2006)$

- Current footprint (2010)

\section{Fuel End Use by Sector}

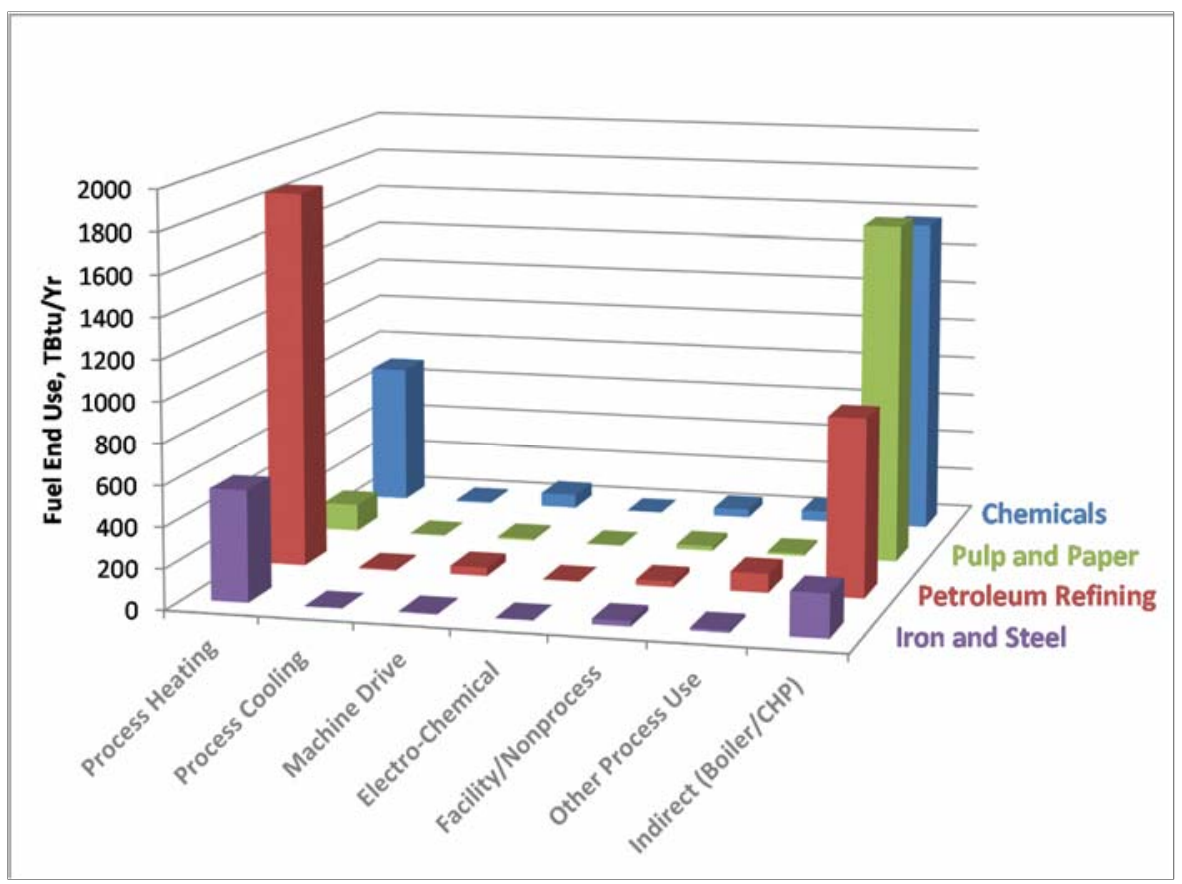




\section{Electrical End Use by Sector}

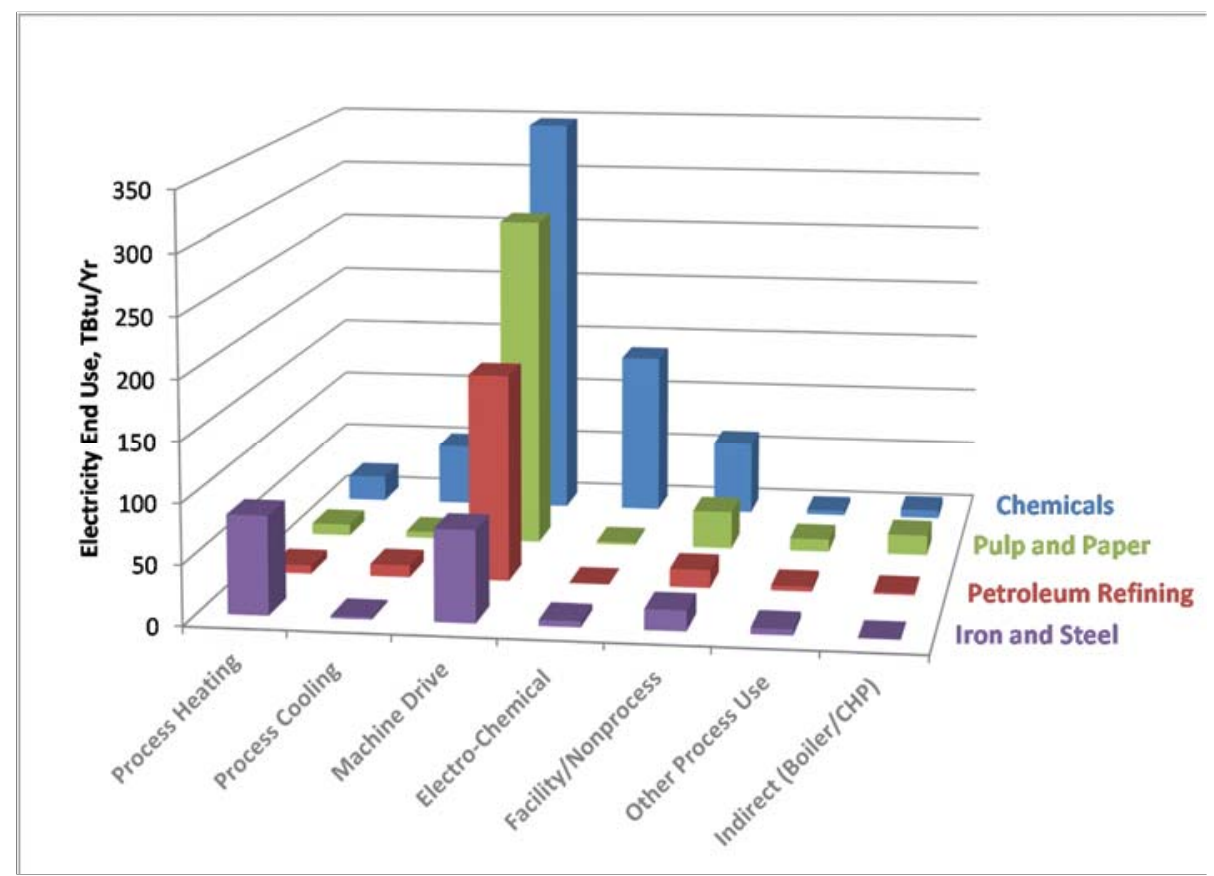

\section{Economy-wide lifecycle energy impacts - starts with technology}

- Identify opportunities for manufacturing impacts in clean energy production and use.

- Target timely, high-impact, foundational clean energy technologies with the potential to transform energy use and accelerate their introduction into the US economy.

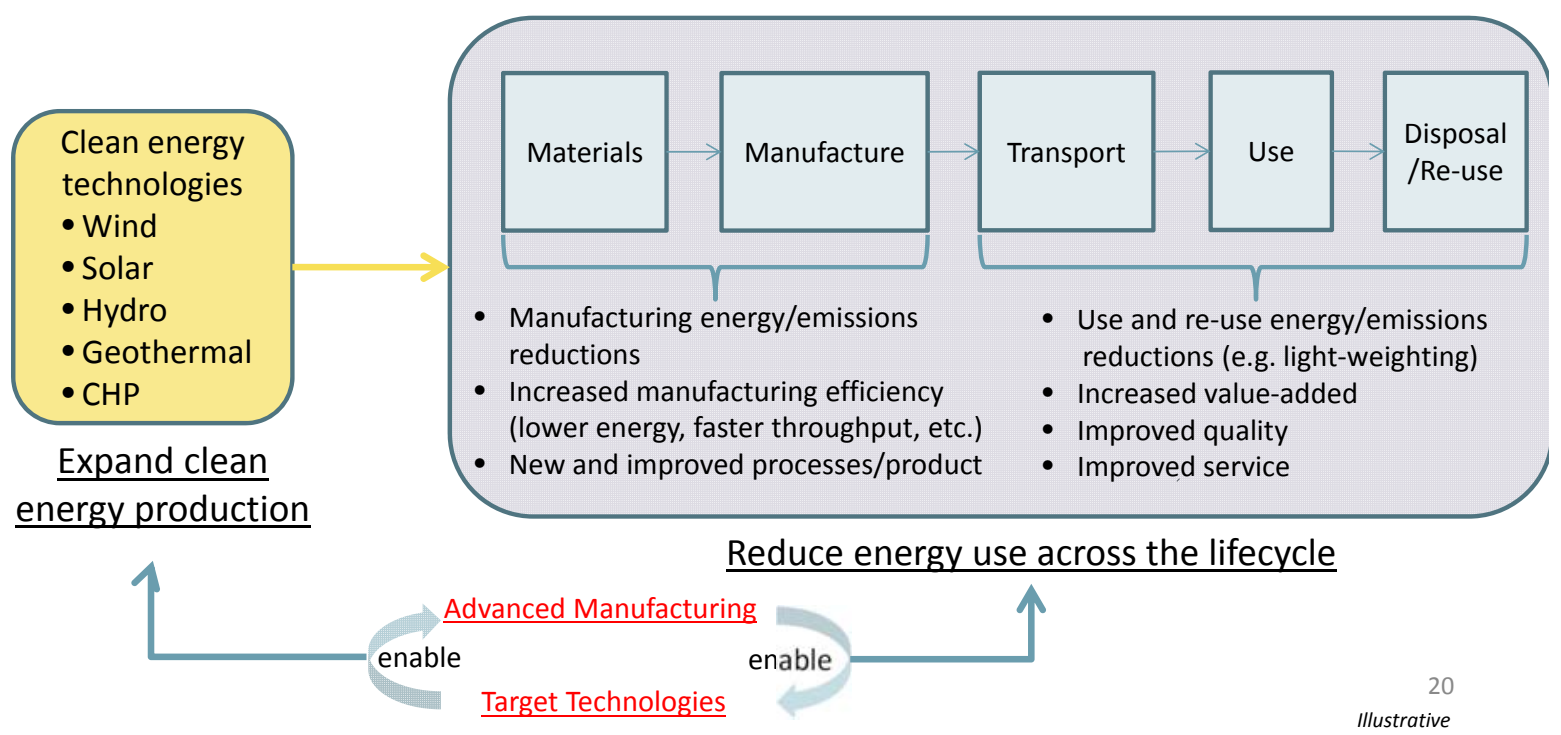




\section{Economy-wide lifecycle energy impacts - starts with technology}

- Identify opportunities for manufacturing impacts in clean energy production and use.

- Target timely, high-impact, foundational clean energy technologies with the potential to transform energy use and accelerate their introduction into the US economy.

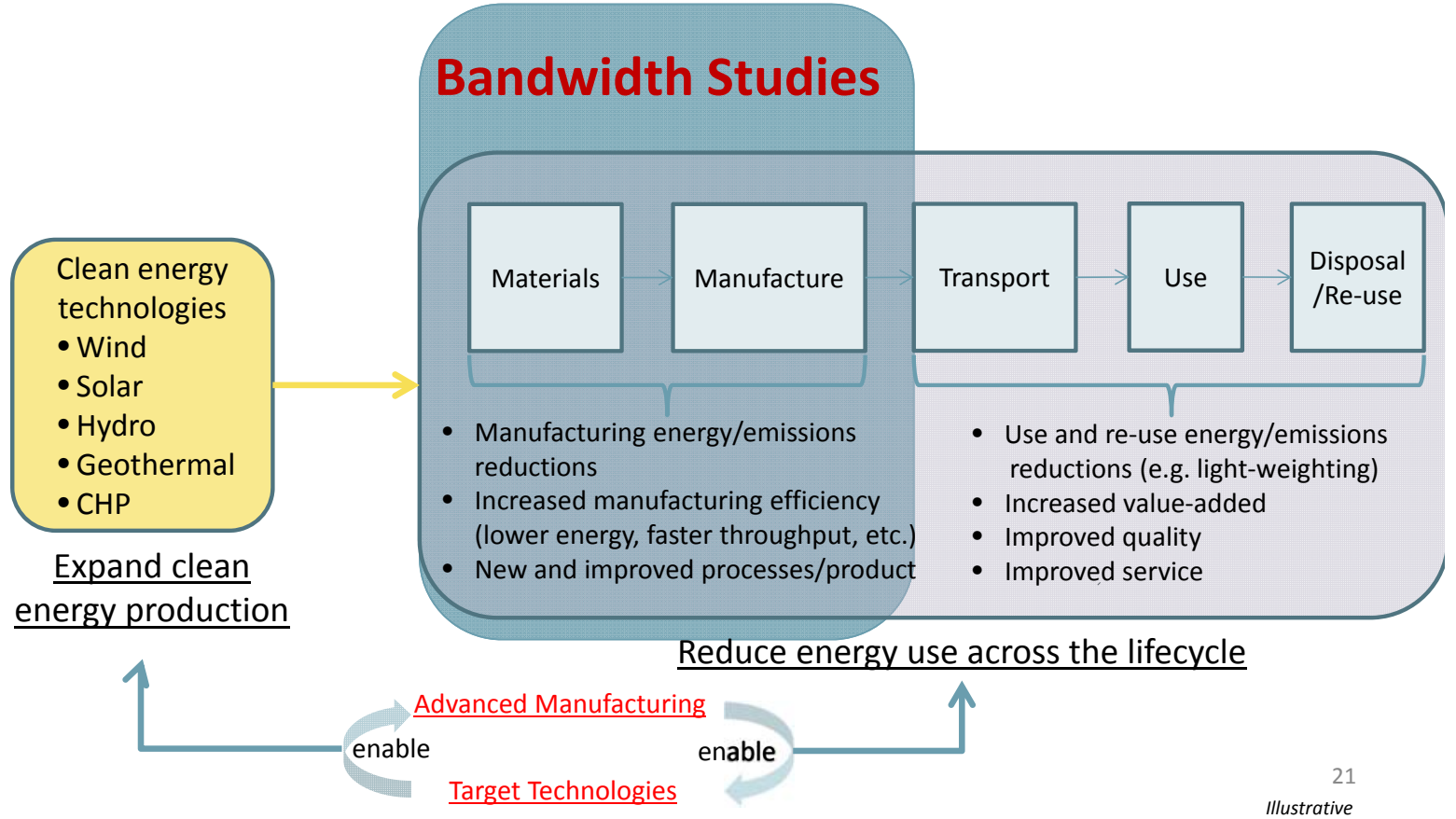

\section{Chemical Bandwidths - CA, SOA, PM and TM}

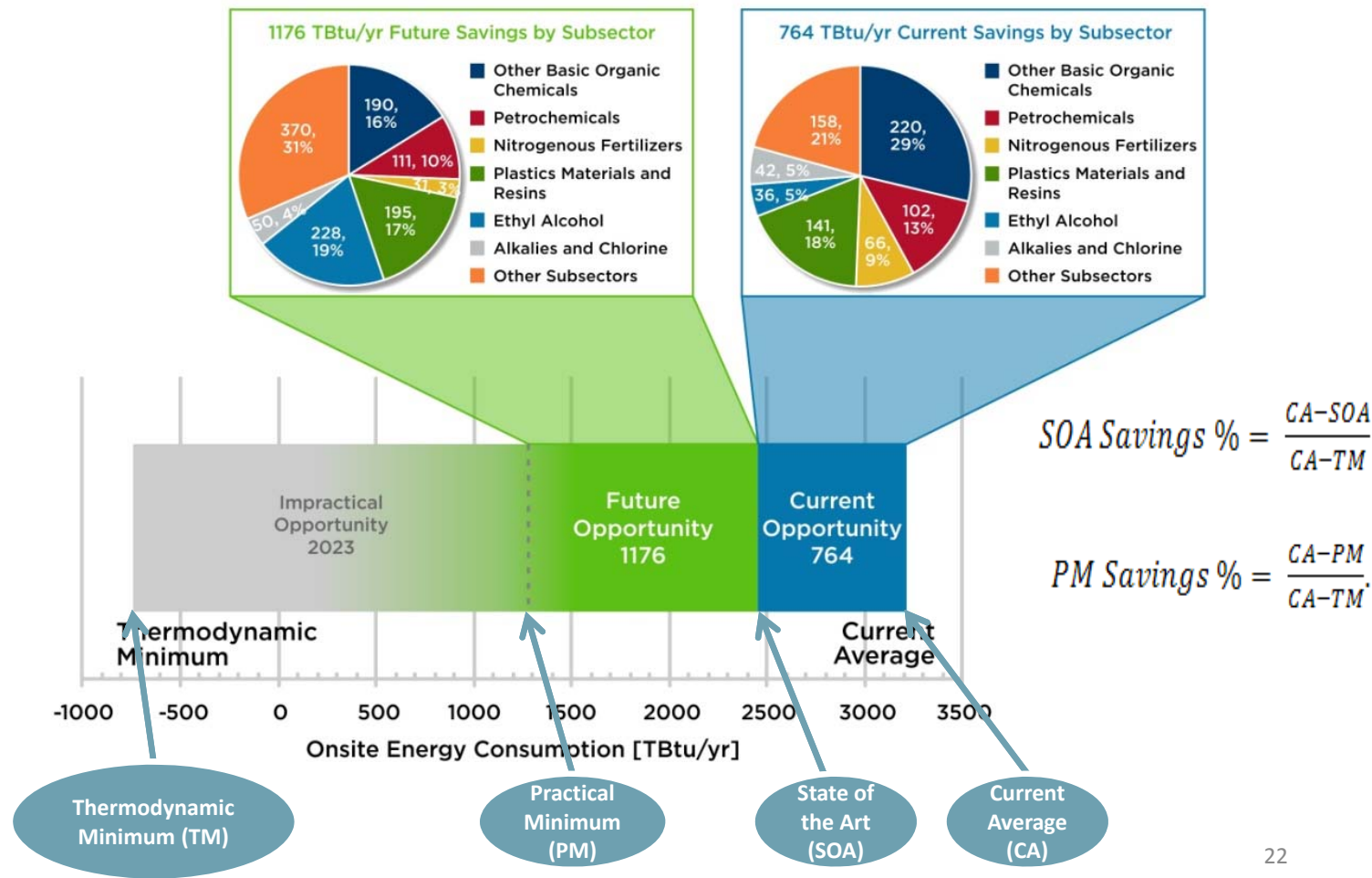


I would like to show the single pie chart first, maybe start with one generic colored pie labeled Current Savings by Process Area with Process Area 1, Process Area 2...thru 6.

Then show the bar showing generic current opp, future opp, impr opp, no numbers in generic version.

Finally link the two pies with the bar, maybe animation showing connecting expansion lines.

All generic, no sector, no numbers. You can just use one of existing to mock up numbers. Sabine Brueske, 5/18/2014

\section{Energy Intensive Industries - Bandwidths}

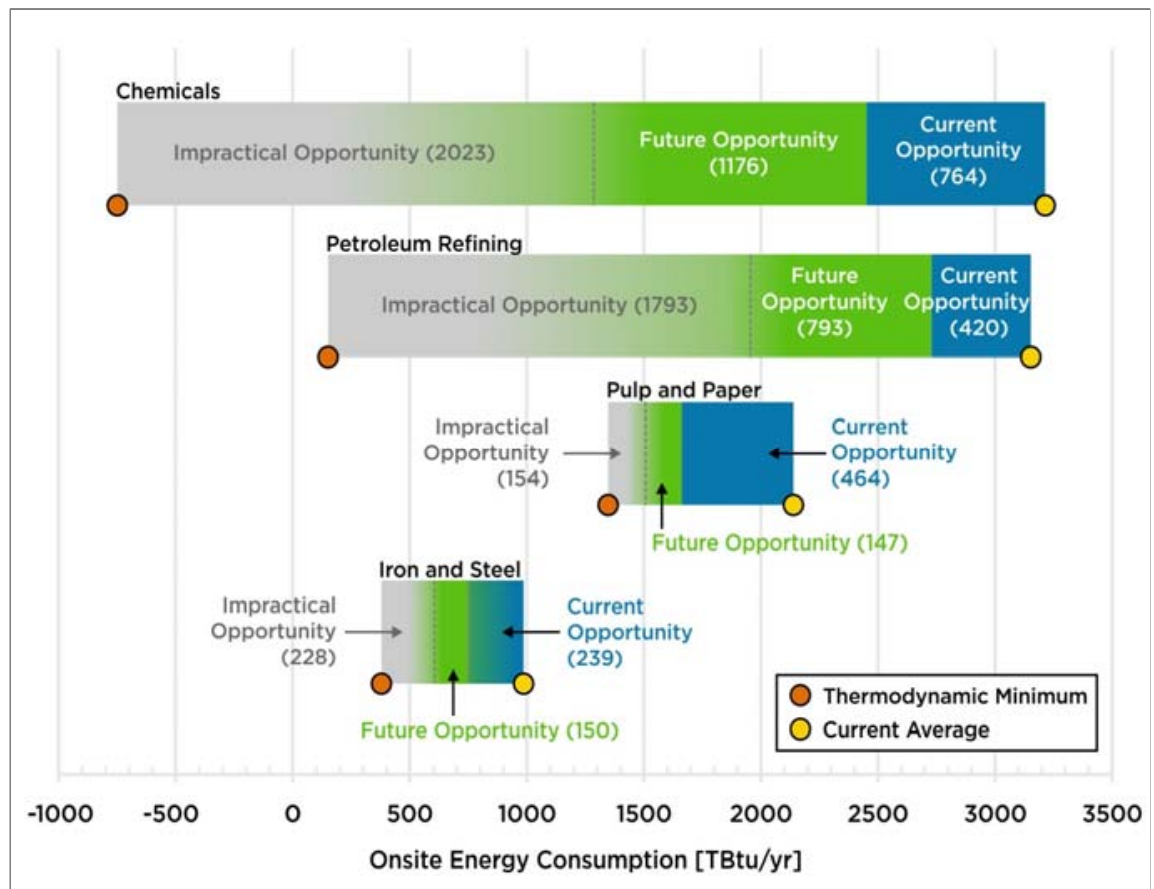




\section{Expanding the perspective... Materials Flows through Industry (MFI)}

Aluminum Materials Flows - U.S. and Carada, 2009 Billions of Pounds

\begin{tabular}{|c|c|c|}
\hline btu/b & primary & secondary \\
\hline $\begin{array}{l}\text { Current } \\
\text { average }\end{array}$ & $\begin{array}{c}26,000 \\
\square\end{array}$ & 2,200 \\
\hline $\begin{array}{l}\text { Practically } \\
\text { achievable }\end{array}$ & 20,000 & 925 \\
\hline $\begin{array}{l}\text { Current } \\
\text { savings } \\
\text { potential }\end{array}$ & $\begin{array}{l}\text { 5,000 btu/lb } \\
\text { Process } \\
\text { IImprovement }\end{array}$ & 1,275 \\
\hline $\begin{array}{l}\text { Theeretical } \\
\text { minimum }\end{array}$ & 10,200 & 510 \\
\hline
\end{tabular}

Ker Opportunities:
A. Materials shift - Technologies to enable increase in
secondary aluminum use by manufacturing sector.
B. End-of-lifo shift - Technologies to enable greater
capture and use of 7.6 billion pounds aluminum (llandfill
+ scrap export).
C. Process Improvements-Technologles to Improve
primary aluminum processing.
Now opportunities throughout the system-in materials
design, product design, manufacturing, use and re-use.

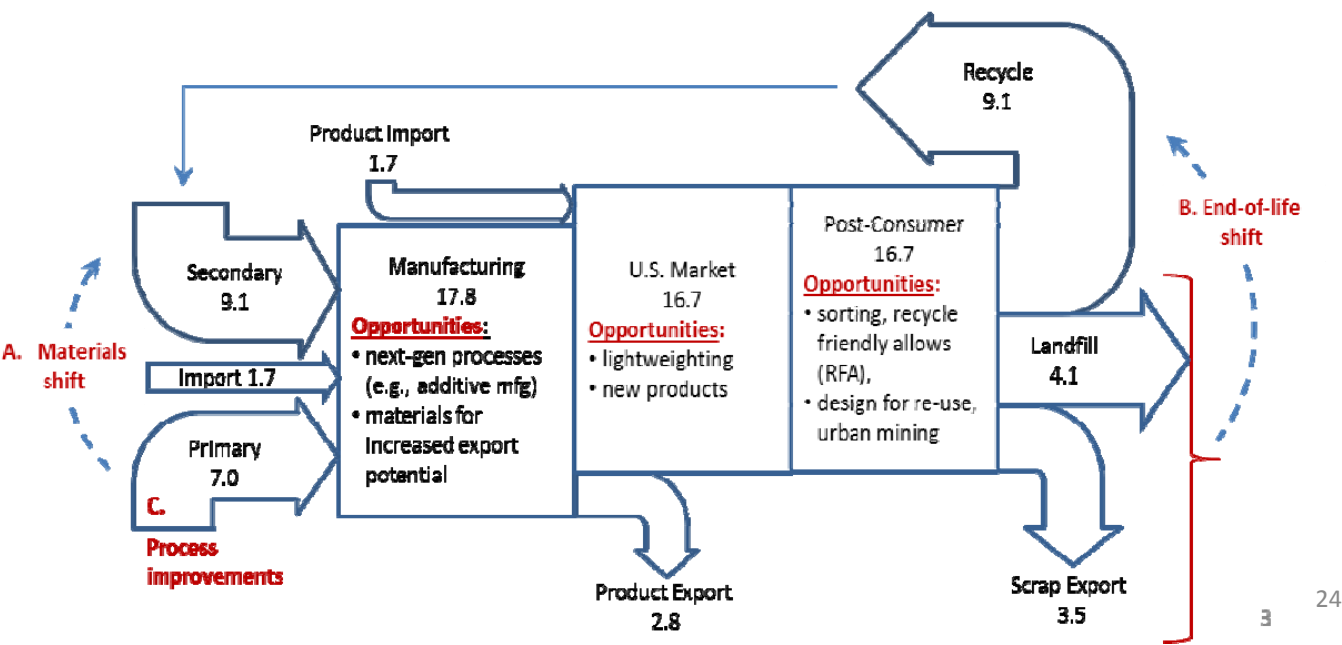

\section{Economy-wide lifecycle energy impacts - starts with technology}

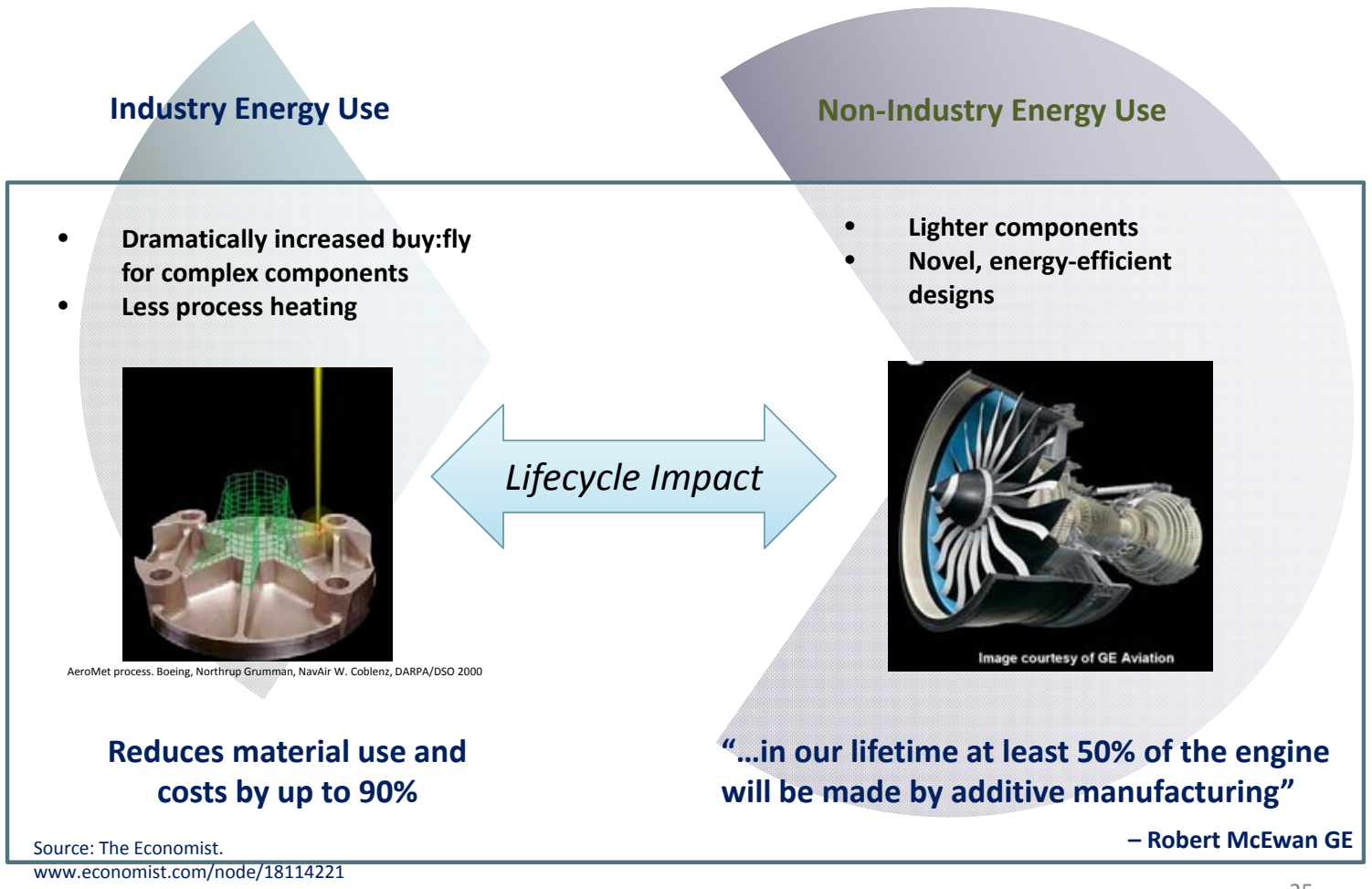




\section{Economy-wide lifecycle energy impacts - continues with technology}

- Identify opportunities for manufacturing impacts in clean energy production and use.

- Target timely, high-impact, foundational clean energy technologies with the potential to transform energy use and accelerate their introduction into the US economy.

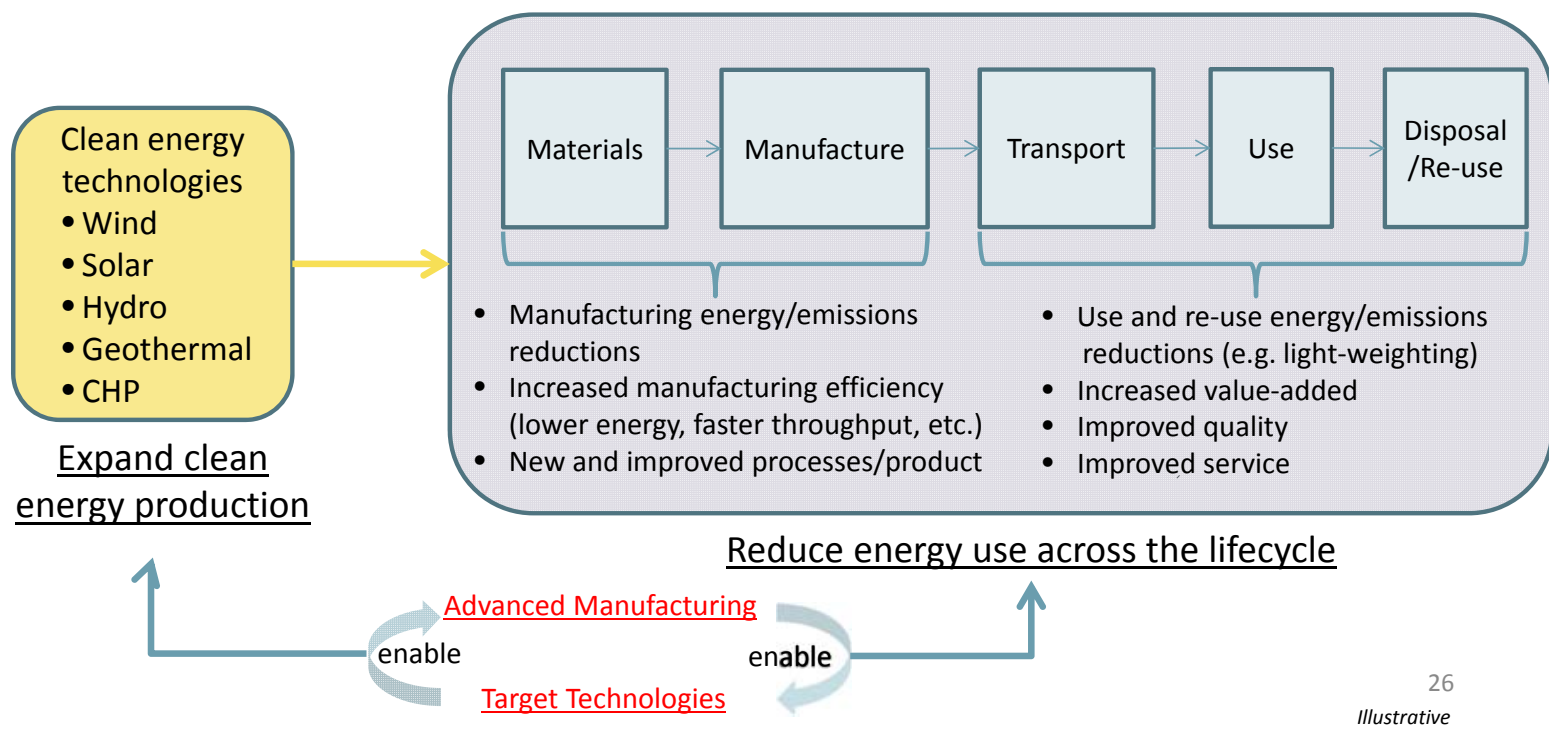

\section{Economy-wide lifecycle energy impacts - continues with technology}

- Identify opportunities for manufacturing impacts in clean energy production and use.

- Target timely, high-impact, foundational clean energy technologies with the potential to transform energy use and accelerate their introduction into the US economy.

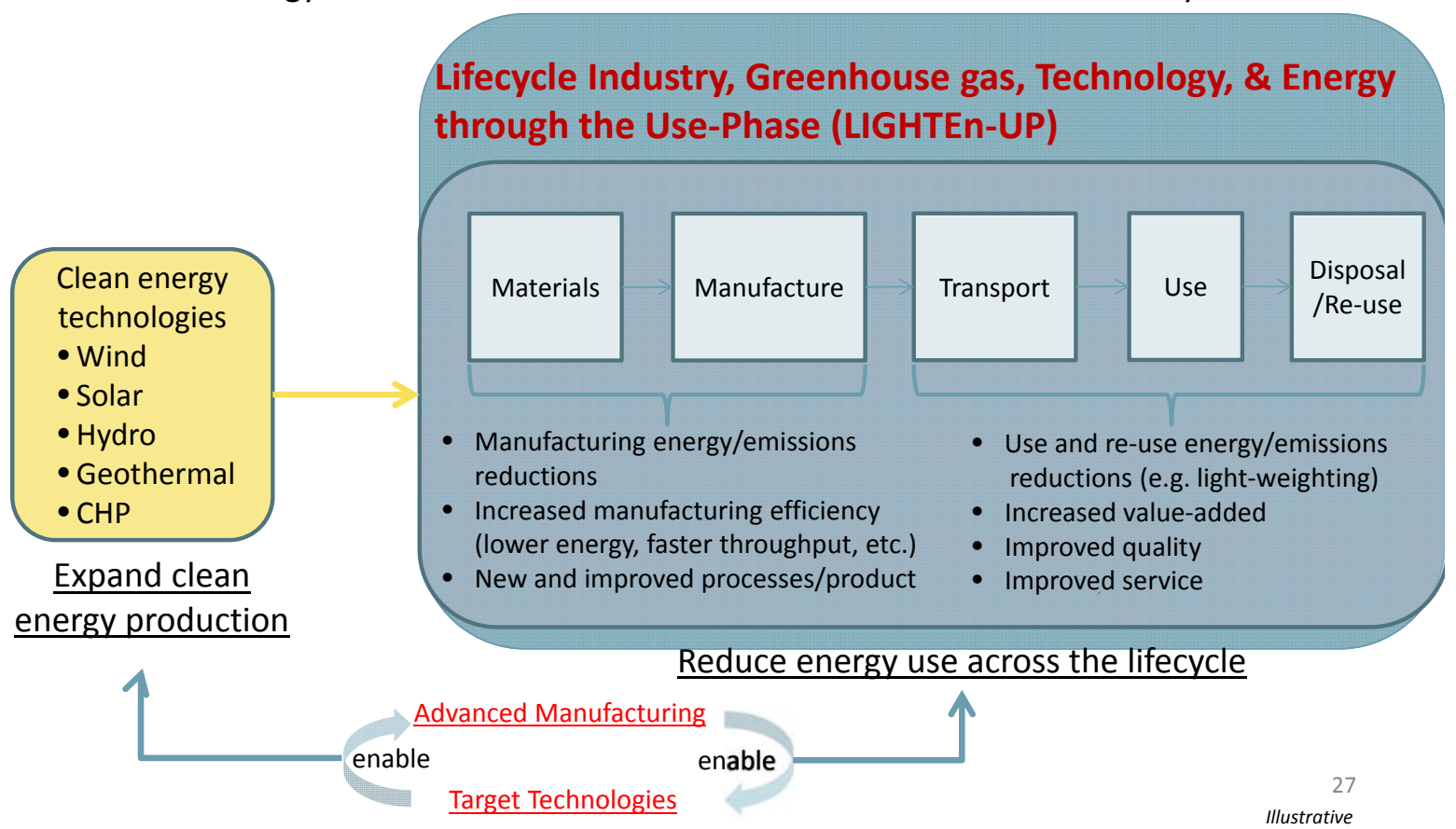




\section{LIGHTEn-UP Tool - Publically Available U.S. Energy Consumption Data}

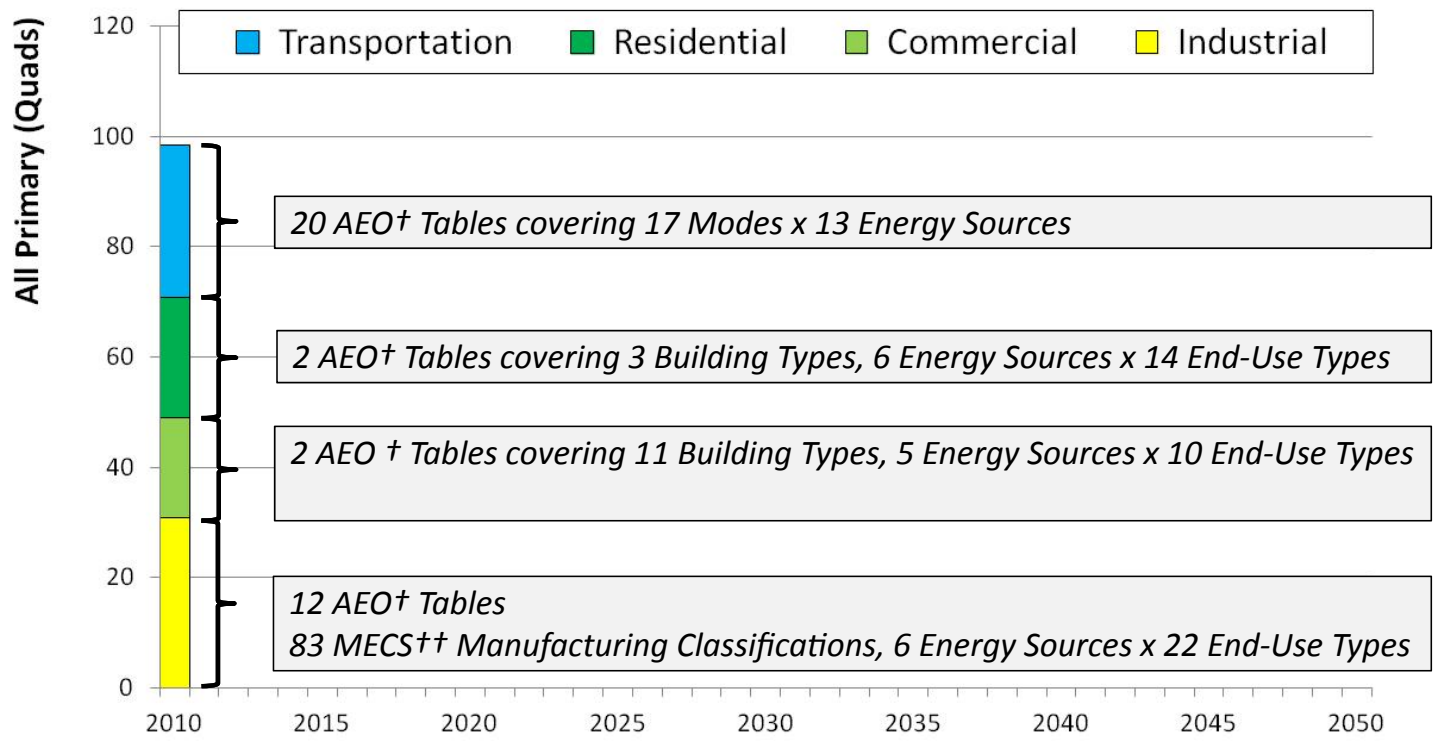

+ Annual Energy Outlook (AEO) Tables

+† Manufacturing Energy Consumption Survey

\section{Protocol - Distilling scenarios to Three Key Variables}

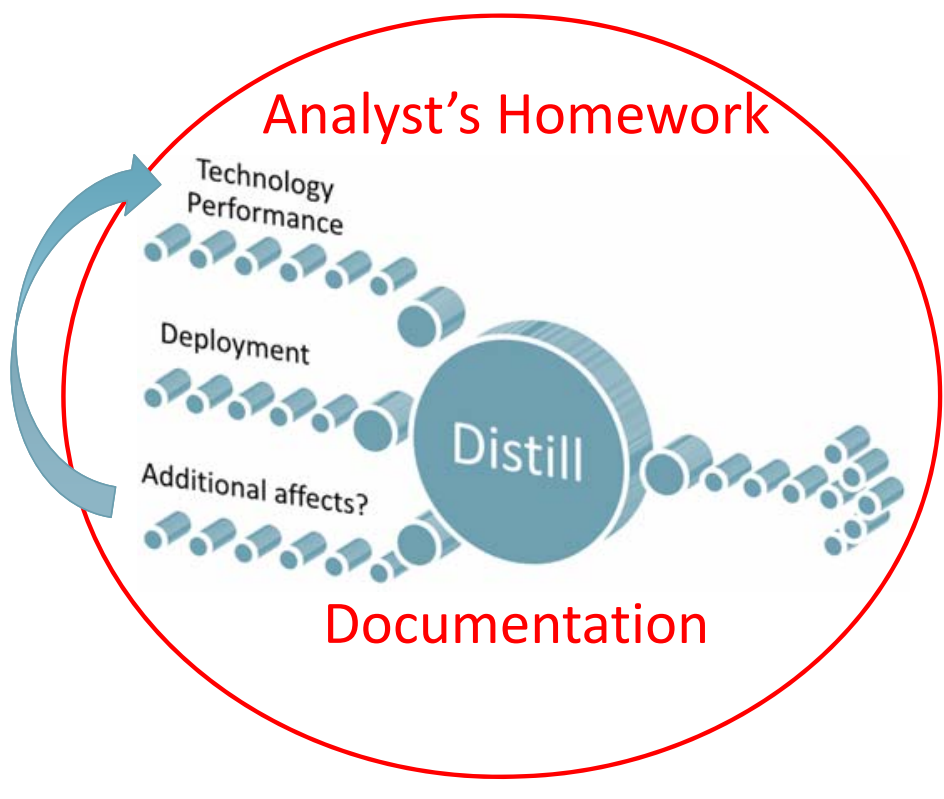

Three Key Variables For LIGHTEn-UP Tool

Where?

(Sector \& end-use)

What?

(Energy Impact)

When?

(Start \& End years) 


\section{Where will the impact be?}

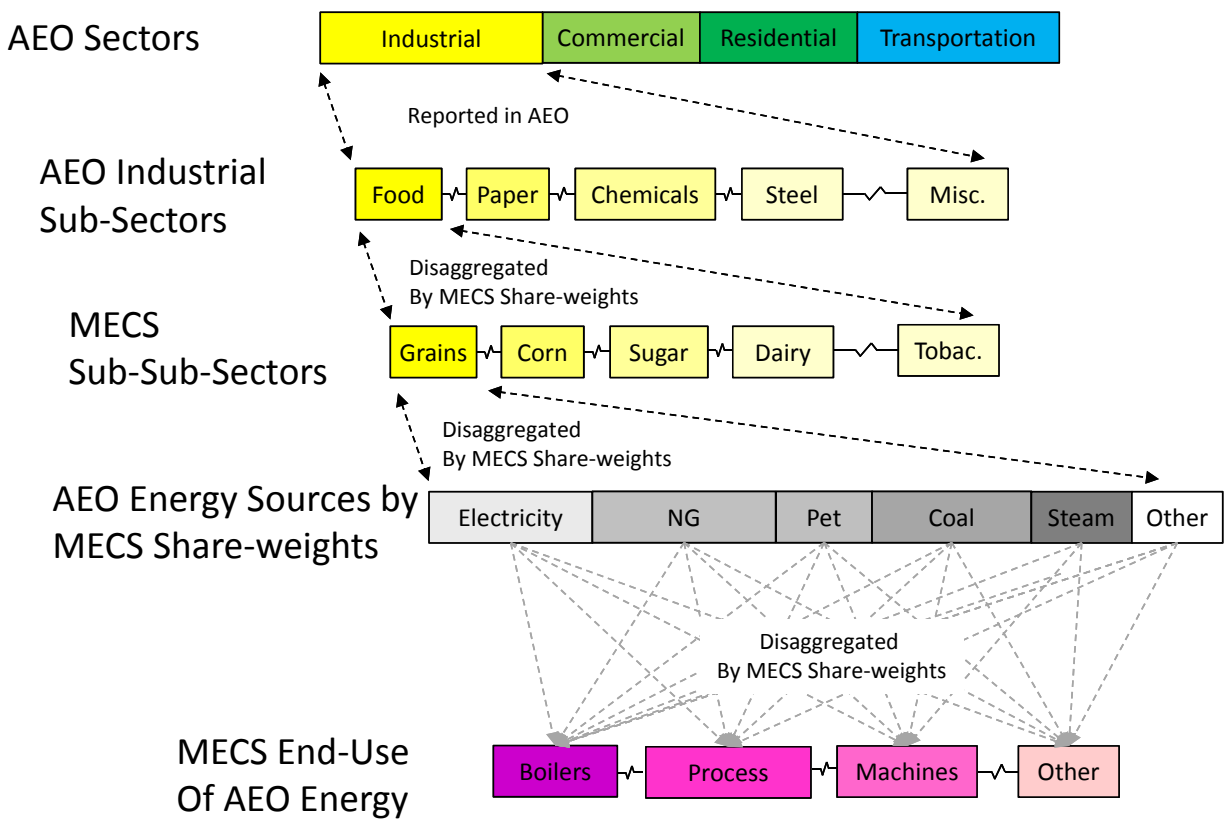

\section{What will the impact be?}

Technical Adoption Potential \% \& Relative Energy Savings \%

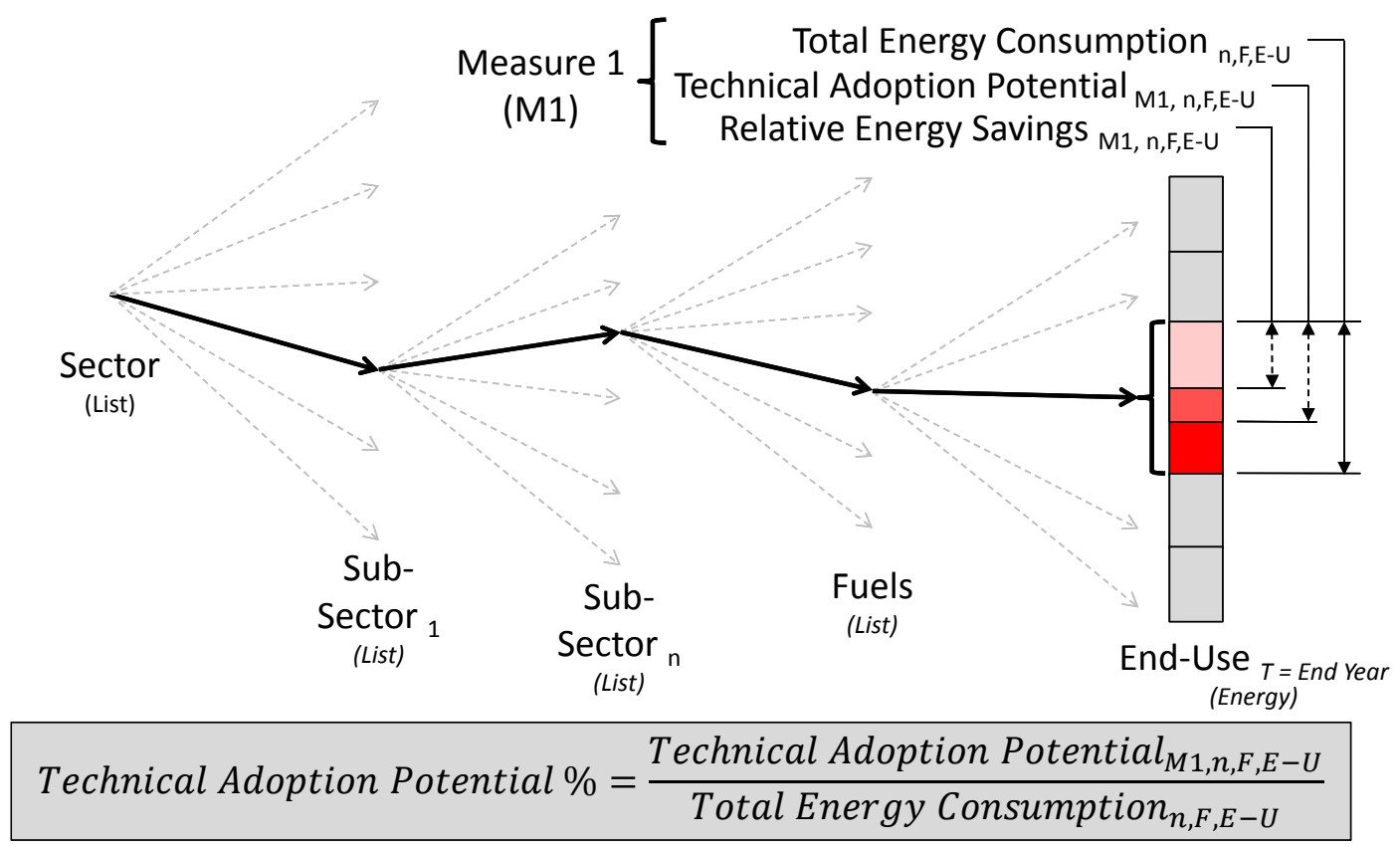

Relative Energy Savings $\%=\frac{\text { Relative Energy Saving } S_{M 1, n, F, E-U}}{\text { Technical Adoption Potential }{ }_{M 1, n, F, E-U}}$ 


\section{Time - and when will the impact occur...?}

Where? What? When?

\begin{tabular}{|c|c|c|c|c|c|c|c|}
\hline \multicolumn{3}{|c|}{ Where: Which Sector \& End-Use? } & \multicolumn{3}{|c|}{ What Impact at End Year } & \multicolumn{2}{|c|}{ When? } \\
\hline $\begin{array}{c}\text { Industrial } \\
\text { Commercial } \\
\text { Residential } \\
\text { Transportation }\end{array}$ & Sub- & $\mathrm{Er}$ & \begin{tabular}{|c|} 
Technical \\
Adoption \\
Potential \%
\end{tabular} & $\begin{array}{c}\text { Relative } \\
\text { Energy } \\
\text { Savings \% }\end{array}$ & $\begin{array}{c}\text { Growth } \\
\text { Rate } \\
\text { Assumption }\end{array}$ & $\begin{array}{l}\text { Start } \\
\text { Year }\end{array}$ & $\begin{array}{l}\text { End } \\
\text { Year }\end{array}$ \\
\hline
\end{tabular}
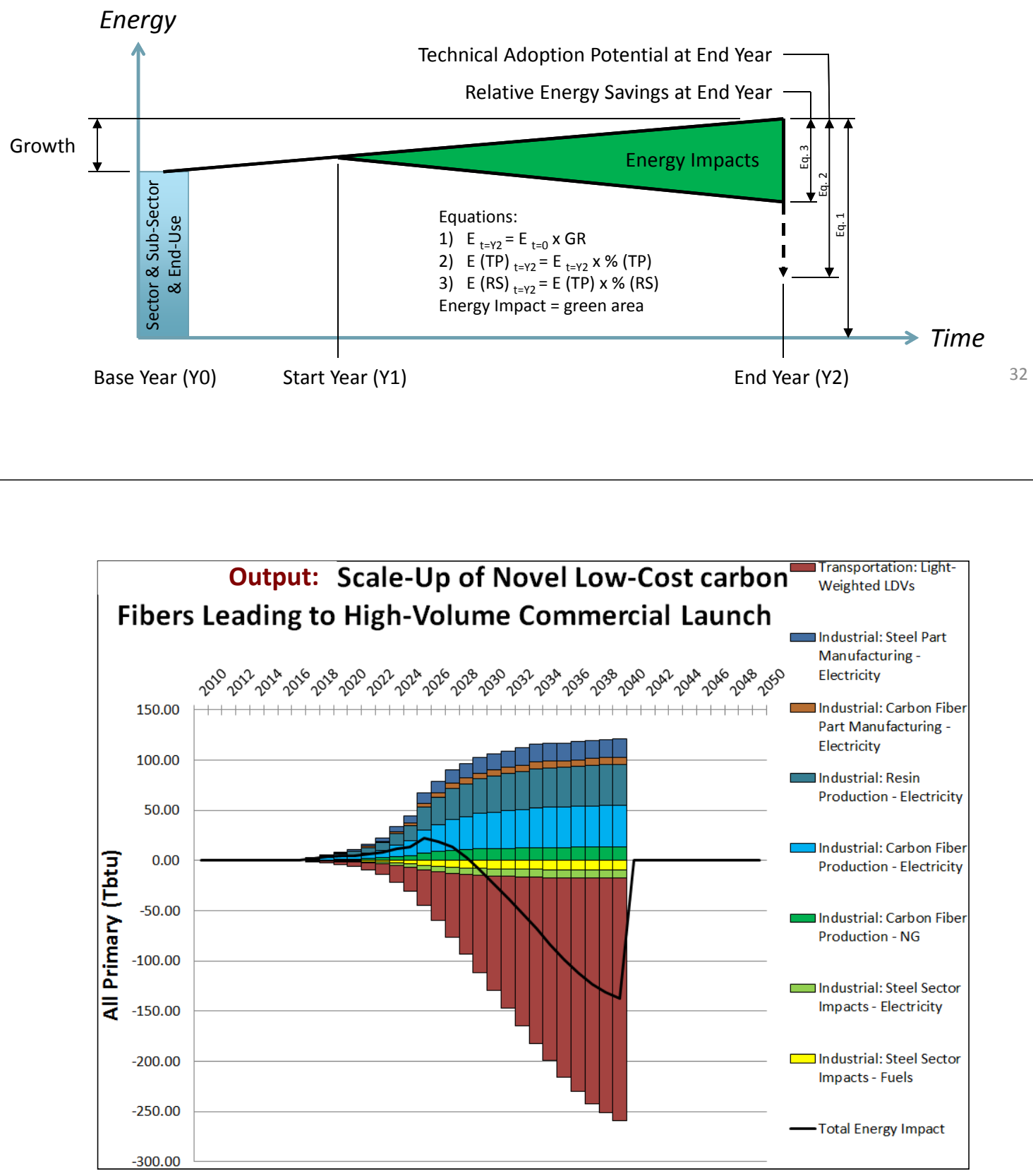

- $\quad$ LIGHTEn_UP shows fleet annual net energy impact (black line) increasing in initial years as CFRP production ramps up

- Beyond year 2030, net energy savings are realized as use phase benefits accrue (i.e. black line falls below x-axis)

- Within industrial sector:

- Energy increases in carbon fiber and resin sectors due to increased CFRP production

- Energy decrease in steel sector due to avoided steel production 
Energy Consumption Savings from Lightweighting Carbon Fiber Reinforced Plastics (CFRP) vs. Steel; Improved CF (polyolefin) vs. current CF (polyacrylonotrile)
Why manufacturing energy use matters - accounting for vehicle turnover.

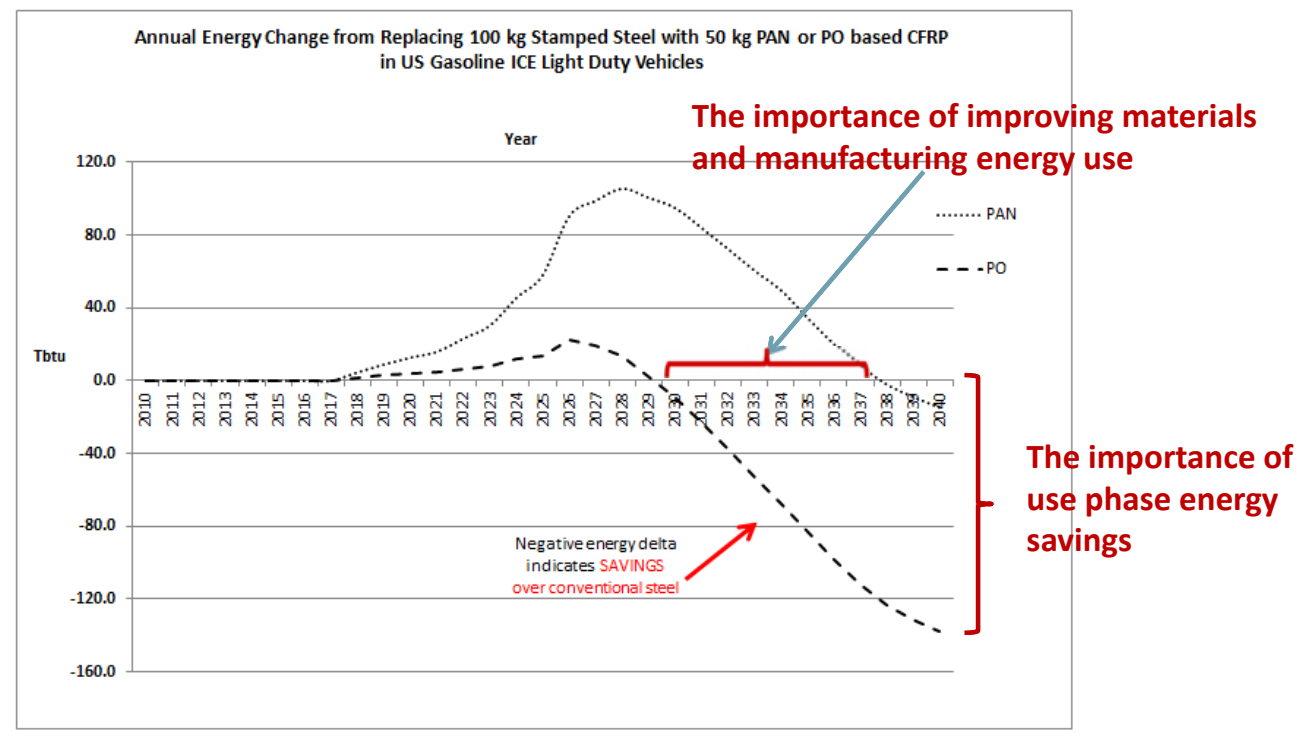

- Per vehicle savings of 2600 MJ per PAN vehicle and 11,500 MJ per PO vehicle

- Net energy impact of PO (dashed line) in US LDV fleet also compared with PAN (dotted line)

- Significantly greater materials and manufacturing energy investment with PAN - net energy savings temporally delayed and lesser magnitude

\title{
Thank You!
}

\author{
Joe Cresko \\ Joe.cresko@ee.doe.gov
}

Team:

Alberta Carpenter - NREL

Sujit Das - ORNL

Diane Graziano -ANL

Maggie Mann - NREL

William Morrow - LBNL

Eric Masanet - Northwestern

Sachin Nimbalkar - ORNL

Arman Shehabi - LBNL 


\section{Metrics for Sustainable Products and Processes}

I. S. Jawahir

Professor of Mechanical Engineering,

James F. Hardymon Endowed Chair in Manufacturing Systems, and

Director of Institute for Sustainable Manufacturing (ISM)

www.ism.uky.edu

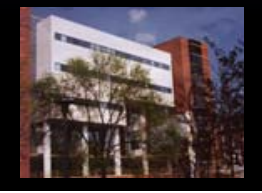

NIST UMD Workshop on Sustainable Construction and Manufacturing June 12 13, 2014

\section{Introduction:}

\section{Sustainability as the Basis for Sustainable Growth and Value Creation}

- Sustainability is a global phenomenon

- Sustainability IS NOT Sustainment, but is the basis for sustainable growth and value creation

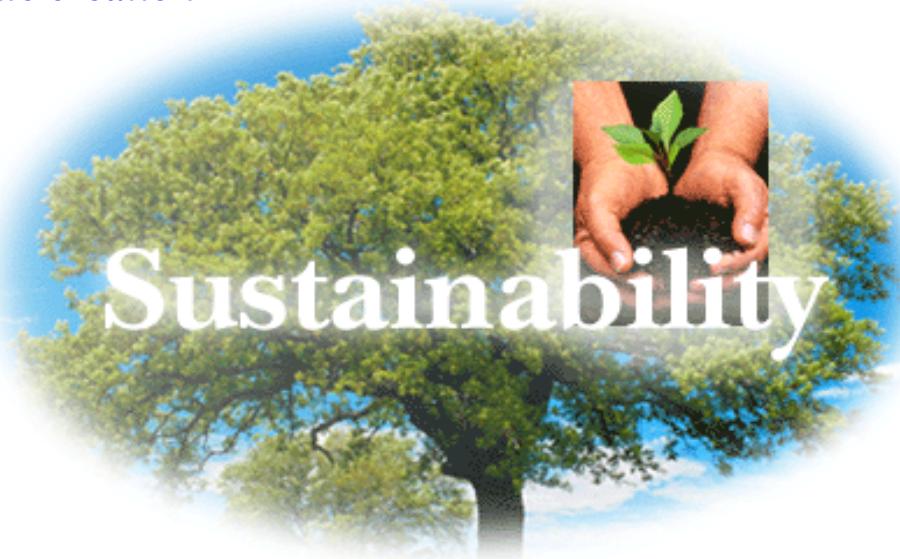

- Designing sustainable products and developing sustainable manufacturing processes have been a major research focus in sustainable manufacturing

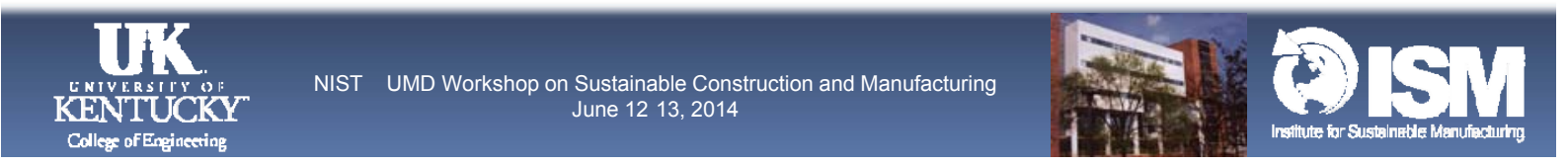




\section{Innovation-based Sustainable Manufacturing}
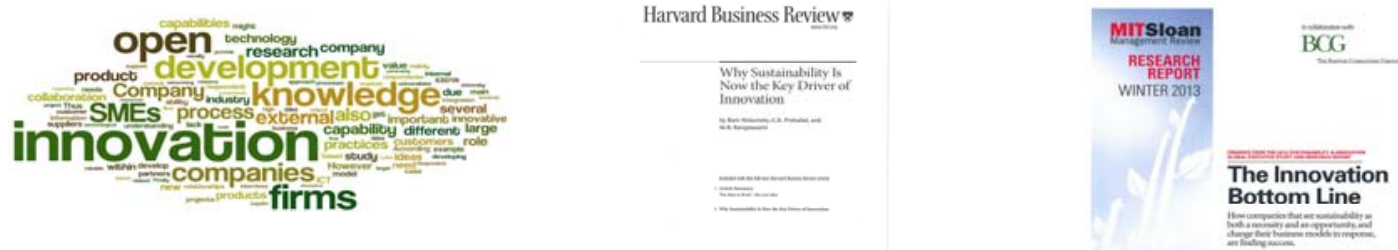

Sustainability is the driver for innovation

Innovation promotes accelerated growth in manufacturing

Manufacturing is the engine for wealth generation and societal well-being

Societal well-being and economic growth heavily depend on the level and quality of education and training

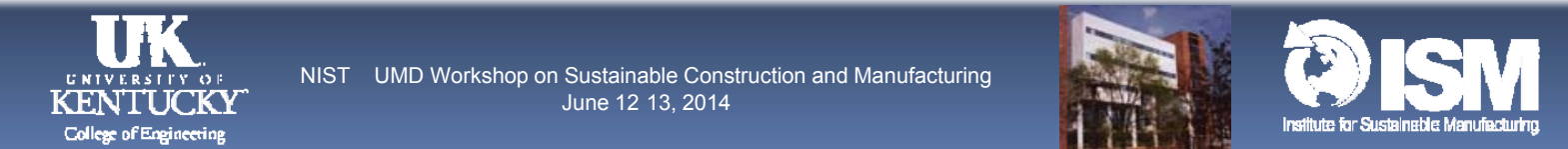

\section{The Foundation of Sustainable Development}

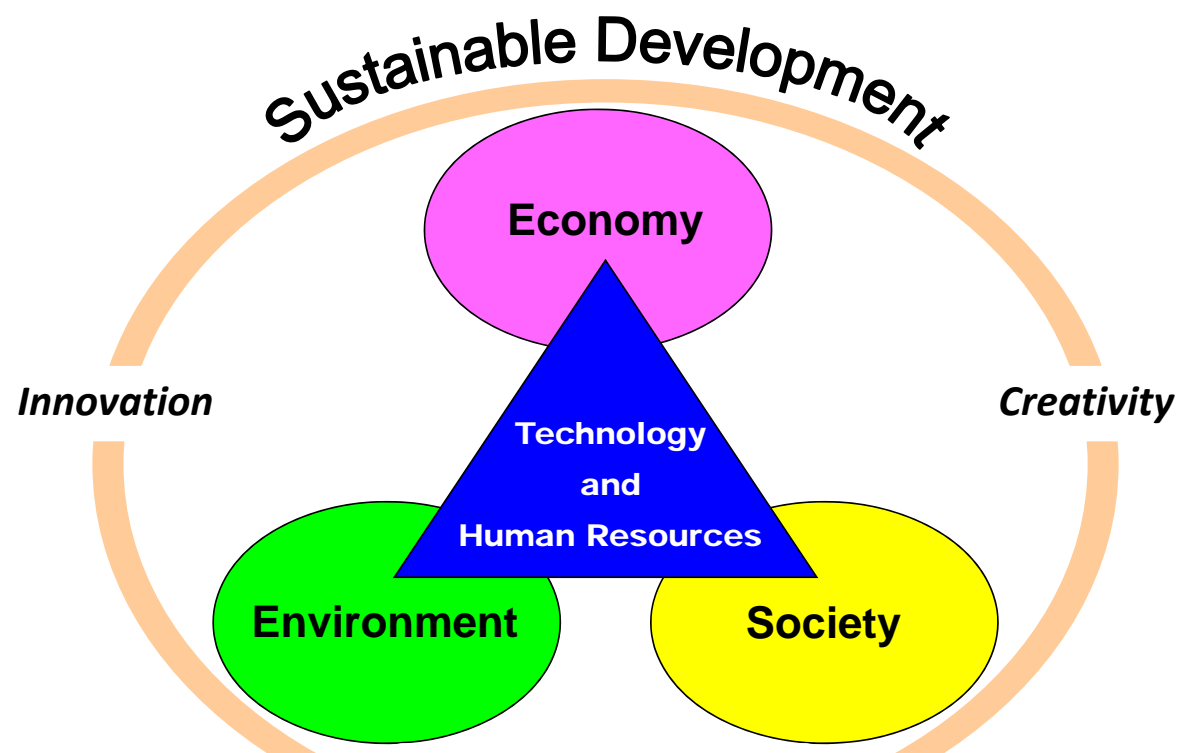

Education \& Training 


\section{Sustainable Manufacturing: Definitions}

Numerous definitions and descriptions exist for sustainable manufacturing:

- US Department of Commerce, 2009

- NACFAM, 2009

- NIST, 2010

- ASME, 2011, 2013

- NSF 2013

almost all definitions fall short of showing the connectivity among the integral elements - No connectivity shown between sustainability and innovation or value creation

Sustainable manufacturing offers a new way of producing functionally superior products innovative sustainable technologies and manufacturing methods through the coordination of capabilities across the entire supply chain, not just the process chain

- Sustainable manufacturing must enable sustainable value creation for all stakeholders.
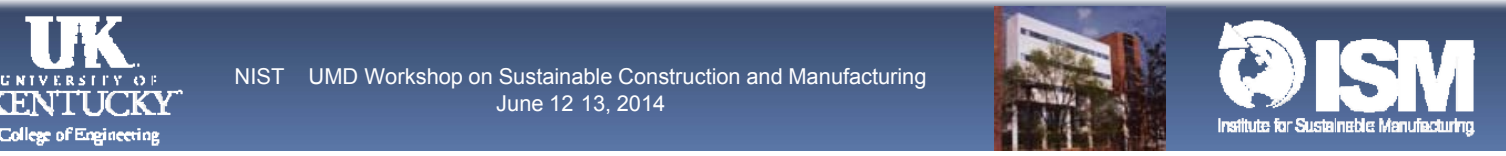

\section{Sustainable Manufacturing: Revised Definition}

Sustainable manufacturing must:

- demonstrate reduced negative environmental impact,

- offer improved energy and resource efficiency,

- generate minimum quantity of wastes,

- provide operational safety, and

- offer improved personall health

while maintaining and/or improving the product and process quality

Source: J ayal et al. (2010) and J awahir (2012) - Adapted from US Department of Commerce (2009) 


\section{Sustainable Manufacturing: Basic Elements}

\section{Expectations:}

- Reducing energy consumption

- Reducing waste

- Reducing material utilization

- Enhancing product durability

- Increasing operational safety

- Reducing toxic dispersion

- Reducing health hazards/Improving health conditions

- Consistently improving manufacturing quality

- Improving recycling, reuse and remanufacturing

- Maximizing sustainable sources of renewable energy

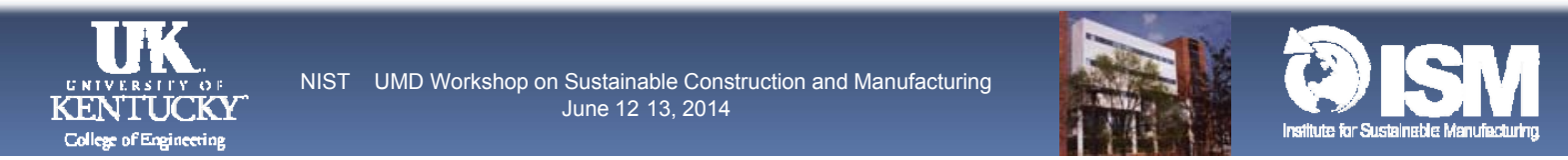

\section{ISM Focus}

\section{Products}

\section{Processes}




\section{Holistic and Total Life-cycle Approach}

Emphasis on all four product life-cycle stages
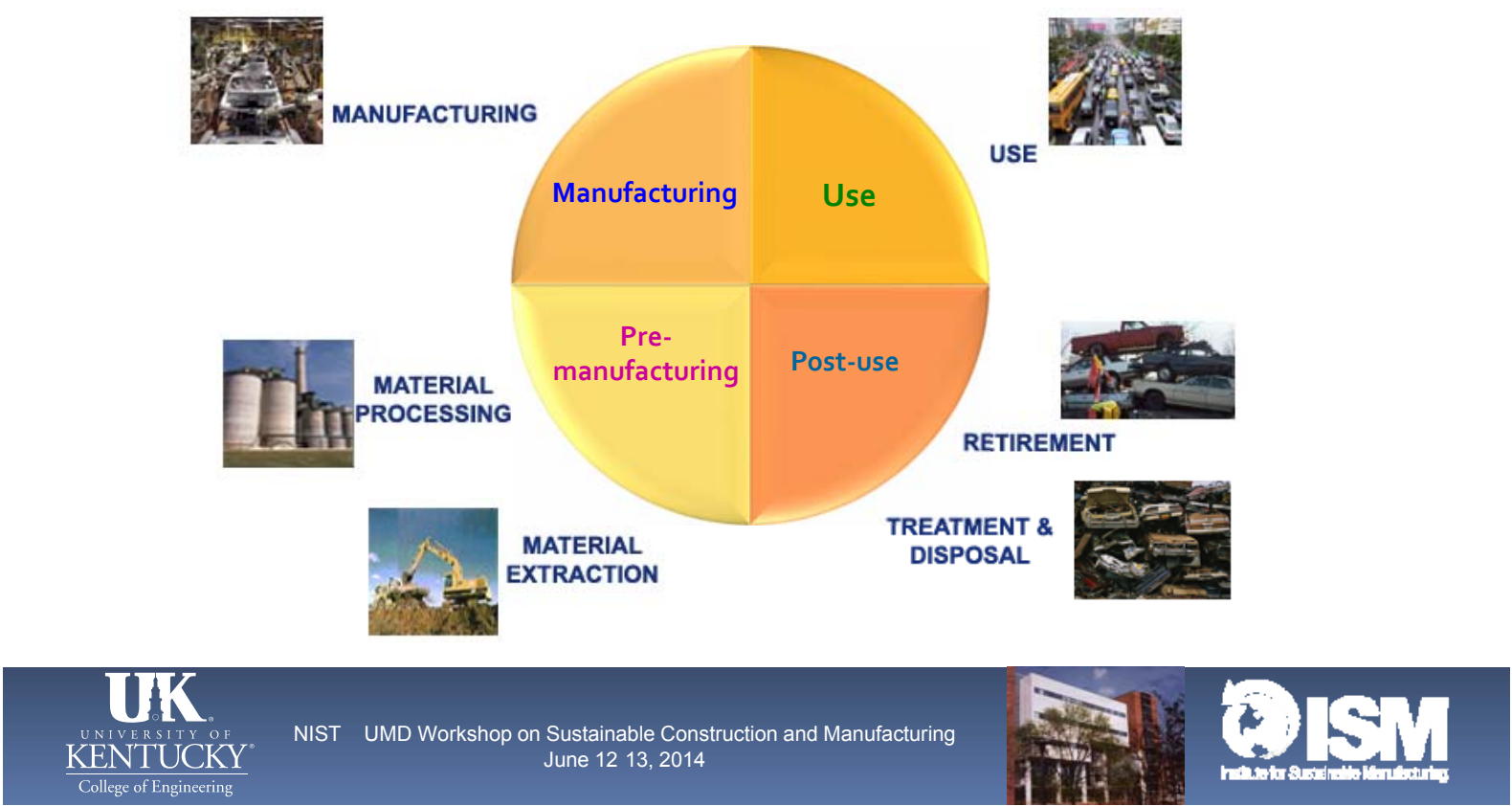

\section{Closed-loop Material Flow - The 6R Approach}

\section{R \\ CONCEPT}
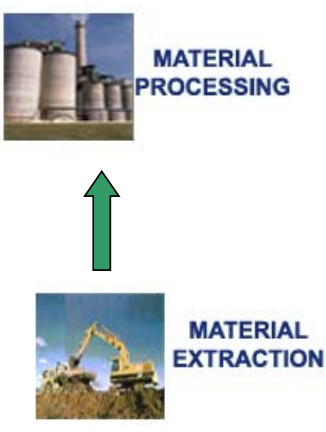
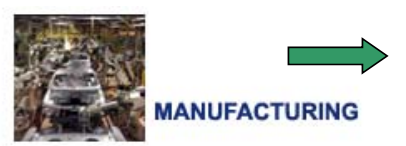

MANUFACTURING
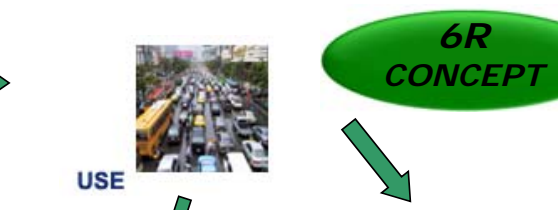
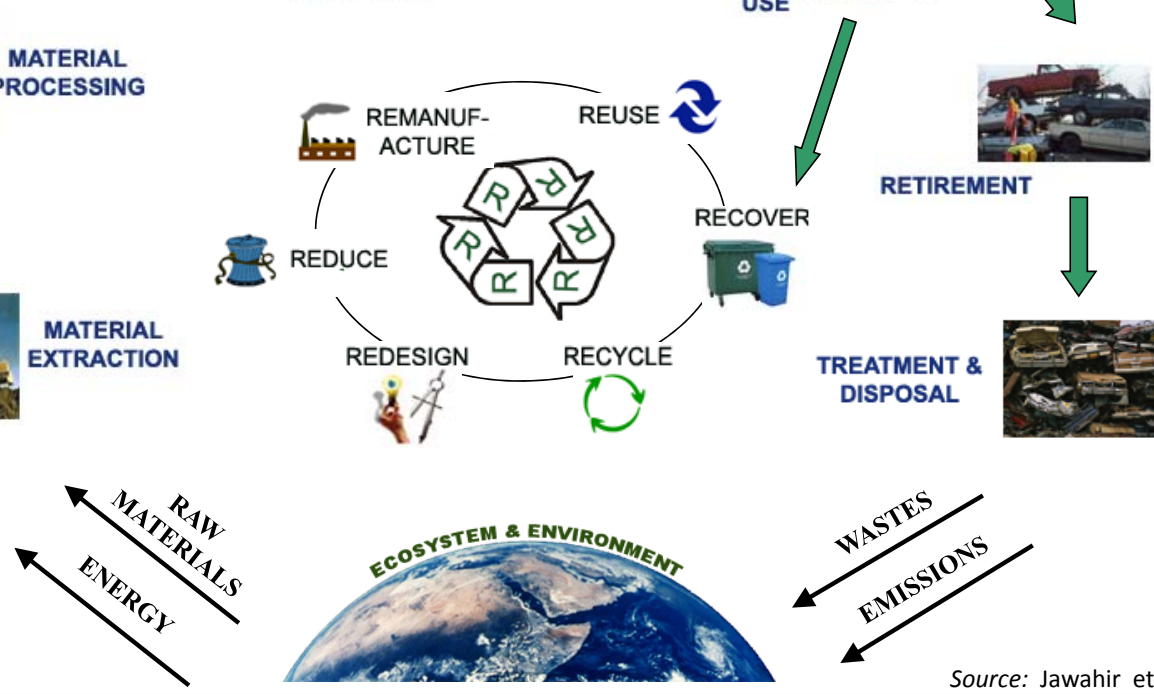

RETIREMENT

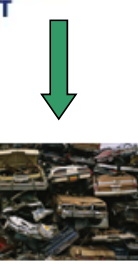

REATMENT \&
DISPOSAL

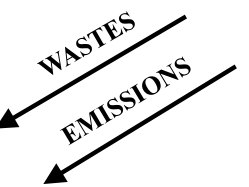

Source: Jawahir et al. (2006) 


\section{Evolution of Sustainable Manufacturing}

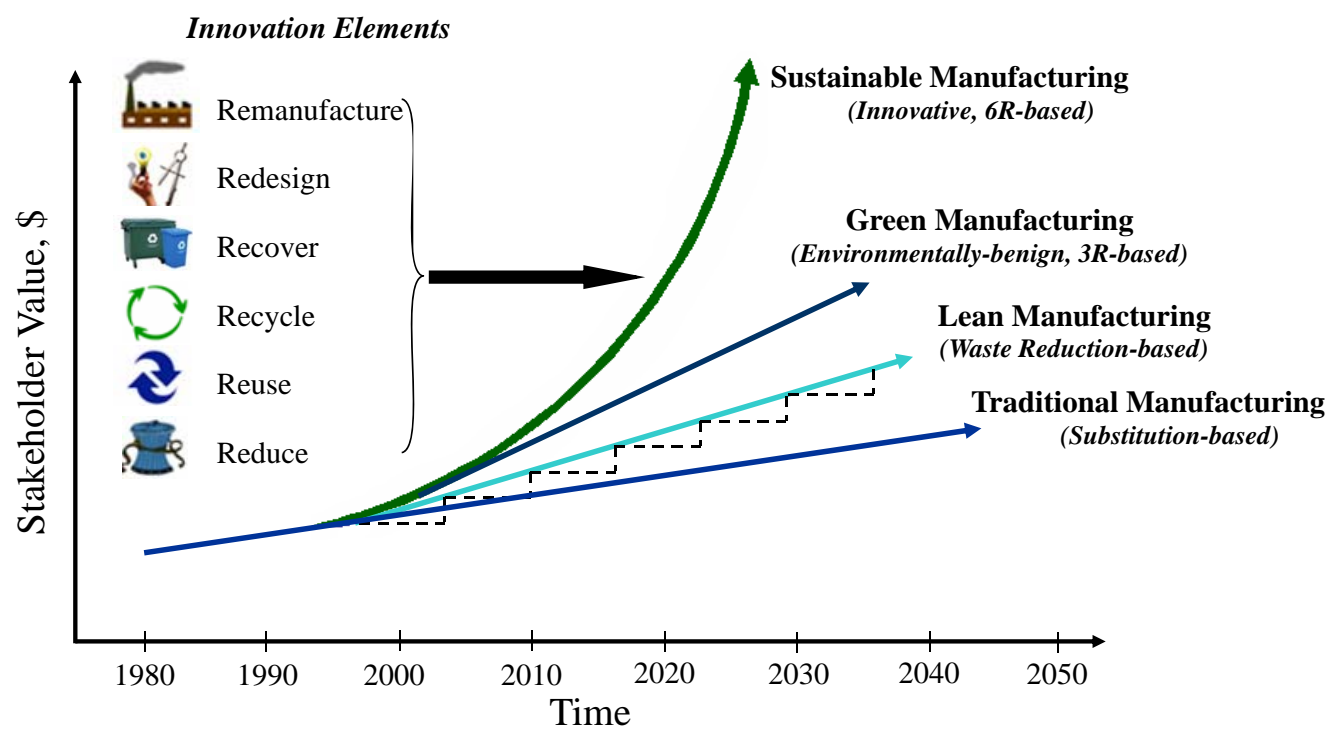

\section{Total Life-cycle 6R Applications for Sustainable Products}

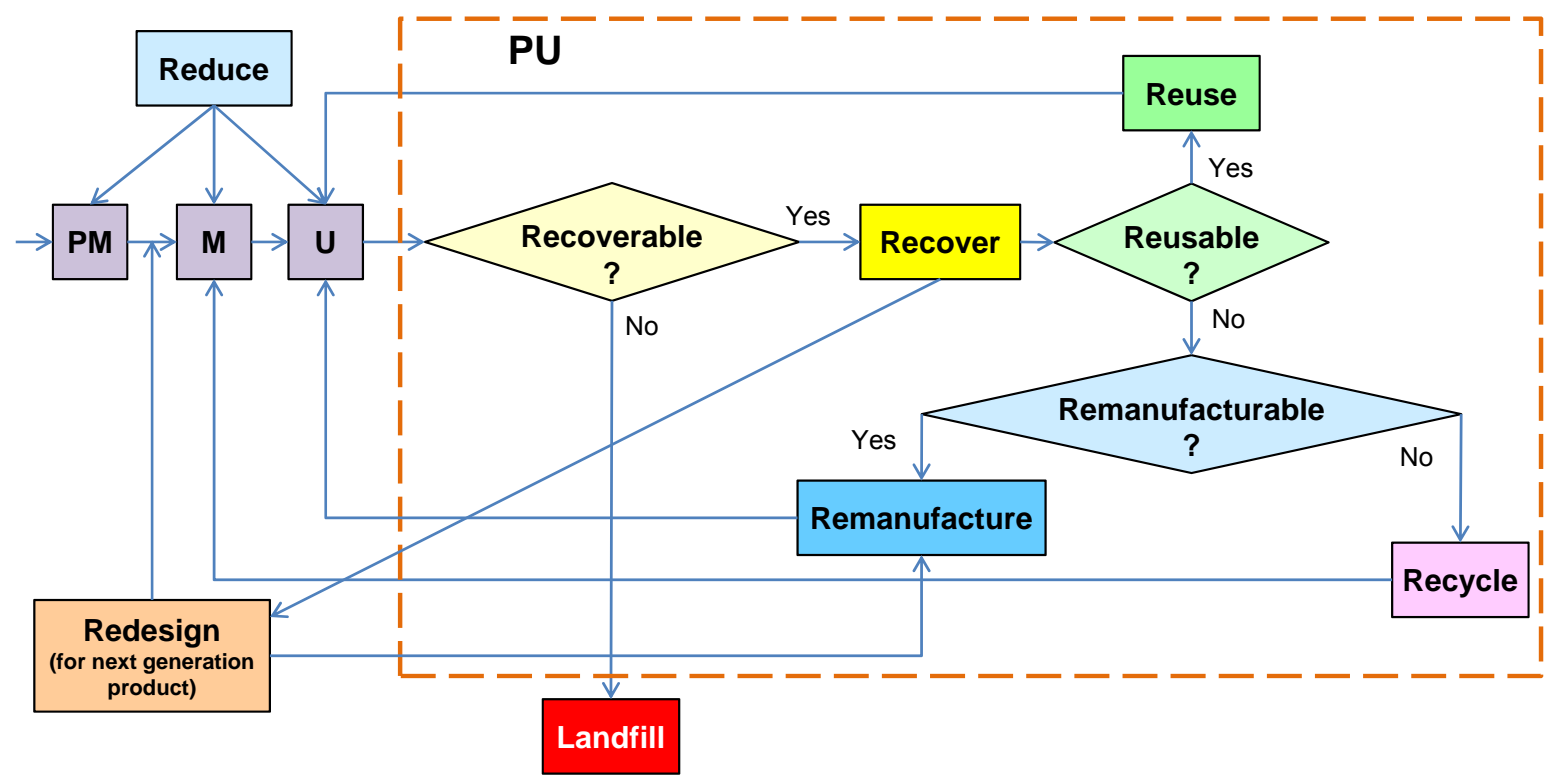




\section{Overview of Existing Sustainability Measurement Systems}

\section{A list of existing measurement systems}

\begin{tabular}{|l|l|}
\hline \multicolumn{1}{|c|}{ Indicator Set } & \multicolumn{1}{c|}{ components } \\
\hline Global Reporting Initiative (GRI) & 70 indicators \\
\hline Dow Jones Sustainability Index (DJSI) & 12 criteria based single indicator \\
\hline 2005 Environmental Sustainability Indicators & 76 building blocks \\
\hline 2006 Environment Performance Indicators & 19 Indicators \\
\hline United Nations Committee on Sustainable Development Indicators & 50 indicators \\
\hline OECD Core indicators & 46 indicators \\
\hline Indicator database & 409 indicators \\
\hline Ford Product Sustainability Index & 8 indicators \\
\hline GM Metrics for Sustainable Manufacturing & 46 Metrics \\
\hline ISO 14031 environmental performance evaluation & 155 example indicators \\
\hline Wal-Mart Sustainability Product Index & 15 questions \\
\hline Environmental Indicators for European Union & 60 indicators \\
\hline Eco-Indicators 1999 & 3 main factors based single indicator \\
\hline
\end{tabular}

(Feng et al. 2010)

\section{Uis}

\section{Overview of Existing Sustainability Measurement Sy stems (Cont.)}

\section{Comparison of the existing measurement systems}

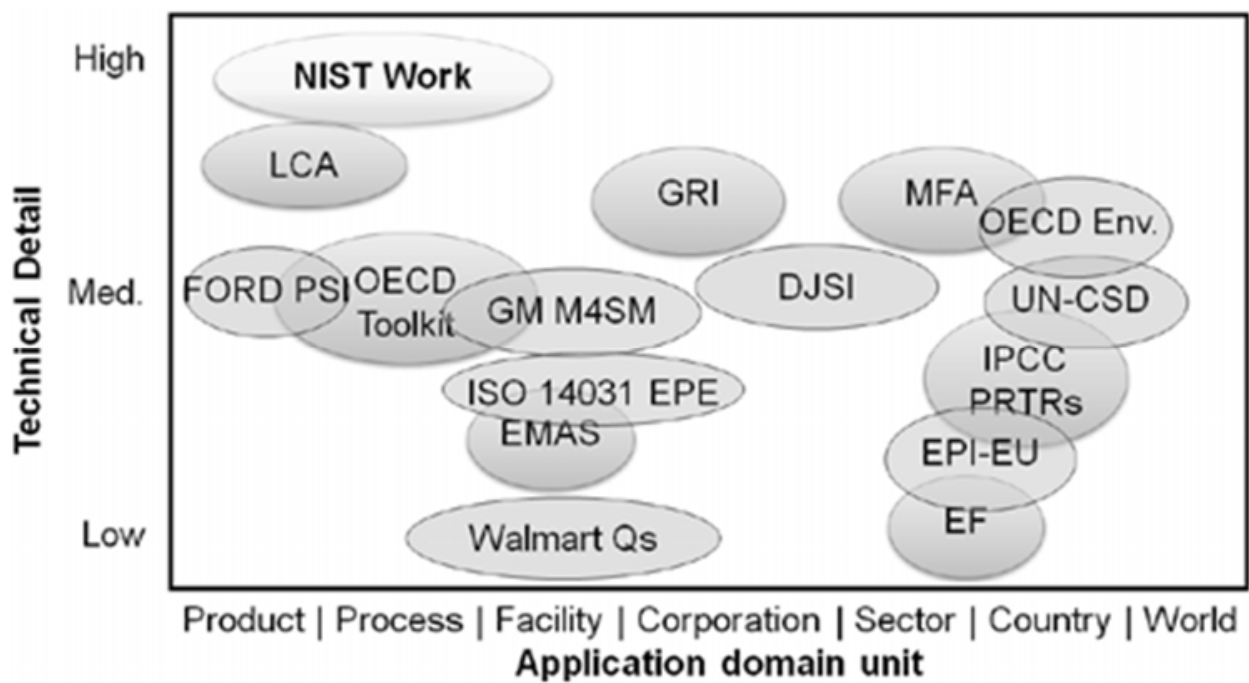

Application domain unit

(reng et al. 2010)

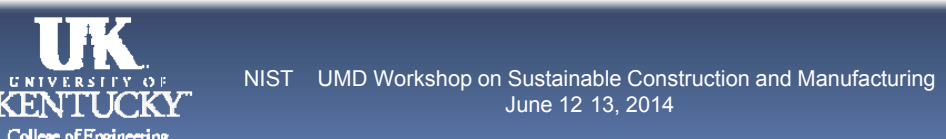




\section{Product and Process Metrics for \\ Sustainable Manufacturing: NIST-sponsored Project}

Project Title: Development of Metrics, Metrology and a Framework for Product-Process Ontology for Interoperability in Model-Based Sustainable Manufacturing

Project Team: Faculty: Dr. I.S. Jawahir, Dr. F. Badurdeen, Dr. O.W. Dillon, Jr., Dr. K. Rouch Graduate Students: T. Lu, M. Shuaib, X. Zhang, A. Huang, C. Stovall

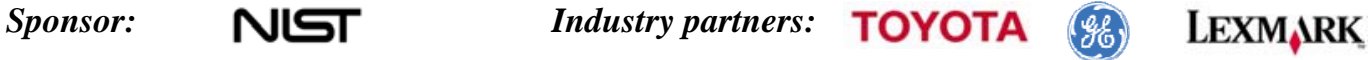

Project Objective: To develop and implement tools and principles for quantitative evaluation of manufactured products and their manufacturing processes from the aspect of sustainable manufacturing

\section{Metrics for Sustainable Manufacturing}

- Manufacturing is an engine for wealth generation, and achieving sustainability in manufacturing is crucial to economy

- There is a critical need for developing improved metrics to evaluate the sustainability performance of a product and its manufacturing processes

- Metrics can help to improve decision-making with optimized product and process design for sustainable manufacturing

\section{Project Summary}

- The major sustainability elements and metrics of products and processes for sustainable manufacturing identified

- A framework for developing comprehensive product and process metrics for sustainable manufacturing developed

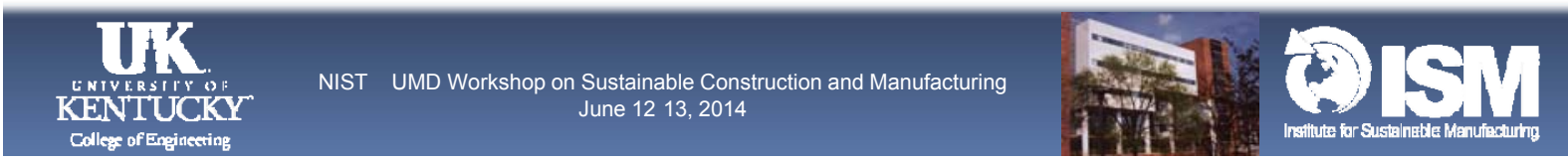

\section{Product Design for Sustainability}

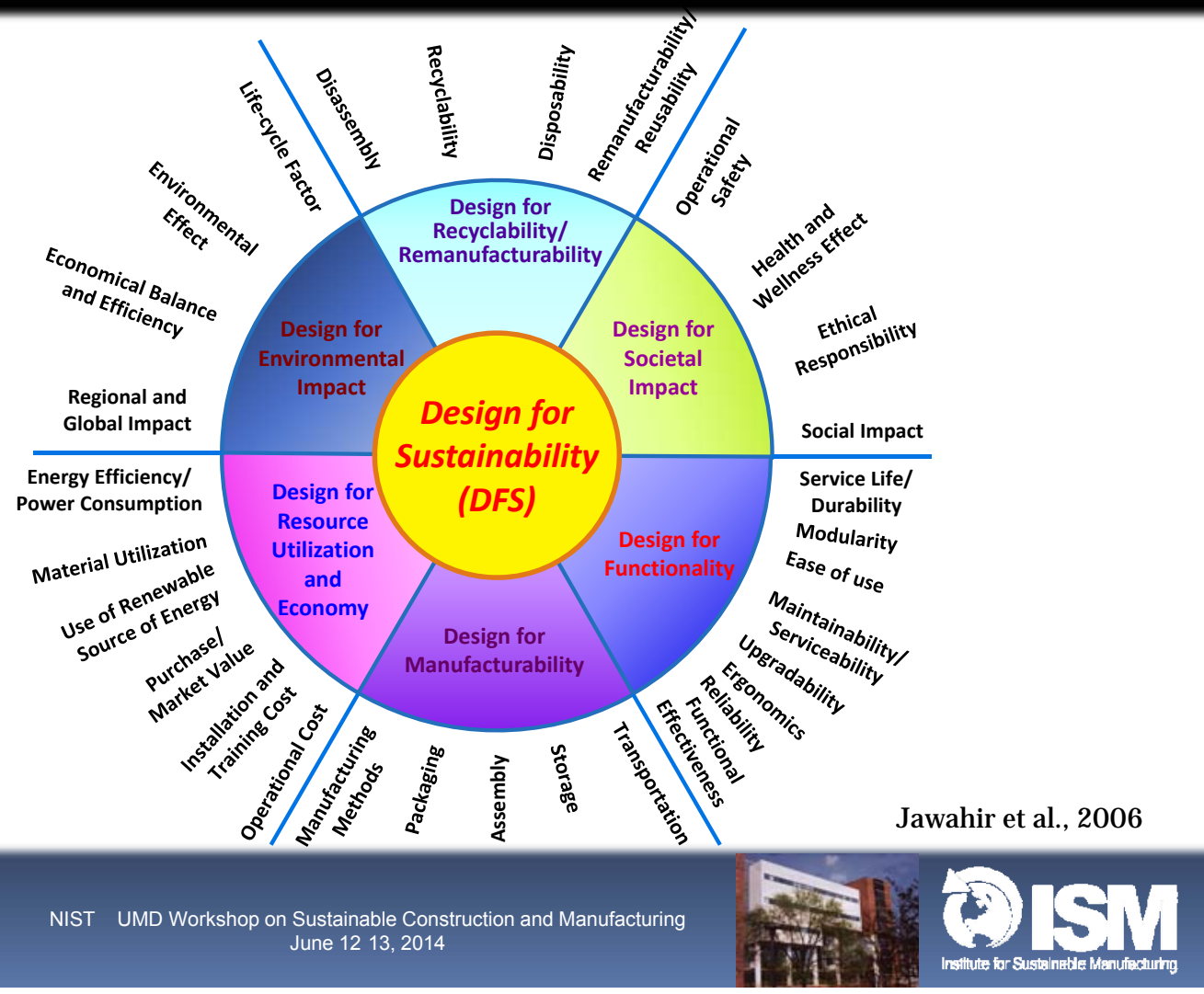




\section{Hierarchical Structure of Product Sustainability Evaluation Method}

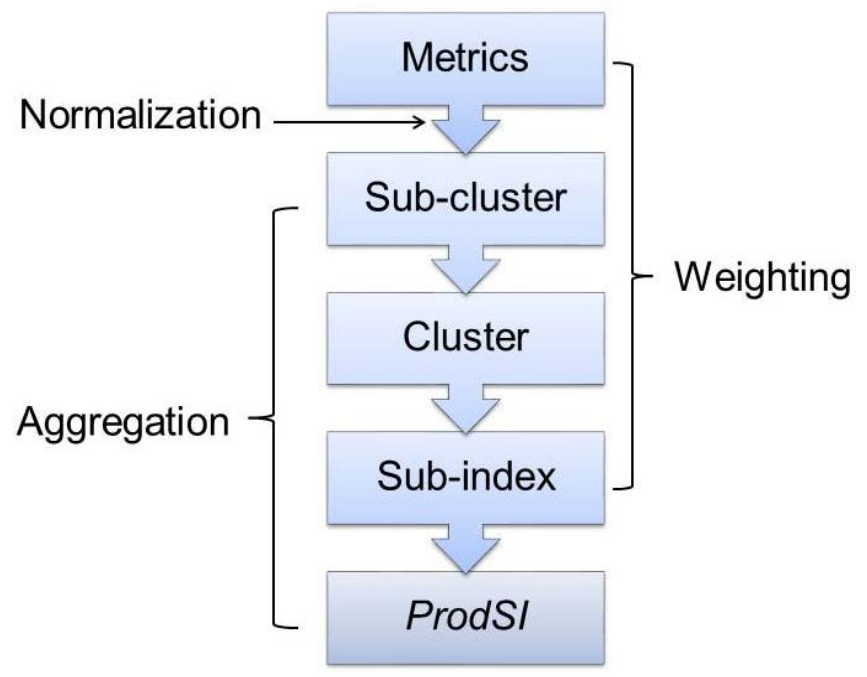

\section{Product Clusters}

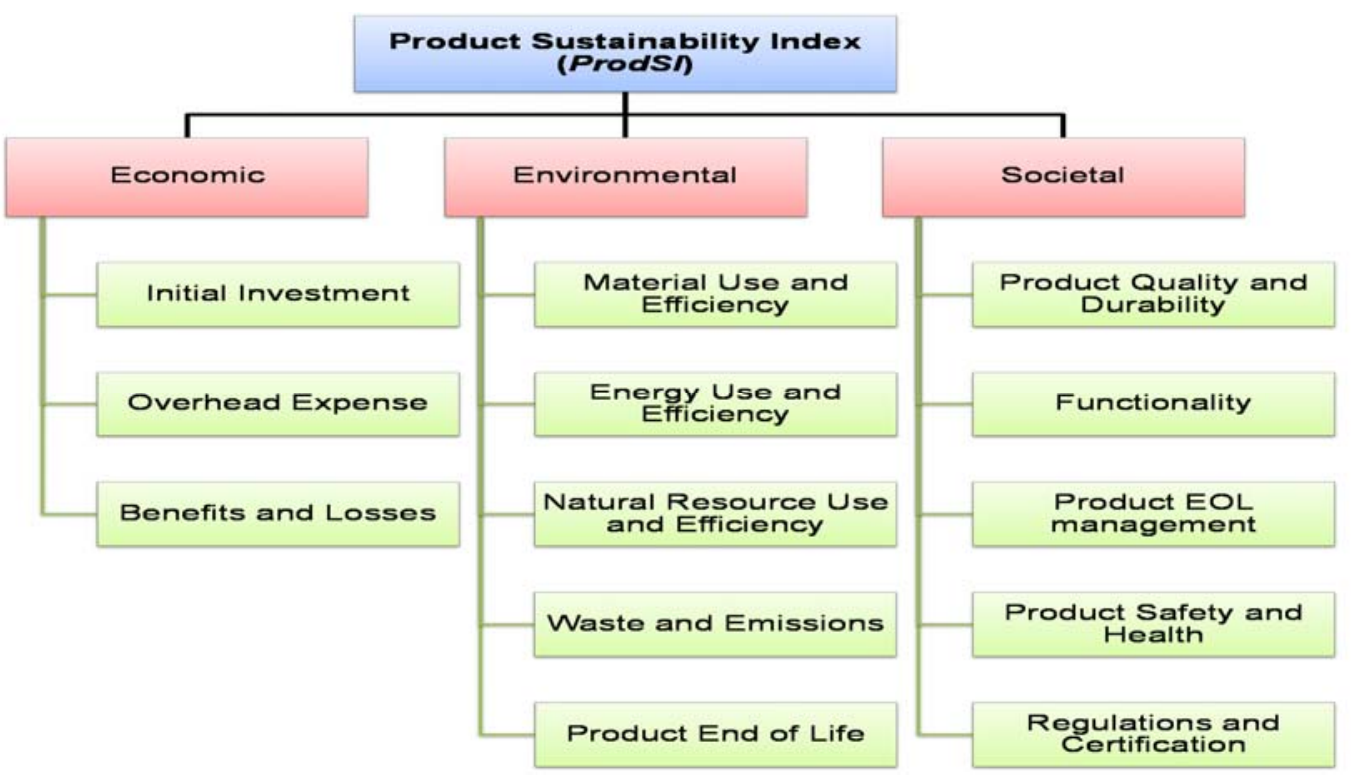




\section{Example Metrics for Product Clusters and Life-cycle Stages}

\begin{tabular}{|c|c|c|c|c|c|c|}
\hline Metrics Clusters & Example Metrics & $\begin{array}{c}\text { Unit } \\
\text { (D/L } \\
\text { dimensionless) }\end{array}$ & $\begin{array}{l}\text { PM } \\
\text { (pre- } \\
\text { mfg.) }\end{array}$ & $\underset{(m f g .)}{M}$ & $\begin{array}{c}\mathbf{U} \\
\text { (use) }\end{array}$ & $\begin{array}{c}\text { PU } \\
\text { (post- } \\
\text { use) }\end{array}$ \\
\hline Residues & $\begin{array}{c}\text { Emissions Rate (carbon-dioxide, sulphur- } \\
\text { oxides, nitrous-oxides etc.) }\end{array}$ & mass/unit & $\sqrt{ }$ & $\sqrt{ }$ & $\sqrt{ }$ & $\sqrt{ }$ \\
\hline \multirow{2}{*}{ Energy Use and Efficiency } & Remanufactured Product Energy & kWh/unit & & $\sqrt{ }$ & $\sqrt{ }$ & $\sqrt{ }$ \\
\hline & Maintenance/ Repair Energy & kWh/unit & & & $\sqrt{ }$ & \\
\hline $\begin{array}{c}\text { Product End-of-Life } \\
\text { Management }\end{array}$ & Design-for-Environment Expenditure & $\$ / \$(D / L)$ & & $\sqrt{ }$ & & \\
\hline Material Use and efficiency & Restricted Material Usage Rate & mass/unit & $\sqrt{ }$ & $\sqrt{ }$ & & $\sqrt{ }$ \\
\hline Water Use and Efficiency & Recycled Water Usage Rate & gallons/unit & $\sqrt{ }$ & $\sqrt{ }$ & & $\sqrt{ }$ \\
\hline Cost & Product Operational Cost & \$/unit & & & $\sqrt{ }$ & \\
\hline Innovation & Average Disassembly Cost & \$/unit & & & & $\sqrt{ }$ \\
\hline Profitability & Profit & \$/unit & & $\sqrt{ }$ & & \\
\hline \multirow{2}{*}{ Product Quality } & Defective Products Loss & \$/unit & & $\sqrt{ }$ & & \\
\hline & Warranty Cost Ratio & \$/unit & & & $\sqrt{ }$ & \\
\hline Education & Employee Training & Hours/unit & $\sqrt{ }$ & $\sqrt{ }$ & & $\sqrt{ }$ \\
\hline \multirow{2}{*}{$\begin{array}{l}\text { Customer } \\
\text { Satisfaction }\end{array}$} & Repeat Customer Ratio & $(\mathrm{D} / \mathrm{L})$ & & $\sqrt{ }$ & $\sqrt{ }$ & \\
\hline & Post-Sale Service Effectiveness & $(D / L)$ & & & $\sqrt{ }$ & \\
\hline $\begin{array}{c}\text { Product End-of-Life } \\
\text { Management }\end{array}$ & Ease of Sustainable Product Disposal & \$/unit & & & $\sqrt{ }$ & \\
\hline \multirow{2}{*}{$\begin{array}{l}\text { Product Safety } \\
\text { and Societal Well-being }\end{array}$} & Product Processing Injury Rate & incidents/unit & $\sqrt{ }$ & $\sqrt{ }$ & & $\sqrt{ }$ \\
\hline & Landfill Reduction & mass/unit & $\sqrt{ }$ & $\sqrt{ }$ & $\sqrt{ }$ & $\sqrt{ }$ \\
\hline
\end{tabular}

UK KENIUCKY Collegs of Enginetring

\section{Process Sustainability Elements}

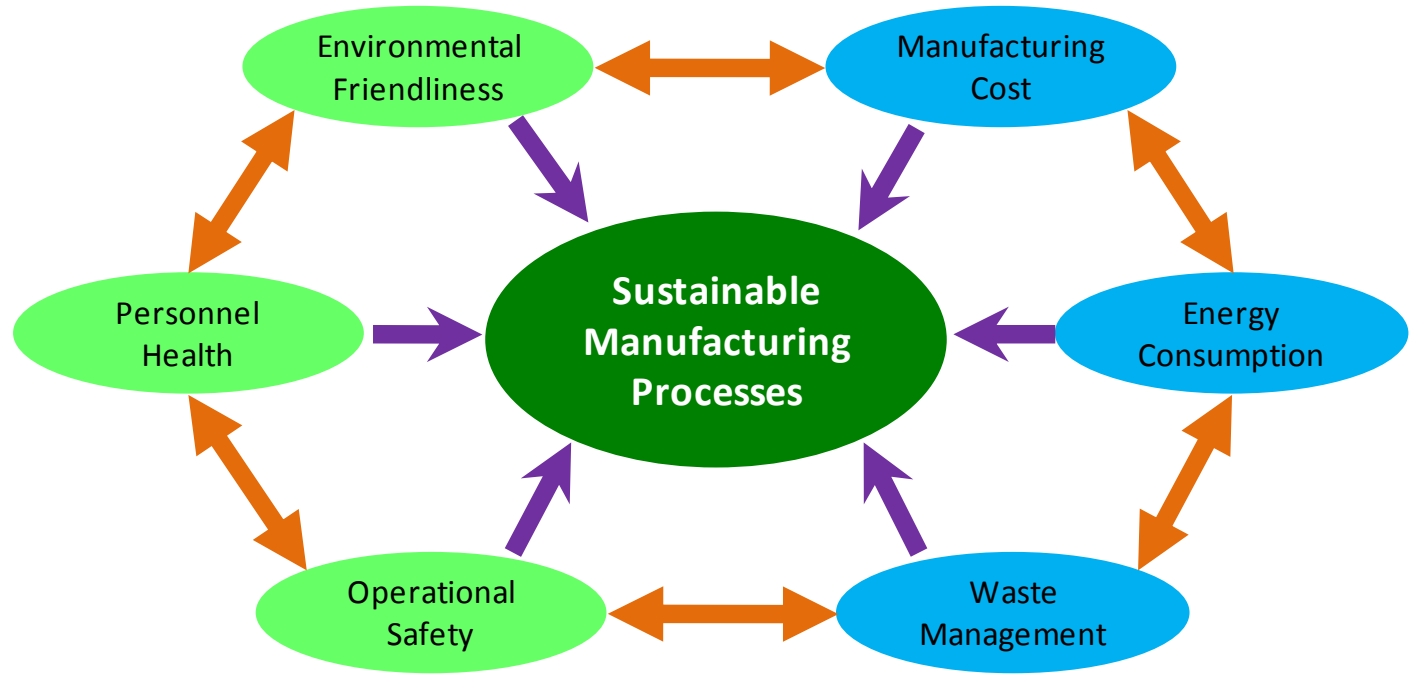

(Wanigarathne et al., 2004) 


\section{Process Sustainability Metrics}

\begin{tabular}{|c|c|c|}
\hline Environmental Impact & Energy Consumption & Cost \\
\hline $\begin{array}{l}\mathrm{GHG} \text { emission from energy consumption of the } \\
\text { line (ton } \mathrm{CO}_{2} \text { eq./unit) } \\
\text { Ratio of renewable energy used (\%) } \\
\text { Total water consumption (ton/unit) } \\
\text { Mass of restricted disposals (kg/unit) } \\
\text { Noise level outside the factory (dB) }\end{array}$ & $\begin{array}{l}\text { In-line energy consumption (kWh/unit) } \\
\text { Energy consumption on maintaining facility } \\
\text { environment (kWh/unit) } \\
\text { Energy consumption on transportation into/out of } \\
\text { the line (kWh/unit) } \\
\text { Ratio of use of renewable energy (\%) }\end{array}$ & $\begin{array}{l}\text { Labor cost (\$/unit) } \\
\text { Cost for use of energy (\$/unit) } \\
\text { Cost of consumables (\$/unit) } \\
\text { Maintenance cost (\$/unit) } \\
\text { Cost of by-product treatment (\$/unit) } \\
\text { Indirect labor cost (\$/unit) }\end{array}$ \\
\hline Operator Safety & Personnel Health & Waste Management \\
\hline $\begin{array}{l}\text { Exposure to Corrosive/toxic chemicals } \\
\text { (points/person) } \\
\text { Exposure to high energy components } \\
\text { (points/person) } \\
\text { Injury rate (injuries/unit) }\end{array}$ & $\begin{array}{l}\text { Chemical contamination of working environment } \\
\left(\mathrm{mg} / \mathrm{m}^{3}\right) \\
\text { Mist/dust level }\left(\mathrm{mg} / \mathrm{m}^{3}\right) \\
\text { Noise level }(\mathrm{dB}) \\
\text { Physical load index (dimensionless) } \\
\text { Health related absenteeism rate }(\%)\end{array}$ & $\begin{array}{l}\text { Mass of disposed consumables (kg/unit) } \\
\text { Consumables reuse ratio (\%) } \\
\text { Mass of mist generation (kg/unit) } \\
\text { Mass of disposed chips and scraps (kg/unit) } \\
\text { Ratio of recycled chips and scraps (\%) }\end{array}$ \\
\hline
\end{tabular}

\section{Three-level Process Sustainability Metrics for Energy Consumption}

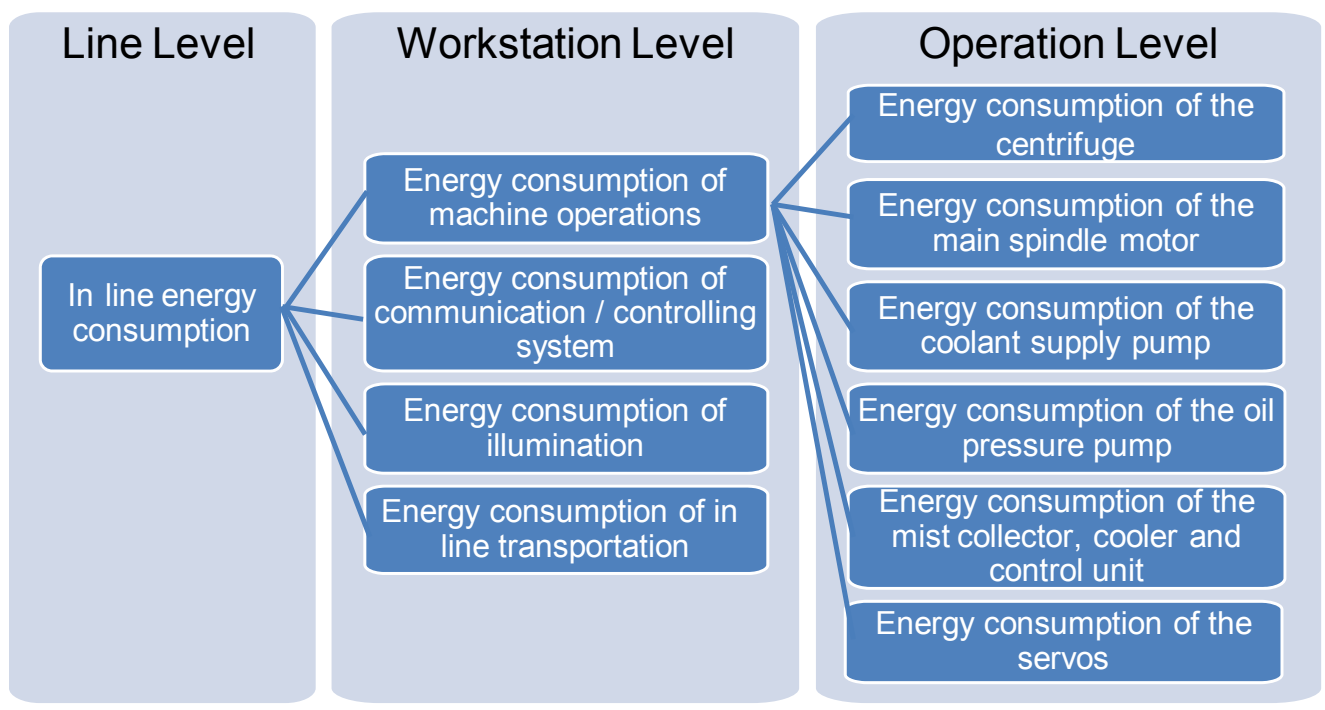




\section{Process Sustainability Clusters and Sub-clusters}

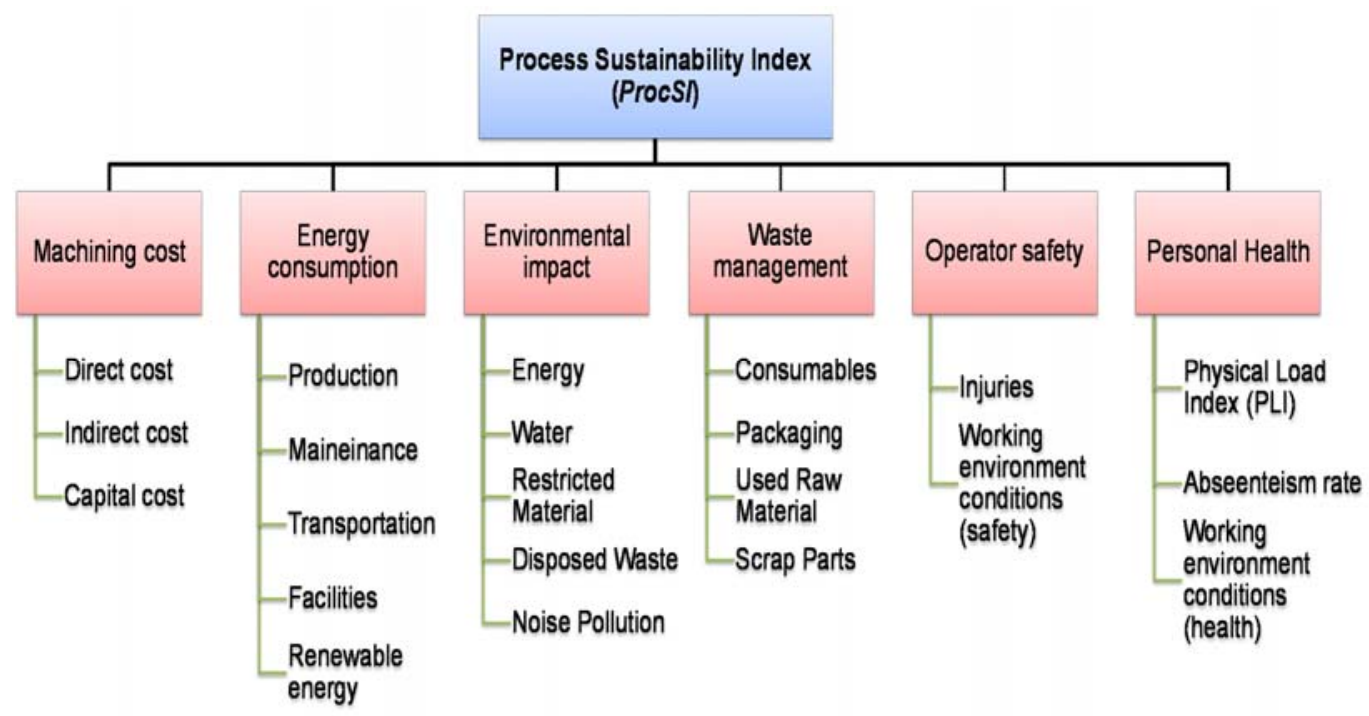

\section{ProdSI and ProcSI Evaluation}

$$
\begin{aligned}
\text { ProdSI } & =\frac{1}{3}(E C+E v+S o)=\frac{1}{3}\left(\sum_{i=1}^{3} w_{i}^{C} C_{i}+\sum_{i=4}^{8} w_{i}^{C} C_{i}+\sum_{i=9}^{13} w_{i}^{C} C_{i}\right) \begin{array}{l}
C_{m}=\sum_{S} S C_{j} w_{j}^{s c} \forall j \\
S C_{n}=\sum_{k} M_{k}^{m} \forall j
\end{array} \\
\text { ProcSI } & =\frac{1}{6} \sum_{i=1}^{6} C_{i}=\frac{1}{6}\left(C_{1}+C_{2}+\frac{1}{5} \sum_{i=10}^{14} w_{i}^{s c} S C_{i}+\frac{1}{4} \sum_{i=15}^{18} w_{i}^{s c} S C_{i}+\frac{1}{3} \sum_{i=19}^{21} w_{i}^{s c} S C_{i}+\frac{1}{2} \sum_{i=22}^{23} w_{i}^{s c} S C_{i}\right) \\
S C_{n} & =\sum w_{j}^{m} M_{j} \forall j
\end{aligned}
$$




\section{Examples of ProdSI and ProcSI}

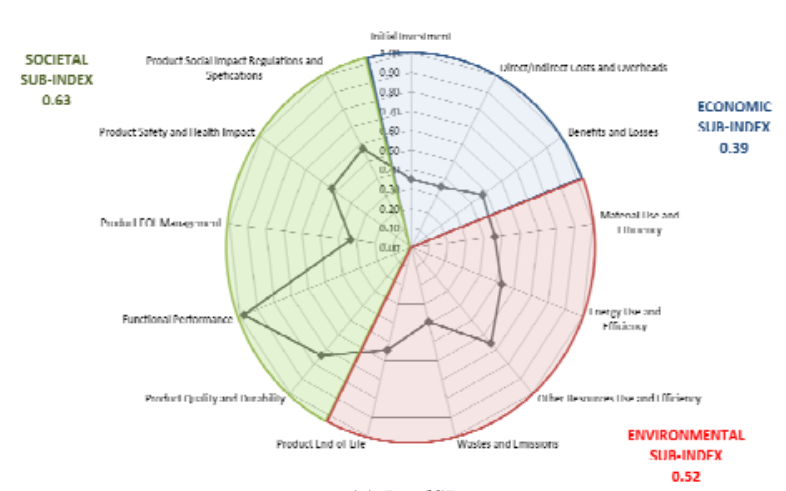

(a) ProdSI

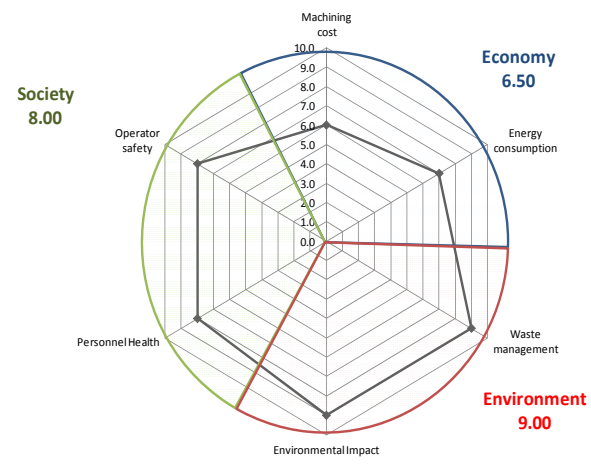

(b) ProcSI

\section{Sustainability Improvement in Products and Processes}

Case studies were conducted on three major manufactured products
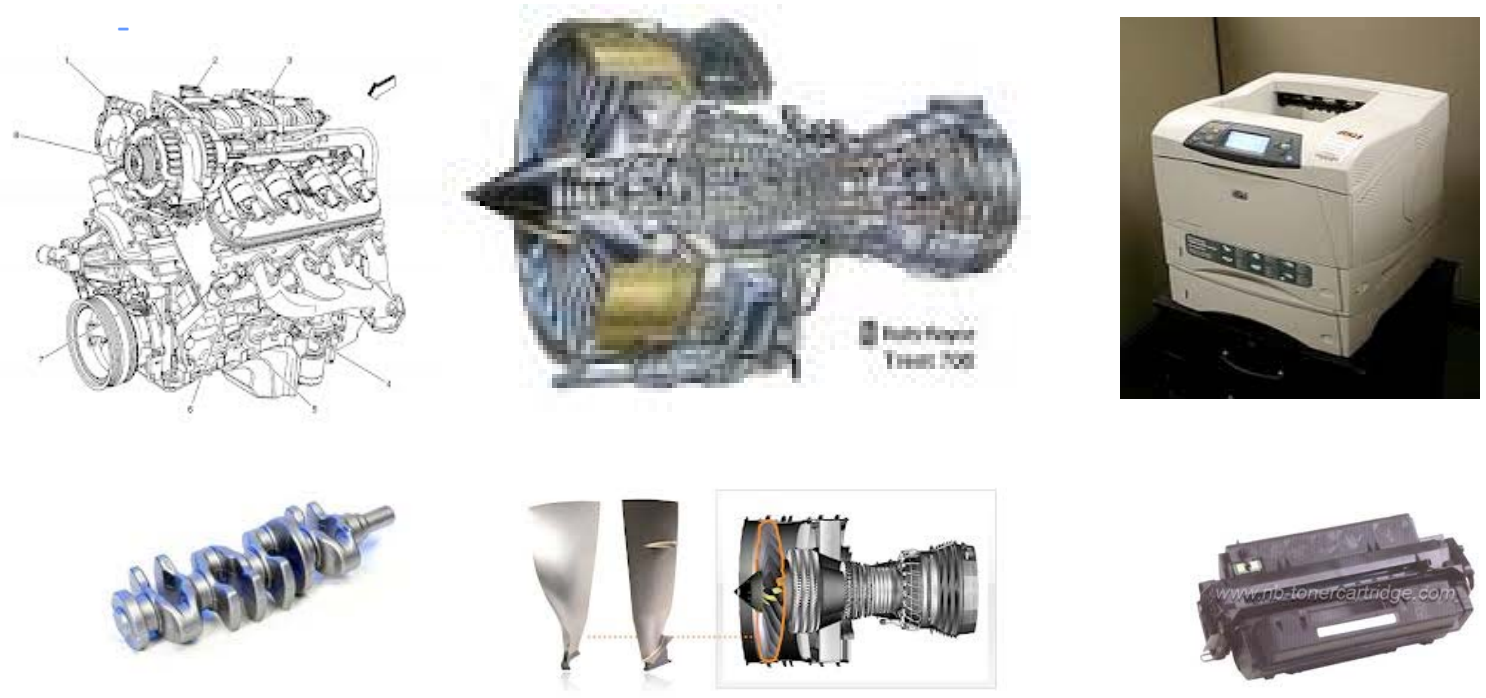


\section{Implementing Product and Process Sustainability Metrics}

\section{Current State:}

- Considerable effort in the manufacturing industry, with corporate commitment to sustainability

- Promotion of dedicated educational and training programs and workforce development

\section{Limitations:}

- Slow progress and limited effectiveness in implementing sustainable practices --- No economic benefits shown, and no standards despite significant push for regulatory measures

- Difficulty in identifying relevant tools and techniques for evaluation

- Complexity in measuring and quantifying sustainability elements in manufactured products and manufacturing processes

\section{Outlook and Opportunity:}

- Metrics-based evaluation of sustainable products and processes offers an new opportunity for quantitative evaluation of sustainability in manufacturing

- Sustainability is the driver for innovation

- Significantly improved manufacturing productivity through product/process innovation

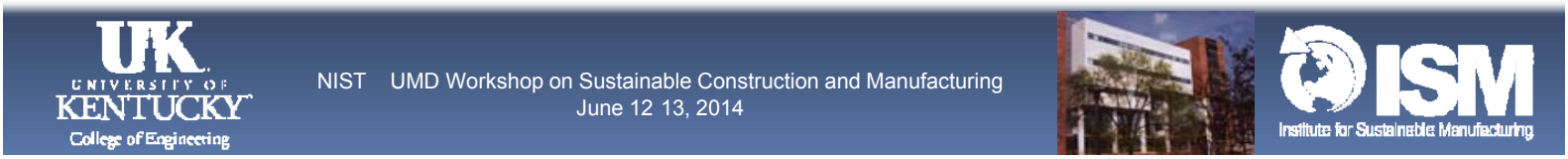

\section{Acknowledgements}

- Project Sponsor: NIST (Award No: 60NANB10D009) 2010-13

- Industry Participants:

GE-Aviation

Toyota Motor Manufacturing

Lexmark International 

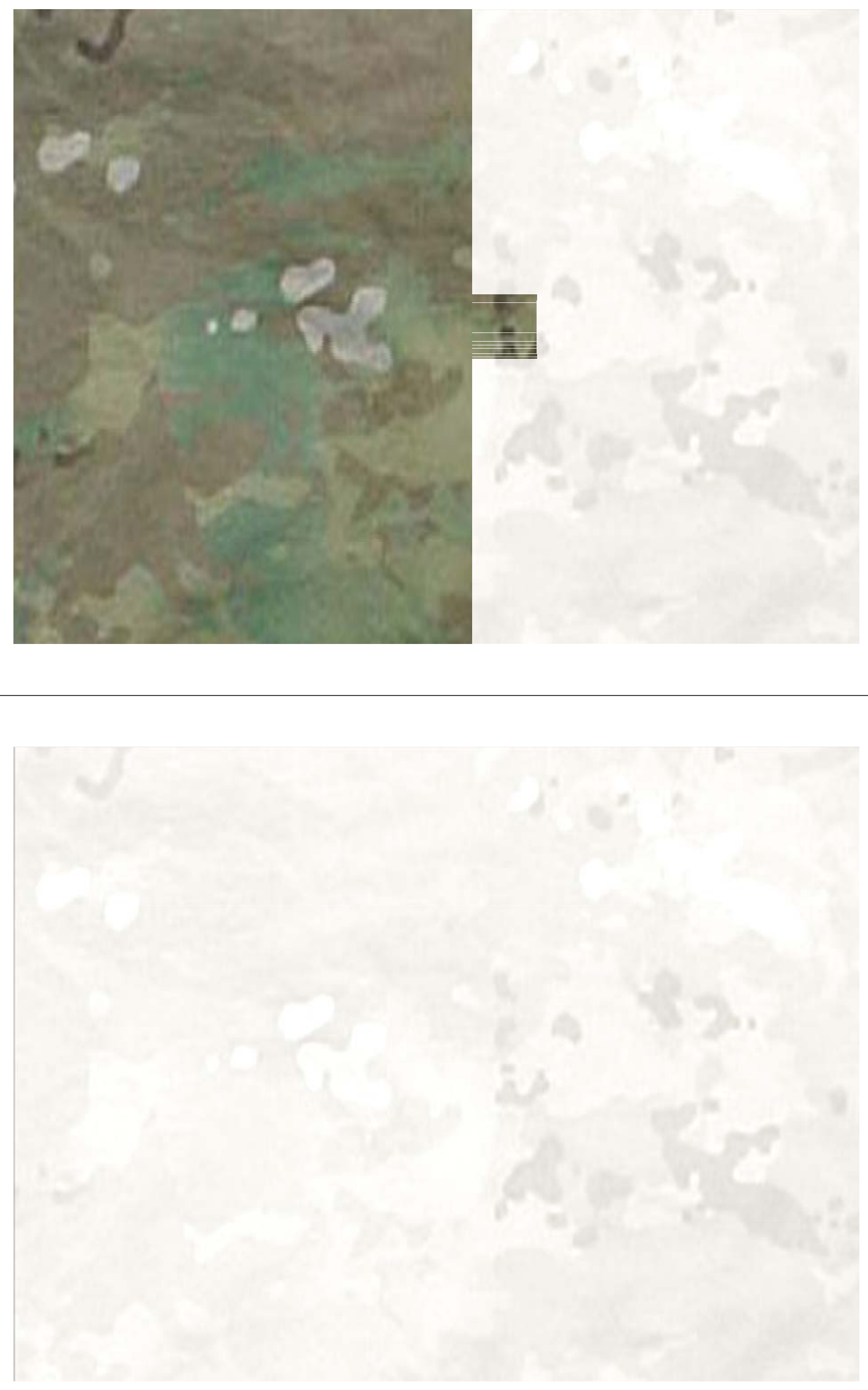


\section{An Owner-Builder Perspective (continued)}

Some additional thoughts ......

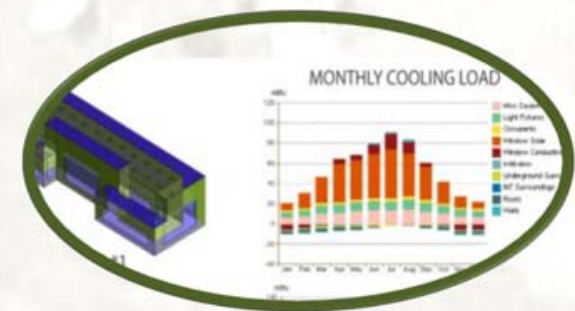

$\rightarrow$ Measure only what we need to know

$\rightarrow$ How are we informed what that is?

$\rightarrow$ Are dashboards more effective than meters?

$\rightarrow$ Is there a role for BIM?

$\rightarrow$ Require measures that hold a designer/builder accountable

$\rightarrow$ We have had success with air tightness and infrared testing

$\rightarrow$ Help us discern Designer/Building/User affects on building performance

$\rightarrow$ Need something more....

\section{Sample Army MDMS Display work in progress}

Compare against

reference building monthly consumption to detect seasonal trends
Compare across

climate zones for same building type

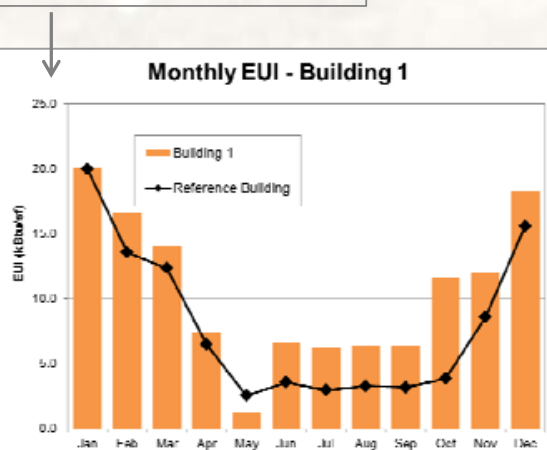

Annual EUI - Building 1

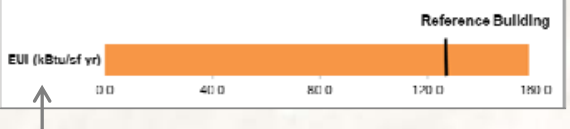

Compare annual EUI of 'your' building with reference building
TEMF Reference Building Annual EUI Across Climate Zones

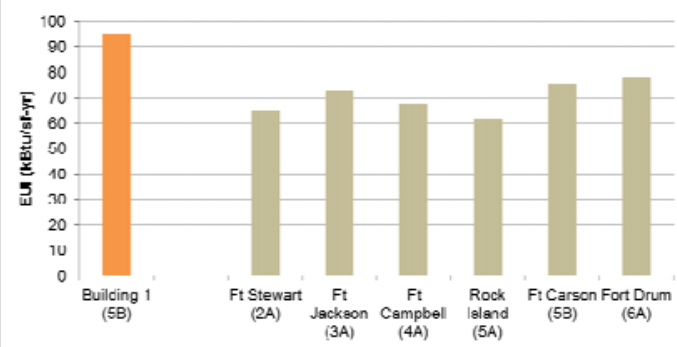

Fort Carson (5B) Annual Reference Building EUI

Compare across building types in same climate zone

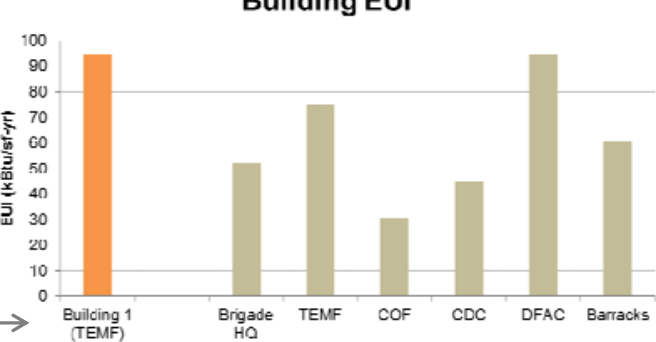




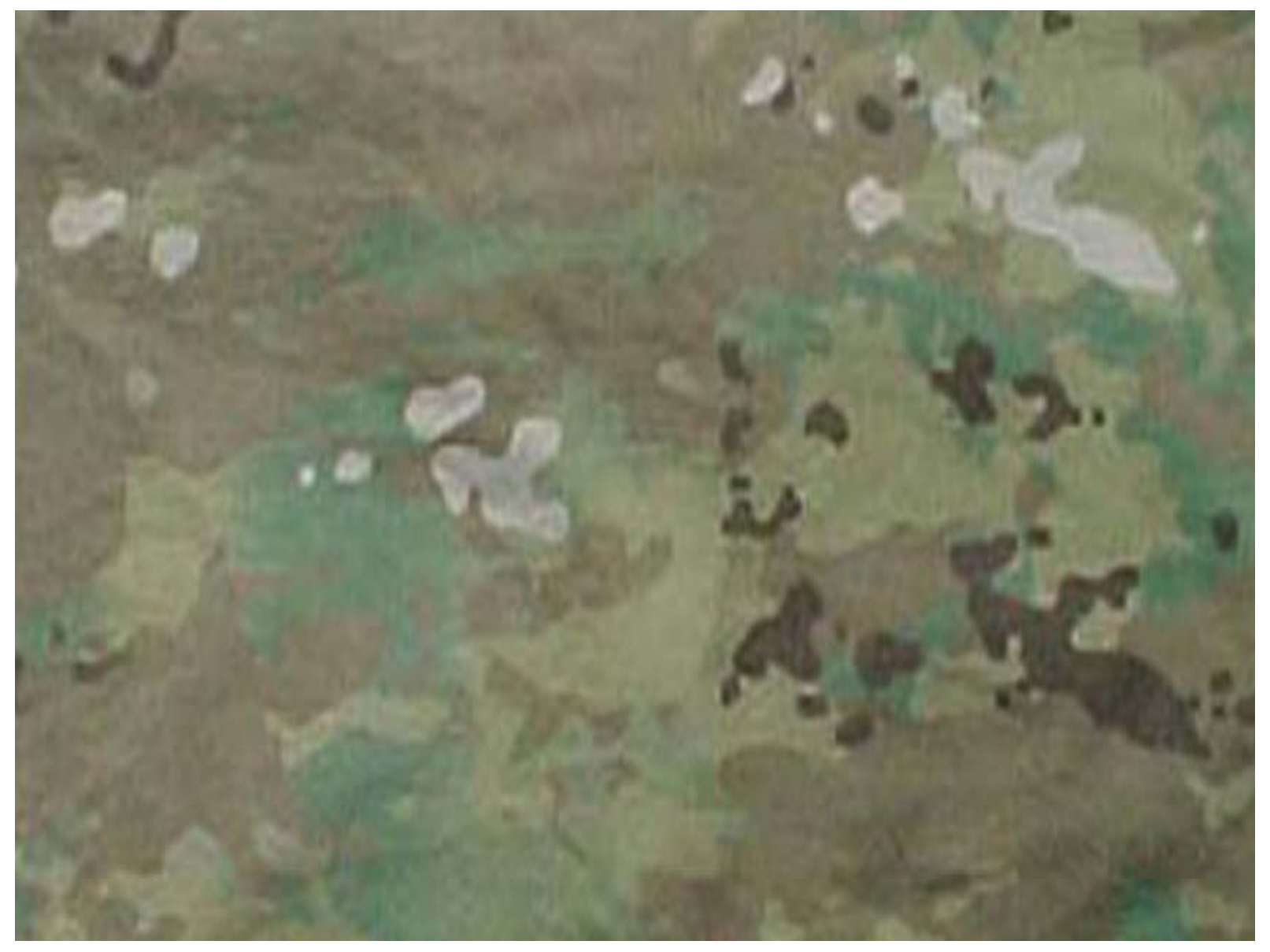


Bo Kasal,

Fraunhofer WKI, Braunschweig, Germany

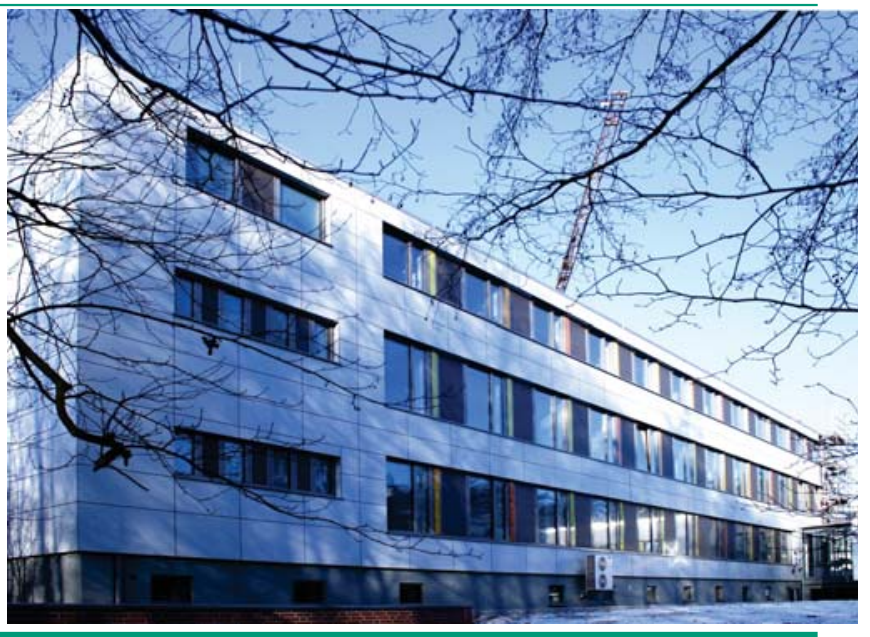

\section{The Fraunhofer-Gesellschaft}

\section{Research and development}

- Application-oriented research of direct use to businesses and for the benefit to society

- Application-oriented basic research

- Departmental research for the German Federal Ministry of Defense

Business community

- Institutes work as profit centers

- One-third of the budget consists of income from industrial projects

- Spinoffs by Fraunhofer researchers are encouraged

Contracting partners/clients

- Industrial and service companies

- Public sector

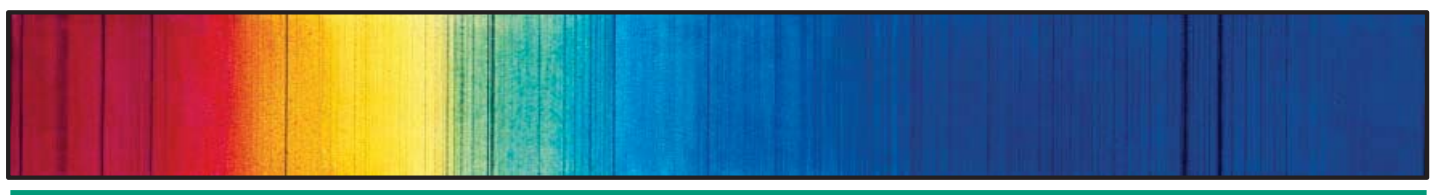


of which 1.7 billion euros is generated through contract research.

- $2 / 3$ of this research revenue derives from contracts with industry and from publicly financed research projects.

- 1/3 is contributed by the German federal government and the Länder governments in the form of institutional financing.

International collaboration through representative offices in Europe, the US, Asia and the Middle East

Discovery of the

"Fraunhofer lines" in

the solar spectrum

New methods for

processing lenses

Director and partner

in a glassw orks
The FraunhoferGesellschaft
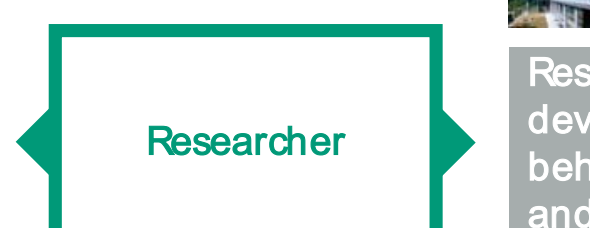

Research and

development on

behalf of industry

and state

\section{mp3 music format,}

white LED, high-

resolution thermal

camera

Research volume:

approx. 2.0 billion

euros annually 


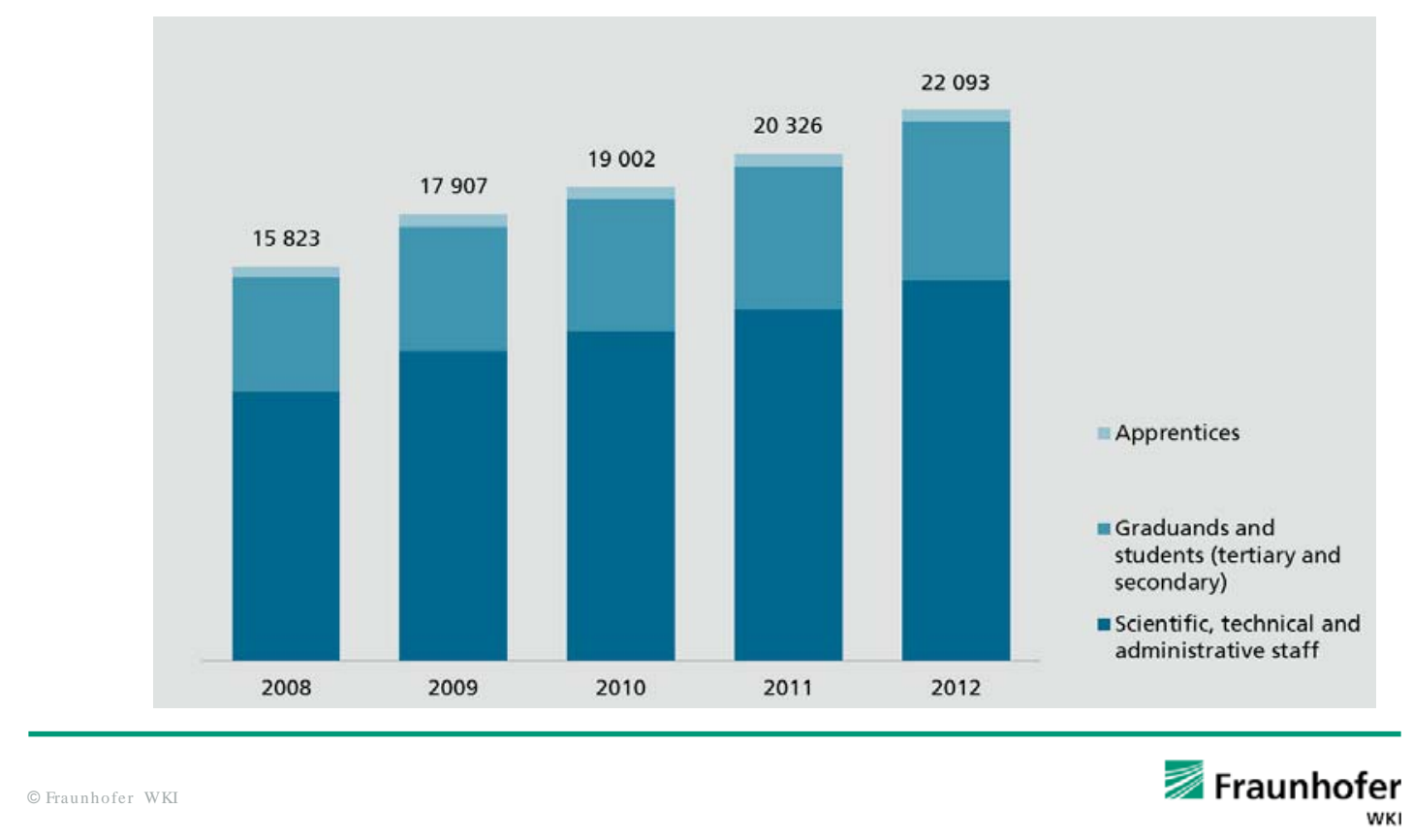

\section{Fraunhofer Alliances}

Adaptronics

Additive Manufacturing

Advancer

Ambient Assisted Living AAL

Automobile Production

Building Innovation

Cleaning Technology

Cloud Computing

2(e) Digital Cinema

(Q) E-Government

Embedded Systems
Energy

Food Chain Management

Lightweight Structures

Nanotechnology

Optic Surfaces

Photocatalysis

Polymer Surfaces POLO

Simulation

Traffic and Transportation

Vision

Water Syst ems (SysWasser) 

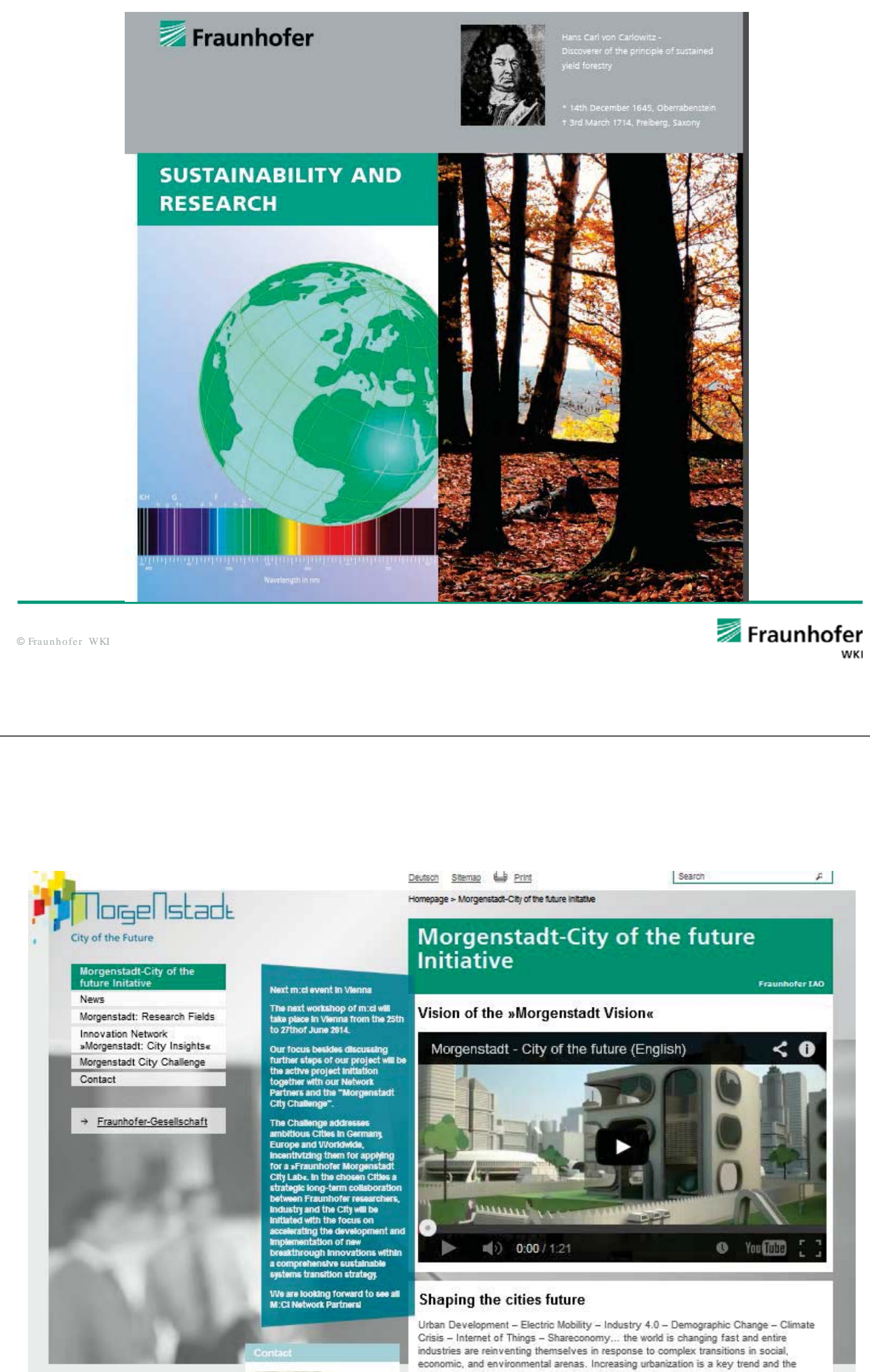

Devischn Sthenas $\in$ Print

L search

$=1$

Homepage $>$ Morgenstas-Chy or the Wuure intashe

Morgenstadt-City of the future Initiative

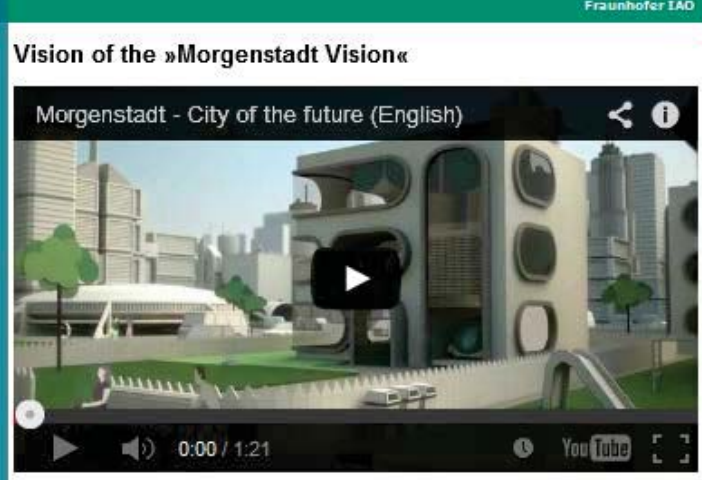

Shaping the cities future

Urban Development - Electric Mobiilty - Industry 4.0 - Demographic Change - Climate Crisis - Internet of Things - Shareconomy... the world is changing fast and entire industries are reinventing themselves in response to complex transitions in social, economic, and environmental arenas. Increasing urbanization is a key trend and the 


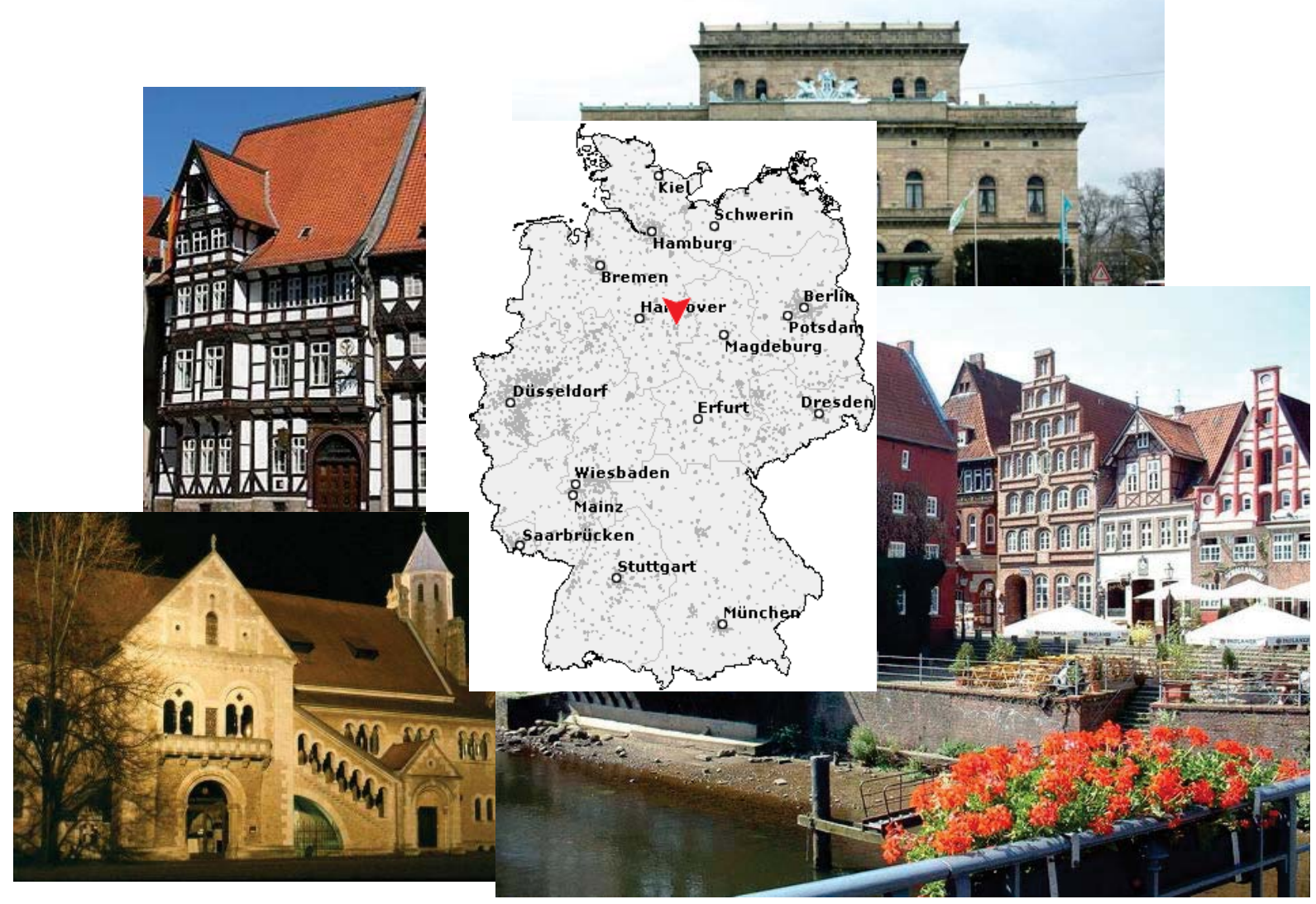

\section{Phases of construction}

- land development phase

- material production phase

- construction phase

- building function/use phase

- maintenance and repair phase

- deconstruction and recycling phase 
communication

\section{Material production phase}

- production of building materials

- can be speculative if not defined for a specific project with known suppliers 


\section{Building function/use phase}

- can be measured/quantified

- building can be instrumented and data collected

- energy use

water use

- building comfort parameters....... 


\section{Deconstruction}

- speculative

- no good data avaiable

- hard to predict 


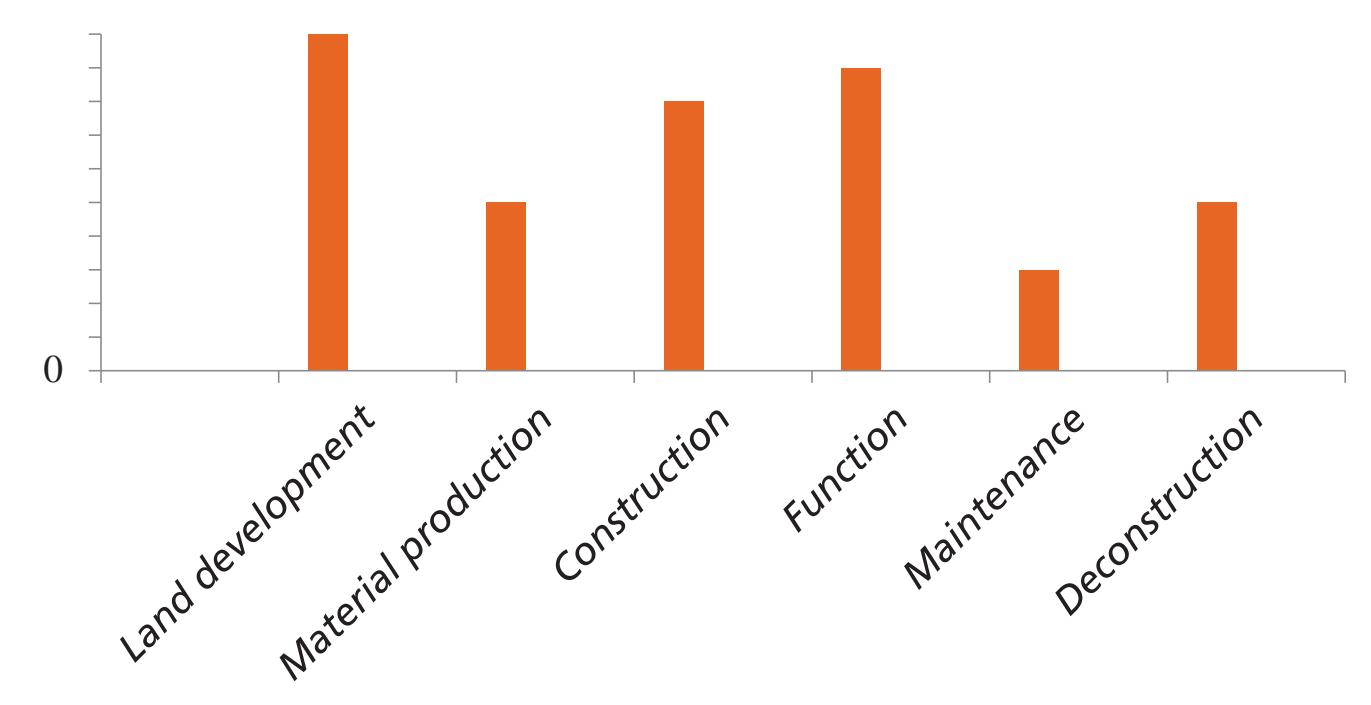

(i)

\section{Sources of uncertainty}

- Random error and statistical variation (measurement error)

- Systematic error and subjective judgment

- Linguistic imprecision (Assigning quantitative parameter estimates based on qualitative descriptors)

- Variability (data variability)

- Inherent randomness and unpredictability

- Expert uncertainty and disagreement

- Approximation 


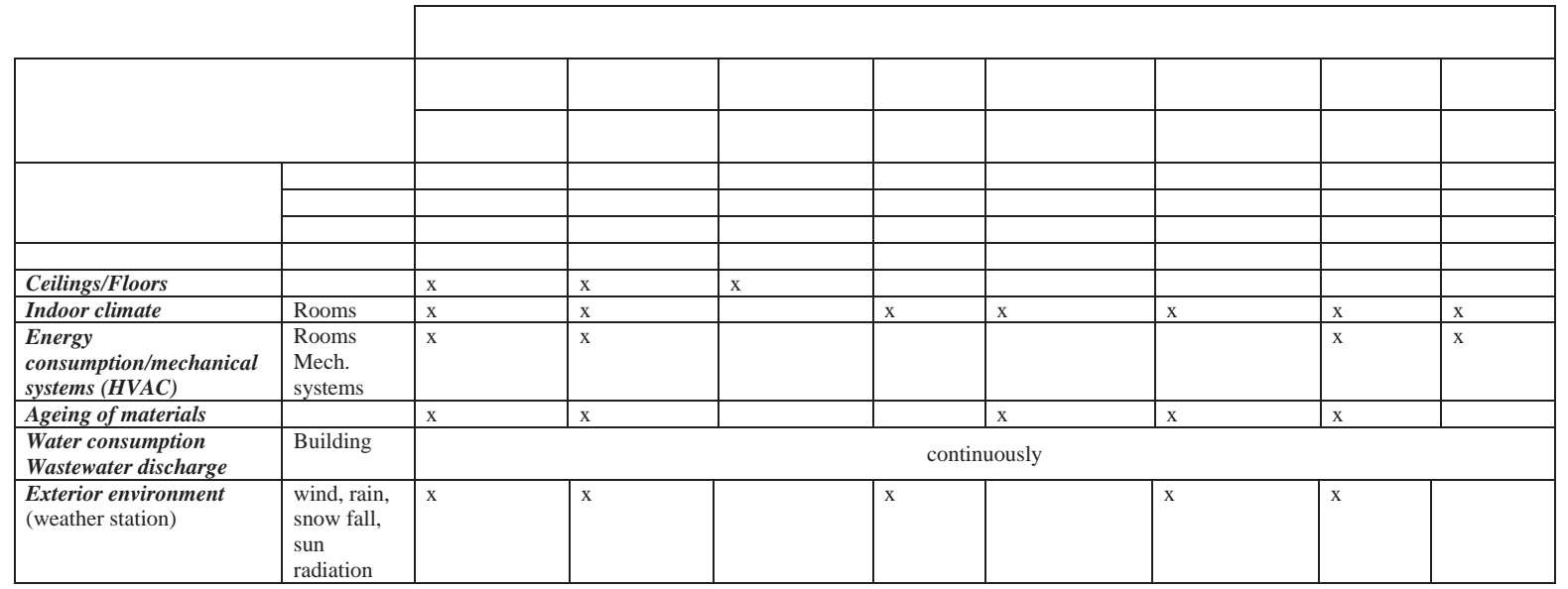

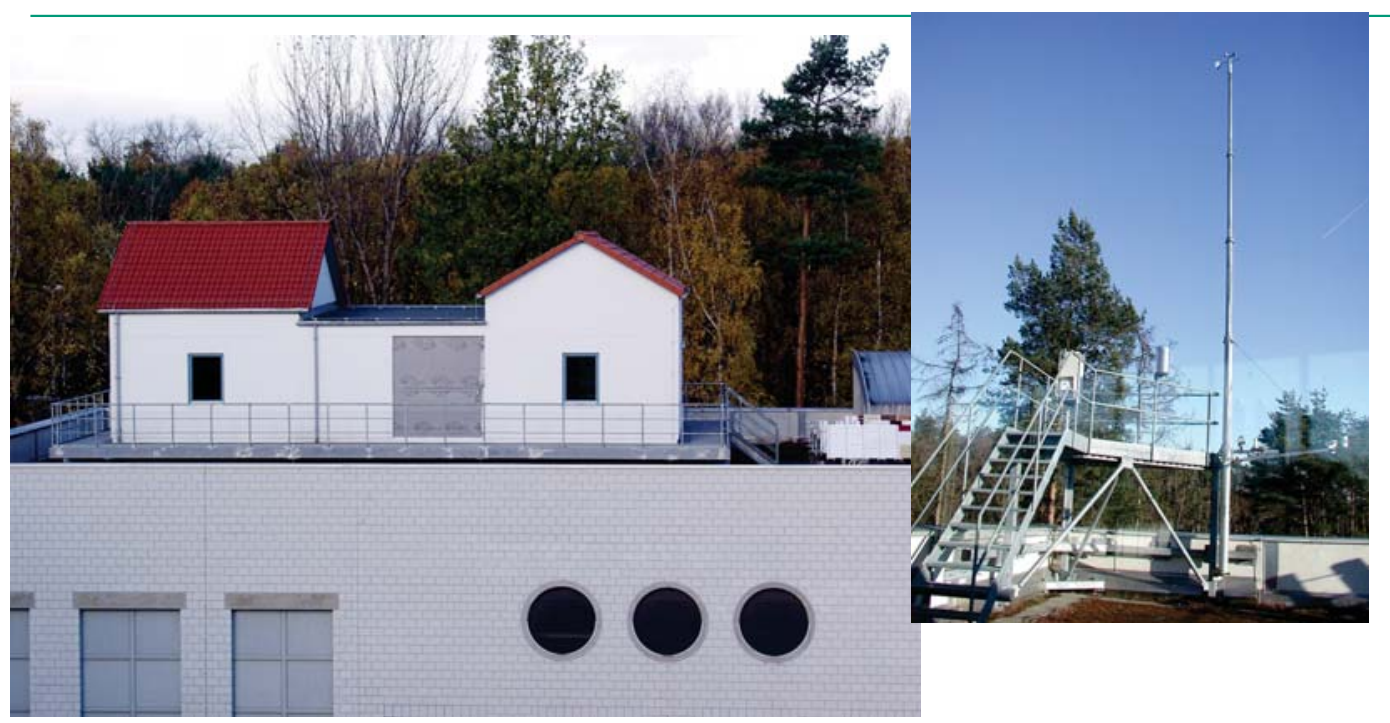




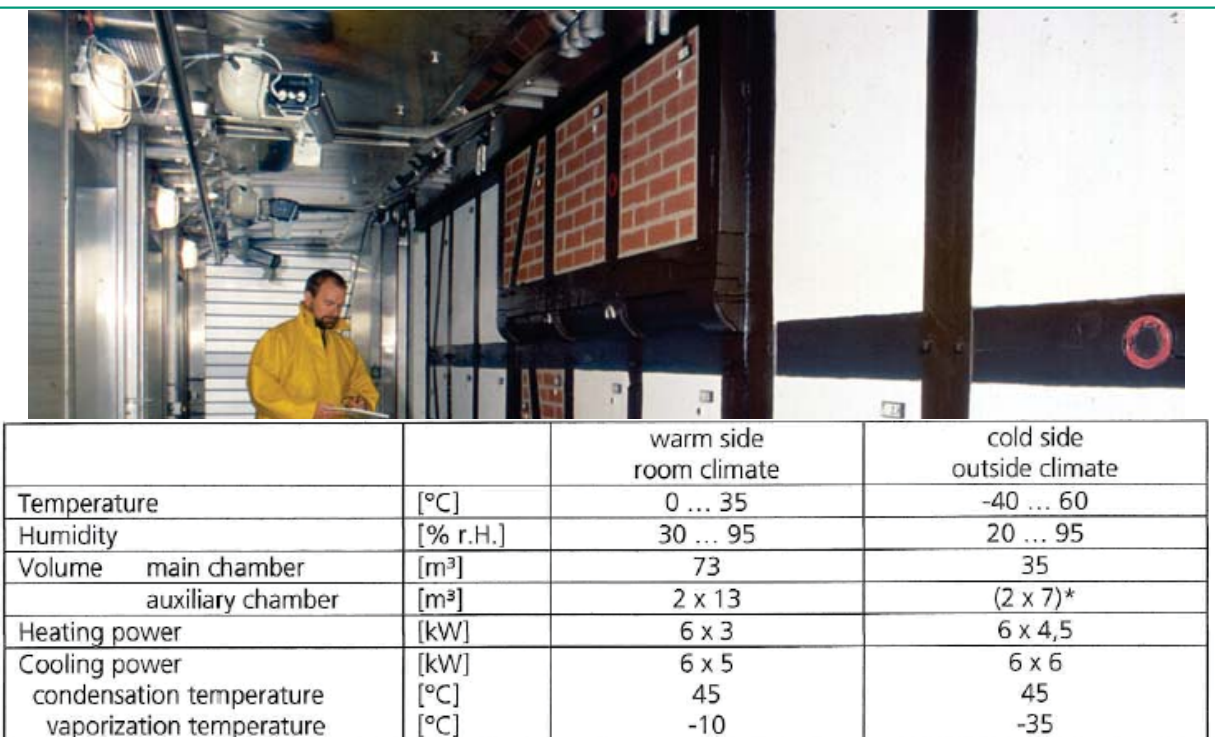

* Standby chambers for sun- and rain simulators

A Relative Humidity Sensor

Thermistor

Condensation Sensor
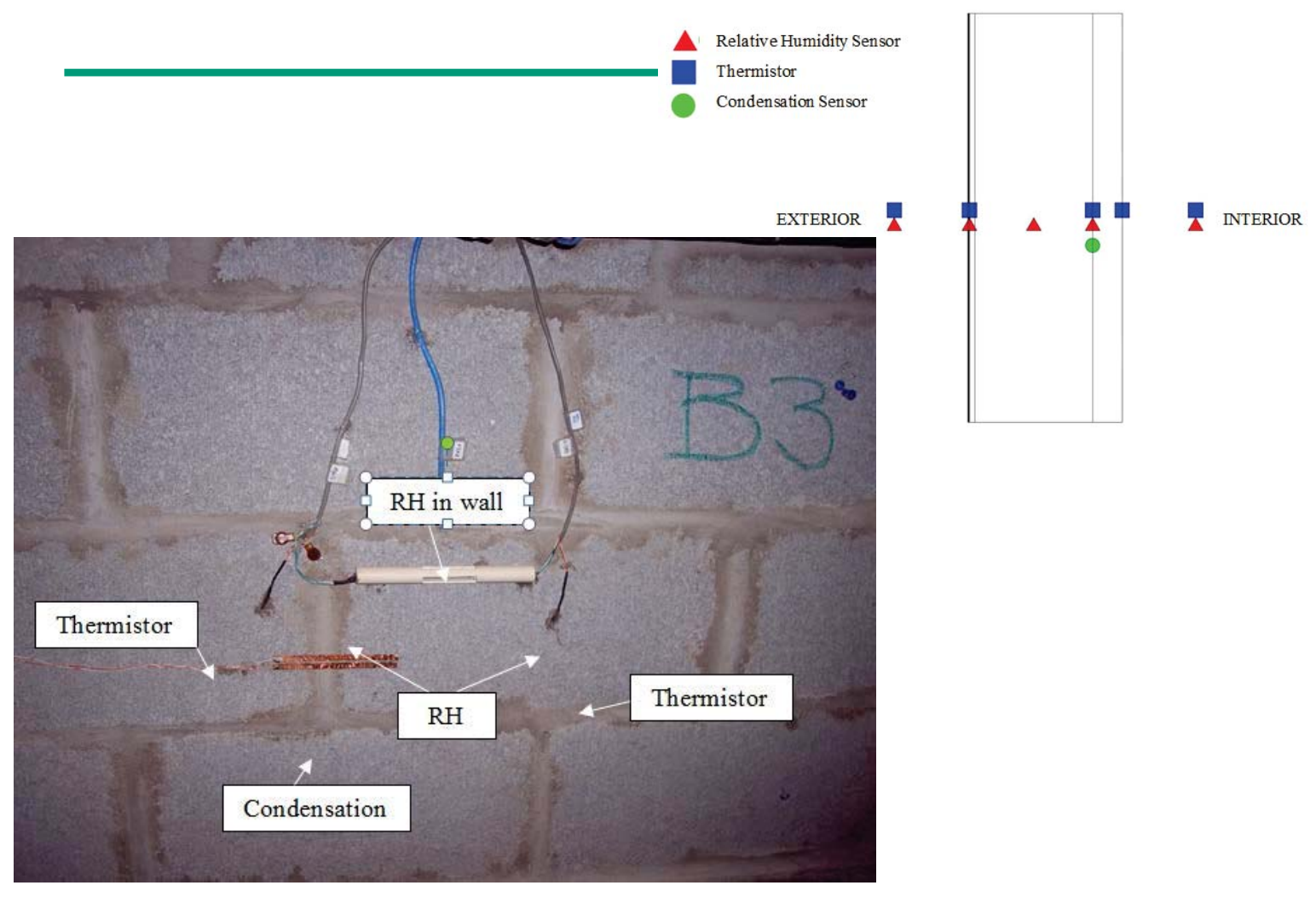


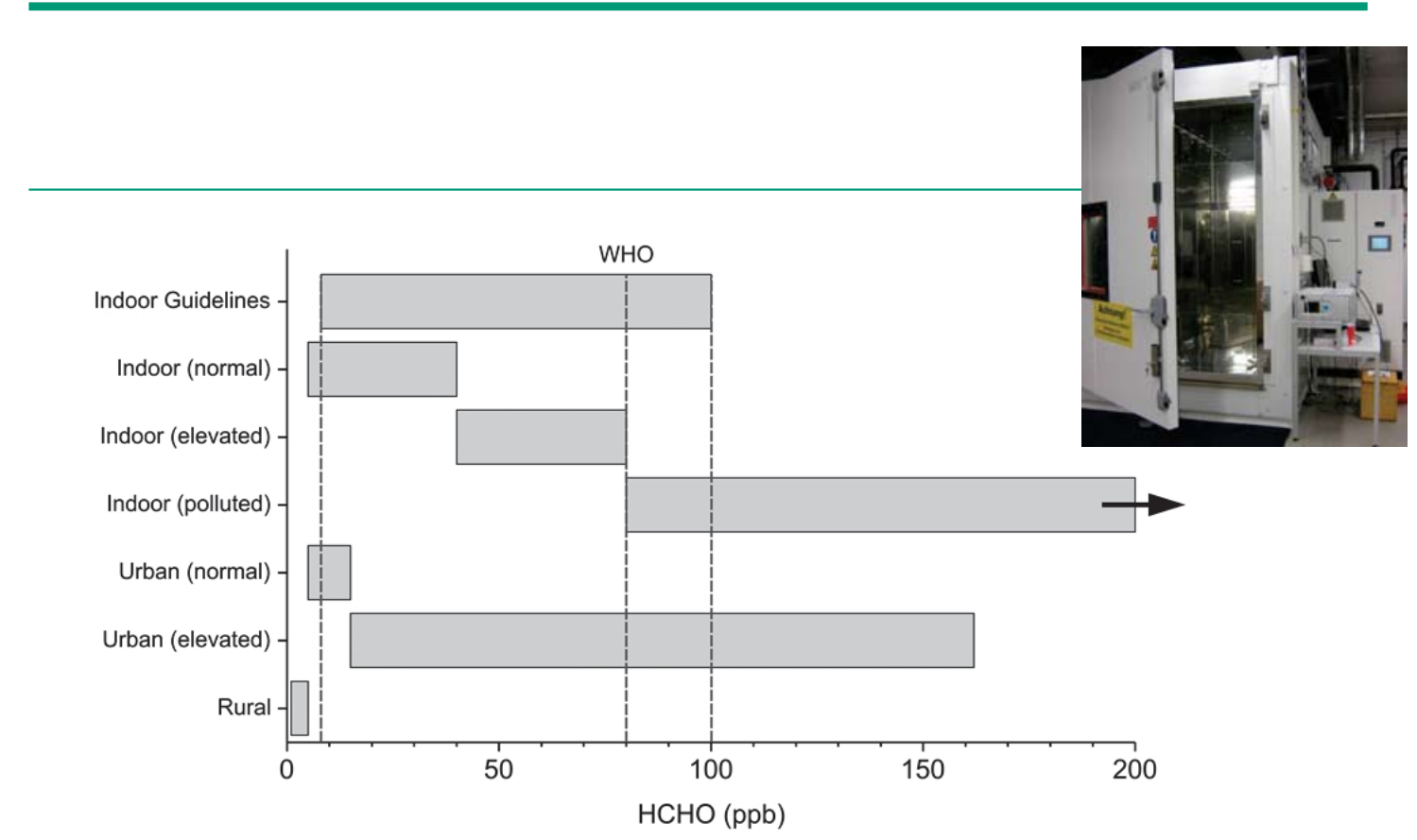

Salthammer (2013) Angew. Chem. Int. Ed. 52, 3320-3327

\section{Indoor air quality-example of inconsistencies ( $\mathrm{HCHO}$ )}

California /
USA

Japan

Russia

China
CARB

Phase 2

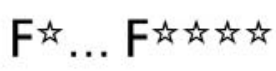

E1
PB: $0.09 \mathrm{ppm}$

MDF: $0.11 \mathrm{ppm}$

Thin MDF: $0.13 \mathrm{ppm}$

PLY: $0.05 \mathrm{ppm}$

F放神 (JIS chamber): $0.005 \mu \mathrm{g} / \mathrm{h} \cdot \mathrm{m}^{3}$

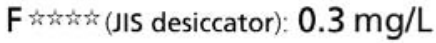

$\mathrm{F}$ 粮解 can be used indoor without any restriction coated PB: $0.1 \mathrm{ppm}$

probably new (July 1st, 2014): $0.01 \mathrm{ppm}$

PLY: $0.1 \mathrm{ppm}$

PB: $8 \mathrm{mg} / 100 \mathrm{~g}$ dry board

$\mathrm{E} 1: \leq 0.1 \mathrm{ppm}$

$\leq 9.0 \mathrm{mg} / 100 \mathrm{~g}$ dry board

$\mathrm{E2} *$ : $\leq 30 \mathrm{mg} / 100 \mathrm{~g}$ dry board

*use for indoor air only after surface treatment 
Europe E1 E2

13986 building products

(reference chamber method EN 717-1):

$\mathrm{E} 1: \leq 0.1 \mathrm{ppm} \quad\left(\bumpeq 0.124 \mathrm{mg} / \mathrm{m}^{3}\right)$

$\mathrm{E} 2:>0.1 \mathrm{ppm} \quad\left(\triangleq 0.124 \mathrm{mg} / \mathrm{m}^{3}\right)$

$<0.24 \mathrm{ppm}\left(\triangleq 0.3 \mathrm{mg} / \mathrm{m}^{3}\right)$

Germany

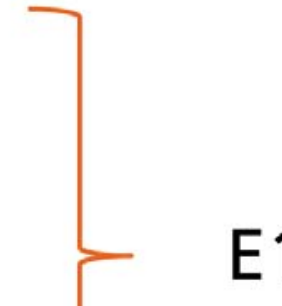

E1 building products and

Denmark

furniture

Italy

Sweden

\section{Assesment of building sustainability}

- considered „soft science“

- number of standards available

- many parameters subjective or speculative ${ }^{1}$

- using of materials from renewable resources makes the building not automatically sustainable

- stochastic approaches desirable $e^{1,2}$

1. Shannon M. Lloyd and Robert Ries. (2007) Characterizing, Propagating, and Analyzing Uncertainty in Life-Cycle Assessment A Survey of Quantitative Approaches. Journal of Industrial Uncertainty in Life-

2. 2. Miller, Shelie A., Stephen Moysey, Benjamin Sharp and Jose Alfaro. (2013) “A Stochastic Approach to Model Dynamic Systems in Life Cycle Assessment." Journal of Industrial Ecolog. 17(3): $352-362$

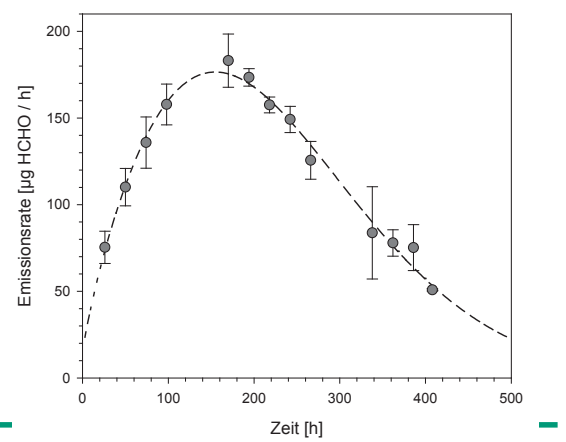


- people in rich countries use 10x more natural resources than those in poor countries

Our ability to move tow ards sustainability may be limited.

Perhaps, our solutions should be adjusted to the needs of the $80 \%$ of the population

Sources: http://unstats.un.org/unsd/demographic/products/dyb/dyb2011/Table 01.pdf; http://unstats.un.org/unsd/demographic/products/socind/default.htm (table

1c); http://mdgs.un.org/unsd/mdg/Resources/Static/Products/Progress2012/English2012 pdf. http://www fao org/docrep/016/i3010e/i3010e.pdf (State of the World's Forests 2012); Williams, M. 2002. Deforesting the earth: from prehistory to global crisis. Chicago, USA, University of Chicago Press.

http://www.fao.org/docrep/013/11757e/i1757e.pdf; https://www.cia.gov/library/publications/the-world-factbook/rankorder/2004rank.htmls

http://iresearch.worldbank.org/PovcalNet/index.htm?1; http://www.prb.org/pdf12/2012-population-data-sheet eng.pdf

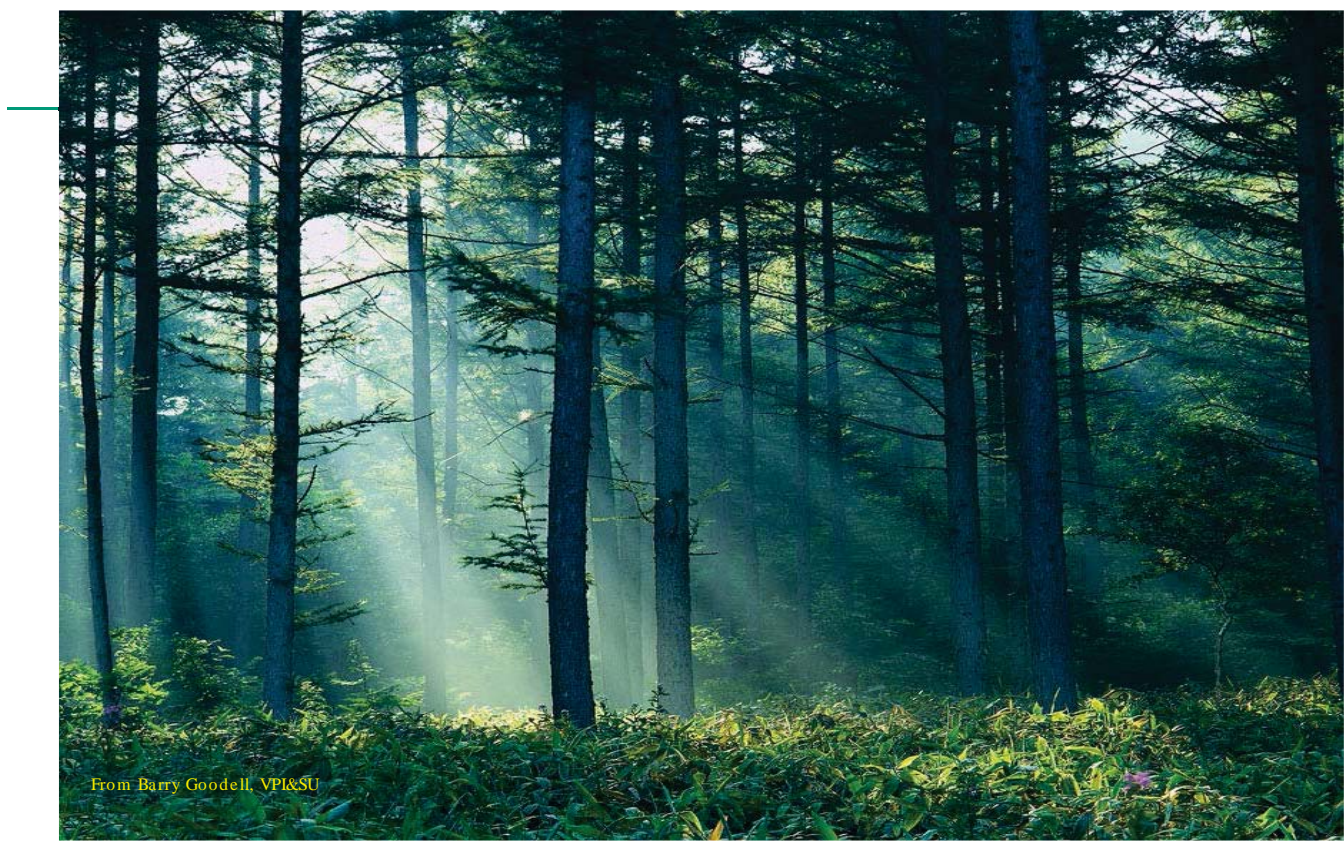


CURRENT \& FUTURE OPPORTUNITIES FOR MEASURES OF

HIGH PERFORMANCE

GREEN BUILDINGS

A DECADE OF GREEN BUILDING

RESULTS ON THE

GROUND 


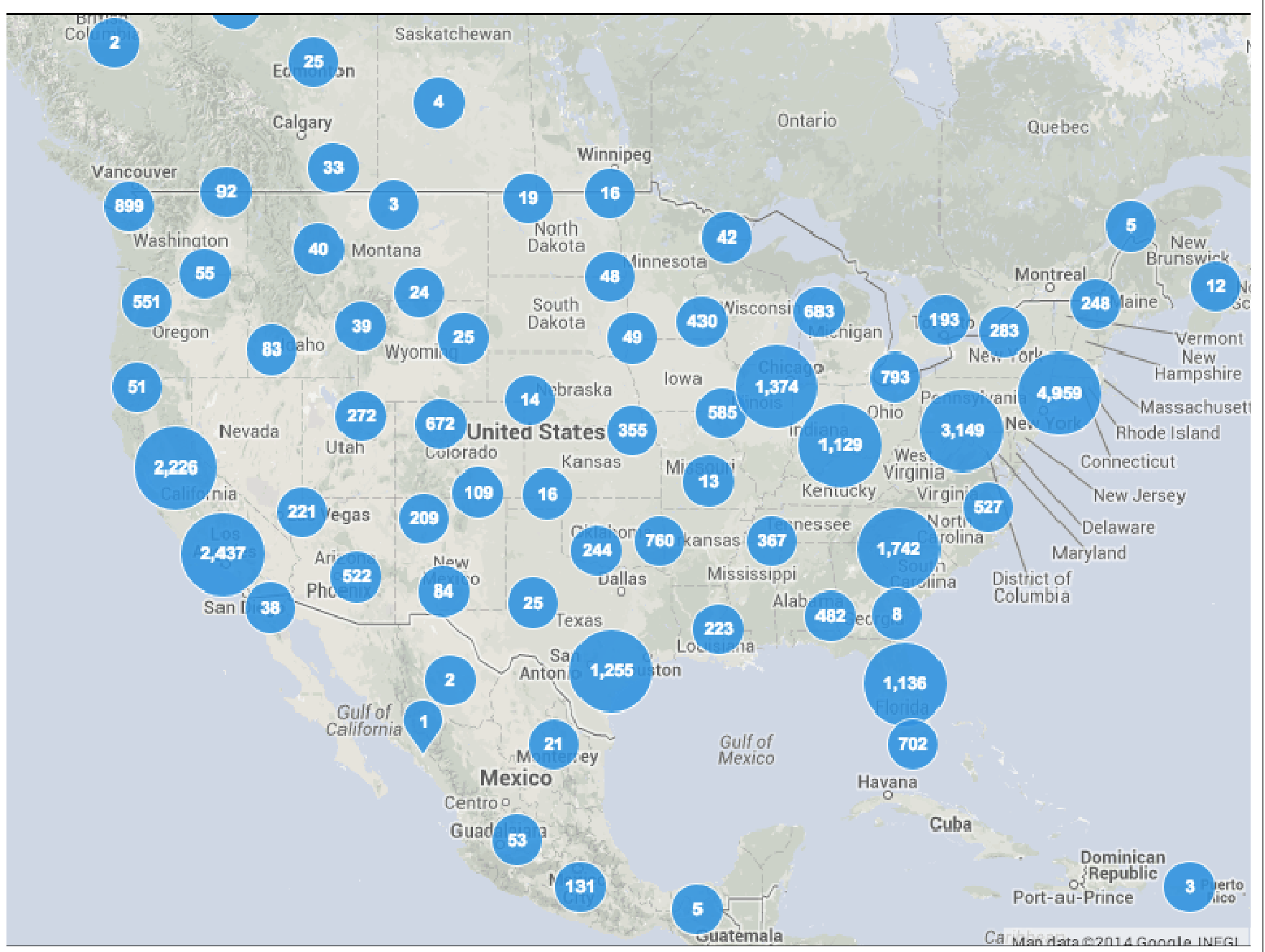

LEED AND ENERGY STAR: 74,265 BUILDINGS WITH $>2,000$ GREEN ATTRIBUTES AND PERFORMANCE MEASURES 


\section{ENERGY}

ASHRAE 90.1

TITLE 24

ENERGY STAR

RENEWABLE ENERGY

GREEN POWER

\section{SITE DESIGN}

ACCESSIBILITY

STORMWATER

HEAT ISLAND

\section{OCCUPANTS}

\section{WATER}

FIXTURE EFFICIENCY LANDSCAPING PROCESS

\section{MATERIALS}

SOURCE RECYCLED CONTENT END-OF-LIFE

SATISFACTION

COMFORT

CONTROL

\section{IMPLIED VALUE OF METRICS}

\section{RANK}

1

2

3
RATING SYSTEMS

OPERATIONAL ENERGY

OPERATIONAL WATER

MATERIALS 


\section{IMPLIED VALUE OF METRICS}

\begin{tabular}{|c|c|c|}
\hline RANK & $\begin{array}{c}\text { RATING } \\
\text { SYSTEMS }\end{array}$ & ENV IMPACT \\
\hline 1 & OPERATIONAL ENERGY & $\begin{array}{l}\text { OCCUPANT BEHAVIOR \& } \\
\text { PERFORMANCE }\end{array}$ \\
\hline 2 & OPERATIONAL WATER & OPERATIONAL ENERGY \\
\hline 3 & MATERIALS & MATERIALS \\
\hline 4 & $\begin{array}{l}\text { BEHAVIOR \& } \\
\text { SATISFACTION }\end{array}$ & OPERATIONAL WATER \\
\hline
\end{tabular}

\section{IMPLIED VALUE OF METRICS}

\begin{tabular}{|c|c|c|c|}
\hline RANK & $\begin{array}{c}\text { RATING } \\
\text { SYSTEMS }\end{array}$ & $\begin{array}{c}\text { ENV } \\
\text { IMPACT }\end{array}$ & $\begin{array}{l}\text { FINANCIAL } \\
\text { IMPACT }\end{array}$ \\
\hline 1 & $\begin{array}{l}\text { OPERATIONAL } \\
\text { ENERGY }\end{array}$ & $\begin{array}{c}\text { OCCUPANT } \\
\text { BEHAVIOR \& } \\
\text { PERFORMANCE }\end{array}$ & $\begin{array}{c}\text { OCCUPANT } \\
\text { BEHAVIOR \& } \\
\text { PERFORMANCE }\end{array}$ \\
\hline 2 & $\begin{array}{l}\text { OPERATIONAL } \\
\text { WATER }\end{array}$ & $\begin{array}{l}\text { OPERATIONAL } \\
\text { ENERGY }\end{array}$ & $\begin{array}{l}\text { OPERATIONAL } \\
\text { ENERGY }\end{array}$ \\
\hline 3 & MATERIALS & MATERIALS & $\begin{array}{c}\text { OPERATIONAL } \\
\text { WATER }\end{array}$ \\
\hline 4 & $\begin{array}{l}\text { BEHAVIOR \& } \\
\text { SATISFACTION }\end{array}$ & $\begin{array}{l}\text { OPERATIONAL } \\
\text { WATER }\end{array}$ & MATERIALS \\
\hline
\end{tabular}




\section{A SCENARIO OF FUTURE DATA AVAILABILITY}

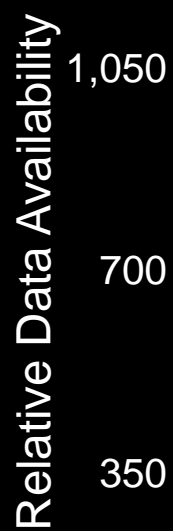

0

Energy

INTERESTED IN THIS CHALLENGE?

EXPLORE:

CONTACT:

FOLLOW@CHRISPYKE 


\section{Introduction to Breakout Sessions}

Richard N. Wright, Dist.M.ASCE, NAE

June 12, 2014

\section{Sustainability in Construction and Manufacturing}

- No separation between construction and manufacturing because constructed facilities are manufactured products.

- For both, we are interested in sustainability over their whole life cycles.

- Generally similar measurement issues are expected, but distinctions should be noted as they occur to a breakout session team. 


\section{Objectives of Breakout Sessions}

- Identify knowledge gaps and research needs relating to measurement science for sustainable construction and manufacturing

- Provide suggestions in the form of problems, descriptions, analyses, recommendations and actions for the consideration of NIST

\section{Breakout Sessions}

1. Measurement science (definition, standards, metrics, indicators and ratings)

2. Systems (aggregation, linkages, system of systems, sustainability-resilience synergy and interdependencies)

3. Planning, design and supply chain (lifecycle analyses and treatments, and material and energy efficiency)

4. Economic, environmental and social aspects (valuation, impacts and behavior). 


\section{Breakouts Are Not Silos}

We expect synergies to arise as similar or identical issues/problems are identified and dealt with in two or more breakouts.

Breakouts do provide different starting foci.

We hope this helps capture the most important measurement science needs.

Draw upon the workshop papers and presentations and your own experiences.

\section{Breakout Forms}

1. Problem Definition: Problem Name, Problem Description (Drafted in advance by the co-moderators)

2. Recommendation: Name, Root Cause, Recommendation, Action Plan, Roles

3. Breakout Team: Name, Affiliation, Email, Phone 


\section{Problem Description}

\begin{tabular}{|l|l|}
\hline Problem Title & \multicolumn{1}{|c|}{ Problem Description } \\
\hline & \\
\hline & \\
\hline & \\
\hline & \\
\hline & \\
\hline & \\
\hline & \\
\hline & \\
\hline & \\
\hline
\end{tabular}

NIST Workshop on Measurement Science for Sustainable Construction and Manufacturing, June 12-13, 2014

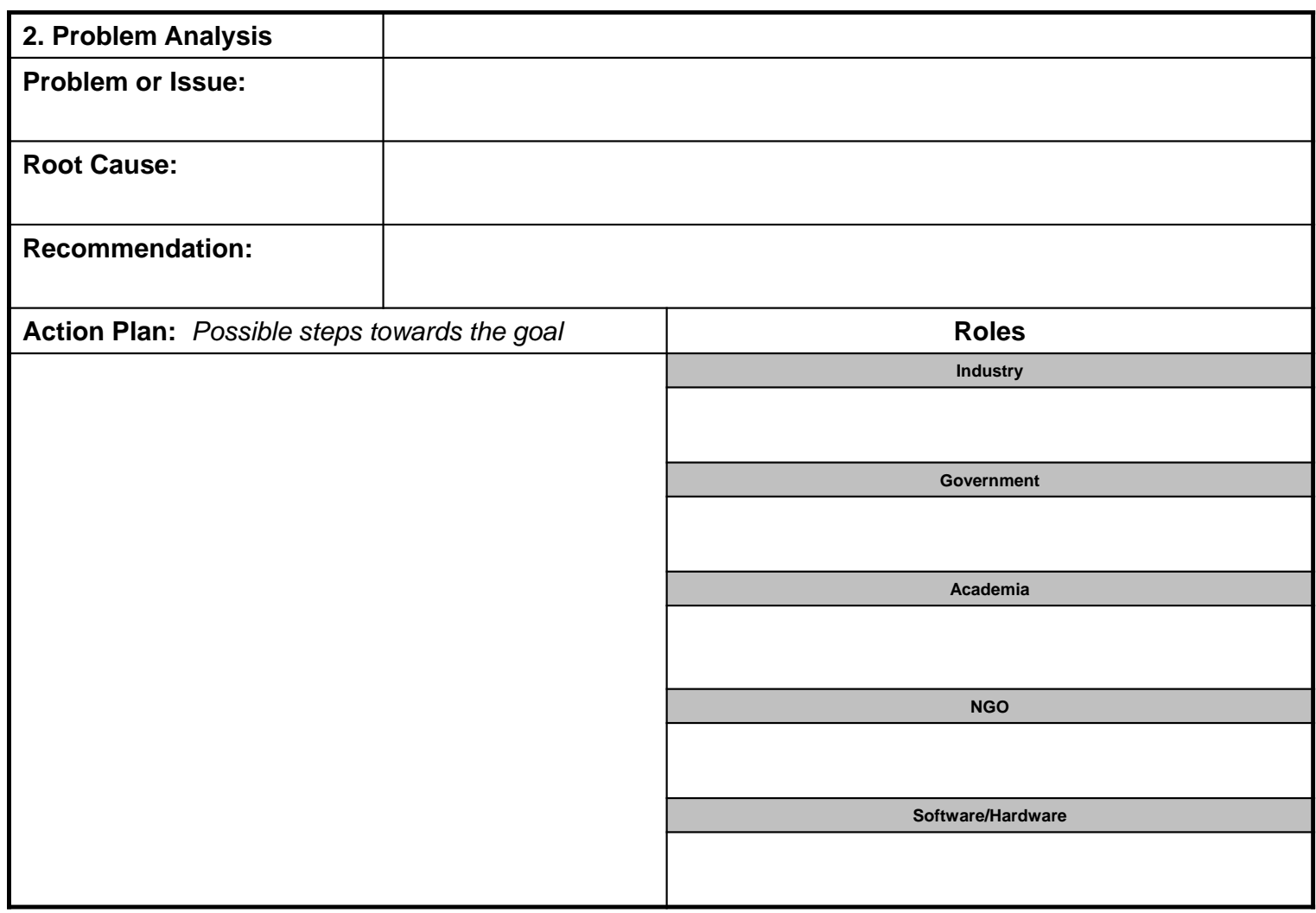




\section{Breakout Team}

\begin{tabular}{|l|l|}
\hline Name/Affiliation & Email/Phone \\
\hline & \\
\hline & \\
\hline & \\
\hline & \\
\hline & \\
\hline & \\
\hline & \\
\hline & \\
\hline & \\
\hline & \\
\hline
\end{tabular}

NIST Workshop on Measurement Science for Sustainable Construction and Manufacturing, June 12-13, 2014

\section{Breakout Schedule}

In advance, co-moderators select a person to provide a summary of outcomes at the closing session.

8:45: Problem definitions -identify, describe and assign key problems/issues to working groups (one or more participants)

9:15: Problems analysis - working groups analyze individual problems/issues

\section{9:45: Break}

10:00: Presentation/discussion of analyses

10:45: Working groups complete analyses responding to discussions.

11:00: Breakouts end. 


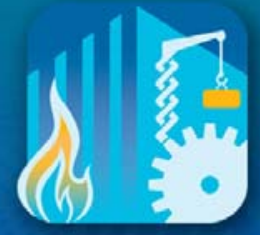

NIST-UMD Workshop on Measurement Science for Sustainable Construction and Manufacturing

Charge to the Breakout Groups

Dr. Joannie Chin Acting Deputy Director Engineering Laboratory NIST

\section{NLT}
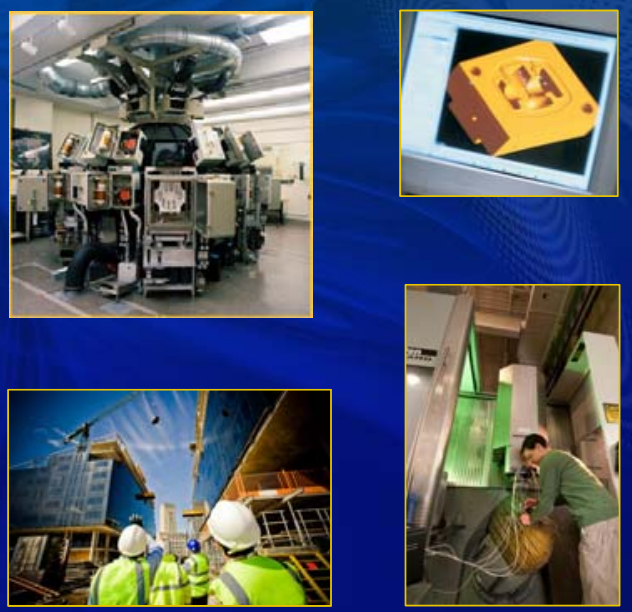

\section{NIST's Mission}

To promote U.S. innovation and industrial competitiveness by advancing measurement science, standards, and technology in ways that enhance economic security and improve our quality of life

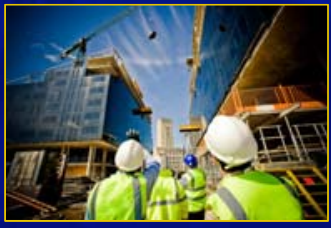




\section{NIST Laboratories}
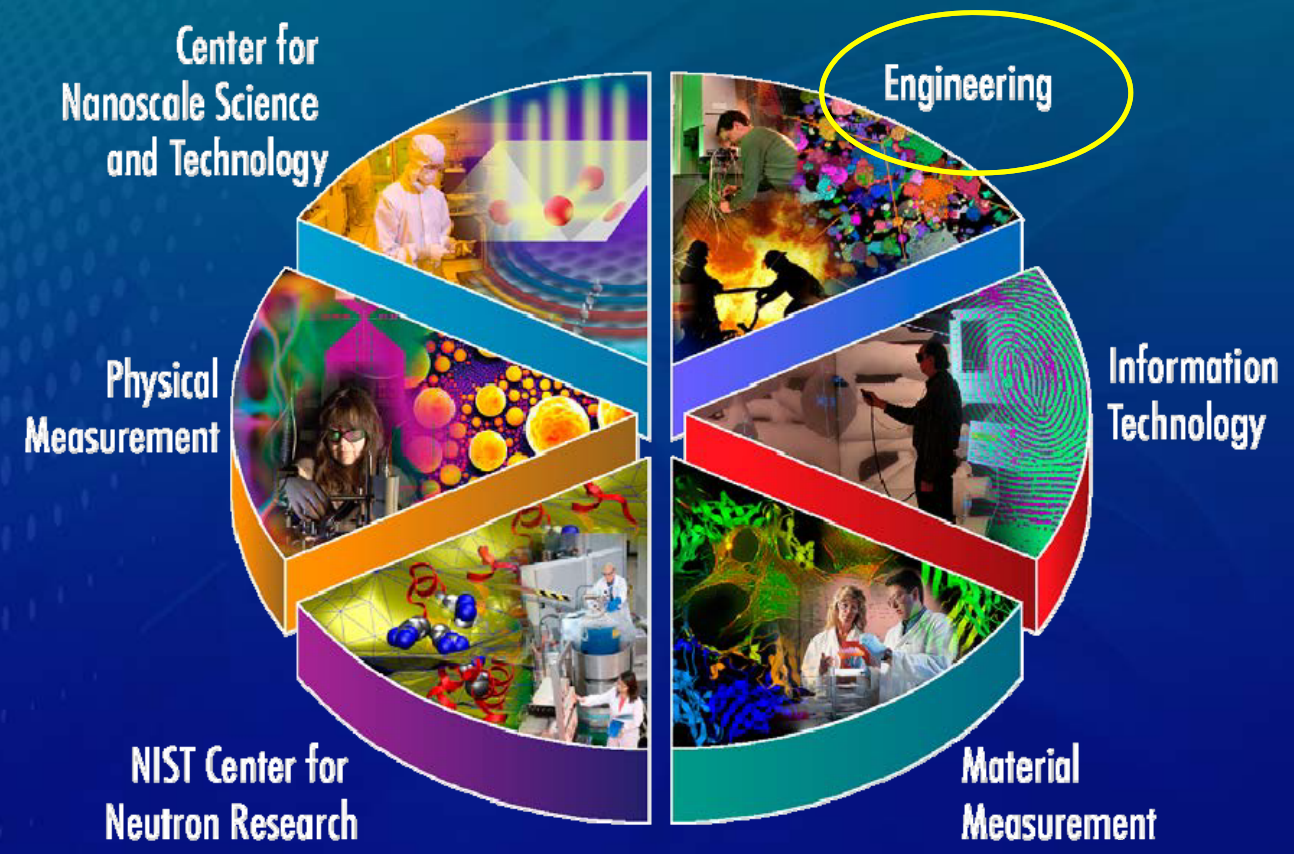

\section{Engineering Lab (EL) Mission}

To promote U.S. innovation and industrial competitiveness in areas of critical national priority by anticipating and meeting the measurement science and standards needs for technology-intensive manufacturing, construction, and cyber-physical systems in ways that enhance economic prosperity and improve the quality of life. 


\section{EL Core Capabilities}

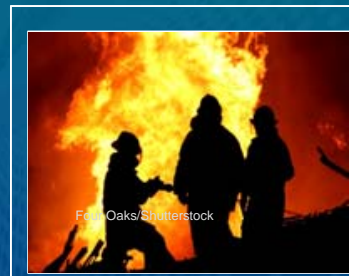

Fire protection, fire physics, materials flammability

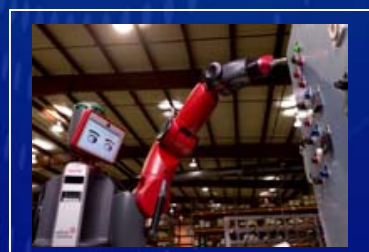

Intelligent sensing, control, robotics and automation

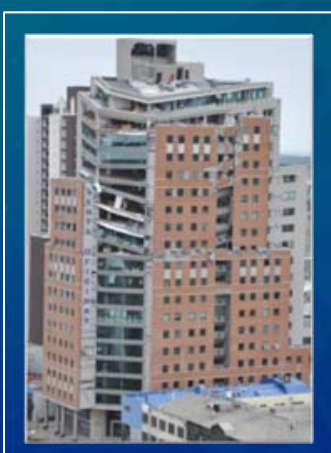

Structural

analysis, disaster and failure studies

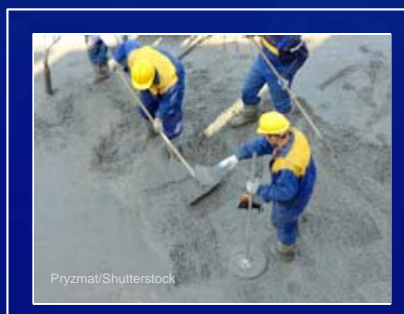

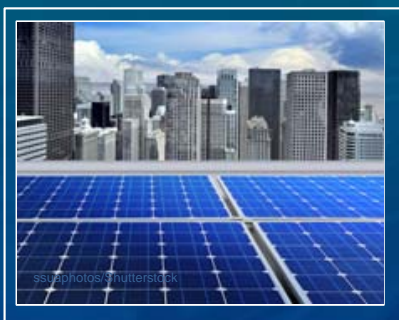

Building and

renewable energy, indoor environment, and building systems performance measurement

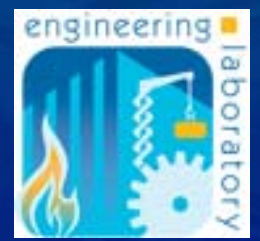

Sustainability, durability, and service life prediction of engineered materials

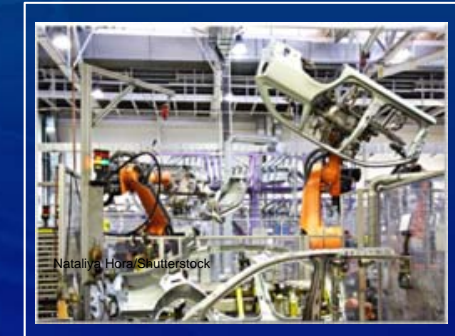

Systems integration, information modeling, model-based engineering

Partnering Strategies with Industry, Academia and Other Federal Agencies

- Planning and Roadmapping Workshops

- Testbeds, Facilities, and Tools

- Codes and Standards Engagement

- Cooperation Mechanisms

- NIST Sponsored Events

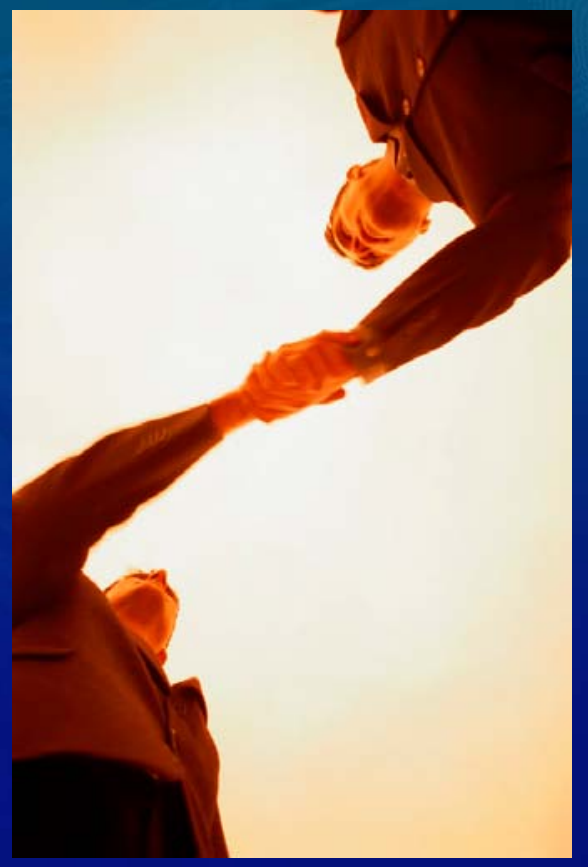




\section{Engineering Laboratory Strategic Goals}

- Smart Manufacturing, Construction,

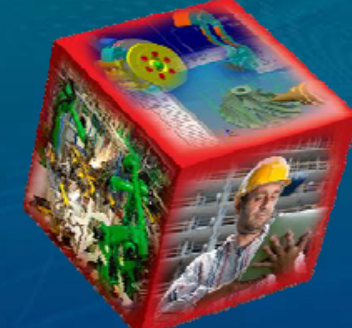
and Cyber-Physical Systems

- Sustainable and Energy-Efficient Manufacturing, Materials, and Infrastructure

- Disaster-Resilient Buildings, Infrastructure, and Communities

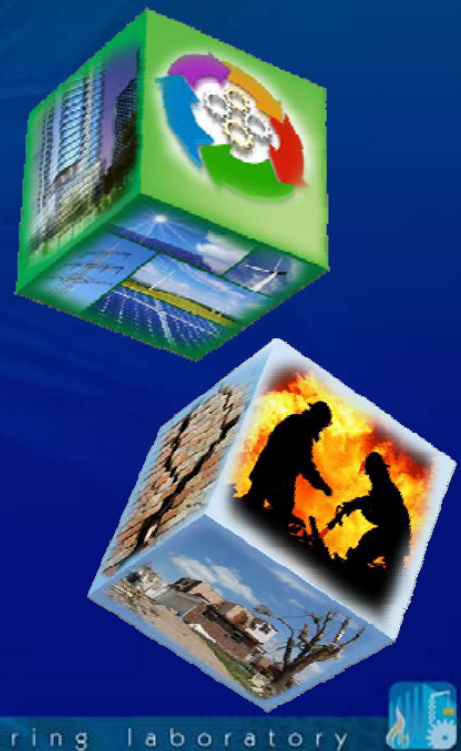

Sustainable and Energy-Efficient Manufacturing, Materials, and Infrastructure

- Sustainable Manufacturing

- Sustainable Engineered Materials

- Net-Zero Energy, HighPerformance Buildings

- Embedded Intelligence in

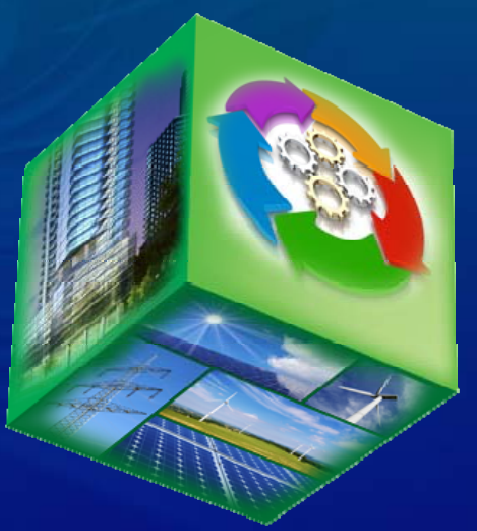
Buildings 


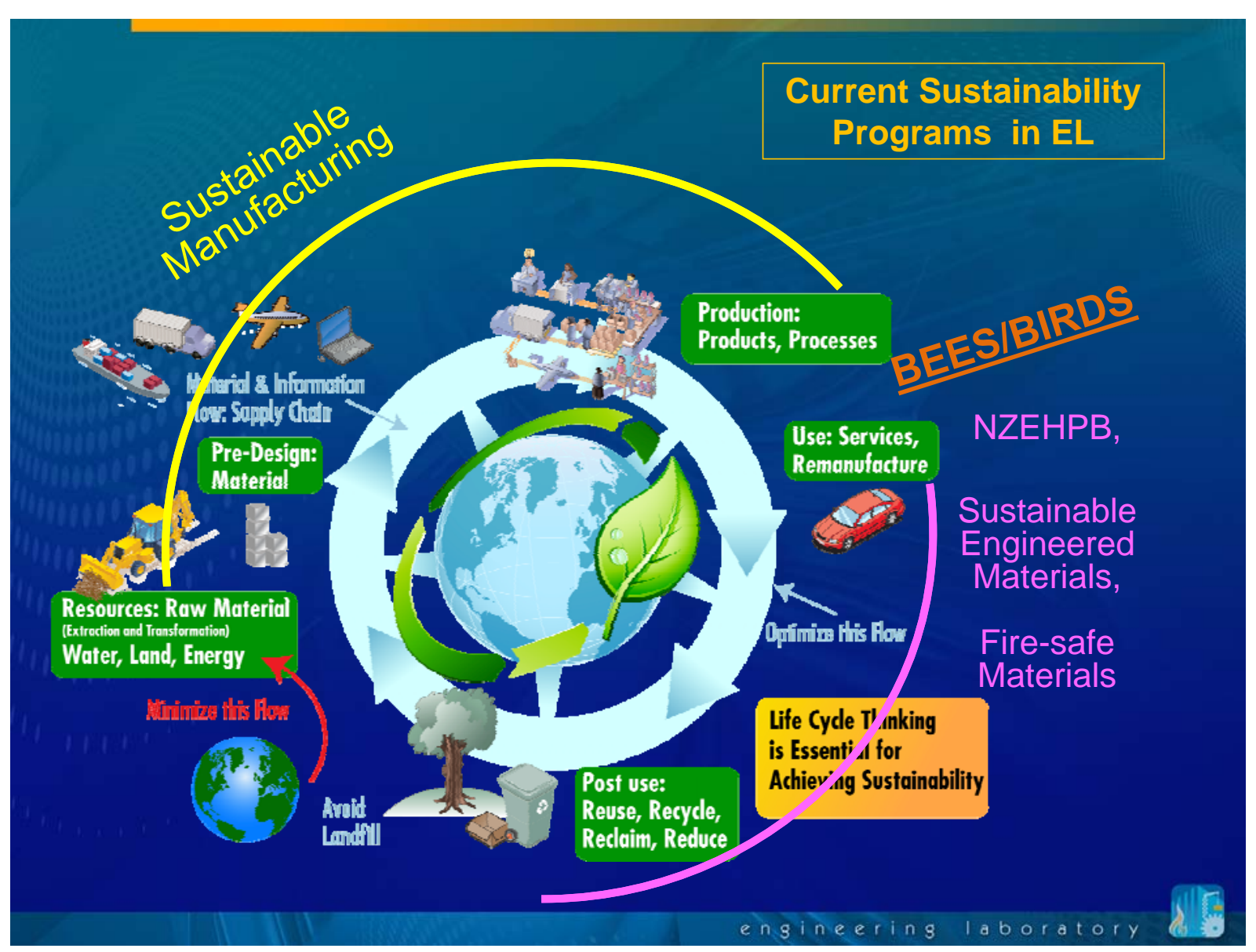

\section{BEES and BIRDS}

- Building for Environmental and Economic Sustainability (BEES)

- Sustainability Performance of Similar Building

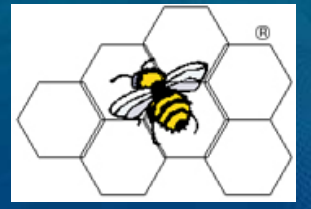
Products

- Building Industry Reporting and Design for Sustainability (BIRDS)

- Sustainability Performance of Whole Building Designs
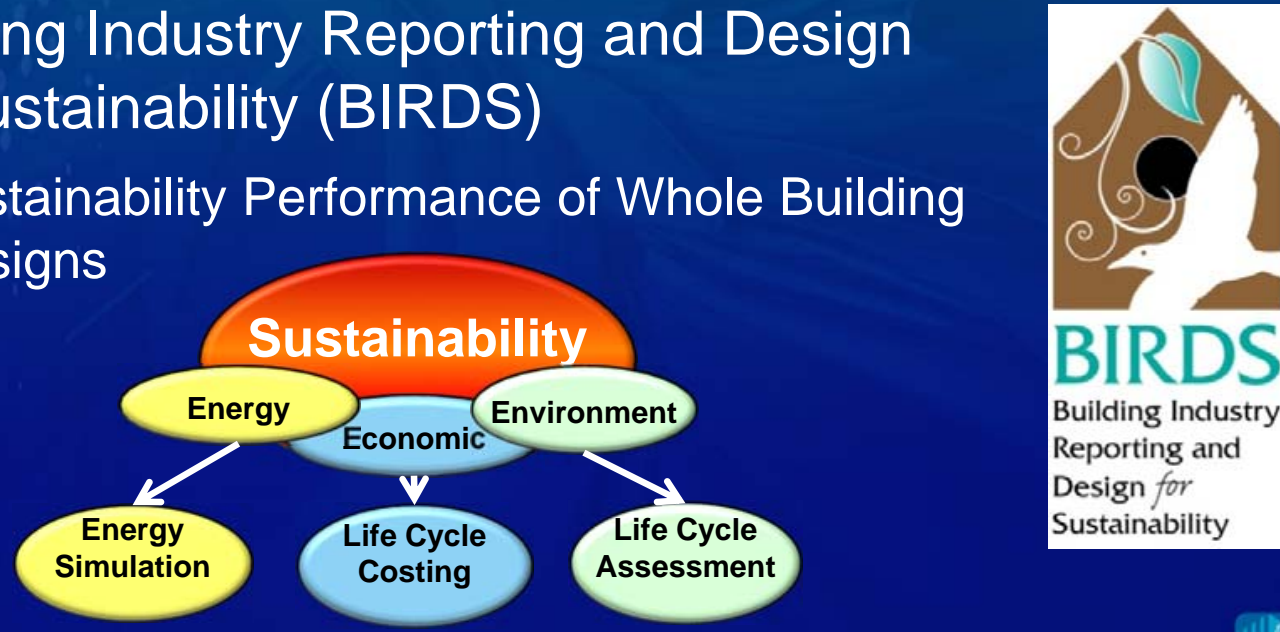
Research Facilities and

\section{Testbeds}

- Virtual Cement and Concrete Testing Laboratory

- Integrating Sphere for Service Life Prediction of Materials

- Virtual Cybernetic Building Testbed

- Smart Grid Testbed Facility

- Solar Photovoltaic Systems

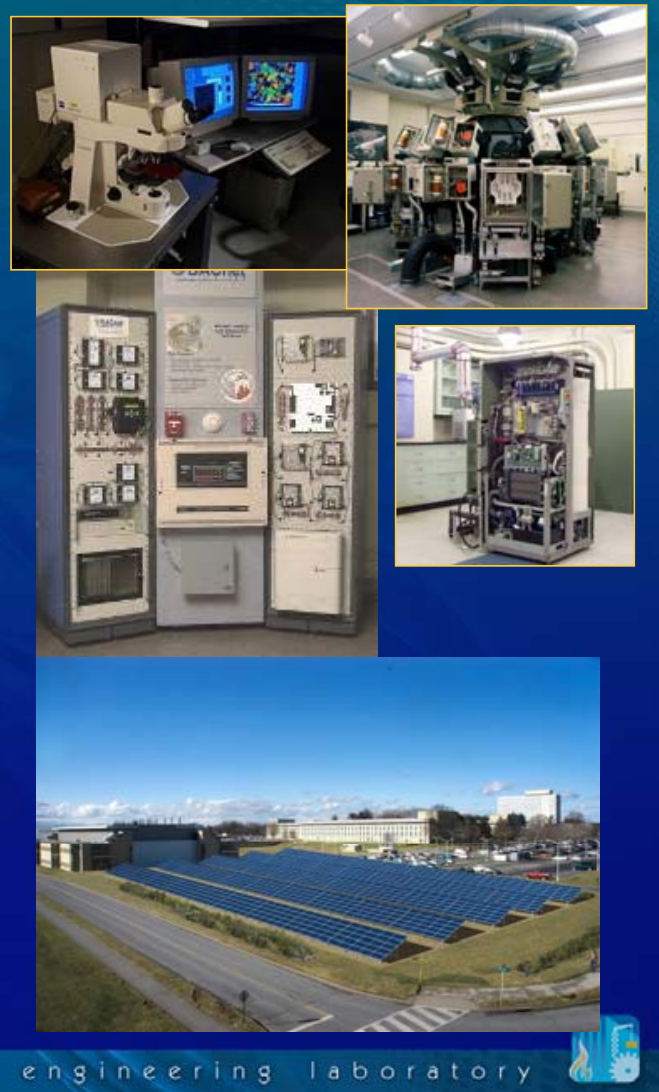

\section{Net-Zero Energy Residential Test Facility}

- Demonstrate net-zero energy for residence similar in appearance to surrounding homes

- Provide a test bed for in-situ measurements of advanced components and systems

- Quantify energy use reductions using embedded intelligence

- Compare actual installed performance to controlled laboratory measurements
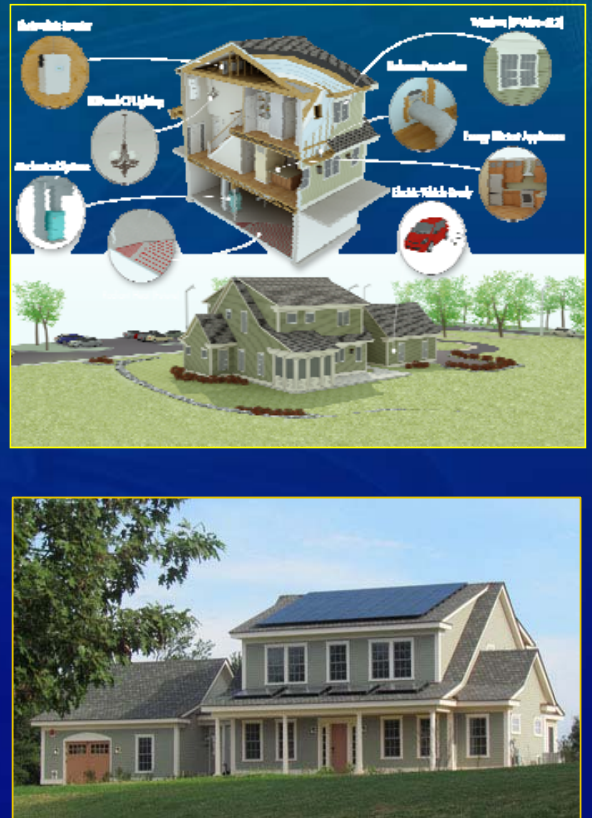


\section{Breakout Groups}

- Workshop Objective:

Identify knowledge gaps and research needs in measurement science for sustainable construction and manufacturing.

- Measurement Science:

- Scientific and technical basis for standards, codes, and practices

- Includes: performance metrics; measurement and testing methods; predictive modeling and simulation tools; test and calibration protocols; reference materials, artifacts and data; evaluation of technologies, systems, and practices (including uncertainty analysis); devices and instruments

\section{Breakout Groups}

- Breakout Categories:

- Measurement science (definition, standards, metrics, indicators and ratings)

- Systems (aggregation, linkages, system of systems, sustainability-resilience synergy and interdependencies)

- Planning, design and supply chain (lifecycle analyses and treatments, and material and energy efficiency)

- Economic, environmental and social aspects (valuation, impacts and behavior). 


\section{Anticipated Outcomes}

- Guidance document that will serve as a roadmap for NIST's future programs in sustainability, and help facilitate our technology transfer and implementation mission.

- Document will include:

- Definition of sustainability relevant to construction and manufacturing

- Appropriate sustainability metrics

- Systems level considerations

- Economic valuation and impacts

- Research gaps and needs 


\section{Measurement science (definition, standards, metrics, indicators and ratings)}

\begin{tabular}{|c|c|}
\hline Problem Title & Problem Description \\
\hline $\begin{array}{c}\text { Sustainability science is } \\
\text { unclear }\end{array}$ & $\begin{array}{c}\text { Bring together physical, natural, and social sciences and } \\
\text { engineering for defining sustainability }\end{array}$ \\
\hline $\begin{array}{c}\text { Measuring is challenging } \\
(2 \mathrm{a})\end{array}$ & $\begin{array}{c}\text { Identify metrics and requirements for assessing } \\
\text { sustainability }\end{array}$ \\
$\begin{array}{c}\text { Not all things we care about } \\
\text { are measurable (2b) }\end{array}$ & Find ways of introducing weights of these things we care \\
about
\end{tabular}

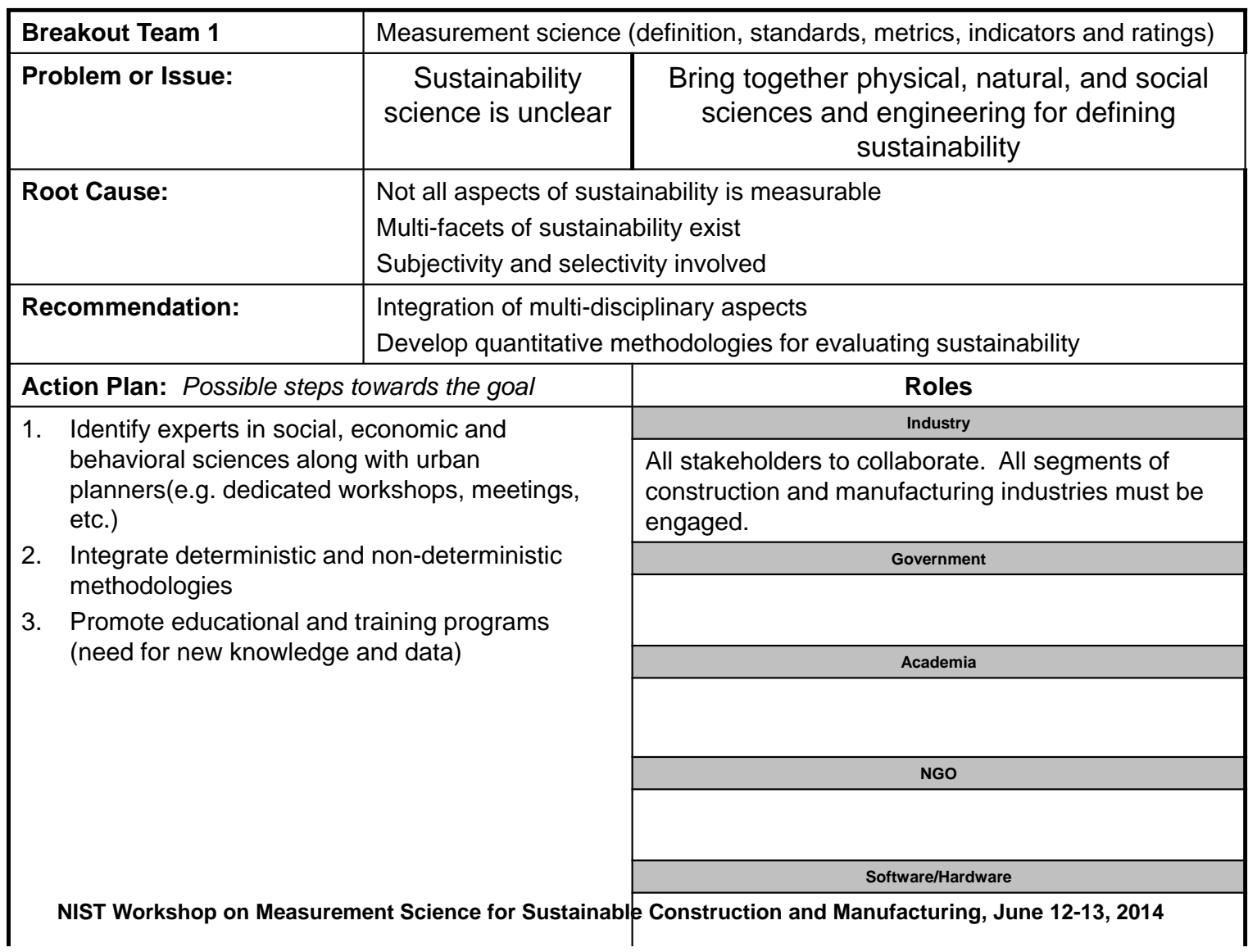




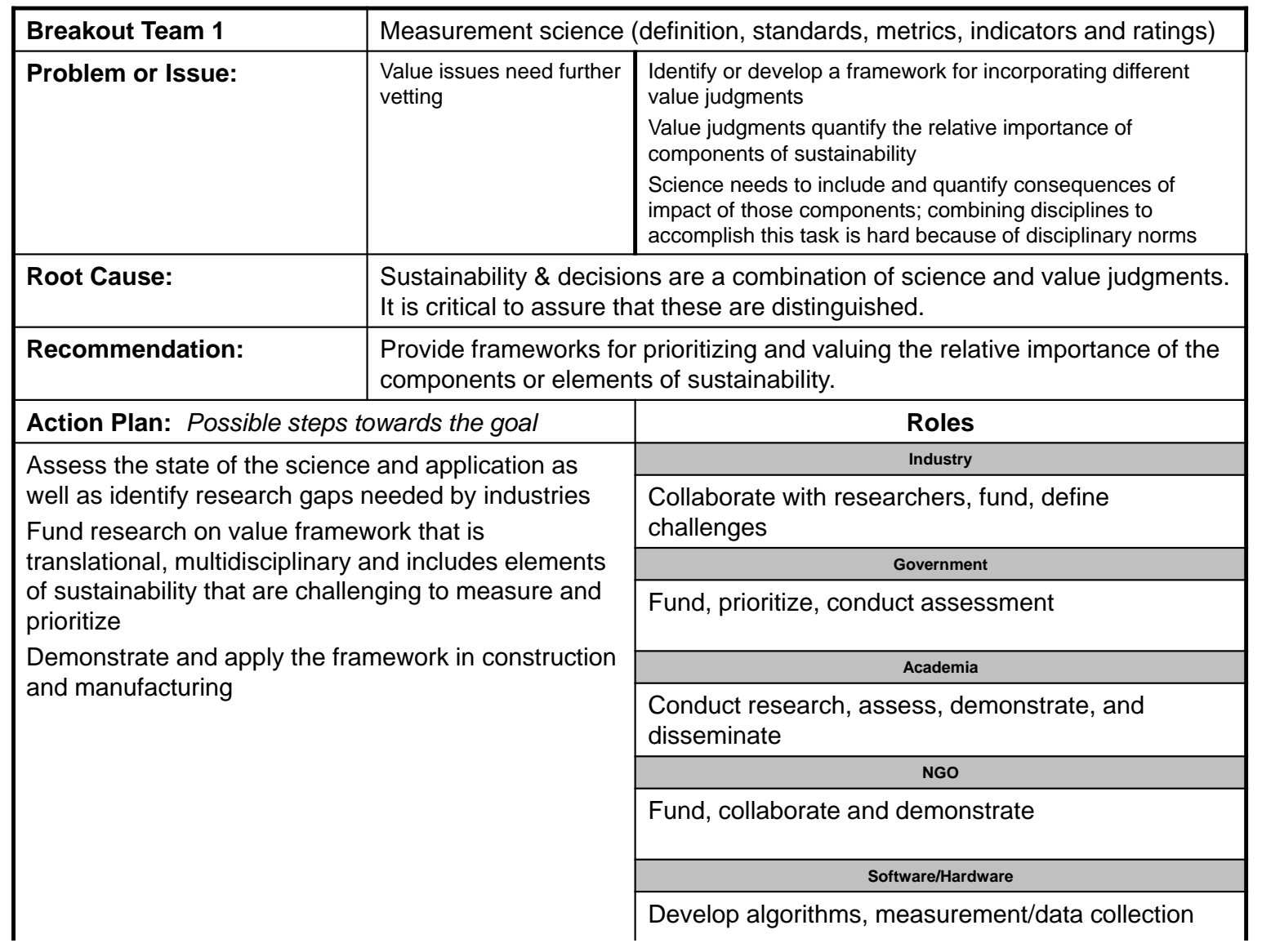

\begin{tabular}{|c|c|c|}
\hline $\begin{array}{l}\text { Breakout } \\
\text { Team } 1\end{array}$ & \multicolumn{2}{|c|}{ Measurement science (definition, standards, metrics, indicators and ratings) } \\
\hline $\begin{array}{l}\text { Problem or } \\
\text { Issue: }\end{array}$ & $\begin{array}{l}\text { Measuring is challenging }(2 a) \\
\text { Not all things we care about are } \\
\text { measurable }(2 b)\end{array}$ & $\begin{array}{l}\text { Identify measurements and requirements for } \\
\text { assessing sustainability } \\
\text { Find ways of introducing weights of these things we } \\
\text { care about }\end{array}$ \\
\hline Root Cause: & \multicolumn{2}{|c|}{$\begin{array}{l}\text { Dynamics of the multidimensional nature of issues } \\
\text { Values are relative and not easily quantifiable }\end{array}$} \\
\hline $\begin{array}{l}\text { Recommenda } \\
\text { tion: }\end{array}$ & \multicolumn{2}{|c|}{$\begin{array}{l}\text { Create a framework for system identification } \\
\text { Identify metrics and indicators } \\
\text { Identify or create methodology for assigning relative weights to values that we care about } \\
\text { Identify or create assessment methodology for decision making }\end{array}$} \\
\hline \multicolumn{2}{|c|}{ Action Plan: Possible steps towards the goal } & Roles \\
\hline \multirow{4}{*}{\multicolumn{2}{|c|}{$\begin{array}{l}\text { Create a framework for system identification } \\
\text { Identify metrics and indicators } \\
\text { Identify or create methodology for assigning relative } \\
\text { weights to values that we care about } \\
\text { Identify or create assessment methodology for } \\
\text { decision making }\end{array}$}} & Industry \\
\hline & & All stakeholders to collaborate \\
\hline & & Government \\
\hline & & \\
\hline & & Academia \\
\hline & & NGO \\
\hline \multicolumn{3}{|c|}{ NIST Workshop on Measurement Science for Sustainable } \\
\hline
\end{tabular}




\begin{tabular}{|c|c|c|}
\hline Breakout Team 1 & \multicolumn{2}{|c|}{ Measurement science (definition, standards, metrics, indicators and ratings) } \\
\hline Problem or Issue: & $\begin{array}{l}\text { Uncertainty in } \\
\text { measurement }\end{array}$ & $\begin{array}{l}\text { Develop methodologies for assessing } \\
\text { uncertainty }\end{array}$ \\
\hline Root Cause: & \multicolumn{2}{|c|}{$\begin{array}{l}\text { Sources: Definition, time horizon, interactions (systems) } \\
\text { Types: Variability, lack of information, approximations } \\
\text { Quantification methods: Probabilistic \& non-probabilistic frameworks }\end{array}$} \\
\hline Recommendation: & \multicolumn{2}{|c|}{$\begin{array}{l}\text { Identify sources, Identify types, Develop frameworks/methods to assess } \\
\text { uncertainty }\end{array}$} \\
\hline \multicolumn{2}{|c|}{ Action Plan: Possible steps towards the goal } & Primary Roles \\
\hline \multirow{2}{*}{\multicolumn{2}{|c|}{$\begin{array}{l}\text { Identify high-value problem areas as anchors for } \\
\text { uncertainty-related tasks. }\end{array}$}} & Industry \\
\hline & & Establish relevance, feasibility \\
\hline \multicolumn{2}{|c|}{$\begin{array}{l}\text { For each problem area, follow recommendation } \\
\text { above. }\end{array}$} & Government \\
\hline \multirow{4}{*}{\multicolumn{2}{|c|}{ 5. Disseminate and educate. }} & Provide leadership, policy, investment and incentives \\
\hline & & Academia \\
\hline & & Fundamental research, training \\
\hline & & Human resource development \\
\hline \multirow{4}{*}{\multicolumn{2}{|c|}{ 6. Obtain feedback and improve steps 1 to 5 . }} & NGO \\
\hline & & $\begin{array}{l}\text { Provide liaison among society, researchers and } \\
\text { practitioners }\end{array}$ \\
\hline & & Software/Hardware \\
\hline & & Software needed to implement methods \\
\hline
\end{tabular}

NIST Workshop on Measurement Science for Sustainable Construction and Manufacturing, June 12-13, 2014

\section{Breakout Team 1. Measurement science}

\begin{tabular}{|c|c|}
\hline Name/Affiliation & Email/Phone \\
\hline Anne Caldas/ANSI & acaldas@ansi.org/212-642-4914 \\
\hline Subhas Sikdar/EPA & Sikdar.subhas@epa.gov/513-569-7528 \\
\hline Daniel Castro/Georgia Tech & dcastro@gatech.edu/404-385-6964 \\
\hline I.S. Jawahir/University of Kentucky & is.Jawahir@uky.edu/859-323-3239 \\
\hline Bilal Ayyub/University of Maryland & ba@umd.edu/301-405-1956 \\
\hline Stephen Mawn/ASTM & smawn@astm.org/610-832-9726 \\
\hline Sankaran Mahadevan/Vanderbilt & $\frac{\text { Sankaran.mahadevan@Vanderbilt.edul }}{615-322-3040}$ \\
\hline Melissa Kenney/University of Maryland & Melissa.kenney@noaa.gov/202-419-3477 \\
\hline Nasim Uddin/University of Alabama & nuddin@uab.edu/205-934-8432 \\
\hline $\begin{array}{l}\text { Mohammad Heidarinejad/University of } \\
\text { Maryland }\end{array}$ & muh182@umd.edu/301-405-1624 \\
\hline 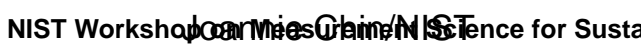 & 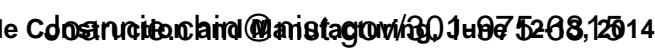 \\
\hline
\end{tabular}




\section{Systems Break-Out Session: Selected 3 Problems}

\begin{tabular}{|l|l|}
\hline \multicolumn{1}{|c|}{ Problem Title } & \multicolumn{1}{c|}{ Problem Description } \\
\hline $\begin{array}{l}\text { System boundary } \\
\text { setting }\end{array}$ & $\begin{array}{l}\text { Since all systems are connected from micro to macro scale, } \\
\text { how can one establish boundaries for analysis? }\end{array}$ \\
\hline $\begin{array}{l}\text { Loss of fidelity in } \\
\text { aggregation }\end{array}$ & $\begin{array}{l}\text { How can one perform aggregated, high-level system-level } \\
\text { analysis without losing important fine-grain details? }\end{array}$ \\
\hline $\begin{array}{l}\text { Coupling of human and } \\
\text { natural processes }\end{array}$ & $\begin{array}{l}\text { What methods are useful for characterizing the linkages } \\
\text { among mechanistic processes designed by humans and } \\
\text { organic processes that have evolved in nature? }\end{array}$ \\
\hline $\begin{array}{l}\text { Predictive assessment } \\
\text { for sustainability and } \\
\text { resilience }\end{array}$ & $\begin{array}{l}\text { How can decision makers assess the potential ecological, } \\
\text { economic, and social impacts of new policies or technologies } \\
\text { a priori without empirical knowledge? }\end{array}$ \\
\hline $\begin{array}{l}\text { Understanding cross- } \\
\text { scale interactions }\end{array}$ & $\begin{array}{l}\text { Are there tractable methods available for practitioners to } \\
\text { understand the complex interactions within a system of } \\
\text { systems across multiple spatial and temporal scales? }\end{array}$ \\
\hline $\begin{array}{l}\text { General vs. specified } \\
\text { resilience }\end{array}$ & $\begin{array}{l}\text { Can systems be designed for "inherent" resilience to } \\
\text { disruptions in general, rather than to specified threats? }\end{array}$ \\
\hline $\begin{array}{l}\text { Justification of need for } \\
\text { systems approach }\end{array}$ & $\begin{array}{l}\text { How can issues that require systems thinking be identified } \\
\text { and communicated, with an appropriate business case? }\end{array}$ \\
\hline $\begin{array}{l}\text { Establishment of } \\
\text { accepted practice }\end{array}$ & $\begin{array}{l}\text { How can we establish commonly accepted, credible methods, } \\
\text { practices, and data, with compelling examples? }\end{array}$ \\
\hline
\end{tabular}

NIST Workshop on Measurement Science for Sustainable Construction and Manufacturing, June 12-13, 2014

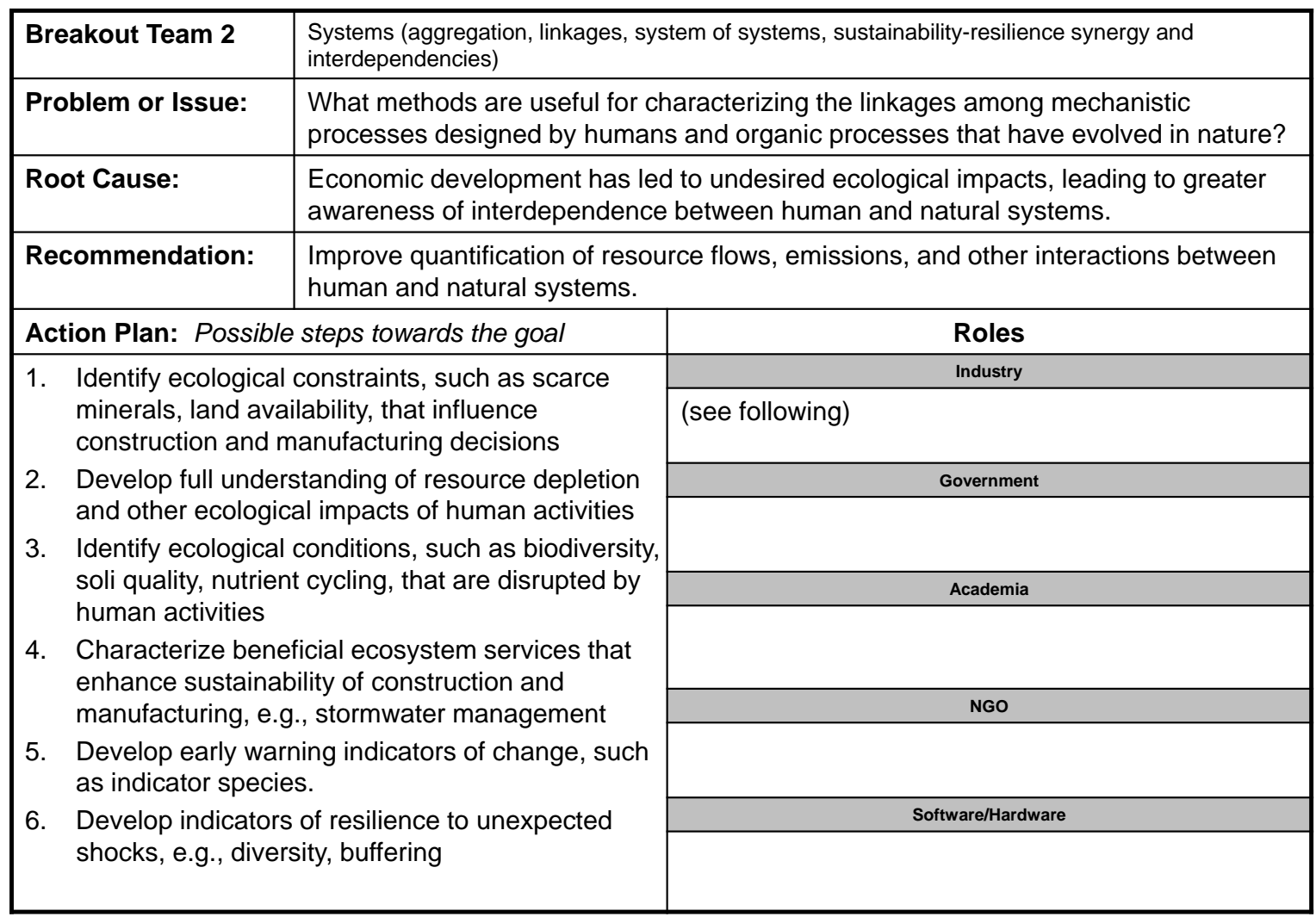




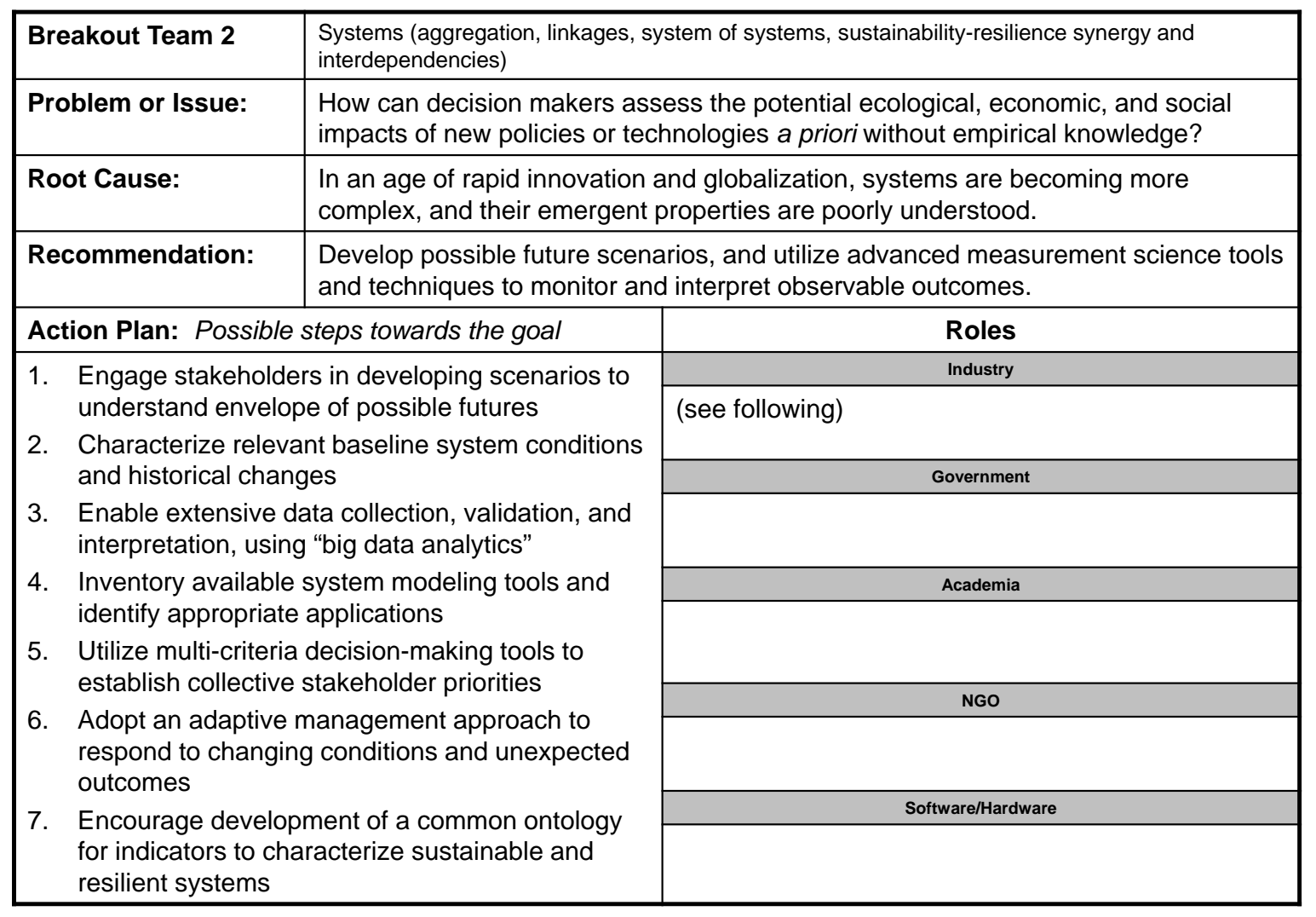

NIST Workshop on Measurement Science for Sustainable Construction and Manufacturing, June 12-13, 2014

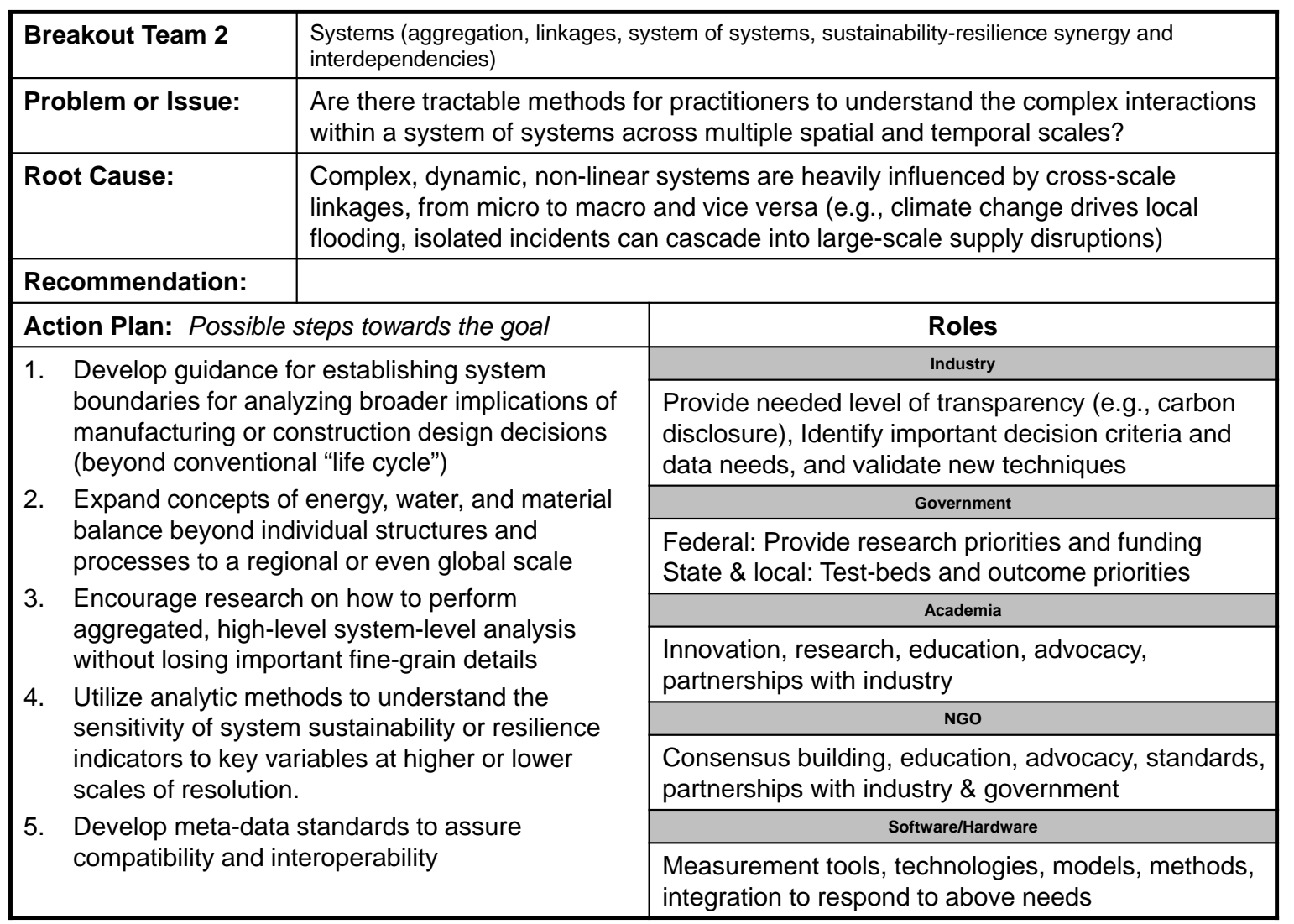

NIST Workshop on Measurement Science for Sustainable Construction and Manufacturing, June 12-13, 2014 


\section{Breakout Team 2. Systems}

\begin{tabular}{|l|l|}
\hline \multicolumn{1}{|c|}{ Name/Affiliation } & \multicolumn{1}{c|}{ Email/Phone } \\
\hline Joseph Fiksel* & Fiksel.2@osu.edu 614-226-5678 \\
\hline John Carberry* & johncarberry01@comcast.net 302-738-4063 \\
\hline Vilas Mujumdar & $\underline{\text { V mujumdar41@yahoo.com 703-938-2117 }}$ \\
\hline Chris Renschler & rensch@buffalo.edu 716-645-0480 \\
\hline Bill Anderson & wanderson@tisp.org 202-302-9170 \\
\hline Matthew Dahlhausen & Matthew.dahlhausen@gmail.com 216-618-0753 \\
\hline Eric Coffman & Eric.coffman@montgomerycountymd.gov 240-777-5595 \\
\hline $\begin{array}{l}\text { Ryan Colker } \\
\text { (comments via e-mail) }\end{array}$ & rcolker@nibs.org 202-289-7800 \\
\hline & \\
\hline
\end{tabular}

${ }^{*}$ co-moderators

NIST Workshop on Measurement Science for Sustainable Construction and Manufacturing, June 12-13, 2014 


\section{Planning, design and supply chain (lifecycle analyses and treatments, and material and energy efficiency)}

\begin{tabular}{|c|l|}
\hline Problem Title & \multicolumn{1}{c|}{ Problem Description } \\
\hline $\begin{array}{c}\text { How to apply systems thinking during planning } \\
\text { and design of systems that considers } \\
\text { interdependencies \& trade-offs between } \\
\text { economic, environmental and societal impacts? }\end{array}$ & $\begin{array}{l}\text { Sustainability-oriented interventions often involve trade-offs between } \\
\text { various activities along the value chain. Without a systems-oriented } \\
\text { approach, the impact of these interdependencies are difficult to evaluate. }\end{array}$ \\
\hline $\begin{array}{c}\text { How to develop predictive models that can } \\
\text { realistically estimate future cross-company and } \\
\text { cross-supply chain economic, environmental or } \\
\text { societal impacts? }\end{array}$ & $\begin{array}{l}\text { Sustainability improvements often take a long-term to materialize and } \\
\text { benefits are likely to accrue across the supply chain. However, existing } \\
\text { frameworks do not lend themselves to accurately determine cross- } \\
\text { company benefits, economic or otherwise. Can predictive models be } \\
\text { developed to realistically predict the influence of such improvement } \\
\text { efforts? Can models be developed to predict impacts of emergent and } \\
\text { future conditions; to evaluate and design adaptive alternatives? }\end{array}$ \\
\hline $\begin{array}{c}\text { How to ensure designed systems have the } \\
\text { resilience to withstand disruptive events and } \\
\text { operational turbulence? }\end{array}$ & $\begin{array}{l}\text { Global supply chains are increasingly exposed to uncertain events and } \\
\text { disruptions. The sustainability performance of supply chains is } \\
\text { catastrophically affected when such unpredictable events occur. } \\
\text { Quantitatively models for evaluating interdependent risks between supply } \\
\text { chain partners and methods to analyze their propagation through the } \\
\text { supply chains are lacking. }\end{array}$ \\
\hline $\begin{array}{c}\text { How to develop a common nomenclature and } \\
\text { terminology related to sustainability that can be } \\
\text { across the supply chain? }\end{array}$ & $\begin{array}{l}\text { Sustainability is a relatively new concept and common language for } \\
\text { talking about it does not yet exist. The definition of sustainability itself } \\
\text { varies from person to person, making it difficult to address the aspects of } \\
\text { the issue and develop effective ways to measure it. Establishing } \\
\text { consistent, standard terminology for talking about sustainability will help } \\
\text { to align researchers and manufacturers communicating about common } \\
\text { issues and designing products that address those needs. }\end{array}$ \\
\hline
\end{tabular}

\section{Planning, design and supply chain (lifecycle analyses and treatments, and material and energy efficiency)}

\begin{tabular}{|c|l|}
\hline Problem Title & \multicolumn{1}{c|}{ Problem Description } \\
\hline $\begin{array}{c}\text { How to increase data sharing and } \\
\text { interoperability between relevant stakeholders } \\
\text { across the supply chain? }\end{array}$ & $\begin{array}{l}\text { In this electronic age, companies amass considerable data related to their } \\
\text { products, processes and systems. However, this data is not used } \\
\text { effectively to produce actionable information; in situations where such } \\
\text { information is available, it is not shared across the supply chain to increase } \\
\text { benefits to all stakeholders. }\end{array}$ \\
\hline $\begin{array}{c}\text { How to design products, processes and } \\
\text { systems to increase remanufacturing, } \\
\text { recycling and end-of-life management? }\end{array}$ & $\begin{array}{l}\text { To enable closed-loop material flow across multiple life-cycles of products, } \\
\text { they must be designed and manufactured to enable better } \\
\text { remanufacturing, recycling and end-of-life management. }\end{array}$ \\
\hline $\begin{array}{c}\text { How to routinely optimize reverse logistics } \\
\text { operations given uncertainty in quality and } \\
\text { quantity of end-of-life products? }\end{array}$ & $\begin{array}{l}\text { The uncertainties in the quality and quantity of product flow in reverse } \\
\text { supply chains makes it difficult for companies to engage in these activities } \\
\text { profitably. What strategies can be implemented to encourage OEMs to } \\
\text { engage in reverse logistics operations? }\end{array}$ \\
\hline $\begin{array}{c}\text { How to ensure material and energy efficiency } \\
\text { become integral steps during the planning } \\
\text { and design of products, processes and } \\
\text { systems/supply chains? }\end{array}$ & $\begin{array}{l}\text { Assessment categories currently being used in standard LCA analyses } \\
\text { don't allow for a comprehensive analysis of material and energy efficiency. } \\
\text { What tools can be used and how can LCA be complemented? }\end{array}$ \\
\hline
\end{tabular}




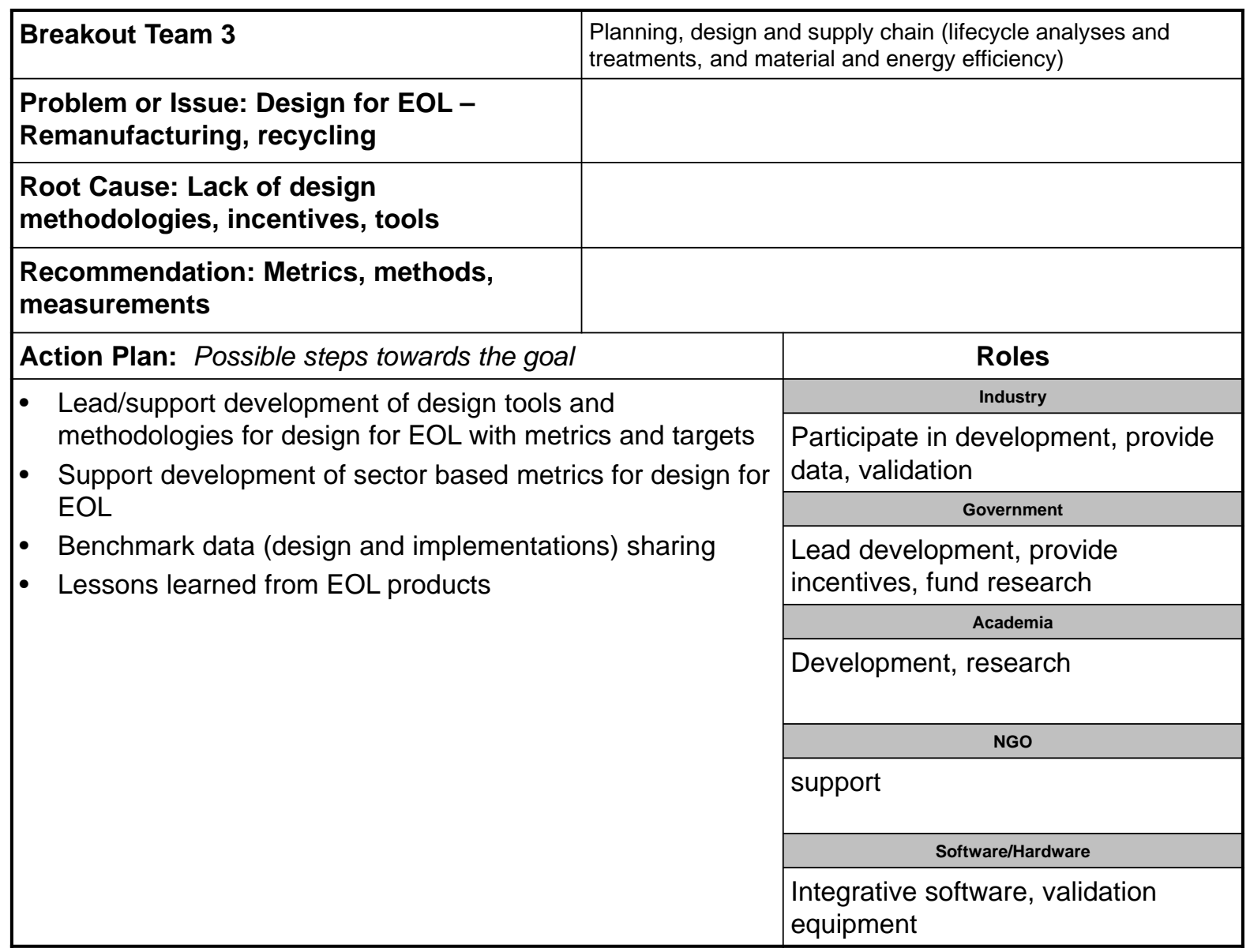

NIST Workshop on Measurement Science for Sustainable Construction and

Manufacturing, June 12-13, 2014

\begin{tabular}{|c|c|c|}
\hline & \multicolumn{2}{|c|}{$\begin{array}{l}\text { Planning, design and supply chain (lifecycle analyses and } \\
\text { treatments, and material and energy efficiency) }\end{array}$} \\
\hline & \multicolumn{2}{|c|}{$\begin{array}{l}\text { How to increase data sharing and interoperability between } \\
\text { relevant stakeholders across the supply chain? }\end{array}$} \\
\hline \multicolumn{3}{|c|}{$\begin{array}{l}\text { Root Cause: Lack of Integrated } \\
\text { approaches, incentives, tools }\end{array}$} \\
\hline \multicolumn{3}{|c|}{$\begin{array}{l}\text { Recommendation: Metrics, methods, } \\
\text { measurements }\end{array}$} \\
\hline \multicolumn{2}{|c|}{ Action Plan: Possible steps towards the goal } & Roles \\
\hline \multirow{10}{*}{\multicolumn{2}{|c|}{$\begin{array}{l}\text { Developments of frameworks for reverse logistics and } \\
\text { metrics for measuring effectiveness } \\
\text { - Support development of standard data exchange }\end{array}$}} & Industry \\
\hline & & $\begin{array}{l}\text { Participate in development, provide } \\
\text { data, validation }\end{array}$ \\
\hline & & Government \\
\hline & & $\begin{array}{l}\text { Lead development, provide } \\
\text { incentives, fund research }\end{array}$ \\
\hline & & Academia \\
\hline & & Development, research \\
\hline & & NGO \\
\hline & & support \\
\hline & & Software/Hardware \\
\hline & & $\begin{array}{l}\text { Integrative software, validation } \\
\text { equipment }\end{array}$ \\
\hline
\end{tabular}




\begin{tabular}{|c|c|}
\hline Breakout Team 3 & Planning, design and supply chain (lifecycle analyses and treatments, and material and energy efficiency) \\
\hline Problem or Issue: & $\begin{array}{l}\text { Sustainability impacts improvements often-occur at different points during the life of the product or structure and may take a } \\
\text { long-term to materialize and as benefits are likely to accrue across the supply chain. However, existing frameworks do not lend } \\
\text { themselves to accurately determine time dependent cross-company benefits (environmental, economic or societal). Can } \\
\text { predictive models be developed to realistically predict the influence of such improvement efforts? Can models be developed to } \\
\text { predict impacts of emergent and future conditions; to evaluate and design adaptive alternatives? }\end{array}$ \\
\hline Root Cause: & $\begin{array}{l}\text { Analysis approaches tend to take a unit process view and overall impacts are treated on an additive basis rather than a time } \\
\text { series, integrated system view. }\end{array}$ \\
\hline \multirow[t]{3}{*}{ Recommendation: } & $\begin{array}{l}\text { 1) Not only collect } L C I / L C A \text { data for materials and products in a national database but also typical use statistics such as } \\
\text { recovery and reuse rates, typical product lifespans, and incremental impacts to assembly or building operational cycles. }\end{array}$ \\
\hline & $\begin{array}{l}\text { 2) Research should be conducted on developing a system of prioritization matrices that quantify the trade offs of various } \\
\text { impacts over time and "present-values" those impacts into a comparable form. Note: this may seem to be impossible but only if } \\
\text { it is looked at in absolute terms rather than a tool that could be used to assess a variety of scenarios. }\end{array}$ \\
\hline & $\begin{array}{l}\text { 3) Develop a tool to utilize these matrices in relation to product and building design decisions across the cradle-to-cradle } \\
\text { lifecycle of the product or building as a contribution to the initial decision making process. }\end{array}$ \\
\hline \multirow[t]{11}{*}{$\begin{array}{l}\text { Action Plan: Possible steps } \\
\text { towards the goal }\end{array}$} & Roles \\
\hline & Industry \\
\hline & $\begin{array}{l}\text { Industry should be prepared to collect and share necessary data (reuse and recovery rates, operational impacts and typical } \\
\text { lifespans) just as EPD data is shared. }\end{array}$ \\
\hline & Government \\
\hline & $\begin{array}{l}\text { Serve as a catalyst to this process through further definition of the issues involved, sponsoring research projects and promoting } \\
\text { the concept. Government should maintain and manage the database. Perhaps the tool development should be driven through } \\
\text { an organization such as NIST so that the base level of the tool is cross-disciplinary, cross-industry and extensible,. }\end{array}$ \\
\hline & Academia \\
\hline & Engage in meaningful, creative research \\
\hline & NGO \\
\hline & Industry trade organizations need o take the lead in collection of industry wide data and support the effort. \\
\hline & Software/Hardware \\
\hline & Tool has to be credible but not overly complex in order to encourage its utilization. \\
\hline
\end{tabular}

\begin{tabular}{|c|c|c|}
\hline Breakout Team 3 & \multicolumn{2}{|c|}{ Planning, design and supply chain (lifecycle analyses and treatments, and material and energy efficiency) } \\
\hline Problem or Issue: & \multicolumn{2}{|c|}{$\begin{array}{l}\text { How to apply systems thinking during planning and design of systems that considers interdependencies \& trade-offs } \\
\text { between economic, environmental and societal impacts? }\end{array}$} \\
\hline Root Cause: & \multicolumn{2}{|c|}{$\begin{array}{l}\text { Lack of information about the total life cycle issues of, materials, processes, and products, data } \\
\text { ownership, lack of understanding of process capabilities in terms of energy, material, and water } \\
\text { Perception that sustainability cost more }\end{array}$} \\
\hline Recommendation: & \multicolumn{2}{|c|}{$\begin{array}{l}\text { Develop Design for sustainable supply chain for risk-based better multi-criteria decision making. } \\
\text { Develop data standards, analytical tools that can readily consume data, }\end{array}$} \\
\hline \multicolumn{2}{|c|}{ Action Plan: Possible steps towards the goal } & Roles \\
\hline \multirow{4}{*}{\multicolumn{2}{|c|}{$\begin{array}{l}\text { Develop industry challenge problems for } \\
\text { benchmarking and understanding of process } \\
\text { capabilities in terms of energy, material, and water } \\
\text { Seamless information flow across supply network } \\
\text { for all lifecycle phases through data standards }\end{array}$}} & Industry \\
\hline & & Challenge problems, change perspective on sustainability as competitiveness \\
\hline & & Government \\
\hline & & $\begin{array}{l}\text { Promote and enable standards, better informed policy instruments, consumer } \\
\text { awareness, promote high risk research for long term benefits }\end{array}$ \\
\hline \multirow{2}{*}{\multicolumn{2}{|c|}{$\begin{array}{l}\text { Promote code for America makes (crowd sourcing) } \\
\text { for developing analytical tools for risk-based better } \\
\text { multi-criteria decision making }\end{array}$}} & Academia \\
\hline & & $\begin{array}{l}\text { Education and training, work with industry to develop science for sustainable } \\
\text { construction and manufacturing, develop curriculum that reflects industry and }\end{array}$ \\
\hline \multirow{4}{*}{\multicolumn{2}{|c|}{$\begin{array}{l}\text { Promote better life cycle thinking of cradle to } \\
\text { cradle process and explain it in terms of value } \\
\text { system than first cost. } \\
\text { Robust and adaptable models of life cycle analysis } \\
\text { and synthesis for spatial and temporal uncertainties }\end{array}$}} & \\
\hline & & NGO \\
\hline & & $\begin{array}{l}\text { Industry and technology roadmap, help develop better policy instruments, better } \\
\text { balance of public and private good. And partnership }\end{array}$ \\
\hline & & Software/Hardware \\
\hline \multicolumn{3}{|r|}{ stainable_Construction ar } \\
\hline
\end{tabular}




\begin{tabular}{|c|c|c|}
\hline Breakout Team 3 & \multicolumn{2}{|c|}{$\begin{array}{l}\text { Planning, design and supply chain (lifecycle analyses and treatments, and material and energy } \\
\text { efficiency) }\end{array}$} \\
\hline Problem or Issue: & \multicolumn{2}{|c|}{$\begin{array}{l}\text { Resilience - How to ensure designed systems have the resilience to withstand disruptive } \\
\text { events and operational turbulence? }\end{array}$} \\
\hline Root Cause: & \multicolumn{2}{|c|}{$\begin{array}{l}\text { Lack of: 1) Performance criteria at a component level 2) Performance data of components } \\
\text { against the climate change spectrum 3) Sensitivity of matrices in life cycle cost analysis and } \\
\text { risk assessment modeling }\end{array}$} \\
\hline Recommendation: & \multicolumn{2}{|c|}{$\begin{array}{l}\text { NIST should define performance criteria against the climate change spectrum at the } \\
\text { component and building levels. This will allow decision makers to use the appropriate } \\
\text { indicators for better decisions. }\end{array}$} \\
\hline \multicolumn{2}{|c|}{$\begin{array}{l}\text { Action Plan: Possible steps towards the } \\
\text { goal }\end{array}$} & Roles \\
\hline \multirow{6}{*}{\multicolumn{2}{|c|}{$\begin{array}{l}\text { 1. Develop and publish } \\
\text { component-level performance } \\
\text { criteria. } \\
\text { 2. Evaluate and compare US } \\
\text { regional codes to develop } \\
\text { climate change spectrum. } \\
\text { 3. See "Roles" section for } \\
\text { further actions. }\end{array}$}} & Industry \\
\hline & & $\begin{array}{l}\text { 1) Provide all the basis of design at a molecular level to NIST so they can test and define } \\
\text { criteria. 2) Provide system integration modeling so NIST can complete testing. }\end{array}$ \\
\hline & & Government \\
\hline & & Use and enforce criteria through acquisition regulation. \\
\hline & & Academia \\
\hline & & Provide criteria to students, the future implementers and building owners. \\
\hline & & NGO \\
\hline & & Use criteria to propose changes to policy and regulation. \\
\hline & & Software/Hardware \\
\hline & NIST Works & $\begin{array}{l}\text { Tools utilizing NIST performance criteria to allow for users to predict for better decision } \\
\text { making. } \\
\text { p on Measurement Science for Sustainable Construction and }\end{array}$ \\
\hline
\end{tabular}
Manufacturing, June 12-13, 2014

\section{Breakout Team 3, question 8, Joe Cresko and Kathi Futornick}

Problem or Issue: restating: "Data sharing and interoperability between relevant stakeholders across the supply chain is insufficient to enable improvements in EE and ME"

\section{Root Cause:}

Planning, design and supply chain (lifecycle analyses and treatments, and material and energy efficiency)

How to increase data sharing and interoperability between relevant stakeholders across the supply chain?

\begin{tabular}{|c|c|c|}
\hline . Cause. & \multicolumn{2}{|c|}{$\begin{array}{l}\text { agent type problem). } \\
\text { Supply chains are highly variable, and estimating as well as allocating } \\
\text { benefits is complicated. }\end{array}$} \\
\hline Recommendation: & \multicolumn{2}{|c|}{$\begin{array}{l}\text { Build off of existing, appropriate tools/models, and ultimately standardize } \\
\text { underlying data and tool architectures. }\end{array}$} \\
\hline \multicolumn{2}{|l|}{ Action Plan: Possible steps towards the goal } & Roles \\
\hline \multirow{5}{*}{\multicolumn{2}{|c|}{$\begin{array}{l}\text { 1. Define materials efficiency and energy efficiency in this context. } \\
\text { 2. Identify existing, appropriate tools/models - possibly include embodied energy; } \\
\text { materials flows through the economy; cross-sector energy impacts; energy use of } \\
\text { (specific) products through their lifecycle; } \\
\text { 3. Build upon those tools/models (one example framework could be embodied energy } \\
\text { and cross-sectoral energy impacts tools being develop by DOE; another could be } \\
\text { BEES tool at NIST). } \\
\text { 4. Materials certification - currently, certifications are required for products marketed } \\
\text { to EU; underlying data analysis should be standardized/verified and then could be } \\
\text { utilized }\end{array}$}} & Industry \\
\hline & & $\begin{array}{l}\text { Examples: engage in standards development, and } \\
\text { implementation }\end{array}$ \\
\hline & & Government \\
\hline & & $\begin{array}{l}\text { Examples: NIST work with standards groups (ISO, } \\
\text { ANSI, etc.); DOE work with industry on voluntary } \\
\text { programs; USG to collaborate on } \\
\text { tools/models/databases }\end{array}$ \\
\hline & & Academia \\
\hline \multirow{2}{*}{\multicolumn{2}{|c|}{$\begin{array}{l}\text { 5. Include in the existing tools/models, or develop additional model frameworks to } \\
\text { include other materials-associated "externalities" that directly or indirectly impact } \\
\text { costs such as environmental, labor, regulatory, risks. }\end{array}$}} & $\begin{array}{l}\text { Examples: engage in standards development, and } \\
\text { work with local regulatory agencies. Take } \\
\text { leadership role in defining sustainability, materials } \\
\text { efficiency, etc., and develop training/tools/etc. } \\
\text { useful to industry and society. }\end{array}$ \\
\hline & & NGO \\
\hline \multicolumn{2}{|c|}{$\begin{array}{c}\text { NIST Workshop on Measurement Science for Sustainable } \\
\text { Manufacturing, June 12-13, } 2014\end{array}$} & onstruction and \\
\hline
\end{tabular}




\section{Problem or Issue:}

How to develop a common nomenclature and terminology related to sustainability that can be used across the supply chain?

\section{Root Cause:}

No consistent definition for sustainability

\section{Recommendation:}

Define needs and impacts (tangible, intangible)

Define common grounds for sustainability in both construction

and manufacturing industries based on their needs to sustain

business and operations while reducing impact on critical

environmental areas.

Quantify uncertainties in statements and criteria. Account for subjectivity such as social aspects.

Action Plan: Possible steps towards the goal

\section{Roles}

Defined Needs to sustain business and impact on the env: Resources

1. energy, fossil fuels

2. water

3. raw materials

Tangible impacts

Environmental <impact

1. climate (carbon emissions and ozone)

2. land

3. water

4. pollution

Economic impact

1. profits

2. Investment

3. Risk

4. Life cycle costs

Intangible impacts

1. social justice

2. health and well being

\begin{tabular}{l} 
Roles \\
\hline Industry \\
\hline $\begin{array}{l}\text { Prrovide sets of criteria relevant to their operations and } \\
\text { ensure practicabilty. }\end{array}$ \\
\hline Government \\
\hline Aefinine priorities and fund accordingly. \\
\hline $\begin{array}{l}\text { Develop scientific framework to minimize subjectivity and } \\
\text { deal with uncertainty. }\end{array}$ \\
\hline NGo \\
\hline Supporting role. \\
\hline Software/Hardware \\
\hline \\
\hline
\end{tabular}




\begin{tabular}{|c|c|}
\hline Breakout Team 3 & $\begin{array}{l}\text { Planning, design and supply chain (lifecycle analyses and } \\
\text { treatments, and material and energy efficiency) }\end{array}$ \\
\hline Problem or Issue: & $\begin{array}{l}\text { How to develop predictive models that can realistically estimate } \\
\text { future cross-company and cross-supply chain economic, } \\
\text { environmental or societal impacts? }\end{array}$ \\
\hline \multicolumn{2}{|l|}{ Root Cause: } \\
\hline \multicolumn{2}{|l|}{ Recommendation: } \\
\hline \multirow[t]{7}{*}{ Action Plan: Possible steps towards the goal } & Roles \\
\hline & Industry \\
\hline & Government \\
\hline & Academia \\
\hline & NGO \\
\hline & Software/Hardware \\
\hline & \\
\hline
\end{tabular}

NIST Workshop on Measurement Science for Sustainable Construction and

Manufacturing, June 12-13, 2014

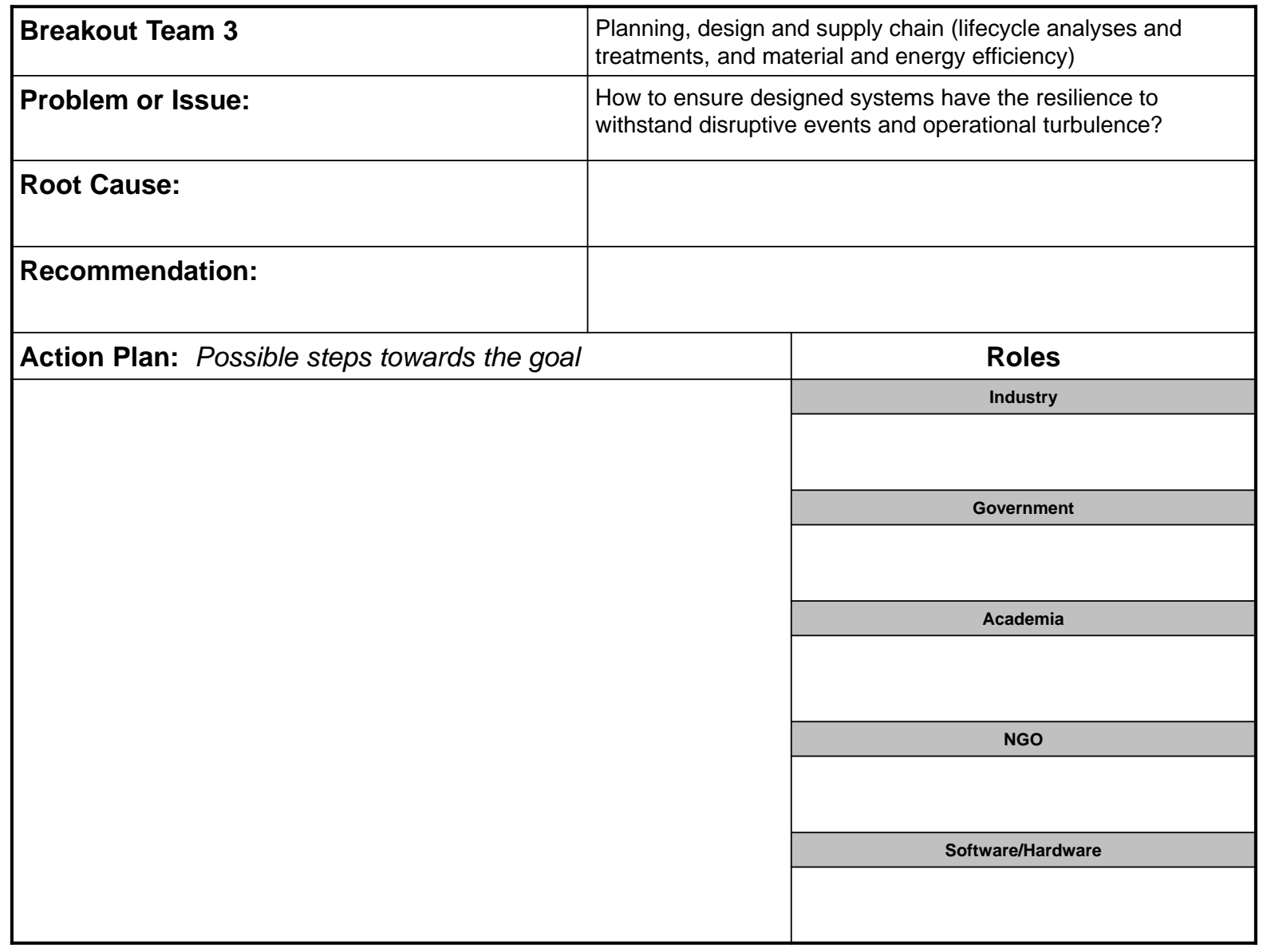


Breakout Team 3. Planning, design and supply chain

\begin{tabular}{|l|l|}
\hline Name/Affiliation & Email/Phone \\
\hline & \\
\hline & \\
\hline & \\
\hline & \\
\hline & \\
\hline & \\
\hline & \\
\hline & \\
\hline
\end{tabular}

NIST Workshop on Measurement Science for Sustainable Construction and

Manufacturing, June 12-13, 2014 


\section{A. JAMES CLARK \\ SCHOOL OF ENGINEERING}

\section{Measurement Science for}

Sustainable Construction and

Manufacturing

\section{Concluding Remarks and Adjournment}

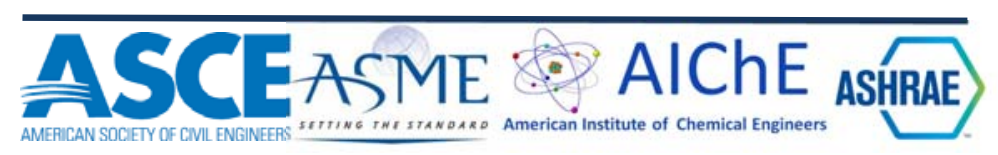

June 13, 2014

\section{Summary}

- Workshop: Measurement Science for Sustainable Construction and Manufacturing

- Background, context, challenges, problems and needs

- Knowledge gaps and research needs

- By the numbers

-80 participants

- 38 papers

-25 speakers and panelists 


\section{Workshop Outcomes}

- Problem lists

- Problem descriptions

- Breakout reports

- Proceedings

- Opportunity

- Send comments

- Send papers

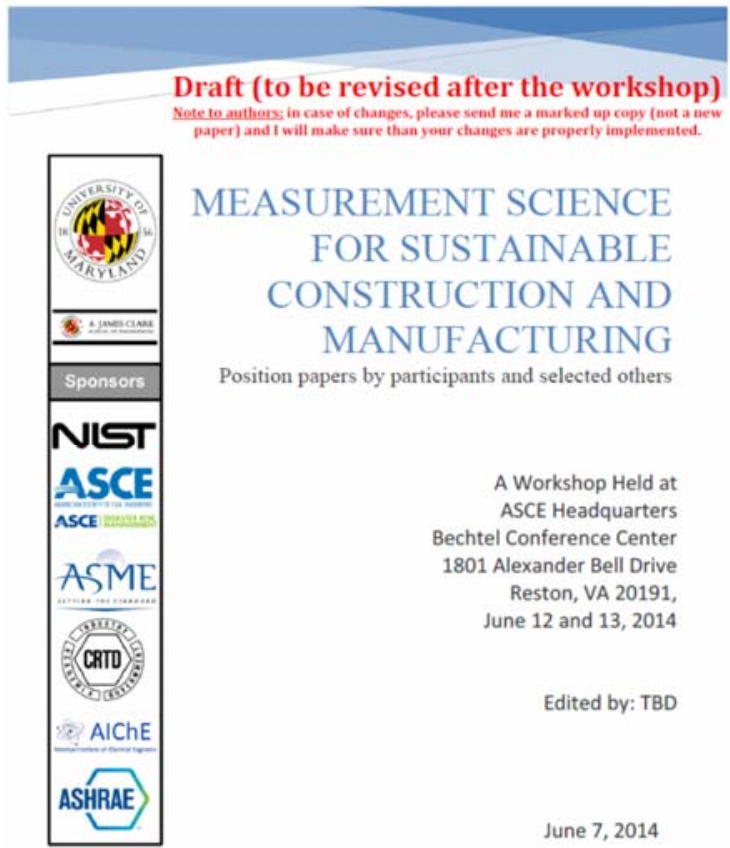

\section{Next Steps}

- Publication of proceedings - public domain

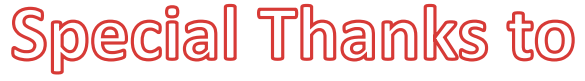

NUST/Drs. Chơn ad Chapman 


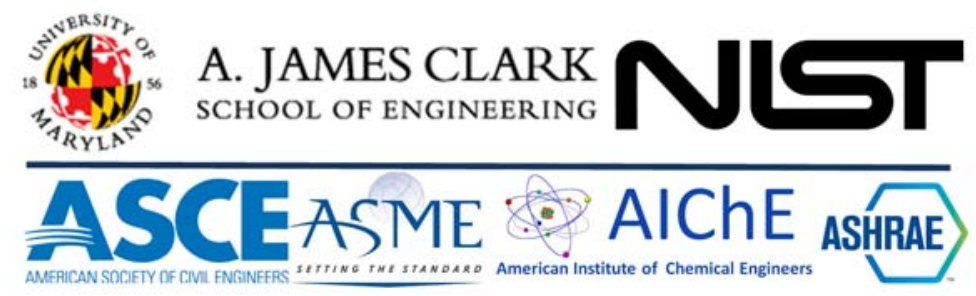

